\title{
Copyright
}

by

Mengjiao Yu

2002 
The Dissertation Committee for Mengjiao Yu Certifies that this is the approved version of the following dissertation:

\section{CHEMICAL AND THERMAL EFFECTS ON WELLBORE STABILITY OF SHALE FORMATIONS}

\section{Committee:}

Mukul M. Sharma, Co-Supervisor

Martin E. Chenevert, Co-Supervisor

Augusto L. Podio

Carlos Torres-Verdin

Lynn E. Katz 


\title{
CHEMICAL AND THERMAL EFFECTS ON WELLBORE STABILITY OF SHALE FORMATIONS
}

\author{
by
}

Mengjiao Yu, B.S., M.Sc.

\author{
Dissertation \\ Presented to the Faculty of the Graduate School of \\ The University of Texas at Austin \\ in Partial Fulfillment \\ of the Requirements \\ for the Degree of
}

Doctor of Philosophy

The University of Texas at Austin

August, 2002 


\section{Dedication}

To my wife Ye Feng 


\section{Acknowledgments}

I am grateful to Dr. Sharma and Dr. Martin E. Chenevert for their continuous technical and financial support throughout my graduate research. Their friendship, enthusiasm, experience, and knowledge were essential for this work.

I would like to thank Dr. Augusto L. Podio, Dr. Carlos Torres-Verdin, and Dr. Lynn E. Katz, for managing time out of their busy schedules to read this dissertation and provide their valuable comments and suggestions.

I am also indebted to my friend Mr. Guizhong Chen and Jianguo Zhang for their friendship and help.

I would like to thank the Department of Petroleum and Geosystems Engineering. The support and encouragement from other faculty and staff in the department are always in my heart.

My special gratitude is to my wife Ye Feng for her patience, support, understanding, and encouragement. 


\title{
CHEMICAL AND THERMAL EFFECTS ON WELLBORE STABILITY OF SHALE FORMATIONS
}

\author{
Publication No.
}

Mengjiao Yu, Ph.D.

The University of Texas at Austin, 2002

Supervisors: Mukul M. Sharma and Martin E. Chenevert

A new three-dimensional wellbore stability model is presented that takes into account thermal stresses and the flux of both water and solutes from drilling fluids (muds) into and out of shale formations. Mechanical stresses around a wellbore placed at any arbitrary orientation in a 3-dimensional stress field are coupled with changes in temperature and pore pressure due to water and solute fluxes. The radial and azimuthal variation in the stress distribution and the "failure index" are computed to check for wellbore failure. This model accounts for the hindered diffusion of solutes as well as the osmotically driven flow of water into the shale. The model for the first time allows a user to study the role of solute properties on wellbore stability.

Results from the model show that a maximum or minimum in pore pressure can be obtained within a shale. This leads to wellbore failure not always at the wellbore wall as is most commonly assumed but to failure at some distance inside the shale. Since the 
fluxes of water and solute, and temperature, are time dependent, a clearly time dependent wellbore failure is observed. The time to wellbore failure is shown to be related to the rate of solute and water invasion. Comparisons with experiments conducted with a variety of solutes on different shales show excellent agreement with model results.

It is shown in this study that the solutes present in the mud play an important role in determining not only the water activity but also in controlling the alteration of pore pressures in shales. To account for this phenomenon a model is presented to compute the flux of both water and solutes into or out of shales. The relative magnitudes of these fluxes control the changes in pore pressure in the shale when it is exposed to the mud. The effect of the molecular size of the solute, the permeability of the shale and its membrane efficiency are some of the key parameters that are shown to determine the magnitude of the osmotic contribution to pore pressure. A range of behavior is observed if the solute is changed while the water activity is maintained constant. This clearly indicates the importance of the solute flux in controlling the pore pressure in shales.

Critical mud weights are obtained by inspecting the stability of the wellbore wall and the entire near wellbore region. Pore pressures at different time and position are investigated and presented to explain the model results. It is shown in this study that the critical mud weights are strongly time dependent. The effects of permeability, membrane efficiency of shale, solute diffusion coefficient, mud activity and temperature changes are presented in this work. The collapse and fracture effects of cooling and heating the formations are also presented. 
A powerful simulation tool has been developed which can be used to perform thorough investigations of the wellbore stability problem. A user-friendly interface has been developed to ease usage. 


\section{Table of Contents}

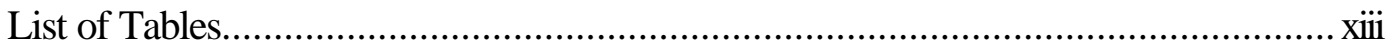

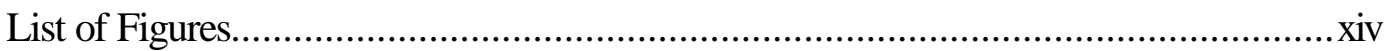

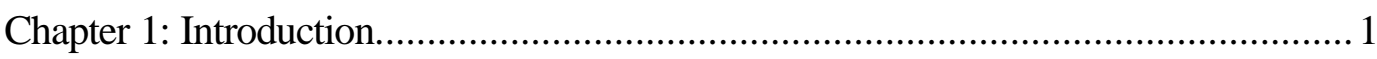

Chapter 2: A General Model for Water and Solute Transport in Shales...................... 7

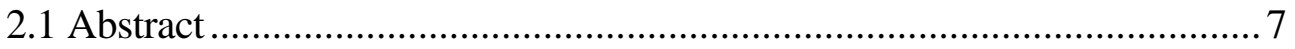

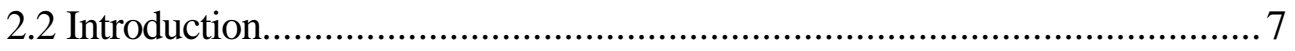

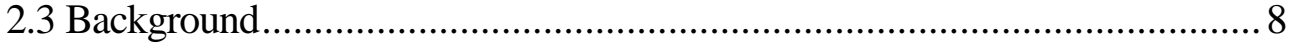

2.3.1 Reflection Coefficient .............................................................. 10

2.3.2 Modified Diffusion Potential......................................................... 11

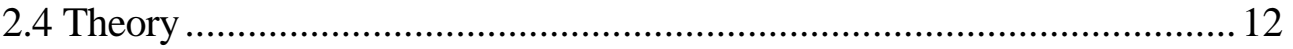

2.4.1 Model Formulation........................................................... 12

2.4.2 Boundary Conditions and Initial Condition: ............................... 15

2.4.3 Numerical Solution Procedure..................................................... 16

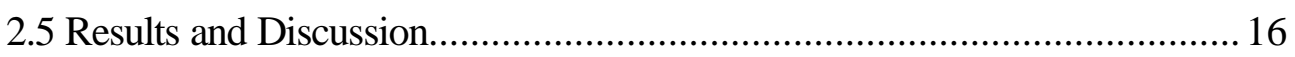

2.5.1 Comparison of Ideal and Non-Ideal Solutions ............................. 17

2.5.2 Mechanisms of Wellbore Instability/Shale Failure........................ 19

2.5.3 Flux of Water and Ions ......................................................... 20

2.5.4 Pore Pressure Profile .............................................................. 21

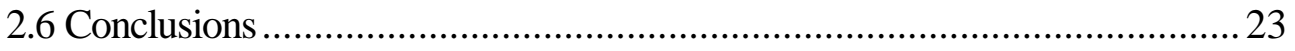

Chapter 3: Water and Ion Transport and its Impact on Swelling Pressures in Shales .. 43

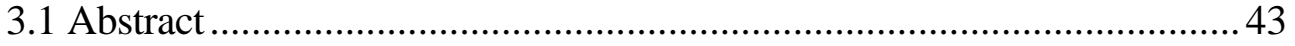

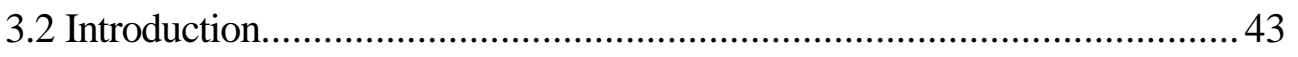

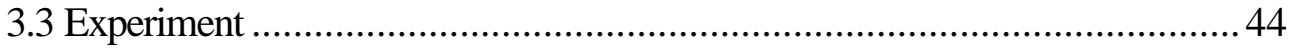




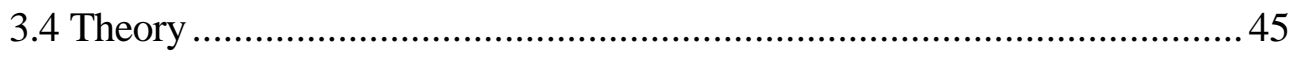

3.5 Experimental Results and Discussion.................................................... 47

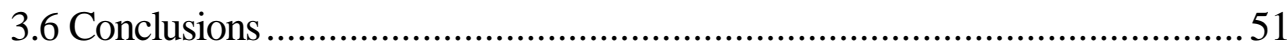

Chapter 4: Water \& Solute Transport in Shales: A Comparison of Simulations with

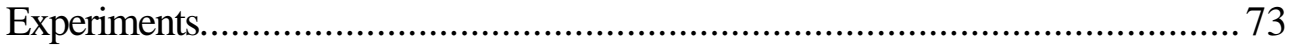

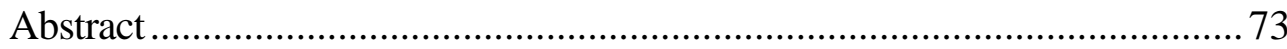

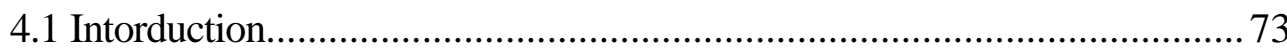

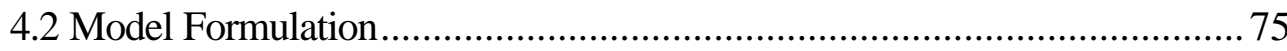

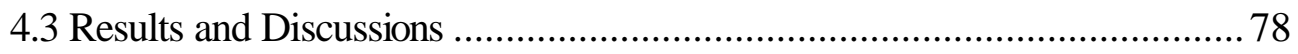

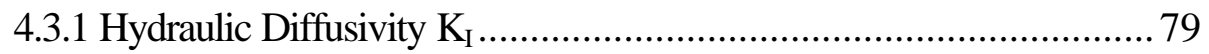

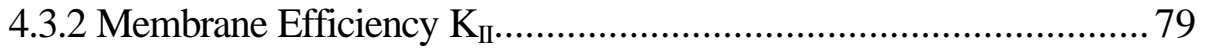

4.3.3 Comparison with Experiments........................................................ 81

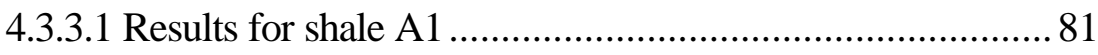

4.3.3.2 Results for shale N1....................................................... 82

4.3.3.3 Results for shale A2 ………………………………....... 83

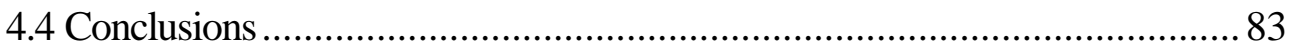

Chapter 5: Chemical-Mechanical Wellbore Instability Model for Shales ................... 102

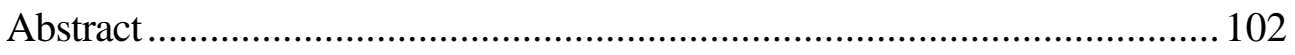

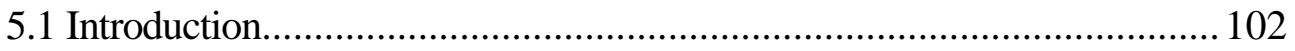

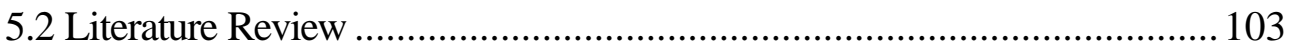

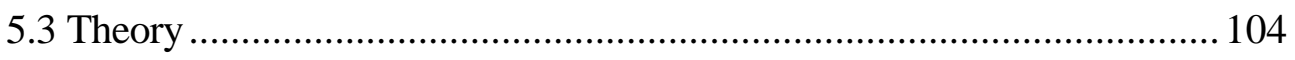

5.3.1 Near Wellbore Stress Distribution............................................... 104

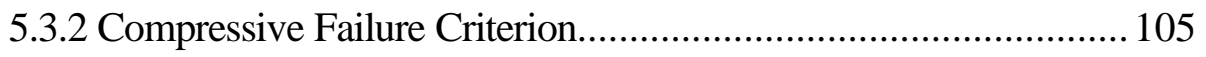

5.3.3 A Model for Pore Pressure Propagation........................................ 106

5.3.4 Estimating Model Input Parameters ............................................... 107

5.3.5 Computer Implementation of the Model....................................... 108 
5.3.6 Reducing Computation Time ……............................................... 108

5.3.7 Visual Wellbore Analysis Tool .......................................................110

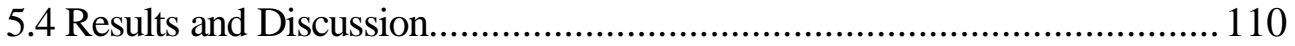

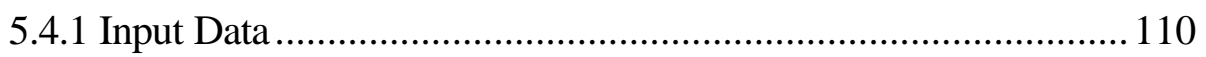

5.4.2 Pore Pressure Profile ……………………………………...... 110

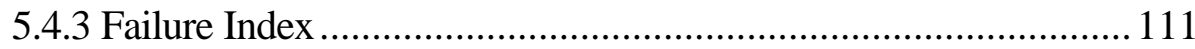

5.4.3.1 Failure at the Wellbore Wall................................................ 112

5.4.3.2 Failure Inside the Formation................................................ 112

5.4.3.3 Time Dependent Failure .................................................... 113

5.4.3.4 What Happens after Failure ............................................... 113

5.4.4 The Effect of Mud Weight.............................................................. 114

5.4.5 The Effect of Shale Properties...................................................... 115

5.4.6 The Effect of Solute Diffusivity ....................................................... 115

5.4.7 The Effect of Drilling Fluid Solute Concentration........................... 116

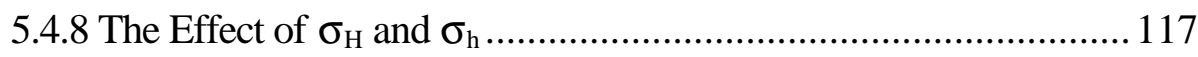

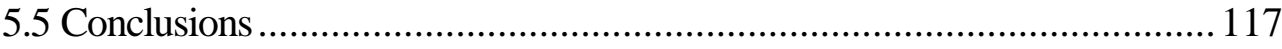

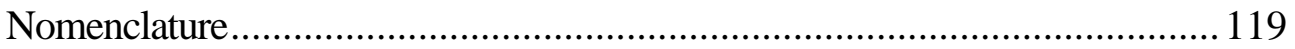

Chapter 6: Chemical and Thermal Effects on Wellbore Stability of Shale Formations 140

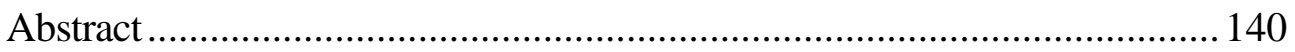

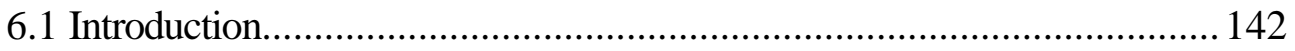

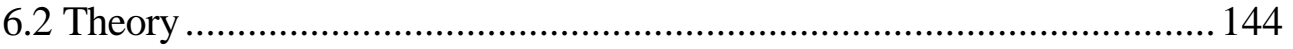

6.2.1 Stresses Induced by Pore Pressure and Formation Temperature Changes ............................................................................ 145

6.2.2 Solute Concentration Profile......................................................... 146

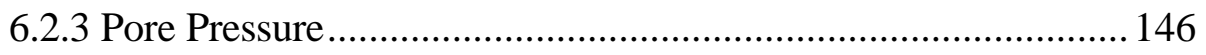

6.2.4 Formation Temperature ………….............................................. 147 


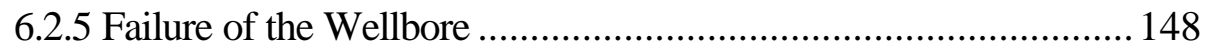

6.2.5.1 Collapse Failure .............................................................. 148

6.2.5.2 Tensile (Breakdown) Failure Criteria .................................. 148

6.3 Computer Implementation.................................................................... 149

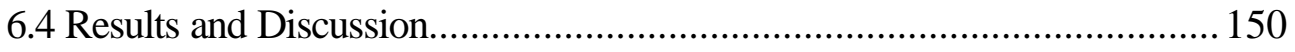

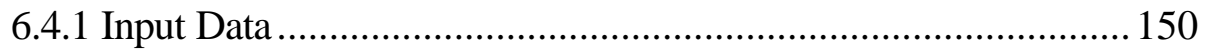

6.4.2 Effect of Hydraulic Diffusivity of the Shale ................................... 150

6.4.3 Effect of Membrane Efficiency ..................................................... 151

6.4.4 Effect of the Diffusion Coefficient ................................................. 152

6.4.5 Effect of Wellbore Inclination..................................................... 153

6.4.6 Effect of Drilling Fluid Concentration and Time-Dependent Collapse Mud Weight .................................................................... 153

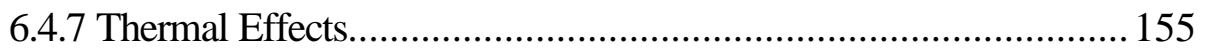

6.4.7.1 Effect of Cooling / Heating on Required Mud Weights ..... 155

6.4.7.2 Effect of Temperature Alterations on Mud Weights...........156

6.4.7.3 Effect of Thermal Expansion Coefficients on Mud Weights........................................................................... 156

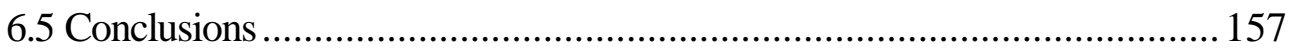

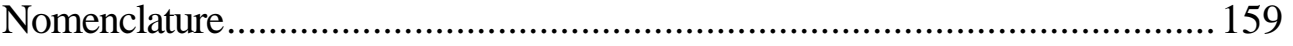

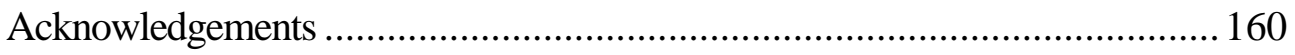

SI Metric Conversion Factors...................................................................... 161

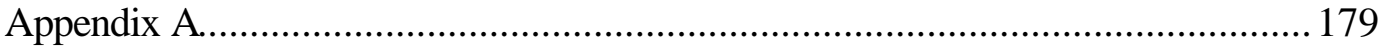

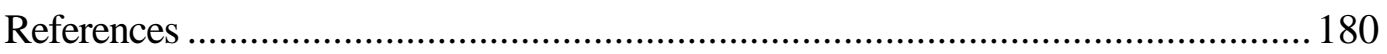

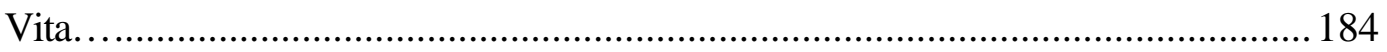




\section{List of Tables}

Table 2.1 Input data .................................................................................... 25

Table 3.1 Input data for comparison of model predictions with experimental data ......53

Table 3.2 Composition of interstitial pore water for Speeton shale [Simpson,1997] ...54

Table 4.1 Values of c and k reported by Ewy and Stankovich [2000]..................... 85

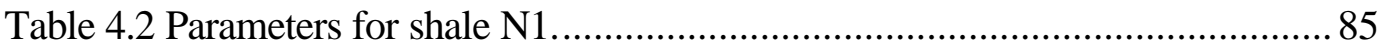

Table 4.3 Model parameters for Shale A2 ........................................................ 86

Table 5.1 Input data for the base case runs................................................. 121

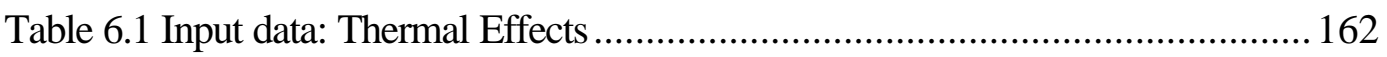

Table 6.2 Input data: Chemical Effects ........................................................ 162

Table 6.3 Input data: Mechanical Effects ......................................................... 163

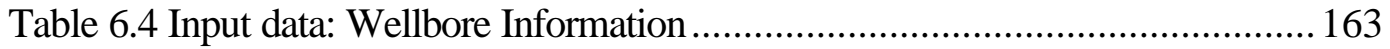

Table 6.5 Input data: Miscellaneous Parameters ............................................. 163 


\section{List of Figures}

Figure 1.1 Gulf of Mexico shale specimens after exposure to various drilling fluids with zero hydraulic pressure differential. (Simpson and

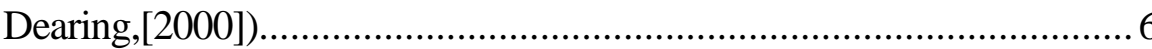

Figure 2.1 Water activity in $\mathrm{NaCl}$ solution as a function of $\mathrm{NaCl}$ concentration.

Data from E. C. W. Clarke and D. N. Grew, J. Phys. Chem. Ref.

Data, 1985, Vol. 14, No. 2, 489-610...............................................26

Figure 2.2 "Diffusion coefficients" for both ideal and non-ideal solutions as a

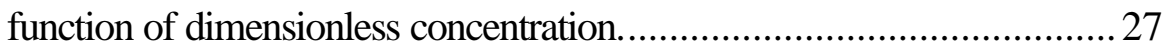

Figure 2.3 Dimensionless concentration profiles of ideal and non-ideal solutions.

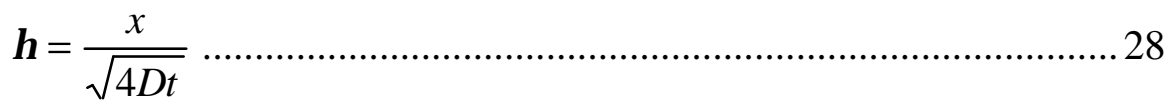

Figure 2.4 Concentration profiles for ideal solution model and non-ideal solution.

(Time $\mathrm{t}=3 \mathrm{hr}$ )

Figure 2.5 Dimensionless pressure profiles for free pressure transmission, ideal solution with osmotic effect and non-ideal solution with osmotic effect.

(Case I)

Figure 2.6 Buildup of pore pressure inside the shale due to water flux into the shale. Concentration of drilling fluid is $0.01 \mathrm{M}$ and the concentration of pore fluid inside the shale is $1 \mathrm{M}$. (Case II, $\mathrm{t}=3 \mathrm{hr}$ ).

Figure 2.7 Solute flux vs. time for ideal and non-ideal solution at shale surface $(\mathrm{x}=0) .($ Case II $)$ 
Figure 2.8 Solvent flux vs. time for ideal and non-ideal solution at shale surface

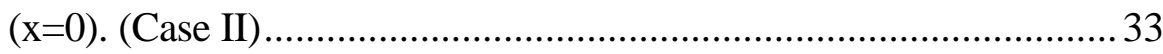

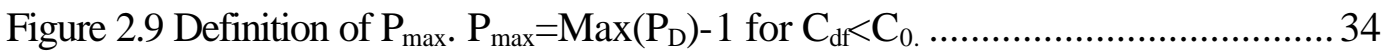

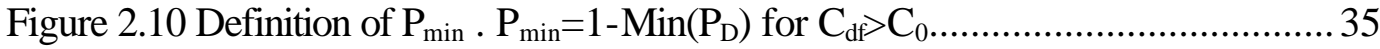

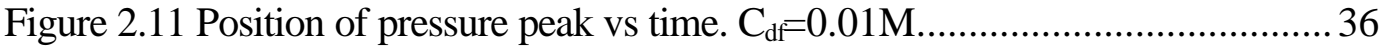

Figure $2.12 \mathrm{P}_{\max }\left(\mathrm{P}_{\min }\right)$ vs concentration of solute of the drilling fluid......................... 37

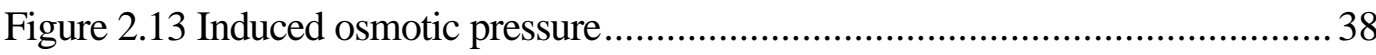

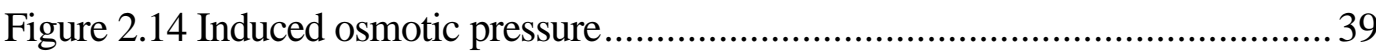

Figure 2.15 The effect of pore fluid concentration.............................................. 40

Figure 2.16 The effect of pore fluid concentration on peak pressure .......................41

Figure 2.17 The effect of pore fluid on pressure peak movement $\left(\mathrm{C}_{\mathrm{dr}}=0.01 \mathrm{M}\right) \ldots \ldots \ldots . .42$

Figure 3.1 Instrumented shale sample (Chenevert and Pernot [1998]) .......................55

Figure 3.2 Test flow chart (Chenevert and Pernot [1998]) ....................................56

Figure 3.3 Water activity in $\mathrm{CaCl}_{2}$ solutions. Data from B.R. Staples and R. L.

Nuttall, J. Phys. Chem. Ref. Data, 1977, Vol. 6, No.2, p. 385-407.....57

Figure 3.4 Diffusion coefficient as a function of dimensionless concentration...............58

Figure 3.5 Diffusion coefficient as a function of dimensionless concentration.

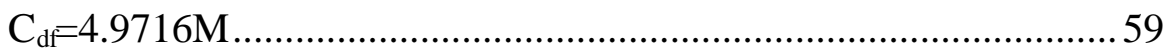

Figure 3.6 Pressure profiles in a constant volume swelling test ...............................60

Figure 3.7 Diffusion coefficient as a function of dimensionless concentration..............6 61

Figure 3.8 Dimensionless concentration profiles calculated from ideal model and non-ideal model.

Figure 3.9 Concentration profile at different time. This concentration profile was computed from the non-ideal model. 
Figure 3.10 Solute flux from the non-ideal model for $\mathrm{C}_{\mathrm{df}}=2.1912 \mathrm{M}$ and

$\mathrm{C}_{\mathrm{df}}=4.9716 \mathrm{M}$. High bulk concentration gives a higher solute flux

Figure 3.11 Water flux from the non-ideal model for $\mathrm{C}_{\mathrm{dr}}=2.1912 \mathrm{M}$ and

$\mathrm{C}_{\mathrm{dr}}=4.9716 \mathrm{M}$. High bulk concentration gives a higher water flux 65

Figure 3.12 Hydraulic pressure profile at different time. This profile was computed

from the non-ideal model.

Figure 3.13 Average hydraulic pressure varies with time from ideal model and nonideal model.

Figure 3.14 Average solute concentration inside the shale varies with time computed from ideal model and non-ideal model. 68

Figure 3.15a The average hydraulic pressure, osmotic pressure and total pressure from non-ideal model for $\mathrm{C}_{\mathrm{dr}}=2.1912 \mathrm{M}$.

Figure 3.15b The Average hydraulic pressure, osmotic pressure and total pressure from non-ideal model for $\mathrm{C}_{\mathrm{d} f}=4.9716 \mathrm{M}$.

Figure 3.16 Comparison of model and experimental data for $\mathrm{C}_{\mathrm{d}}=2.1912 \mathrm{M}$. In this case both the ideal model and non-ideal model give good agreement....71

Figure 3.17 Comparison of model and experimental data for $\mathrm{C}_{\mathrm{d}}=4.9716 \mathrm{M}$. In this case the non-ideal model gives good agreement but the ideal doesn't. .. 72

Figure 4.1 Schematic of shale sample assembly and loading. Ewy and Stankovich [2000]

Figure 4.2 Dimensionless pore pressure as a function of time for different hydraulic diffusion coefficient $\mathrm{K}_{\mathrm{I}}$. No chemical effects applied on shale..... 88

Figure 4.3 Pore pressure as a function of time under large membrane efficiency condition. 89 
Figure 4.4 Pore pressure as a function of time under median membrane efficiency condition.

Figure 4.5 Summary of model parameters and their effects in controlling the behavior of pore pressure. 91

Figure 4.6a Measured pore pressure for shale A1 contacting with $272 \mathrm{~g} / \mathrm{L} \mathrm{NaCl}$.

No membrane behavior exhibited. 92

Figure 4.6b Measured pore pressure for shale A1 contacting with $156 \mathrm{~g} / \mathrm{L} \mathrm{NaCl}$.

No membrane behavior exhibited

Figure 4.7a Matching model predictions with measured data for shale N1 contacting with $267 \mathrm{~g} / \mathrm{L} \mathrm{CaCh}$ to obtain parameters. $\mathrm{P}_{\mathrm{w}}=985 \mathrm{psi}$, $\mathrm{P}_{\mathrm{o}}=15 \mathrm{psi}$

Figure 4.7b Comparison of model predictions with experimental data for shale N1 contacting with $413 \mathrm{~g} / \mathrm{L} \mathrm{CaCh}$ (using parameters obtained from Figure

4.7a). $P_{w}=995 p s i, P_{o}=60 p s i$

Figure 4.8a Matching model predictions with measured data for shale N1 contacting with $272 \mathrm{~g} / \mathrm{L} \mathrm{NaCl}$ to obtain parameters. $\mathrm{P}_{\mathrm{w}}=965 \mathrm{psi}$, $\mathrm{P}_{\mathrm{o}}=10 \mathrm{psi}$. 96

Figure 4.8b Comparison of model predictions with experimental data for shale N1 contacting with $156 \mathrm{~g} / \mathrm{L} \mathrm{NaCl}$ (using parameters obtained from Figure 4.8a). $P_{w}=940 p s i, P_{o}=120 p s i$.

Figure 4.9a Matching model predictions with measured data for shale A2 contacting with $267 \mathrm{~g} / \mathrm{L} \mathrm{CaCh}$ to obtain parameters. $\mathrm{P}_{\mathrm{w}}=1020 \mathrm{psi}, \mathrm{P}_{\mathrm{o}}=5 \mathrm{psi}$. 98 
Figure 4.9b Comparison of model predictions with experimental data for shale A2 contacting with $413 \mathrm{~g} / \mathrm{L} \mathrm{CaCh}$ (using parameters obtained from Figure 4.9a). $P_{w}=955 p s i, P_{0}=50 p s i$ 99

Figure 4.10a Matching model predictions with measured data for shale A2 contacting with $272 \mathrm{~g} / \mathrm{L} \mathrm{NaCl}$ to obtain parameters. $\mathrm{P}_{\mathrm{w}}=1030 \mathrm{psi}$, $\mathrm{P}_{\mathrm{o}}=0$ psi. 100

Figure 4.10b Comparison of model predictions with experimental data for shale A2 contacting with $156 \mathrm{~g} / \mathrm{L} \mathrm{NaCl}$ (using parameters obtained from Figure 4.10a). $P_{w}=1035 p s i, P_{o}=15 p s i$ 101

Figure 5.1 Wellbore configuration and definition of axes and angles...................... 122

Figure 5.2 Wellbore configuration. 123

Figure 5.3 Boundary conditions and initial conditions used.

Figure 5.4 Laboratory measurement of shale properties needed for the model. ........ 125

Figure 5.5 A comparison of numerical and hybrid numerical model....................... 126 Figure 5.6 Pore pressure profile at $\mathrm{t}=5 \mathrm{hr}, \mathrm{C}_{\mathrm{dr}}=4 \mathrm{M} \mathrm{C} \mathrm{C}_{0}=1 \mathrm{M}$. Water is being sucked out of the shale as solutes migrate in.

Figure 5.7 Pore pressure profile at $\mathrm{t}=5 \mathrm{hr}, \mathrm{C}_{\mathrm{dr}}=0.01 \mathrm{M} \mathrm{C}=1 \mathrm{M}$. Here water is being sucked into the shale as solutes are pushed out. This leads to a maximum in pore pressure away from the wellbore wall.

Figure 5.8 An example of Failure at the wellbore wall. (Parameters used are listed in Table 5.1)

Figure 5.8b Failure at wellbore wall. Red color and yellow color indicate failure. 129

Figure 5.9 An example of failure inside the formation. (MW=18lbm/gal, $\mathrm{C}_{\mathrm{dr}}=4 \mathrm{M}$,

$$
\left.\mathrm{C}_{\mathrm{o}}=1 \mathrm{M} \text {, Vertical well, } \sigma_{\mathrm{h}}=\sigma_{\mathrm{H}}\right)
$$


Figure 5.10 An example of time dependent failure ( $r_{w}=5$ in). The wellbore starts to become unstable after 12 hours.

Figure 5.10b A graphical representation of time dependent failure $\left(r_{w}=5\right.$ in). The read and yellow colors indicate failure.

Figure 5.11 Time dependent failure. $r_{w}=15$ in. This graph demonstrates that increasing wellbore radius makes the borehole more stable. This implies that the borehole will achieve an enlarged stable radius.

Figure 5.12 The effect of mud weight on Failure Index. Clearly, as expected, increasing MW leads to stable boreholes.

Figure 5.13a The effect of diffusion coefficient $\mathrm{D}_{\text {eff }}$ on Failure Index. $(\mathrm{t}=6 \mathrm{hr})$. Slower diffusing solutes lead to more unstable boreholes.

Figure 5.13b The effect of diffusion coefficient $\mathrm{D}_{\mathrm{eff}}$ on Failure Index. $(\mathrm{t}=15 \mathrm{hr})$.

Figure 5.14 The effect of drilling fluid salt concentration on Failure Index. Increasing the salt concentration helps to stabilize the wellbore.

Figure 5.15 Stresses and reference coordinate systems (a) In - situ stresses; (b)

Stresses in the local wellbore coordinate system.

Figure 5.16 The effect of maximum and minimum horizontal stress. Stress anisotropy can induce failure.

Figure 5.17 The effect of wellbore azimuth $\left(\sigma_{\mathrm{h}}=0.75, \sigma_{\mathrm{H}}=0.83\right)$. Larger well inclinations usually lead to less stable boreholes.

Figure 6.1 Example of the thermal inputs and the mud-weight-window output for various drilling fluid concentrations

Figure 6.2 Output example of pore pressure distribution around a wellbore after 1 hour. 165 
Figure 6.3 Pore pressure under different permeability conditions as a function of distance from the wellbore surface.................................................. 166

Figure 6.4 Minimum mud weight required to prevent wellbore collapse as a function of hydraulic diffusivity.

Figure 6.5 Minimum mud weight required to prevent wellbore collapse as a function of membrane efficiency.

Figure 6.6 Minimum mud weight required to prevent wellbore collapse as a function of the diffusion coefficient.

Figure 6.7 Minimum mud weight required to prevent wellbore collapse for deviated wells having effective chemical and non-chemical factors acting. 170

Figure 6.8 Pore pressure profiles as a function of distance from the wellbore surface, time, and drilling fluid solute concentration greater than shale. 171

Figure 6.9 Pore pressure profiles as a function of distance from the wellbore surface, time, and drilling fluid solute concentration less than shale..... 172

Figure 6.10 Minimum mud weight required to prevent wellbore collapse as a function of drilling fluid solute concentration. 173

Figure 6.11 Thermal effects on breakdown mud weights for inclined wellbores........ 174

Figure 6.12 Thermal effects on collapse mud weights for inclined wellbores. 175

Figure 6.13 Effect of temperature changes on critical mud weights for vertical wellbores

Figure 6.14 Effect of temperature changes on critical mud weights for horizontal wellbores

Figure 6.15 Effect of thermal expansion coefficients on breakdown mud weights. .... 178 


\section{Chapter 1: Introduction}

Drilling through shale formations often results in wellbore instability problems. Shale failure usually results from reactions between the highly water-sensitive shales and the drilling fluid. The low permeability of shales and the presence of ions and charged surfaces on the constituent clays are factors which make such problems very complex even though numerous efforts have been dedicated to such studies in the past.

It has been estimated that shales make up more than $75 \%$ of drilled formations and cost more than $90 \%$ of all wellbore instability problems. Borehole instability problems cause the industry more than $\$ 1$ billion USD/year. Fundamentally, wellbore stability is a function of how a drilled rock unit behaves in response to the mechanical stresses around a well. Rock failure occurs when the stress exceeds rock strength. Chemical and thermal interactions between the mud and the shale significantly affect the in-situ stress state.

In some cases this problem can be overcome by using oil-based muds. However, environmental concerns have resulted in progressively less frequent use. The industry is thus faced with the need for an environmentally safe water-based fluid. Most water-based fluids are environmentally acceptable, however they lack the inhibitive characteristics of oil-based muds. Unlike oil-based muds, the absence of a semipermeable membrane enables the ions in water-based muds to interact with the pore 
fluid as well as the charged surfaces of clays resulting in the generation of large swelling pressures.

Experimental results have proved the existence of chemical effects on shale pore pressure (Mody and Hale [1993]; Chenevert and Pernot [1998]; O’Brien et al [1996]). Considerable efforts have been made towards modeling borehole instability problems (Wang [1992]; Cui et al [1995], Sherwood [1993]; Mody \& Hale [1993]). None of these studies consider transient effects, and borehole failure only occurs at the wellbore surface. However, field experience and lab observations clearly show that shale failure can occur at some distance inside the shale (Simpson and Dearing [2000]). Also, borehole failure is observed to be strongly time dependent(Simpson and Dearing [2000]).

Typically wellbore instability results in large pieces of shale (i.e. $100 \mathrm{~cm}^{3}$ ) breaking off the wellbore wall, falling to the bottom of the hole, or sticking the drill pipe. This results in drilling delays that can result in additional costs of several hundred thousand dollars. Figure 1.1 shows laboratory results (Simpson and Dearing [2000]) for a wellbore that experienced shale failure after being exposed to a drilling fluid for 53 hours. Analysis of the failed shale pieces showed that failure was probably caused by the invasion of ions. Such ionic flow, as well as water flow, is the main focus of this thesis.

The inability of existing models to predict time dependent wellbore failure inside the shale or to explain the role of solutes is the primary motivation for developing the model presented in this dissertation. 
Shales can be classified as membranes according to Lakshminarayanaiah's [1969] definition: "a phase, usually heterogeneous, acting as a barrier to the flow of molecular and ionic species present in the liquid and/or vapors contacting the two surfaces". The unique properties that distinguish shales from other rocks are related to the problems experienced in drilling though shale formations. The work presented herein is directed towards better understanding these problems. The dissertation is organized as follows.

A general membrane model for non-ideal solutions and shales is presented in Chapter 2. The model provides good insight into the membrane behavior of shales when contacted with water-based fluids. The reflection coefficient provides a measure of the ideality of the shale. The modified diffusion potential is calculated using the model presented. Hydraulic potential, osmotic potential and electrical potential are coupled to calculate the solvent flux, solute flux, and electrical current. A set of phenomenological coefficients is used to couple the driving forces. The reflection coefficient, liquid junction potential and modified diffusion potential can be written in terms of these phenomenological coefficients.

The main objective of the transient flow model presented in Chapter 2 is to provide a way to determine the hydraulic pressure and the solute concentration profiles within the formation as a function of time. The model provides a means for quantifying the problem for a given set of operational conditions. A concentration profile and hydraulic pressure profile for shales are computed from this model. Ionic flow is studied in detail. Non-ideal effects are taken into account to accurately model water and ions fluxes and swelling pressure in the shale. Chemical effects are studied to understand the 
behavior of ions and water transport in shales. The model provides useful information on the transient processes that occur in shales.

The transient flow model presented in Chapter 2 provides an excellent tool for the study of pore pressure variations that occurrs in shales. Chapter 3 is an application of this model that explains the experiments performed by Pernot et al [1998]. In their experiments, the pressure inside the shale was controlled by the hydraulic and osmotic potential. The model presented in Chapter 2 is compared with the experimental data presented in Chapter 3.

R. Ewy et. al. [2000] performed lab tests that recorded the transient pore pressure on one side of the test samples with a no-flow boundary condition on the other side. The model presented in Chapter 2 is compared with experimental data presented by Ewy and Stankovich [2000] in Chapter 4. After the model has been calibrated with one set of experimental data, predictions under other operation conditions can be made. It is shown that the hydraulic conductivity, the membrane efficiency, and the effective diffusion coefficient all have an influence on the pore pressure. Different boundary conditions (no-flow boundary conditions) are applied to the model presented in Chapter 2 so as to simulate the experiments.

The wellbore stability problem experienced in drilling operations is a complicated problem and chemical effects are only one of the important factors in controlling wellbore stability. Chemical effects play a role through changes in pore pressure, which affects the stresses distributions around the wellbore. In Chapter 5, the chemical effects are coupled with the mechanical model to study the more complete problem. Based on the study performed in Chapters 3 and 4, the hydraulic pressure within the shale formations can be increased (or decreased) a considerable amount by 
chemical effects. This phenomenon can greatly alter the stresses around a wellbore. Therefore chemical effects must be taken into account to accurately compute the stresses around the wellbore. The model presented in Chapter 5 combines the chemical model presented in Chapter 2 with traditional rock mechanics model. Unlike traditional mechanics models, this chemical-mechanical wellbore instability model reveals many new views of the wellbore stability problem. For example, traditional models only predict failure on the wellbore surface, but the model presented in Chapter 5 produces three different types of failure. A wellbore can fail at the wellbore surface, inside the formation, and fail with time dependent characteristics (stable when drilled, but fail after a specific time).

In Chapter 6 thermal effects are included into the chemical-mechanical wellbore instability model for shales (presented in Chapter 5). Thermal effects affect mainly the matrix stress, not the pore pressure. A comprehensive program was developed in Chapter 6 that can calculate the pore pressure, stresses distributions, and mud weight window for different depths, well inclinations and wellbore azimuth. This is a very timeconsuming program, and significant effort was made to make this program run faster by simplifying the equations. This simulator was developed in FORTRAN. It was therefore coupled to a user-friendly program in Visual Basic (DRILLER) for better input/output. 

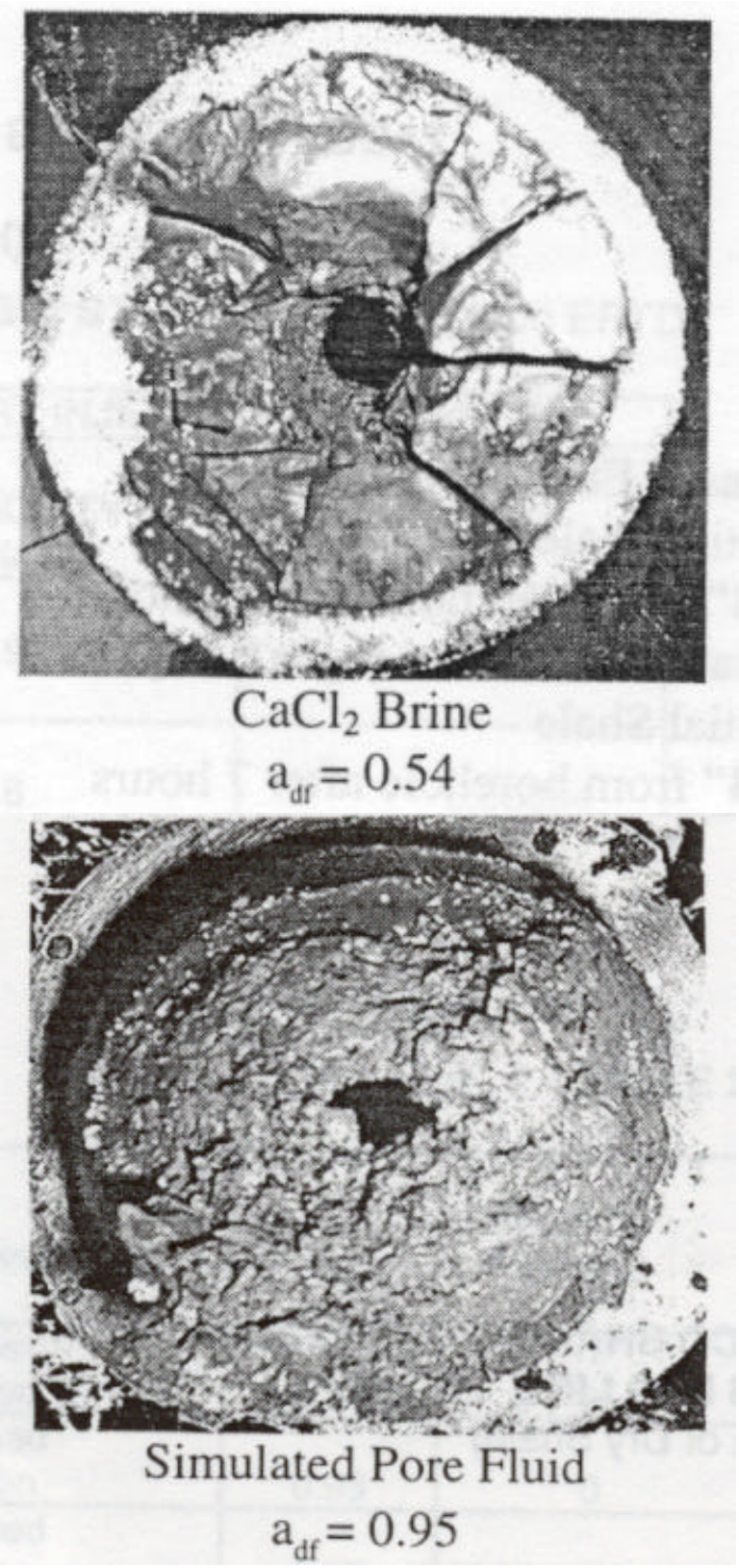

Figure 1.1 Gulf of Mexico shale specimens after exposure to various drilling fluids with zero hydraulic pressure differential. (Simpson and Dearing,[2000]) 


\section{Chapter 2: A General Model for Water and Solute Transport in Shales}

\subsection{ABSTRACT}

A model is presented for the flux of solutes and water into a shale separated by non-ideal solutions. The non-ideality of the electrolyte solutions, both in the bulk and in the shale, are shown to have a significant influence on the computed fluxes and pressures. It is clearly shown that coupling ion and water fluxes together with hydraulic pressures can be used to explain the mechanism of shale failure when the activity of the water and ions inside the shale are different than that in the bulk solution. Osmotic pressure effects are shown to play an important role in controlling the fluxes. Since osmotic pressure is largely determined by the activity coefficient of the ions and water, non-ideal effects must be taken into account to accurately model water and ions fluxes and swelling pressures in the shale.

\subsection{INTRODUCTION}

With increasing environmental demands placed on oil-based drilling fluids, the use of water based muds (WBM) is growing. The use of such mud systems when drilling through troublesome shales can often result in wellbore instability problems due to shale swelling. It has been well documented that the response of swelling shales on wellbore stability depends to a very large extent on the activity of the water and the type of solute present in the aqueous phase of the mud.

This imbalance in water activity between the shale and the WBM induces osmotic flows of ions and water which can cause shale instability. This implies that 
manipulation of the chemical potential or activity of water and ions in WBMs should allow us to better control the stability of shales during drilling. Past work on shale instability has focused on the transport of water into or out of the shale. Lomba et al [2000] pointed out that both the fluxes of water and ions were important. They presented a model for water and ion flux that assumed that the electrolyte solutions were ideal. This provides us with great insight into the problem but does not allow us to make accurate calculations under most realistic conditions which involve non-ideal electrolyte solutions.

This work presents a general model for non-ideal solutions that can be applied to concentrated electrolyte solutions.

\subsection{BACKGROUND}

Near thermodynamic equilibrium, for small concentration gradients the flux of solute and solvent through a membrane is given by,

$$
\left[\begin{array}{c}
J_{V} \\
J_{S} \\
I
\end{array}\right]=\left[\begin{array}{lll}
L_{11} & L_{12} & L_{13} \\
L_{21} & L_{22} & L_{23} \\
L_{31} & L_{32} & L_{33}
\end{array}\right]\left[\begin{array}{c}
\left(\Delta P-\Delta \Pi_{S}\right) \\
\left(\frac{\Delta \Pi_{S}}{C_{S}}\right) \\
\Delta \Phi
\end{array}\right]
$$

where $\mathrm{J}_{\mathrm{V}}$ is the volumetric flow rate of solvent. $\mathrm{J}_{\mathrm{s}}$ and I are the molar flux of solute and electric current. $\Delta \mathrm{P}, \Delta \Pi_{\mathrm{S}}$ and $\Delta \Phi$ are hydraulic pressure, osmotic pressure and electrical potential gradients in the direction of the flow, respectively. $\mathrm{C}_{\mathrm{S}}$ is the concentration of the solute in the solution. $\mathrm{I}_{\mathrm{ij}}$ are phenomenological coefficients that couple the fluxes and driving forces. According to the "Onsager [1931] reciprocal relations", $\mathrm{L}_{\mathrm{ij}}=\mathrm{L}_{\mathrm{ji}}$. 
Rearranging the above equation yields the following expression:

$$
\left[\begin{array}{c}
J_{V} \\
J_{D} \\
I
\end{array}\right]=\left[\begin{array}{lll}
K_{11} & K_{12} & K_{13} \\
K_{21} & K_{22} & K_{23} \\
K_{31} & K_{32} & K_{33}
\end{array}\right]\left[\begin{array}{c}
(\Delta P) \\
\left(\Delta \Pi_{S}\right) \\
\Delta \Phi
\end{array}\right]
$$

We define $J_{D}$ as the differential flow of solute relative to solvent and is given by the following equation:

$$
J_{D}=\frac{J_{S}}{C_{S}}-J_{V}
$$

The phenomenological coefficients are related by the following equations:

$$
\begin{aligned}
& K_{11}=L_{11} \\
& K_{12}=\frac{L_{12}}{C_{S}}-L_{11} \\
& K_{13}=L_{13} \\
& K_{21}=\frac{L_{21}}{C_{S}}-L_{11} \\
& K_{22}=\frac{L_{22}}{C_{S}^{2}}-\frac{L_{21}}{C_{S}}-\frac{L_{12}}{C_{S}}+L_{11} \\
& K_{23}=\frac{L_{23}}{C_{s}}-L_{13} \\
& K_{31}=L_{31} \\
& K_{32}=\frac{L_{32}}{C_{S}}-L_{31} \\
& K_{33}=L_{33}
\end{aligned}
$$

where $\mathrm{C}_{\mathrm{S}}$ is the mean solute concentration between the two systems that are separated by the membrane and it may be regarded as the bulk solute concentration inside the membrane. 
For idealized geometries (such as a cylindrical capillary tube) expressions for the nine phenomenological coefficients $\left(\mathrm{K}_{\mathrm{ij}}\right)$ can be obtained from a solution of the Poisson-Boltzmann (PBE), Navier-Stokes (NSE), and Nernst-Planck (NPE) equations.

Gross and Osterle [1968] developed a space-charge model for charged porous membranes. This model presents equations for the nine coefficients $\left(\mathrm{K}_{\mathrm{ij}}\right)$ coupling the various transport processes. Basu and Sharma [1997] modified the governing equations to account for finite ion sizes, for ion hydration effects, and for variations in dielectric constant. Lomba et al [2000 a, b] presented a transient flux model for ideal solutions. Solute and water fluxes were calculated based on the model.

Sherwood [1995] pointed out that ion exchange plays an important role, affecting not only the rates of transport of ions, but also the mechanical and swelling properties of the shale. The equilibrium state of shale was assumed to be independent of composition and only dependent on the pore pressure. For simplicity, the solution in the pore was ideal with only a single solute present.

Van Oort [1997] presented solutions for fluid pressure, solute diffusion and filtrate invasion around a wellbore. Transient effects were not considered in the study, however, these effects play an important role and affect pressure transmission and solute diffusion.

\subsubsection{Reflection Coefficient}

Kedem and Katchalsky [1962] derived two equations relating the flux of the solvent and solute to differences in hydrostatic and osmotic pressure across membranes (such as shales): 


$$
\begin{aligned}
& J_{V}=L_{p} \Delta P-\sigma L_{P} \Delta \Pi \\
& J_{S}=C_{S}(1-\sigma) J_{V}+\varpi \Delta \Pi
\end{aligned}
$$

The ideality or membrane efficiency of shale membranes may be defined in different ways. Katchalsky and Curran [1965] defined he reflection coefficient to describe the membrane ideality. "Leaky" shales behave as non-ideal semipermeable membranes with reflection coefficient between zero and 1 .

The reflection coefficient can be derived from the flux equations. If we set the flow of solvent to zero and assume that the overall electric current is also zero in Equation 2-2, the reflection coefficient then can be given by

$$
\sigma=\left(\frac{\Delta P}{\Delta \pi}\right)_{J_{v}=0}=\frac{K_{12}-\frac{K_{13} K_{32}}{K_{33}}}{K_{11}-\frac{K_{13} K_{31}}{K_{33}}}
$$

The reflection coefficient provides a measure of osmotic pressures that develop in response to an applied concentration gradient. The closer the reflection coefficient is to 1 , the more the shale/electrolyte system approaches the situation represented by a perfect semi permeable membrane.

\subsubsection{Modified Diffusion Potential}

The reflection cefficient is just one measure of the membrane efficiency of shales. Another way to evaluate the membrane efficiency is the modified diffusion potential. The magnitude of the modified diffusion potential reflects the membrane character of the shale. 
The modified diffusion potential $\left(\mathrm{E}_{\mathrm{p}}\right)$ can be evaluated from the model by setting the electric current equal to zero in Equation 2-1 under conditions where no hydraulic pressure gradient exists.

$$
E_{p}=\left(\frac{\Delta \phi}{\Delta \log C_{s}}\right)_{I=0, \Delta P=0}
$$

The modified diffusion potential can then be given in terms of the phenomenological coefficients by the following equation:

$$
E_{p}=-n_{i} R T C_{s} \frac{K_{32}}{K_{33}}
$$

The value of the modified diffusion potential reflects how close a shale is to a perfect semi-permeable membrane.

\subsection{THEORY}

\subsubsection{Mode I Formulation}

The water activity of the solution is a function of solute concentration,

$$
a_{W}=f\left(C_{S}\right)
$$

The activity of water in different electrolyte solutions can be found from experimental data reported in the literature. Figure 2.1 shows the water activity in a $\mathrm{NaCl}$ solution vs $\mathrm{NaCl}$ concentration as an example.

The osmotic pressure can be computed by the following equation:

$$
\Pi_{S}=-\frac{R T}{V} \ln \left(\frac{a_{W}^{1}}{a_{W}^{b}}\right)=-\frac{R T}{V} \ln \left(\frac{f\left(C_{S}^{1}\right)}{f\left(C_{S}^{b}\right)}\right)
$$

The phenomenological coefficients $\mathrm{L}_{\mathrm{ij}}$ and $\mathrm{K}_{\mathrm{ij}}$ are independent of $\Delta \mathrm{P}, \Delta \Pi_{\mathrm{S}}$ and $\Delta \Phi$. The osmotic pressure gradient can be written as: 


$$
\Delta \Pi_{S}=\frac{R T}{V} \frac{f^{\prime}\left(C_{S}\right)}{f\left(C_{S}\right)} \frac{d C_{S}}{d x}
$$

The continuity equation for the solute can be written as:

$$
\frac{\partial C_{S}}{\partial t}+\frac{\partial J_{S}}{\partial x}=0
$$

where $C_{s}$ is the solute concentration and $J_{s}$ is the solute flux.

Equating the overall current (Equation 2-1) to zero, $\Delta \Phi$ in Equation 2-1 can be solved in terms of $\Delta \mathrm{P}, \Delta \Pi_{\mathrm{s}}$ and the phenomenological coefficients. Equating the overall electric current given by Equation 2-1 to zero $(\mathrm{I}=0)$, and rearranging the equation, the following equation is obtained:

$$
J_{S}=L_{I}\left(\Delta P-\Delta \Pi_{S}\right)+L_{I I} \frac{\Delta \Pi_{S}}{C_{S}}
$$

$\mathrm{L}_{\mathrm{I}}$ and $\mathrm{L}_{\mathrm{II}}$ are coefficients given by the following equations:

$$
\begin{aligned}
& L_{I}=L_{21}-\frac{L_{23} L_{31}}{L_{33}} \\
& L_{I I}=L_{22}-\frac{L_{23} L_{32}}{L_{33}}
\end{aligned}
$$

For one dimensional diffusion, we can substitute Equation 2-20 into Equation 222 to get:

$$
J_{S}=-L_{I} \frac{\partial P}{\partial x}+\left(\frac{L_{I I}}{C_{S}}-L_{I}\right) \frac{R T}{V} \frac{f^{\prime}\left(C_{S}\right)}{f\left(C_{S}\right)} \frac{d C_{S}}{d x}
$$

Inserting Equation 2-24 into this continuity equation yields:

$$
\frac{\partial C_{S}}{\partial t}+\frac{\partial}{\partial x}\left\{-L_{I} \frac{\partial P}{\partial x}+\left(\frac{L_{I I}}{C_{S}}-L_{I}\right) \frac{R T}{V} \frac{f^{\prime}\left(C_{S}\right)}{f\left(C_{S}\right)} \frac{\partial C_{S}}{\partial x}\right\}=0
$$

We make the assumption that $L_{I} \frac{\partial^{2} P}{\partial x^{2}}<<1$ (see Lomba et al [2000]). The above equation can be simplified to: 


$$
\frac{\partial C_{S}}{\partial t}+\frac{\partial}{\partial x}\left\{\left(\frac{L_{I I}}{C_{S}}-L_{I}\right) \frac{R T}{V} \frac{f^{\prime}\left(C_{S}\right)}{f\left(C_{S}\right)} \frac{\partial C_{S}}{\partial x}\right\}=0
$$

The above equation is in the form of a diffusivity equation with the "diffusion coefficient" (D) given by,

$$
D=-\frac{R T}{V}\left(\frac{L_{I I}}{C_{S}}-L_{I}\right) \frac{f^{\prime}\left(C_{S}\right)}{f\left(C_{S}\right)}
$$

Equation 2-26 can be written as:

$$
\frac{\partial C_{S}}{\partial t}+\frac{\partial}{\partial x}\left\{-D \frac{\partial C_{S}}{\partial x}\right\}=0
$$

The conservation of mass applied to the solvent can be written as:

$$
\frac{\partial \rho}{\partial t}+\frac{\partial}{\partial x}\left(\rho J_{v}\right)=0
$$

where $\rho$ is the fluid density and $\mathrm{J}$ is the volumetric flux of solvent. For a slightly compressible fluid, its density can be related to the pressure as follows:

$$
\rho=\rho_{0} \exp \left[c\left(P-P_{0}\right)\right]
$$

where $c$ is the fluid compressibility.

Inserting this equation into Equation 2-29, the following equation can be obtained:

$$
\frac{\partial P}{\partial t}+J_{V} \frac{\partial P}{\partial x}+\frac{1}{c} \frac{\partial J_{V}}{\partial x}=0
$$

Again note that the overall current is zero and substituting the results into Equation 2-2 gives:

$$
J_{V}=K_{I} \Delta P+K_{I I} \Delta \Pi_{S}
$$

where $\mathrm{K}_{\mathrm{I}}$ and $\mathrm{K}_{\mathrm{II}}$ are given by :

$$
\begin{aligned}
& K_{I}=K_{11}-\frac{K_{13} K_{31}}{K_{33}} \\
& K_{I I}=K_{12}-\frac{K_{13} K_{32}}{K_{33}}
\end{aligned}
$$


For one dimensional diffusion, we can substitute Equation 2-20 into Equation 2-

32 and get:

$$
J_{v}=-K_{I} \frac{\partial P}{\partial x}+K_{I I} \frac{R T}{V} \frac{f^{\prime}\left(C_{S}\right)}{f\left(C_{S}\right)} \frac{\partial C_{S}}{\partial x}
$$

Inserting Equation 2-35 into Equation 2-31 gives the following equation:

$$
\frac{\partial P}{\partial t}+\left\{-K_{I} \frac{\partial P}{\partial x}+K_{I I} \frac{R T}{V} \frac{f^{\prime}\left(C_{S}\right)}{f\left(C_{S}\right)} \frac{\partial C_{S}}{\partial x}\right\} \frac{\partial P}{\partial x}+\frac{1}{c} \frac{\partial}{\partial x}\left\{-K_{I} \frac{\partial P}{\partial x}+K_{I I} \frac{R T}{V} \frac{f^{\prime}\left(C_{S}\right)}{f\left(C_{S}\right)} \frac{\partial C_{S}}{\partial x}\right\}=0
$$

Again the assumptions $\left(\frac{\partial P}{\partial x}\right)^{2}<<1$ and $\left(\frac{\partial P}{\partial x}\right)\left(\frac{\partial C_{S}}{\partial x}\right)<<1$ (see Lomba et al

[2000]) are made. Equation 2-36 simplifies to:

$$
\frac{\partial P}{\partial t}-\frac{K_{I}}{c} \frac{\partial^{2} P}{\partial x^{2}}+\frac{K_{I I}}{c} \frac{R T}{V} \frac{\partial}{\partial x}\left\{\frac{f^{\prime}\left(C_{S}\right)}{f\left(C_{S}\right)} \frac{\partial C_{S}}{\partial x}\right\}=0
$$

Equations 2-26 and 2-37 are the general equations for ion and water transport in shales for non-ideal electrolyte solutions.

\subsubsection{Boundary Conditions and Initial Condition:}

Two initial conditions and four boundary conditions are needed to obtain the concentration and pressure profile in the porous medium. The following initial conditions and boundary conditions are applied:

$$
\begin{array}{lll}
t=0 & 0 \leq x \leq \infty, & C_{S}=C_{0} ; P=P_{0} \\
x=0 & t>0, & C_{S}=C_{d f} ; P=P_{W} \\
x=\infty & t>0, & C_{S}=C_{0} ; P=P_{0}
\end{array}
$$

$\mathrm{C}_{0}$ and $\mathrm{P}_{0}$ are the original pore fluid concentration and pore pressure respectively. $\mathrm{P}_{\mathrm{w}}$ is the hydrostatic pressure at the wellbore wall. $\mathrm{C}_{\mathrm{df}}$ is the drilling fluid solute concentration. 
The coefficients $\mathrm{L}_{1}, \mathrm{~L}_{\mathrm{II}}, \mathrm{K}_{\mathrm{I}}$ and $\mathrm{K}_{\mathrm{II}}$ are assumed to be constant even though they can vary with concentration. Average values over the entire concentration range are used when solving the problem.

\subsubsection{Numerical Solution Procedure}

Equations 2-26 and 2-37 were solved numerically in dimensionless form. The following variables were defined:

$$
\begin{aligned}
& \eta=\frac{x}{\sqrt{4 D_{0} t}} \\
& C_{D}=\frac{C_{S}-C_{0}}{C_{d f}-C_{0}} \\
& P_{D}=\frac{P-P_{0}}{P_{W}-P_{0}}
\end{aligned}
$$

The boundary conditions in the transformed variables are as follows:

$$
\begin{array}{lll}
\eta=0 & C_{D}=1 & P_{D}=1 \\
\eta \rightarrow \infty & C_{D}=0 & P_{D}=0
\end{array}
$$

A computer program was developed in FORTRAN to solve the above equations numerically. The concentration and pressure profiles were computed.

\subsection{RESULTS AND DISCUSSION}

The results presented in this work are presented for $\mathrm{NaCl}$ solutions. Similar results can be obtained for solutes using the equations presented in this paper. Table 2.1 lists input data for the base case simulation results presented here. Figure 2.1 shows the water activity for $\mathrm{NaCl}$ solutions as a function of $\mathrm{NaCl}$ solution concentration. The data are fitted by a second order polynomial to be used in the numerical simulations. 


\subsubsection{Comparison of Ideal and Non-Ideal Solutions}

Equation 2-37, which is valid for non-ideal electrolytes, can be reduced to an equation for ideal solutions as follows. The activity $f\left(C_{s}\right)=1$ for ideal solutions.

For an ideally dilute solution:

$$
a_{W}=\gamma_{W} x_{W}=x_{W}=\left(1-n x_{S}\right)
$$

where $\mathrm{x}_{\mathrm{w}}$ and $\mathrm{x}_{\mathrm{s}}$ are mole fraction of water and solute in the solution respectively. $\mathrm{n}$ is the number of dissociated ions in the solution. $\gamma_{\mathrm{w}}$ is the water activity coefficient.

For dilute solutions:

$$
n_{W}+n n_{S} \approx n_{W}
$$

Therefore,

$$
\begin{aligned}
& x_{S}=\frac{n_{S}}{n_{W}+n n_{S}} \approx \frac{n_{S}}{n_{W}}=\frac{V C_{S}}{n_{W}} \\
& a_{W}=f\left(C_{S}\right) \approx 1-n x_{S}=1-\frac{n V C_{S}}{n_{W}}
\end{aligned}
$$

For $\mathrm{n}_{\mathrm{w}}=1$ mole, $\mathrm{V}$ is the molar volume of pure water. The water activity is given by,

$$
a_{W}=f\left(C_{S}\right) \approx 1-n x_{S}=1-n V C_{S}
$$

This shows that the water activity goes to 1 when $\mathrm{C}_{S} \rightarrow 0$ for ideal solutions.

Equation 2-47 gives:

$f^{\prime}\left(C_{S}\right)=-n V$

and

$$
\frac{f^{\prime}\left(C_{S}\right)}{f\left(C_{S}\right)}=-n V
$$

when $\mathrm{Cs} \rightarrow 0$ (dilute ideal solutions). Substituting this equation into Equation 237 gives: 


$$
\frac{\partial P}{\partial t}-\frac{K_{I}}{c} \frac{\partial^{2} P}{\partial x^{2}}-\frac{n R T K_{I I}}{c} \frac{\partial^{2} C_{s}}{\partial x^{2}}=0
$$

which is the corresponding equation in Lomba, et al [2000] for ideal solutions.

The diffusion coefficient defined by Equation 2-27 is plotted in Figure 2.2 for ideal and non-ideal solutions. Clearly for low electrolyte concentrations, the two diffusion coefficients are identical. However, for higher salt concentrations, non-ideal solutions provide high diffusion coefficients implying that the flux of ions into the shale will be higher for non-ideal solutions. Figure 2.3 shows how the faster diffusion results in a deeper diffusion of ions into the shale for non-ideal solutions. Converting the high concentration and $?\left(\eta=\frac{x}{\sqrt{4 D t}}\right)$ into actual depth of penetration in meters, it can be seen that the depth of penetration of ions is typically quite shallow (on the order of 5 to $10 \mathrm{~mm}$ over the period of 3 hours, see Figure 2.4). This slow rate of diffusion of ions occurs because of the extremely low permeability of shale to both water and ions. However, as we will show later, it is this penetration of ions and water into the shale that control the pore pressure and the stability of the shale.

The pressure profiles in the shale are shown in Figure 2.5. It is clearly seen that in the absence of osmotic effects the pressure follows an error function solution with the pressure decaying with distance. However, due to ion and water invasion, the pressure gradient at the face of the shale is extremely large due to osmotic effects. The magnitude of the pressure gradient is directly related to the invasion depth of the ions.

The invasion depth for the ions can be estimated from the simple relation

$$
x_{0}=\eta_{0} \sqrt{4 D t}
$$

Clearly the depth of invasion is proportional to the square root of the diffusion coefficient and to the square root of the contact time. Since the diffusion coefficient is 
directly related to the coupling coefficients and the activity of the aqueous phase through Equation 227, it is clear that the properties of the shale and the non-ideality of the solution play a critical role in determining the invasion depth in the shale.

The magnitude of the pressure change near the wall depends on the fluxes of both the water and the ions. The larger flux of water and ions for non-ideal solutions results in a larger change in pore pressure near $x=0$ due to these fluxes (Figure 2.5, Case I). The magnitude of pressure change is not equal to the osmotic pressure for an ideal membrane but is related to it in a complex manner.

Since the rate of ion/water transport is so much slower than the rate of pressure transmission into the shale, it is reasonable to simplify the problem assuming that the boundary condition at the face of the shale $(\mathrm{x}=0)$ is altered by the flux of water and ions. Existing models approximately represent the pressure profile as the hydraulic pressure minus the osmotic pressure acting at the boundary, followed by an error function solution as given by the diffusivity equation. We can see here that such an approximation misses some important features in the pore pressure profile. The failure of the shale is controlled by the pore pressure very close to the face of the shale (within a few millimeters). This pore pressure must, therefore, be calculated by accurately accounting for water and ion fluxes.

\subsubsection{Mechanisms of Wellbore Instability/Shale Failure}

Figure 2.6 shows an example of the pressure profile in which the water activity in the bulk fluid is higher than the water activity in the shale. This results in a net flux of ions out of the shale and a net flux of water into the shale. The pressure profile shows an 
increase in pore pressure i.e. a weakening of the shale very close to the face $(x=0)$. Figure 2.6 shows that the pressure gradient near the wellbore wall can be extremely large with pore pressures much higher inside the shale than would be expected based on pressure transmission alone in the absence of osmotic effects. This high pore pressure is the primary cause of shale failure.

The magnitude of the osmotic pressure is higher for non-ideal solutions as compared to ideal solutions. This suggests that taking into account non-idealities is important in correctly predicting wellbore instability.

The proposed mechanism of wellbore failure suggested by our model is consistent with several observations of shale failure in which small shale chips are observed to peel off from the wall of the shale as the fluids come in contact with the shale. This gradual "sluffing-off" of the shale is observed for low permeability shales. In the case of high permeability shales such as Gumbo shales, the fluxes of water and ions are much larger and the failure observed in these shales is different in that the entire sample of shale swells and softens.

\subsubsection{Flux of Water and Ions}

In Case II the water activity in the bulk is higher than that in the shale. The flux of water into the shale is positive while the ions are pulled out of the shale. In such cases, the pore pressure tends to increase due to the net influx of water. The rate of water transport decreases in a power law fashion with time (see Figure 2.8). The same is true of the solute (ion) flux (Figure 2.7). As the solute concentration gradient and 
pressure gradient decrease over time the fluxes also decrease. The fluxes of solute and water for ideal solutions are lower than for non-ideal solutions.

\subsubsection{Pore Pressure Profile}

Two types of pore pressure profiles are observed in our simulations. These are shown in Figures 2.9 and 2.10. In Figure 2.10 the solute concentration of bulk fluid is higher than the solute concentration in the shale. As a consequence water is sucked out of the shale and a minimum value of pore pressure is observed at some distance from the inlet face. Conversely when the solute concentration in the shale is higher than the solute concentration in the bulk fluid, water is pushed into the shale and a maximum pressure is observed (Figure 2.9). The location of this pore pressure maximum slowly moves into the shale over a period of time (Figure 2.11). The magnitude of this pressure maximum or minimum is referred to as $\mathrm{P}_{\max }$ or $\mathrm{P}_{\min }$ and depends on the membrane efficiency or reflection coefficient of the shale. The rate which the pressure maximum traverses into the shale depends on the permeability of the shale and the diffusion coefficient of the ions in the shale.

As discussed earlier, the magnitude and location of $\mathrm{P}_{\max }$ has a significant impact on wellbore stability. In general, high pore pressures (positive values of $\mathrm{P}_{\max }$ ) will lead to wellbore instability at some distance from the face of the shale. Negative values of $\mathrm{P}_{\max }$ will result in stabilization of the shale. Our calculations also show that the presence of this maximum is a behavior that is qualitatively different than the pressure profiles assumed in previous work (assume an error function decline in pressure from the wellbore surface). The presence of a maximum or minimum in pressure suggests that 
wellbore failure will most likely occur at some distance into the shale and not at the face of the shale.

Figure 2.12 shows the effects of solute concentration in the bulk on the magnitude of $\mathrm{P}_{\max }$. The pore fluid is assumed to have a concentration of $1 \mathrm{M}$ while drilling fluid concentrations vary from $0.001 \mathrm{M}$ to $4 \mathrm{M}$. As seen in Figure 2.12, as the drilling fluid concentration is increased the pore pressure maximum goes from a positive value to a negative value and is exactly zero when the pore fluid solute concentration is exactly equal to the bulk solute concentration (1M). In general, when $C_{d f}$ is less than $C_{o}$, $\mathrm{P}_{\max }$ is positive while when $\mathrm{C}_{\mathrm{df}}$ is greater than $\mathrm{C}_{0}, \mathrm{P}_{\max }$ is negative. Also shown on Figure 2.12 are the pressure peaks that would be expected if the shale behaves like an ideal semi-permeable membrane. Clearly since the shale behaves as a leaky membrane, the Pmax values are significantly smaller than the ideal osmotic pressure that would be generated. Unfortunately, no simple relationship exists between the ideal osmotic pressure and $\mathrm{P}_{\max }$.

An alternative way of presenting this information is to represent the $\mathrm{P}_{\max }$ as a function of the activity of the water. This is shown in Figure 2.13. Again similar curves are observed. When the water activity in the shale is exactly equal to the water activity in the bulk, $\mathrm{P}_{\max }$ is zero.

From the simulations presented above, the hydrostatic pressure differential between the wellbore and the shale is assumed to be zero. Clearly when drilling, overbalance pressures are maintained between the wellbore and the shale. In such situations, the hydrostatic pressure effects will be superimposed on the osmotic effects that have been emphasized in Figures 2.12 and 2.13. 
By plotting $\mathrm{P}_{\max }$ as a function of the ideal osmotic pressure, a linear relationship is obtained as shown in Figure 2.14. The slope of this line is related to the membrane efficiency of the shale. In this case, the slope of the line was observed to be 0.2.

Figure 2.15 shows the effects of changing pore fluid solute concentration. It is seen that the effect of changing pore fluid concentration is similar to that of changing the the bulk solute concentration. The magnitude of the pressure peak depends on the ratio of Co and $\mathrm{C}_{\mathrm{df}}$ as shown in Figure 2.16.

Figure 2.17 shows how the location of the pressure peak varies with time. As time increases from 3 to 24 hours, the peak's location migrates from about $12 \mathrm{~mm}$ to $50 \mathrm{~mm}$ away from the face of the shale. Clearly the velocity at which this peak moves depends on the permeability of the shale and the diffusivity of the solute into the shale. It should be pointed out that the magnitude of the pressure peak does not dissipate significantly with time as shown in Figure 2.15, the pressure peak for 3 hours and 24 hours is not decreased appreciably.

\subsection{CONCLUSIONS}

A model has been developed to calculate the transient pressure transmission and solute diffusion through low permeability shales. Non-ideality of electrolyte solutions has been taken into account. Results from an ideal model and a non-ideal model have been presented. Based on the above discussion, the following conclusions can be drawn:

Non-ideal effects play an important role in controlling the magnitude of osmotic pressure generated when bringing a shale into contact with a bulk solution with different 
water and ion activity. Including of the effects of non-ideality results in faster diffusion of water and ions into and out of the shale and in larger osmotic pressure induced in the shale. This implies that non-ideal effects must be taken into account to correctly predict wellbore stability in shales.

The flux of water and ions controls the pore pressure and hence the mechanical stability of the shale. Large pore pressure gradients induced by osmotic effects close to the wellbore wall can be an important shale failure mechanism. 
Table 2.1 Input data

\begin{tabular}{|l|l|}
\hline Drilling fluid concentration & $4.0 \mathrm{M}$ (case I)/ 0.01M (Case II) \\
\hline Pore fluid concentration & $1.0 \mathrm{M}$ \\
\hline Drilling fluid pressure (Hydraulic) & $500 \mathrm{psi}$ \\
\hline Initial pore pressure (Hydraulic) & $0 \mathrm{psi}$ \\
\hline PH & 8.0 \\
\hline Temperature & $298 \mathrm{~K}$ \\
\hline Fluid Viscosity & $10^{-3} \mathrm{~kg} \mathrm{~m}^{-1} \mathrm{~S}^{-1}$ \\
\hline Distance between clay platelets & $20 \AA$ \\
\hline $\mathrm{K}_{\mathrm{I}}$ & $2.134 \times 10^{-16} \mathrm{~m}^{3} \mathrm{~s} / \mathrm{kg}$ \\
\hline $\mathrm{K}_{\mathrm{II}}$ & $-4.524 \times 10^{-17} \mathrm{~m}^{3} \mathrm{~s} / \mathrm{kg}$ \\
\hline $\mathrm{L}_{\mathrm{I}}$ & $4.738 \times 10^{-13} \mathrm{~mol} \mathrm{~s}^{\mathrm{k}} \mathrm{kg}$ \\
\hline $\mathrm{L}_{\mathrm{II}}$ & $1.679 \times 10^{-9} \mathrm{~mol}^{2} \mathrm{~s} / \mathrm{kgm}$ \\
\hline
\end{tabular}




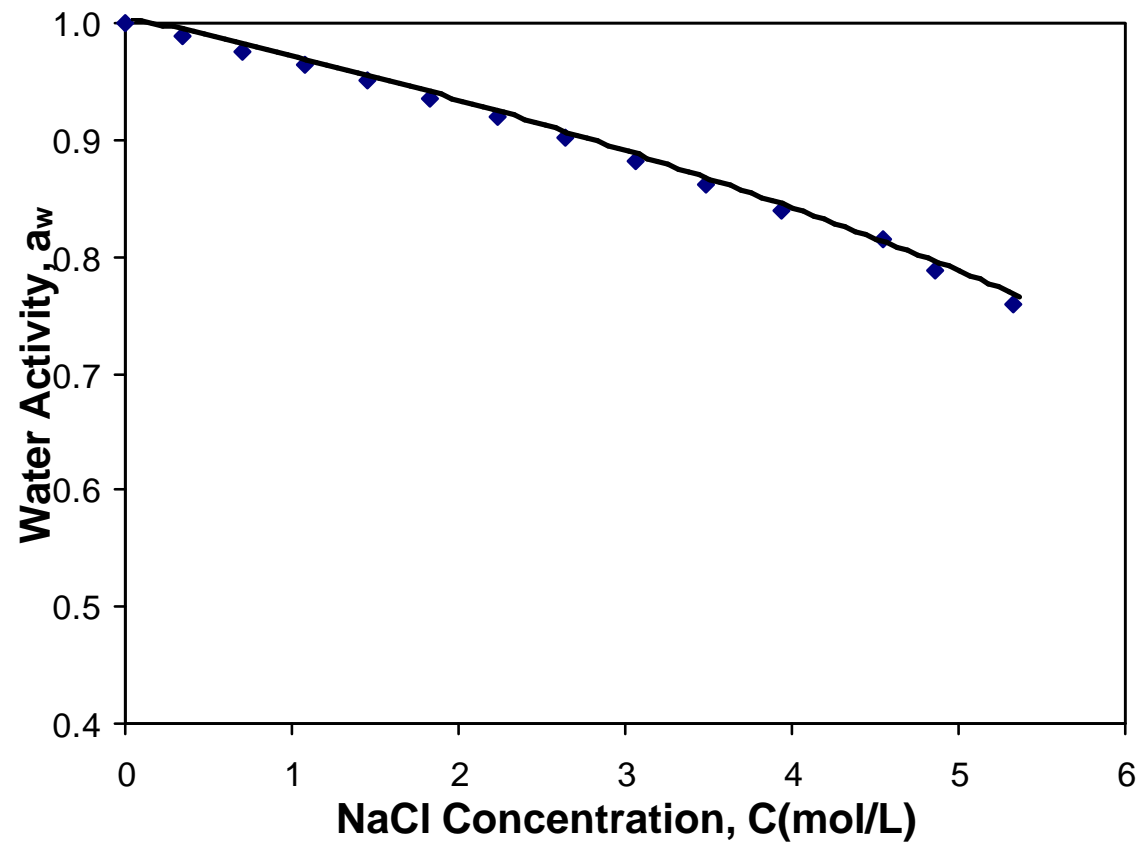

Figure 2.1 Water activity in $\mathrm{NaCl}$ solution as a function of $\mathrm{NaCl}$ concentration. Data from E. C. W. Clarke and D. N. Grew, J. Phys. Chem. Ref. Data, 1985, Vol. 14, No. 2, 489-610. 


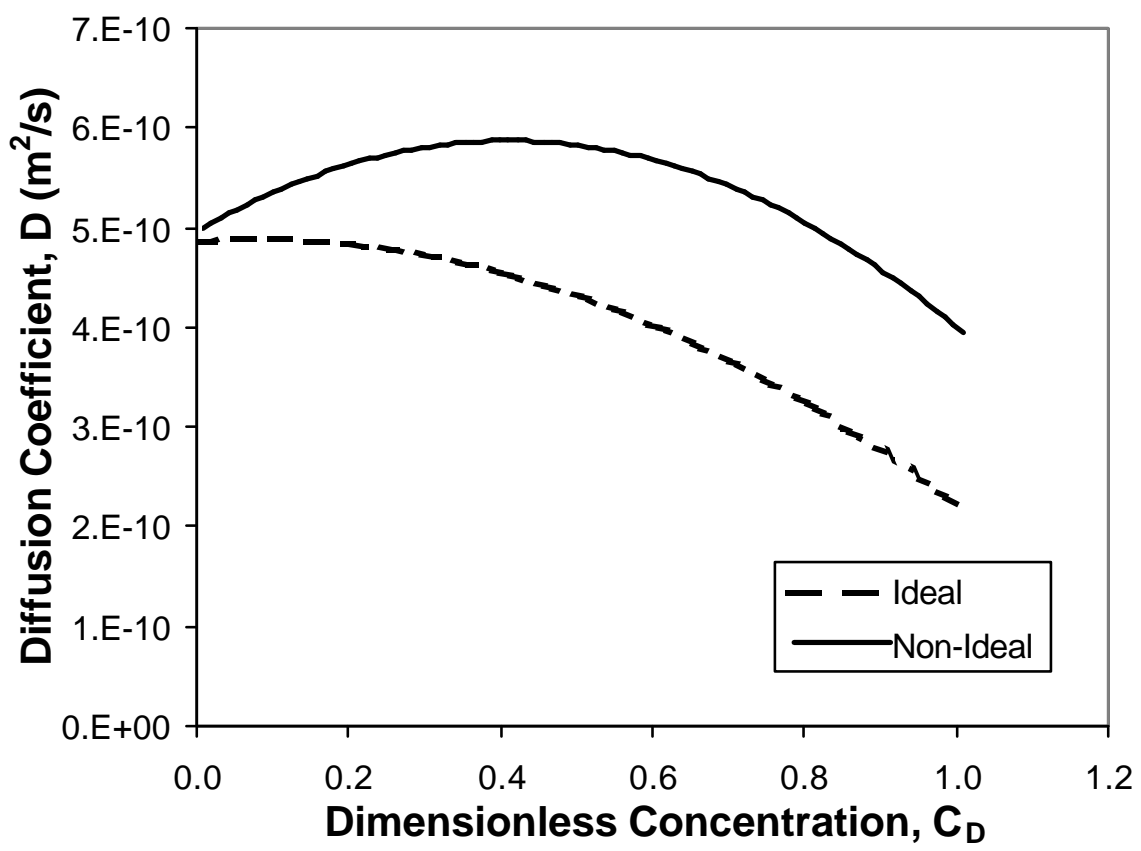

Figure 2.2 "Diffusion coefficients" for both ideal and non-ideal solutions as a function of dimensionless concentration. 


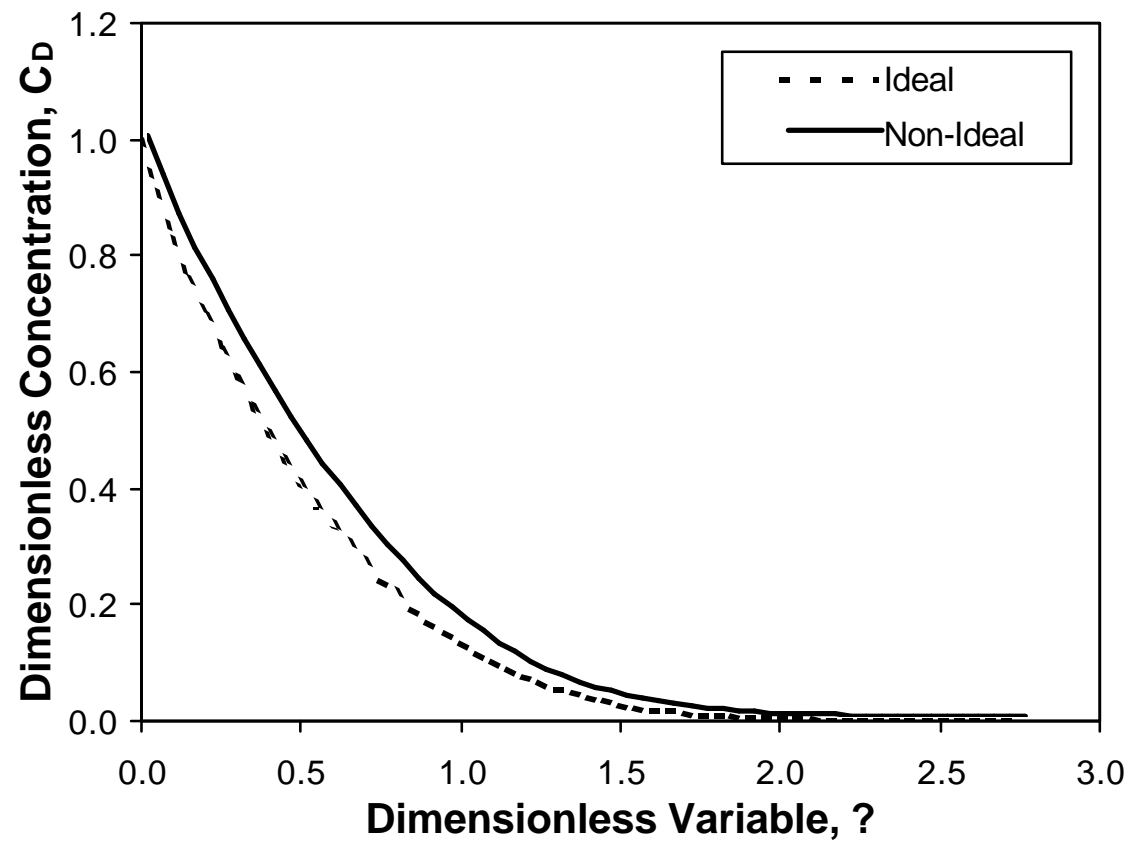

Figure 2.3 Dimensionless concentration profiles of ideal and non-ideal solutions.

$$
\eta=\frac{x}{\sqrt{4 D t}}
$$




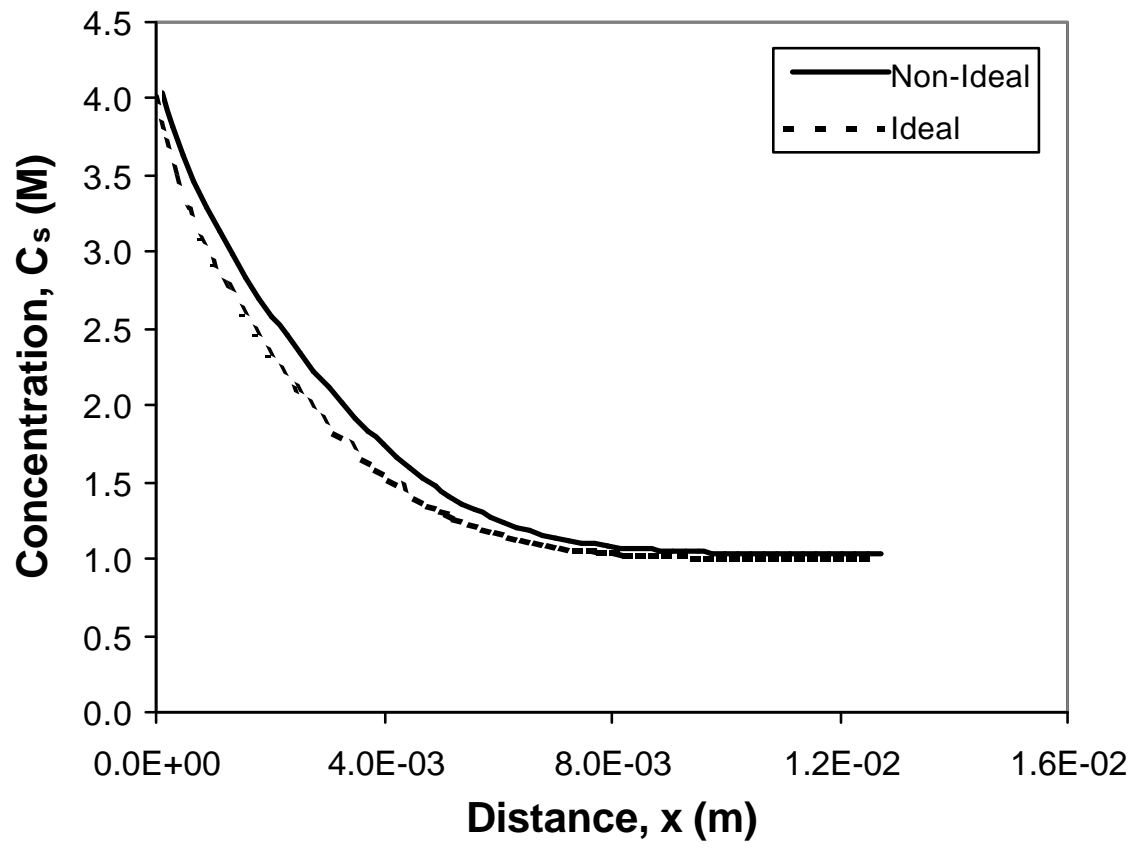

Figure 2.4 Concentration profiles for ideal solution model and non-ideal solution. (Time $\mathrm{t}=3 \mathrm{hr}$ ) 


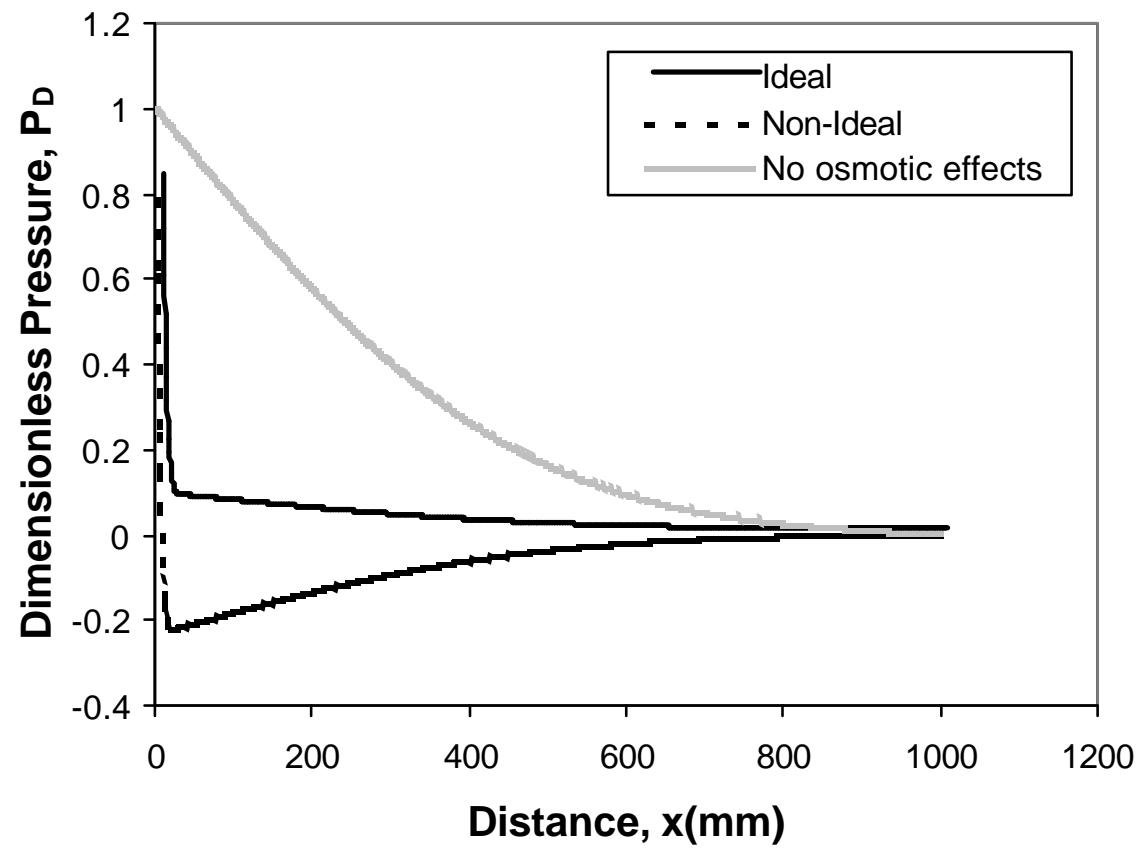

Figure 2.5 Dimensionless pressure profiles for free pressure transmission, ideal solution with osmotic effect and non-ideal solution with osmotic effect. (Case I) 


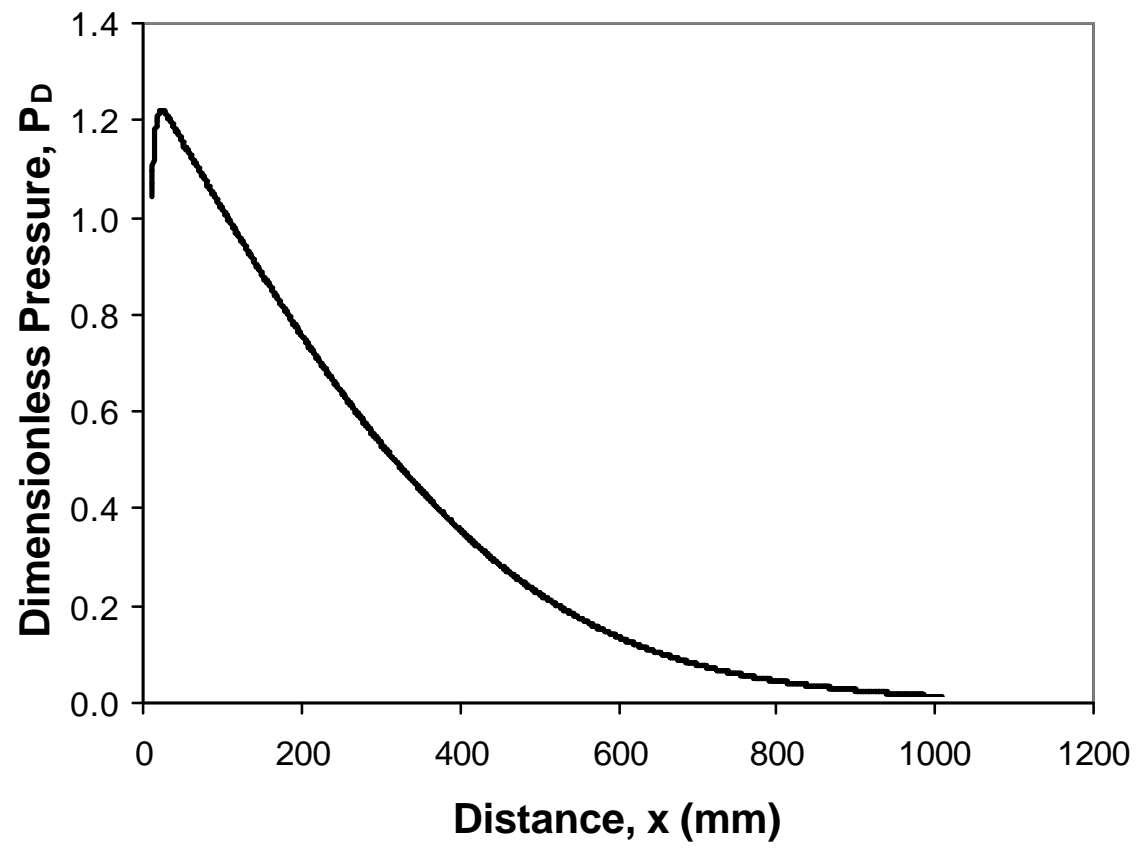

Figure 2.6 Buildup of pore pressure inside the shale due to water flux into the shale.

Concentration of drilling fluid is $0.01 \mathrm{M}$ and the concentration of pore fluid inside the shale is $1 \mathrm{M}$. (Case II, $\mathrm{t}=3 \mathrm{hr}$ ) 


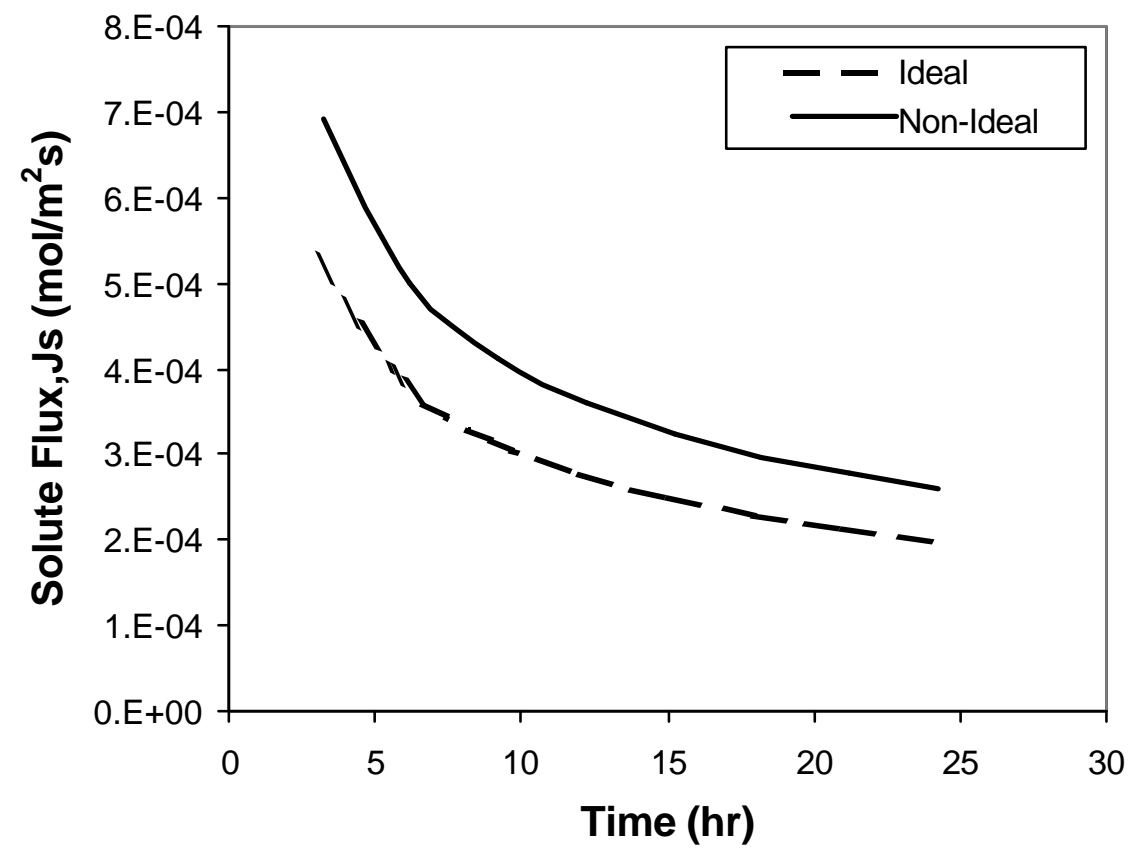

Figure 2.7 Solute flux vs. time for ideal and non-ideal solution at shale surface $(\mathrm{x}=0)$. (Case II) 


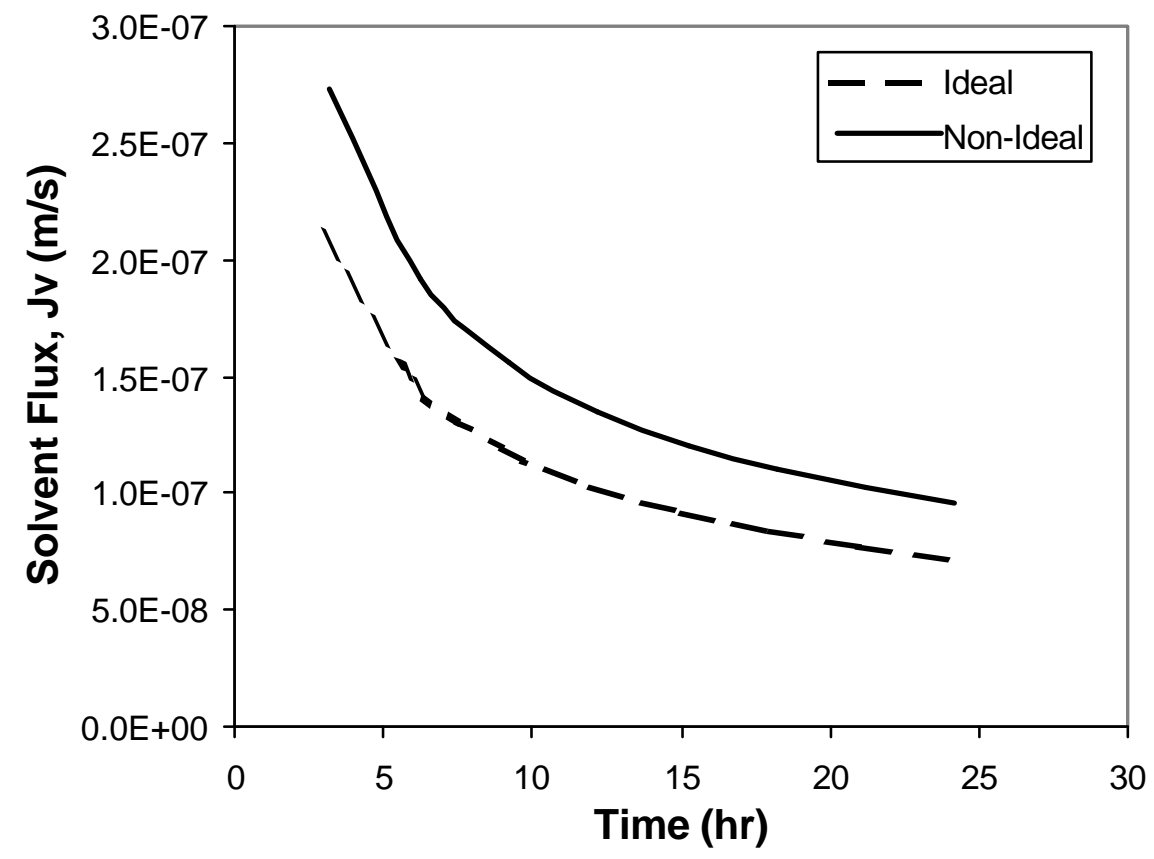

Figure 2.8 Solvent flux vs. time for ideal and non-ideal solution at shale surface $(\mathrm{x}=0)$. (Case II) 


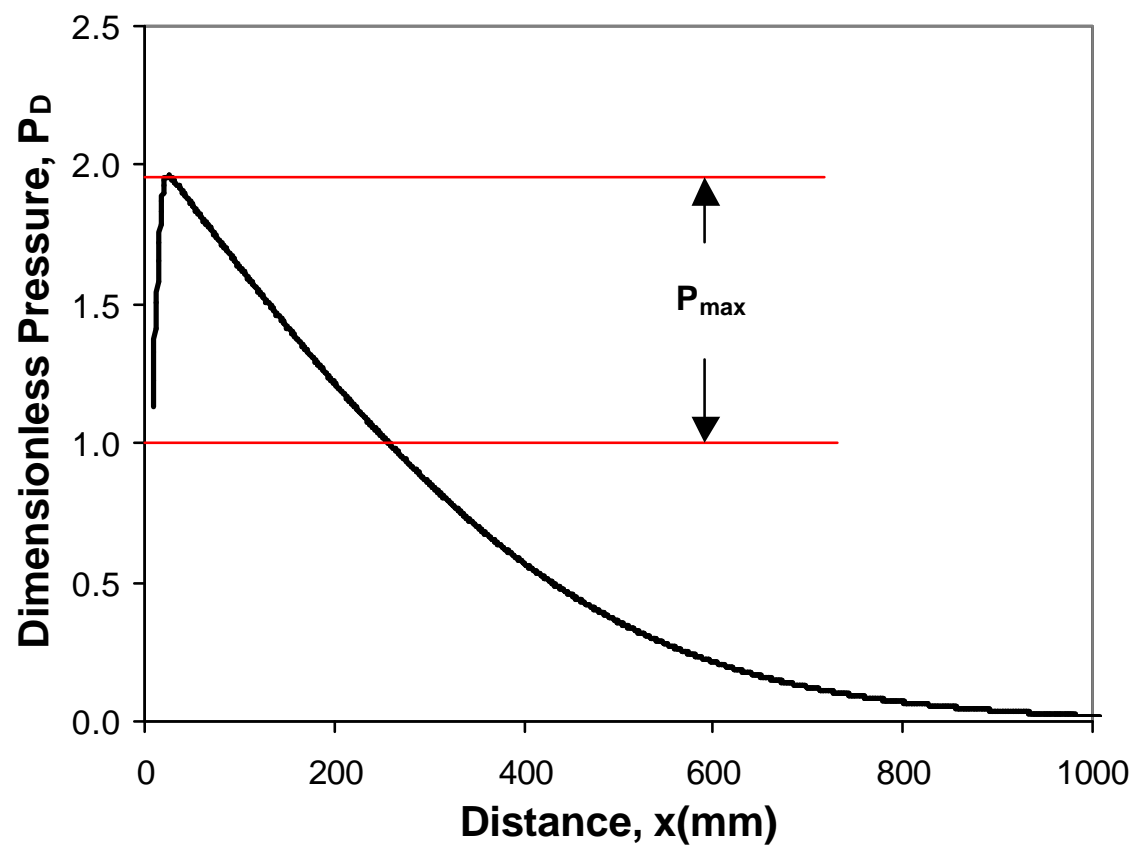

Figure 2.9 Definition of $\mathrm{P}_{\max } . \mathrm{P}_{\max }=\operatorname{Max}\left(\mathrm{P}_{\mathrm{D}}\right)-1$ for $\mathrm{C}_{\mathrm{df}}<\mathrm{C}_{0}$. 


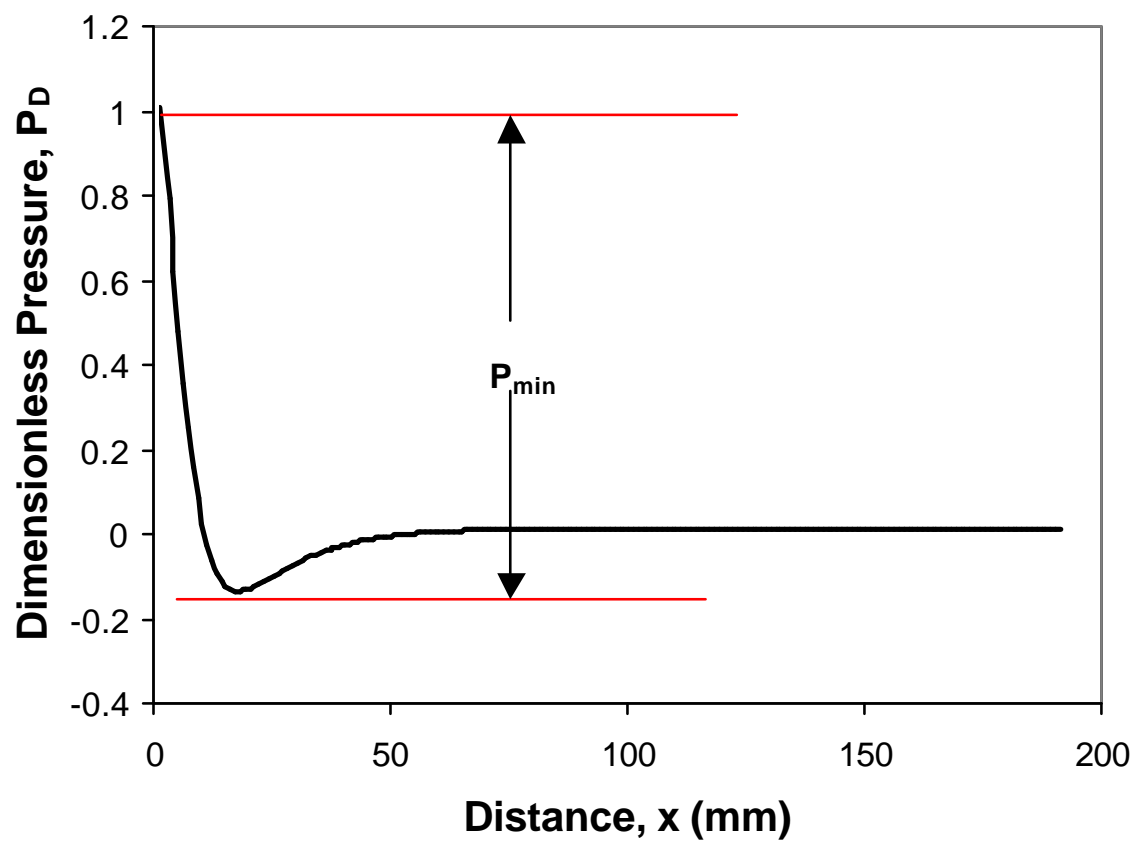

Figure 2.10 Definition of $\mathrm{P}_{\min } \cdot \mathrm{P}_{\min }=1-\mathrm{Min}\left(\mathrm{P}_{\mathrm{D}}\right)$ for $\mathrm{C}_{\mathrm{df}}>\mathrm{C}_{0}$. 


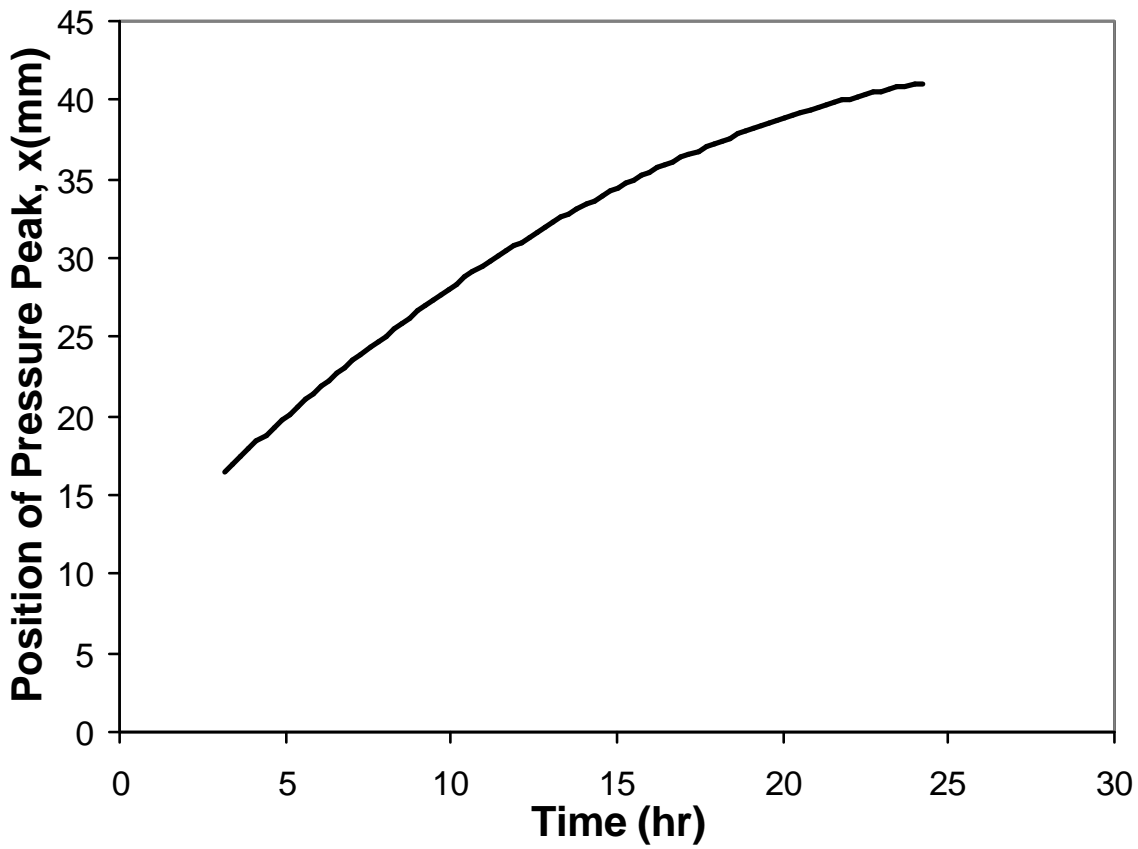

Figure 2.11 Position of pressure peak vs time. $C_{d f}=0.01 M$ 


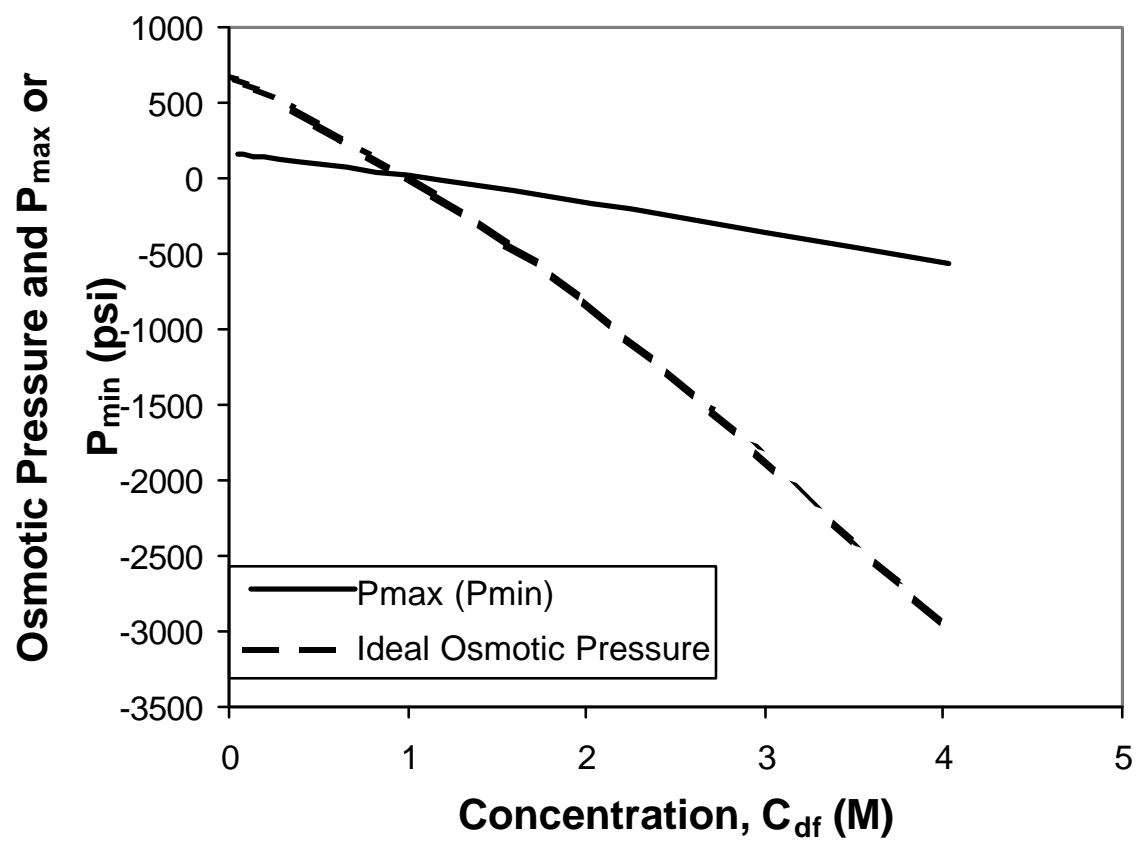

Figure $2.12 \mathrm{P}_{\max }\left(\mathrm{P}_{\min }\right)$ vs concentration of solute of the drilling fluid. 


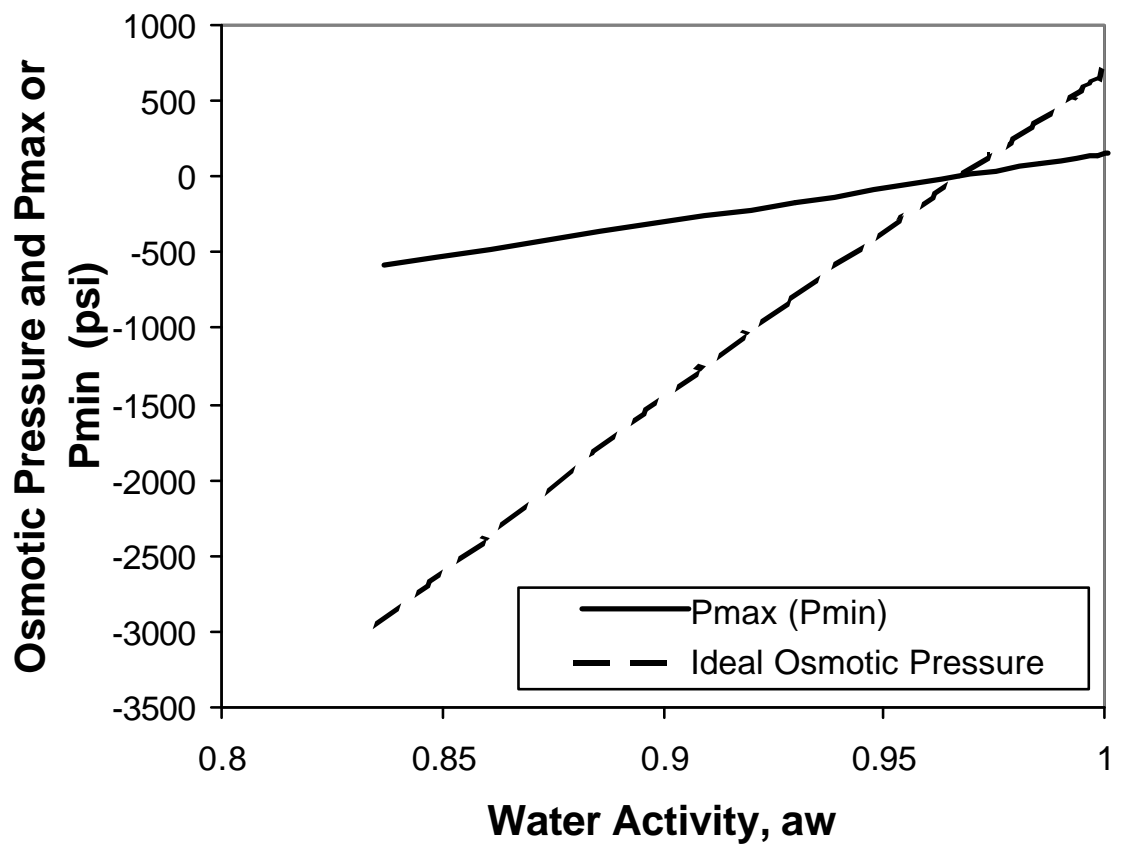

Figure 2.13 Induced osmotic pressure 


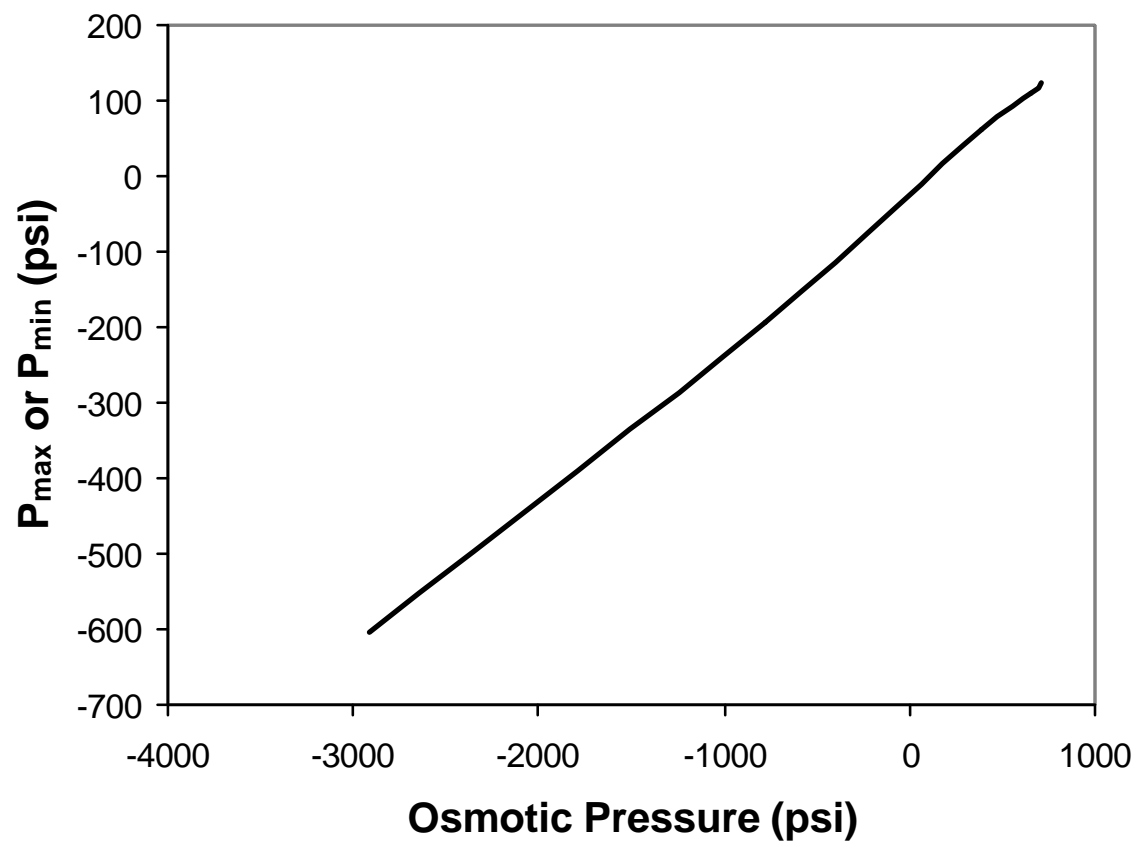

Figure 2.14 Induced osmotic pressure 


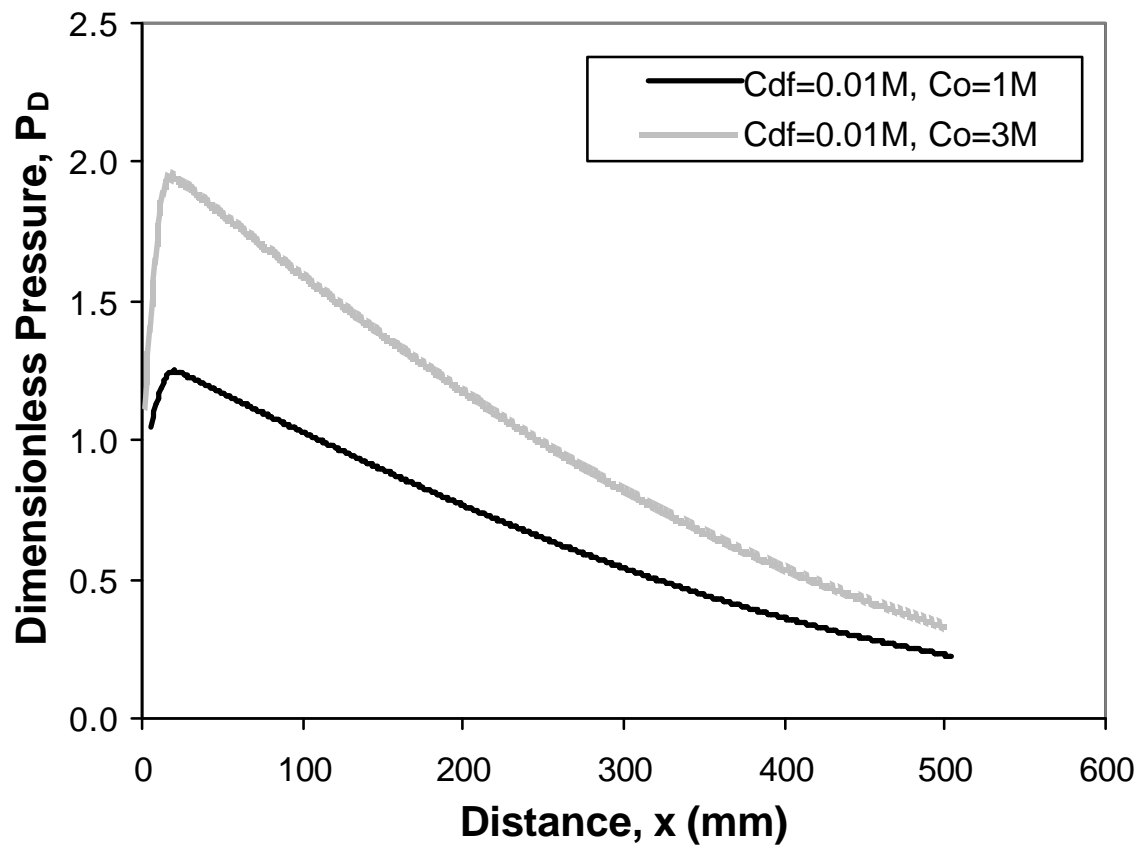

Figure 2.15 The effect of pore fluid concentration 


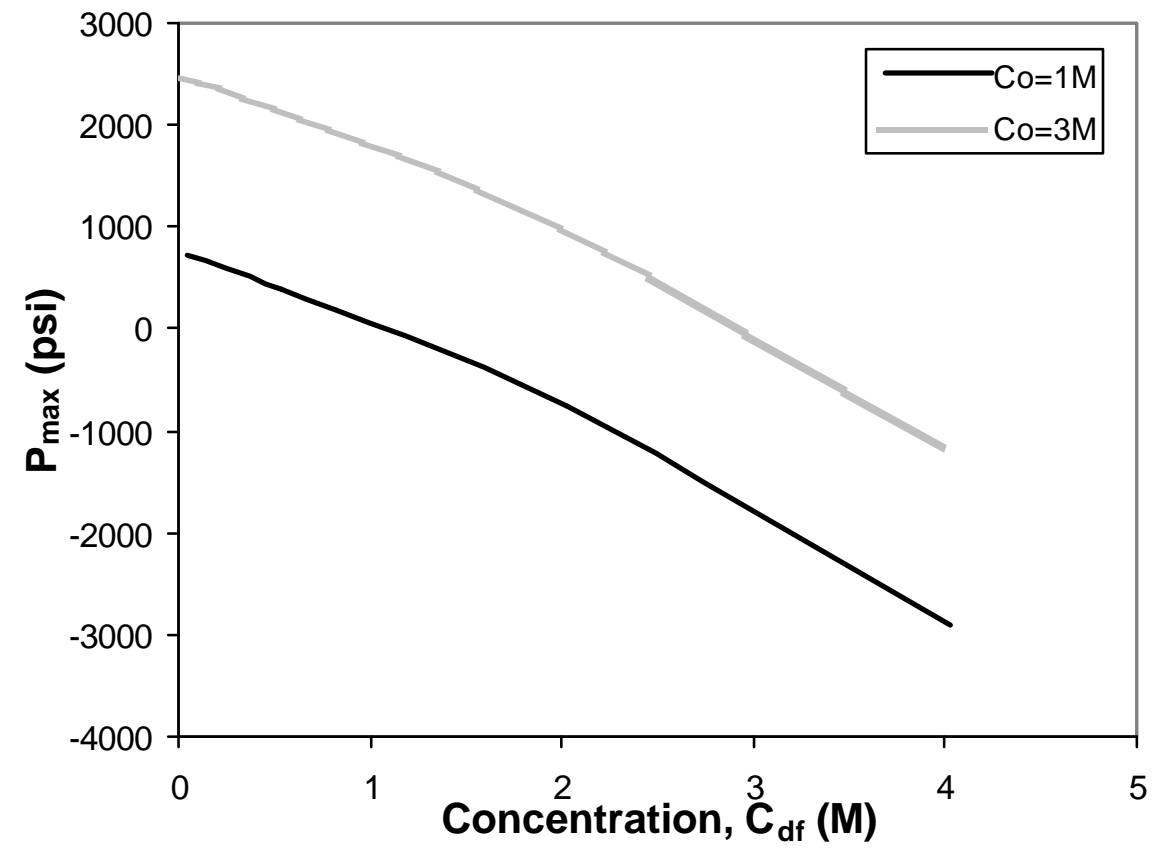

Figure 2.16 The effect of pore fluid concentration on peak pressure. 


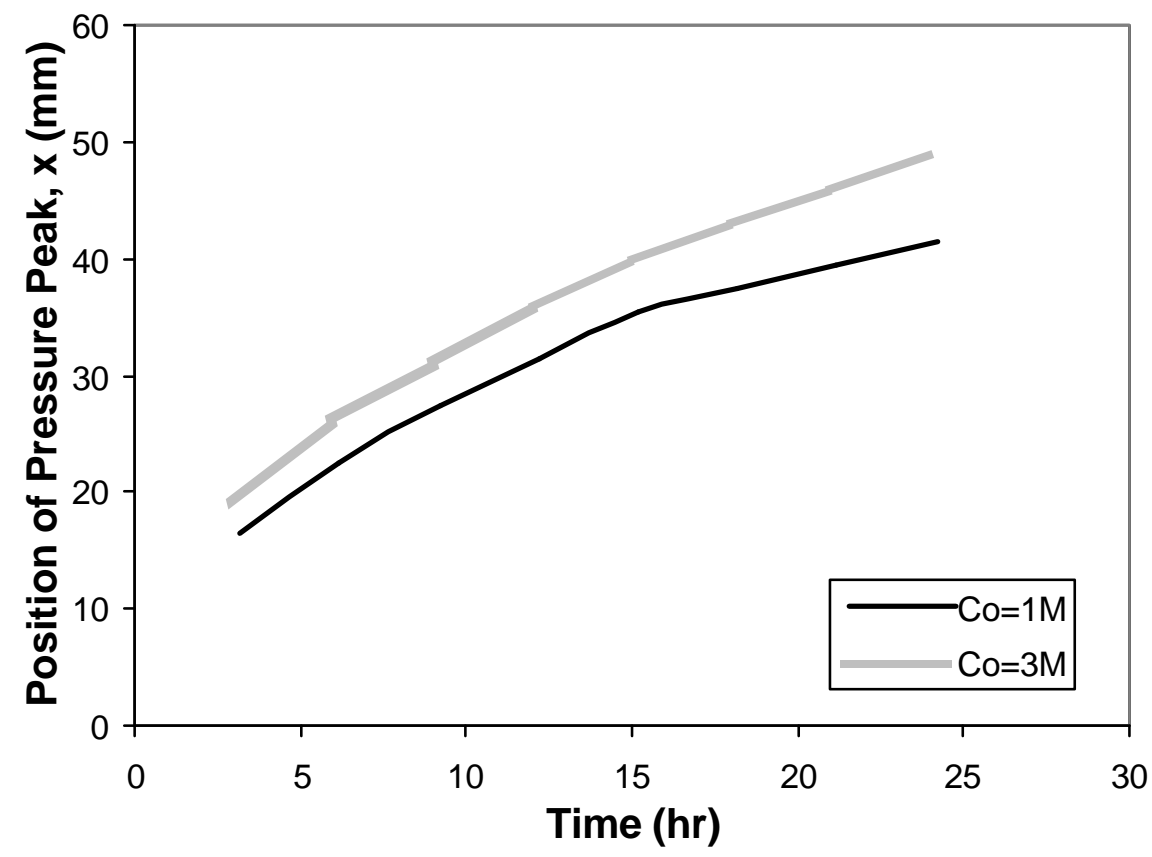

Figure 2.17 The effect of pore fluid on pressure peak movement $\left(\mathrm{C}_{\mathrm{d}}=0.01 \mathrm{M}\right)$. 


\section{Chapter 3: Water and Ion Transport and its Impact on Swelling Pressures in Shales}

\subsection{ABSTRACT}

Constant volume swelling test data are presented for shales brought into contact with concentrated electrolyte solutions. The change of swelling pressures with time is an indirect measure of the flux of water and ions into and out of he shale. Data are compared with simulations of water and ion transport using a general model for nonideal solutions presented in Chapter 2. It is clearly seen that quantitative agreement can be achieved by properly accounting for solution non-ideality when calculating the hydraulic and osmotic fluxes in this model.

\subsection{INTRODUCTION}

Shales are highly compacted sedimentary rocks that have a laminated structure composed of fine-grained material with high clay content. It is well known that due to their large clay content and high ion exchange capacity, many shales exhibit swelling or shrinking when exposed to an electrolyte that has a water activity different from the shale water activity.

The mechanism controlling the hydration and swelling of shale is very complex and not fully understood. It is well recognized that osmotic pressure plays a very important role in determining the swelling properties of clay soils in shales [Low et al. 1958]. Early theories presented for the osmotic swelling of shales [Fritz et al. 1983] reported on the non-ideal membrane behavior of shales that allows both water and ions to be transported in and out of shales to various degrees. Mody [1993] postulated a 
membrane efficiency that was a function of the ion exchange capacity of clay as well as permeability and confining pressure applied. There are numerous attempts to model the equilibrium swelling properties of shales(Van Oort [1997], Ewy and Stankovich [2000], and Mody and Hale [1993]). In this paper we focus on the time dependent or transient behavior of water and ions transported in shales. In earlier work by Lomba [2000] and Yu et al. [2000] a model was presented to model water and ion transport in shales. Lomba et al [2000] assumed ideal solution behavior for the electrolyte leading to two coupled equations for the transmission of hydraulic pressure and osmotic pressure into the shale. Yu et al. [2000] extended the model to non-ideal solutions providing a general form within which the coupled transport of ions and water can be related to the propagation of osmotic and hydraulic pressure into the shale. In the present paper constant volume swelling test results are compared with the Yu and Sharma [2000] model presented earlier.

\subsection{EXPERIMENT}

Figure 3.1 (Chenevert and Pernot [1998]) shows the shale sample instrumented for the swelling test. It consists of a top LVDT (Linear Variable Differential Transformer) support plate, a top anvil, a top porous disk, the rectangular shale sample, a bottom porous disk and a bottom anvil that contains ports for the inlet and outlet flow of test fluid. Figure 3.2 shows a schematic of the test apparatus used for the tests. A computer was used for data acquisition.

During testing, fluid enters through the bottom inlet line, flows through the central hole, then passes through the porous disk and is circulated around the sample. Finally it comes out through the central hole of the top anvil, then exits through the outlet line. 
In this paper, "Speeton" shale (Simpson [1997]) test data were used. This shale is an offshore marine shale, cored from a depth of about $5000 \mathrm{ft}(1524 \mathrm{~m})$ and preserved as much as possible from exposure to air. The properties of the shale can be obtained from Simpson [1996].

During the testing, the sample is held at constant volume and the confining pressure required to achieve this is recorded by the data acquisition system.

\subsection{THEORY}

The water activity of the electrolyte solution is a function of solute concentration,

$$
a_{w}=f\left(C_{s}\right)
$$

The activity of water in different solutions can be found from experiments or literature. Figure 3.3 shows the water activity in $\mathrm{CaCl}_{2}$ solutions vs $\mathrm{CaCl}_{2}$ concentration.

The osmotic pressure can be computed from the following equation:

$$
\Pi_{S}=-\frac{R T}{V} \ln \left(\frac{a_{W}^{1}}{a_{W}^{b}}\right)=-\frac{R T}{V} \ln \left(\frac{f\left(C_{S}^{1}\right)}{f\left(C_{S}^{b}\right)}\right)
$$

The osmotic pressure gradient for 1-D flow can be written as:

$$
\nabla \Pi_{S}=\frac{R T}{V} \frac{f^{\prime}\left(C_{S}\right)}{f\left(C_{S}\right)} \frac{d C_{S}}{d x}
$$

From the coupled flux relations, the solute flux can be written as (Yu et al. 2000):

$$
J_{S}=-L_{I} \frac{\partial P}{\partial x}+\left(\frac{L_{I I}}{C_{S}}-L_{I}\right) \frac{R T}{V} \frac{f^{\prime}\left(C_{S}\right)}{f\left(C_{S}\right)} \frac{\partial C_{S}}{\partial x}
$$

The final form of the continuity equation for the solute is:

$$
\frac{\partial C_{S}}{\partial t}+\frac{\partial}{\partial x}\left\{-D \frac{\partial C_{S}}{\partial x}\right\}=0
$$

where 


$$
D=-\frac{R T}{V}\left(\frac{L_{I I}}{C_{S}}-L_{I}\right) \frac{f^{\prime}\left(C_{S}\right)}{f\left(C_{S}\right)}
$$

Similarly the conservation equation for the solvent can be written as,

$$
\frac{\partial P}{\partial t}-\frac{K_{I}}{c} \frac{\partial^{2} P}{\partial x^{2}}+\frac{K_{I I}}{c} \frac{R T}{V} \frac{\partial}{\partial x}\left\{\frac{f^{\prime}\left(C_{S}\right)}{f\left(C_{S}\right)} \frac{\partial C_{S}}{\partial x}\right\}=0
$$

And the flux of the solvent is given by:

$$
J_{v}=-K_{I} \frac{\partial P}{\partial x}+K_{I I} \frac{R T}{V} \frac{f^{\prime}\left(C_{S}\right)}{f\left(C_{S}\right)} \frac{\partial C_{S}}{\partial x}
$$

A detailed derivation is provided in Chapter 2.

\section{Boundary Conditions and Initial Condition:}

Two initial conditions and four boundary conditions are needed to obtain the concentration profile and pressure profile in the porous medium. The following initial and boundary conditions are applied:

$$
\begin{aligned}
& t=0, \quad 0 \leq x \leq \infty, \quad C_{S}=C_{0} ; P=P_{0} \\
& x=0 \quad t>0, \quad C_{S}=C_{d f} ; P=P_{W} \\
& x=\infty \quad t>0, \quad C_{S}=C_{0} ; P=P_{0}
\end{aligned}
$$

$\mathrm{C}_{0}$ and $\mathrm{P}_{0}$ are the original pore fluid concentration and pore pressure respectively. $\mathrm{P}_{\mathrm{w}}$ is the hydrostatic pressure at the wall and $\mathrm{C}_{\mathrm{df}}$ is the electrolyte concentration in the bulk fluid.

\section{Dimensionless Variables}

The following dimensionless variables were defined to present the solutions of the equations. 


$$
\begin{aligned}
& \eta=\frac{x}{\sqrt{4 D_{0} t}} \\
& C_{D}=\frac{C_{S}-C_{0}}{C_{d f}-C_{0}} \\
& P_{D}=\frac{P-P_{0}}{P_{W}-P_{0}}
\end{aligned}
$$

The boundary conditions can be written in terms of the new variables as follows:

$$
\begin{array}{lll}
\eta=0, & C_{D}=1 & P_{D}=1 \\
\eta \rightarrow \infty & C_{D}=0 & P_{D}=0
\end{array}
$$

\subsection{EXPERIMENTAL RESULTS AND DISCUSSION}

Figure 3.6 shows a schematic of shale samples $\left(\mathrm{a}_{\mathrm{w}}{ }^{\text {sh }}\right)$ brought into contact with an electrolyte solution with water activity $\mathrm{a}_{\mathrm{w}}{ }^{\mathrm{df}}$. At time $\mathrm{t}=0$, there is an activity difference

between the bulk electrolyte and the water in the shale. If $a_{w}^{s h}>a_{w}^{d f}$, this water activity difference results in a net transport of water out of the shale and transport of ions into the shale. As time progresses, this flux of water out of the shale results in a reduction of the hydraulic pressure at the surface as shown in Figure 3.6 (b). Osmotic pressure gradients also pull ions into the shale and this is reflected in the total pressure profile. At equilibrium (infinite time), the water inside the shale has the same chemical potential as in the bulk electrolyte resulting in uniform water activity inside the shale which may be different than the water activity of the bulk solution due to the difference in the electrostatic potential inside the shale. This equilibrium condition reflects the confining 
pressure applied on the water in the shale. The average total pressure is shown in Figure $3.15(a, b)$. It is clear that this average pressure will decrease with time as water is extracted from the shale. This trend is consistent with observations in the experiments reported earlier (Mody and Hale [1993]). The rate of the pressure decline and the final equilibrium confining pressure to hold the shale at constant volume is controlled by the activity of water in the shale and the water activity in the bulk fluid. A quantitative comparison between the model calculations of the ions and water fluxes result in this pressure variation in the shale.

Two experiments were simulated with the model in this paper. Both cases use $\mathrm{CaCl}_{2}$ electrolyte as the bulk solution. Case I uses a concentration of $2.1912 \mathrm{M}$ with a water activity of 0.78 and Case II uses a concentration of $4.9716 \mathrm{M}$ with a water activity of 0.4 .

Parameters available from the experiments were also used in the simulation. Properties of the Speeton shale were obtained from O'Brien, Goins and Simpson [1996] and are listed in Table 3.2. The bulk volume of the shale was constant during the experiment. This means the c-spacing of the shale is constant. The initial overburden is 5400 psi.

Figure 3.3 shows the activity of water in $\mathrm{CaCl}_{2}$ solutions. One can see that the water activity decreases as the solute concentration increases. For concentration of $5 \mathrm{M}$, the activity of water goes below 0.4 .

Figures 3.4 and 3.5 show the "effective diffusion coefficients" as a function of dimensionless concentration for different bulk electrolyte concentrations. The non-ideal model predicts higher diffusion coefficients than the ideal model for both cases. It was 
also found that the diffusion coefficients vary in a different way in the non-ideal model compared to the ideal model.

Figure 3.7 shows the "effective diffusion coefficient" $\left(\mathrm{D}_{\text {eff }}\right)$ as a function of the dimensionless concentration for two different concentrations of $\mathrm{CaCh}_{2}$. These curves are extremely sensitive to the properties (CEC, clay content, and surface area etc.) of shales and the activity of the water as a function of the concentration of the electrolyte. For the case of $\mathrm{CaCl}_{2}$, it is seen that the "diffusion coefficient" increases with dimensionless concentration and its order of magnitude is $10^{-10} \mathrm{~m}^{2} / \mathrm{s}$.

The corresponding concentration as a function of ? is shown in Figure 3.8. It is evident that the concentration profile is sharper for the low concentration electrolyte indicating less penetration into the shale. This is also reflected in Figure 3.9 which indicates that over a period of 24 hours, the ions penetrate $2 \mathrm{~cm}$ for a concentration of 4.97 $\mathrm{M}$ whereas they penetrate $4 \mathrm{~cm}$ for a concentration of $2.91 \mathrm{M}$. This is directly attributable to the higher diffusion coefficient $\mathrm{D}_{\text {eff }}$ value at lower salt concentrations.

The solute flux for the two concentrations are shown in Figure 3.10. Clearly the fluxes are much higher at higher concentration. This is because of the larger ion concentration gradient imposed by the higher salt concentration resulting in a higher molar flux. It should be noted that the solute fluxes are positive, indicating ion flow into the shale. The molar flux for water is shown in Figure 3.11. This figure indicates, as would be expected, that the water flux is negative, i.e., water flows out of the shale. Again, as expected high salt concentration results in larger water fluxes because of the larger gradient in water activity inside the shale.

The net flux of water out of the shale results in changes in pore pressure as shown in Figure 3.12. As water is pulled out of the shale, the pore pressure decreases 
to a minimum with distance. The location of this minimum is closely related to invasion of ions into the shale and the resulting reduction in the flux of water. The pore pressure gradients decrease with time because the flux of water from the solution decreases with time as shown in Figure 3.11. Again, it is clearly shown that the pore pressure gradients are larger for the higher salt concentration.

The change in pore pressure with distance can be averaged to obtain an average hydraulic pressure $\left(\bar{p}=\frac{\int_{0}^{L} p(x) d x}{L}\right)$ as shown in Figure 3.13. It is evident from this figure that the average hydraulic pressure exerted by fluids in the shales goes through a minimum with time. This decrease followed by an increase is a result of movement of water from the outside boundary of the shale to the bulk solution due to the osmotic gradient. The depth of this minimum is larger for the higher salt concentration because of the larger osmotic gradient.

Similarly the average solute concentration inside the shale varies with time as shown in Figure 3.14. As ions diffuse into the shale, the average solute concentration increases with time. This increase in salt concentration results in a permanent change in pore pressure which is reflected in the confining pressure.

The change in average hydraulic pressure, osmotic pressure and total pressure for the shale are shown in Figures 3.15a and 3.15b for the two salt concentrations. The total pressure is the sum of osmotic and hydraulic pressures. It is clear that the changes of the hydraulic pressure due to the flux of water and changes of osmotic pressure due to the fluxes of both water and ions are significant and play an important role in determining the total pressure within the shale. Neglecting either the flux of water or the flux of ions would lead to erroneous results. 
Figure 3.16 compares the confining pressure calculated from our model with that measured experimentally. Clearly the trend observed experimentally is duplicated in the simulation results. Good agreement has been achieved with the changes in confining pressure observed. For sake of completeness, both non-ideal and ideal solution simulations are plotted. It is observed that both the non-ideal and ideal models agree with the experimental observations at lower $\mathrm{CaCh}_{2}$ concentration. However, the ideal model does not match the experimental data at high $\mathrm{CaCh}_{2}$ concentration as shown in Figure 3.17. The quantitative agreement with the experimental data observed for the non-ideal model clearly shows that the proper physics has been adequately represented in our model.

It is clear from our simulations and experiments that osmotic effects can play an important role in driving water and ions into/out of the shale. This can result in significant changes in pore pressure with consequences for wellbore stability.

\subsection{CONCLUSIONS}

Based on the experiments and simulation results presented in this chapter, the following conclusions can be drawn:

1. Accounting for both the flux of water and solutes is required for proper modeling of the pore pressures generated in shales.

2. Shales act as "leaky" membranes which mean both water and ions can penetrate into the shale resulting in systematic changes of osmotic pressure that can be predicted by the model presented in this paper. 
3. The non-ideality of electrolytes plays an important role in determining the flux of water and ions into shales and thus the model presented here for non-ideal electrolytes should be used.

4. Good agreement is observed between the swelling tests performed and the general model for in and water flux. This agreement, although presented for a limited data set, shows that the model correctly represents the physics of the water and ion transport.

5. Further validation of the model presented in Chapter 2 and confirmation of water and ion flux is provided through careful experimentation in Chapter 4. 
Table 3.1 Input data for comparison of model predictions with experimental data

\begin{tabular}{|c|c|}
\hline Drilling fluid concentration & $4.9716 \mathrm{M} / 2.1912 \mathrm{M}$ \\
\hline Pore fluid concentration & $0.01459 \mathrm{M}$ \\
\hline Drilling fluid pressure (Hydraulic) & 2720psi \\
\hline Initial pore pressure (Hydraulic) & 2720psi \\
\hline $\mathrm{pH}$ & 8.0 \\
\hline Temperature & $298 K$ \\
\hline Fluid viscosity & $10^{-3} \mathrm{kgm}^{-1} \mathrm{~s}^{-1}$ \\
\hline Distance between clay platelets & $10 \AA$ \\
\hline $\mathrm{K}_{\mathrm{I}}$ & $7.9141 \times 10^{-17} \mathrm{~m}^{3} \mathrm{~s} / \mathrm{kg}$ \\
\hline $\mathrm{K}_{\text {II }}$ & $-2.40996 \times 10^{-17} \mathrm{~m}^{3} \mathrm{~s} / \mathrm{kg}$ \\
\hline $\mathrm{L}_{\mathrm{I}}$ & $6.5573 \times 10^{-14} \mathrm{~mol} \mathrm{~s} / \mathrm{kg}$ \\
\hline $\mathrm{L}_{\mathrm{II}}$ & $2.3389 \times 10^{-10} \mathrm{~mol}^{2} \mathrm{~s} / \mathrm{kg} \mathrm{m}^{-3}$ \\
\hline
\end{tabular}


Table 3.2 Composition of interstitial pore water for Speeton shale [Simpson,1997]

\begin{tabular}{|l|l|}
\hline $\mathrm{CONSTITUENT}$ & CONCENTRATION, g/l \\
\hline $\mathrm{NaCl}$ & 68.39 \\
\hline $\mathrm{CaCl}_{2}$ & 1.62 \\
\hline $\mathrm{MgCl}_{2} \cdot 6 \mathrm{H}_{2} \mathrm{O}$ & 0.51 \\
\hline $\mathrm{NaHCO}_{3}$ & 1.91 \\
\hline $\mathrm{Na}_{2} \mathrm{SO}_{4}$ & 7.08 \\
\hline $\mathrm{KCl}$ & 0.81 \\
\hline
\end{tabular}




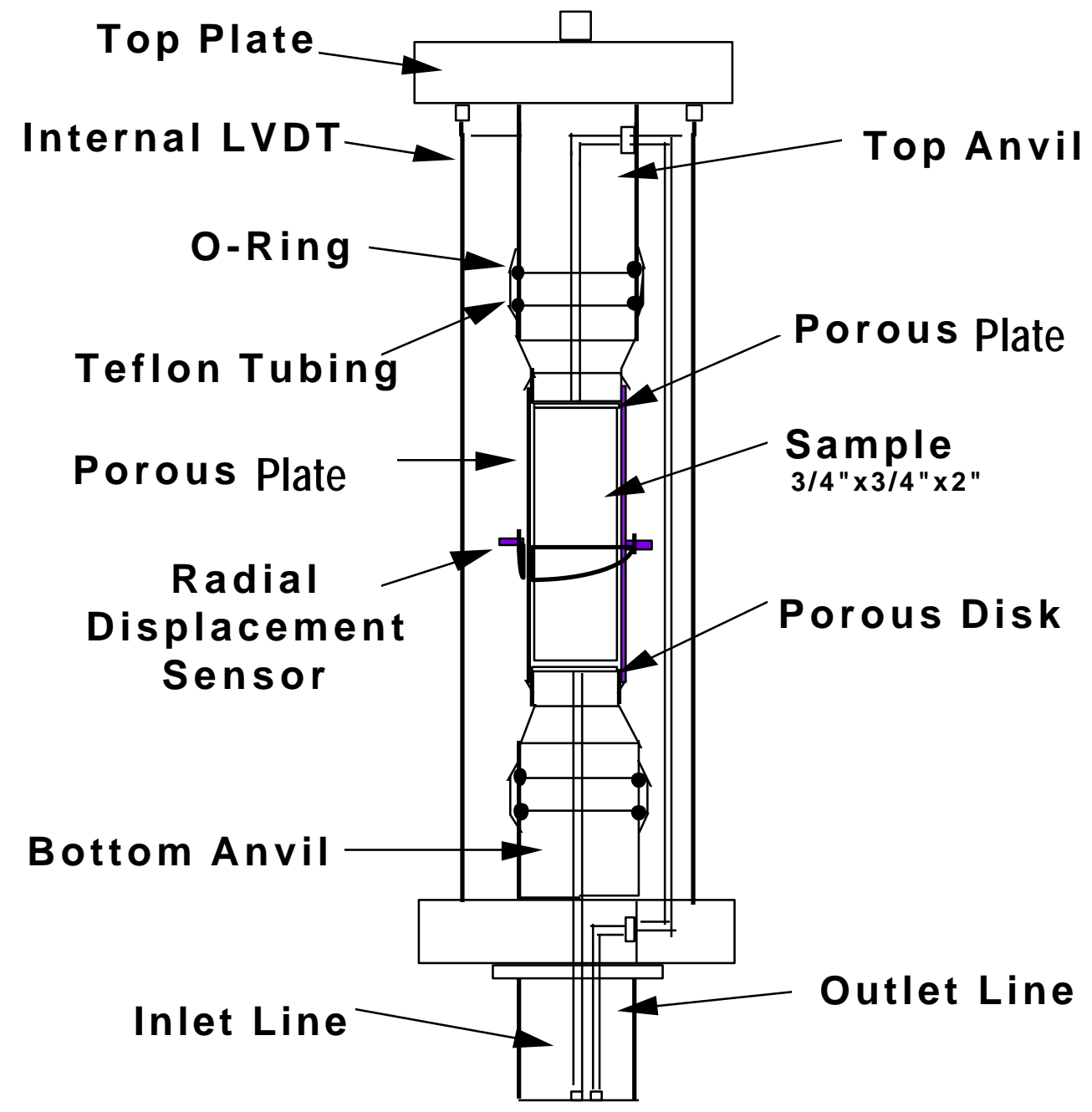

Figure 3.1 Instrumented shale sample (Chenevert and Pernot [1998]) 


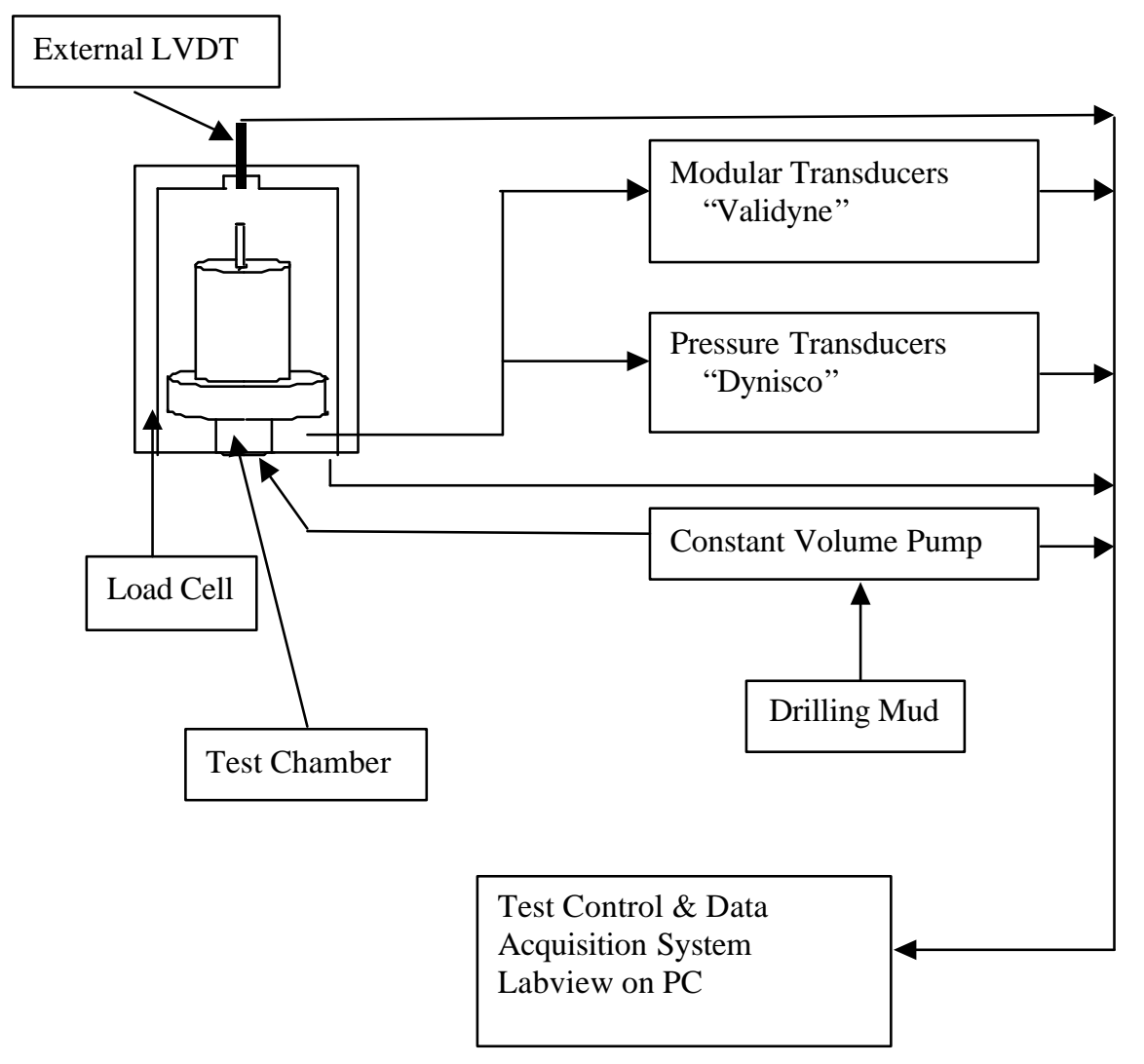

Figure 3.2 Test flow chart (Chenevert and Pernot [1998]) 


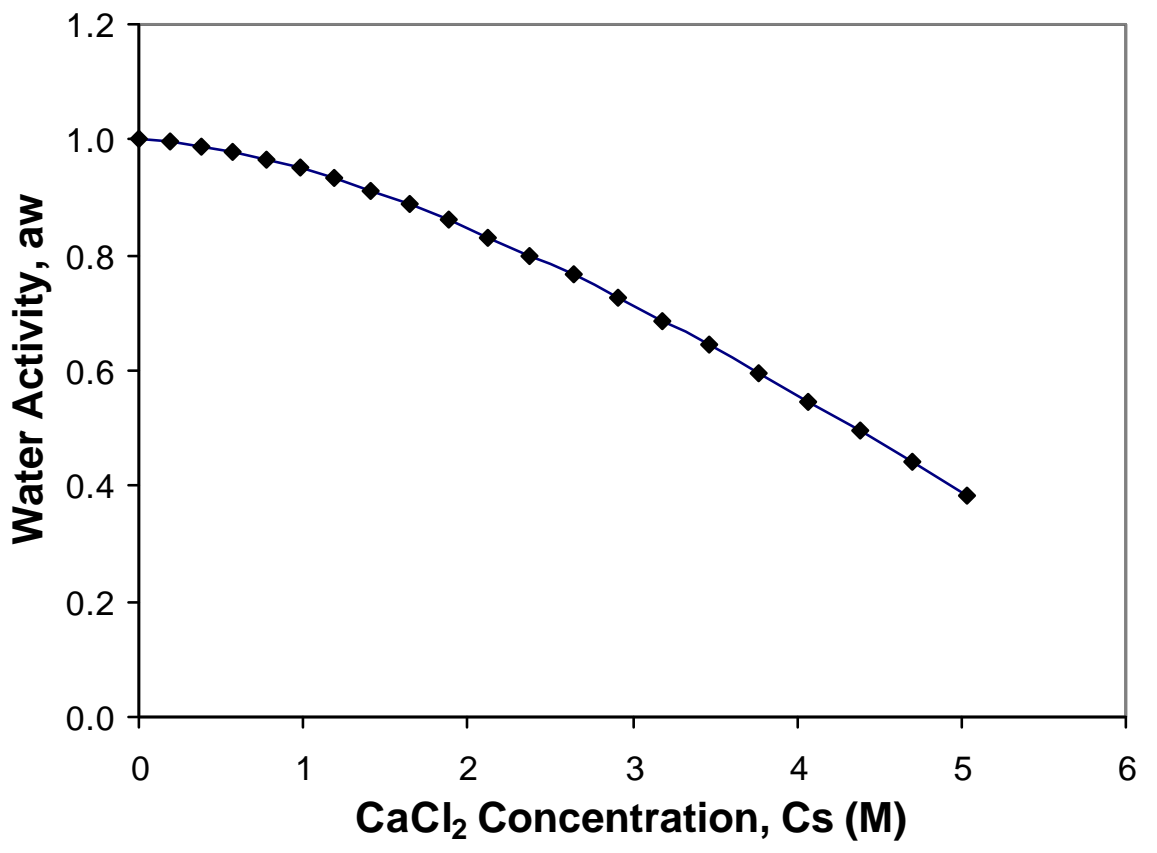

Figure 3.3 Water activity in $\mathrm{CaCl}_{2}$ solutions. Data from B.R. Staples and R. L. Nuttall, J. Phys. Chem. Ref. Data, 1977, Vol. 6, No.2, p. 385-407. 


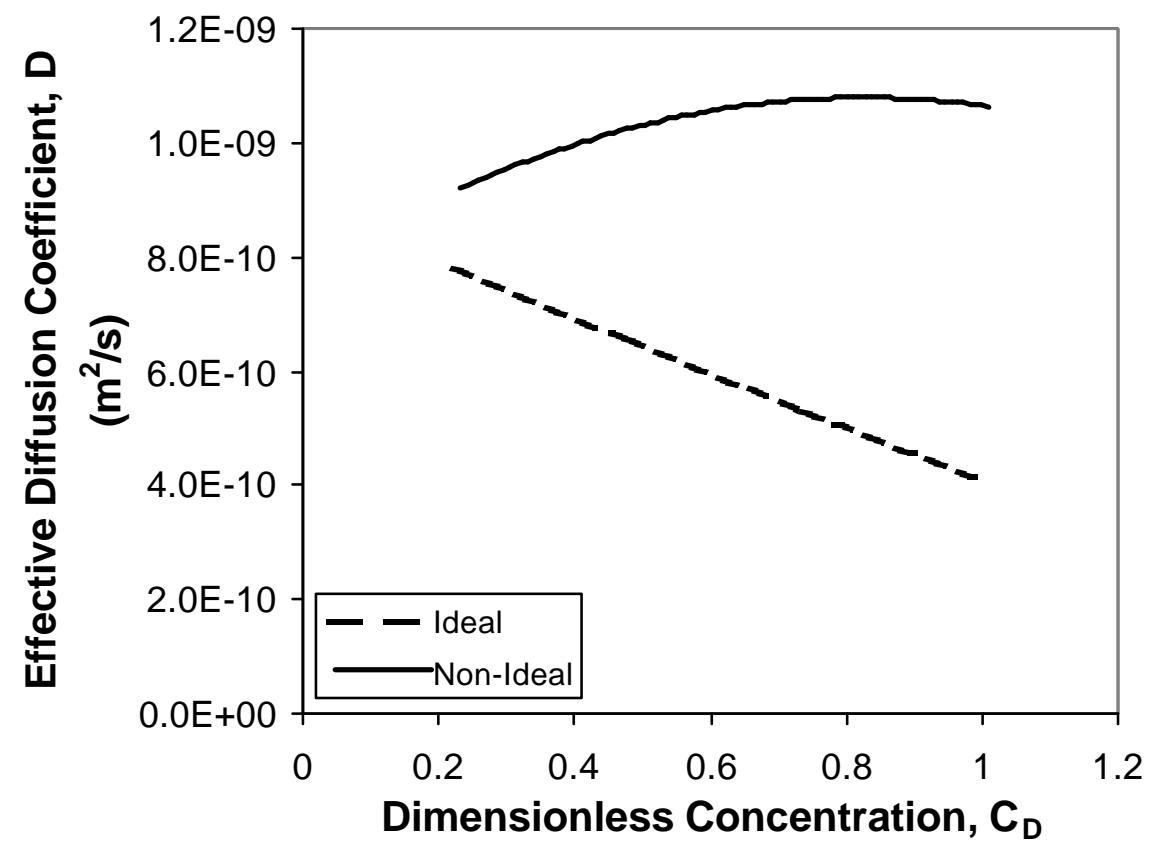

Figure 3.4 Diffusion coefficient as a function of dimensionless concentration. 


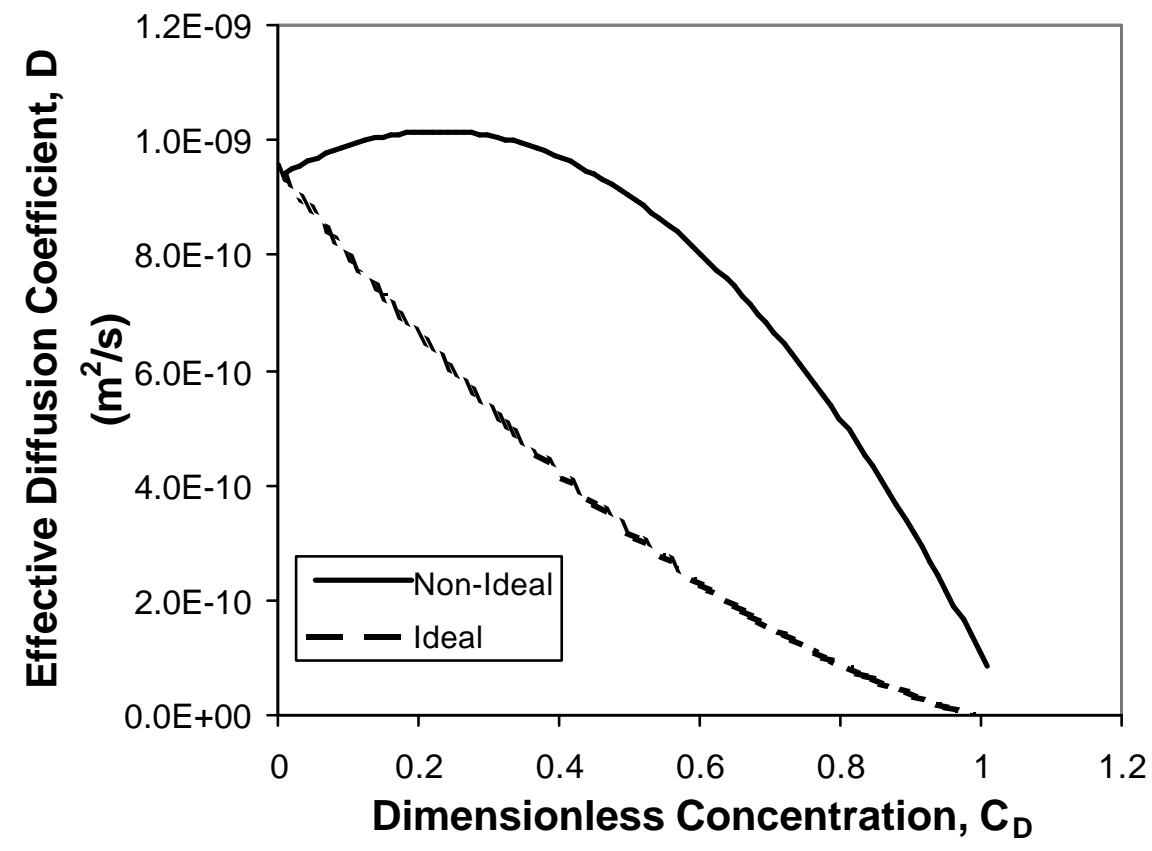

Figure 3.5 Diffusion coefficient as a function of dimensionless concentration. $\mathrm{C}_{\mathrm{d}}=4.9716 \mathrm{M}$ 


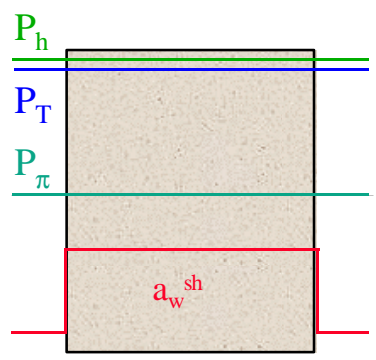

$\mathrm{a}_{\mathrm{w}} \mathrm{df}$

Time $\mathrm{t}=0$

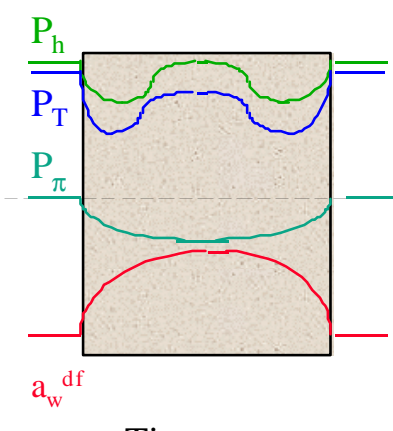

Time $\mathrm{t}$

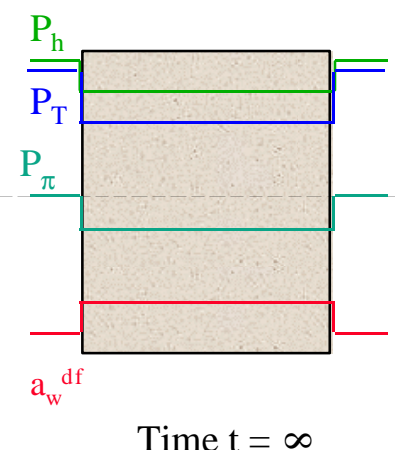

Time $\mathrm{t}=\infty$

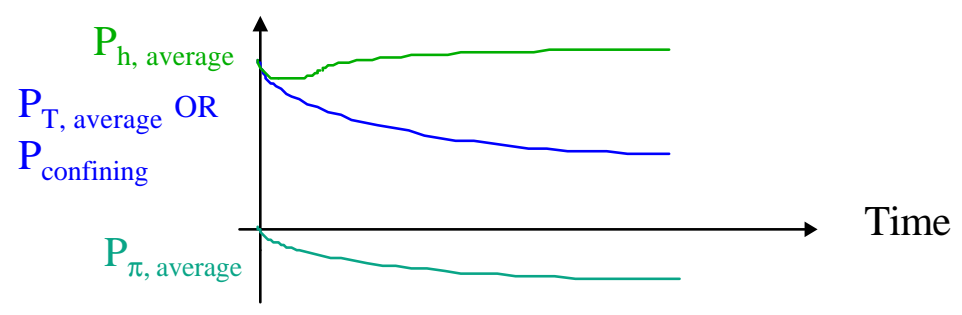

Figure 3.6 Pressure profiles in a constant volume swelling test 

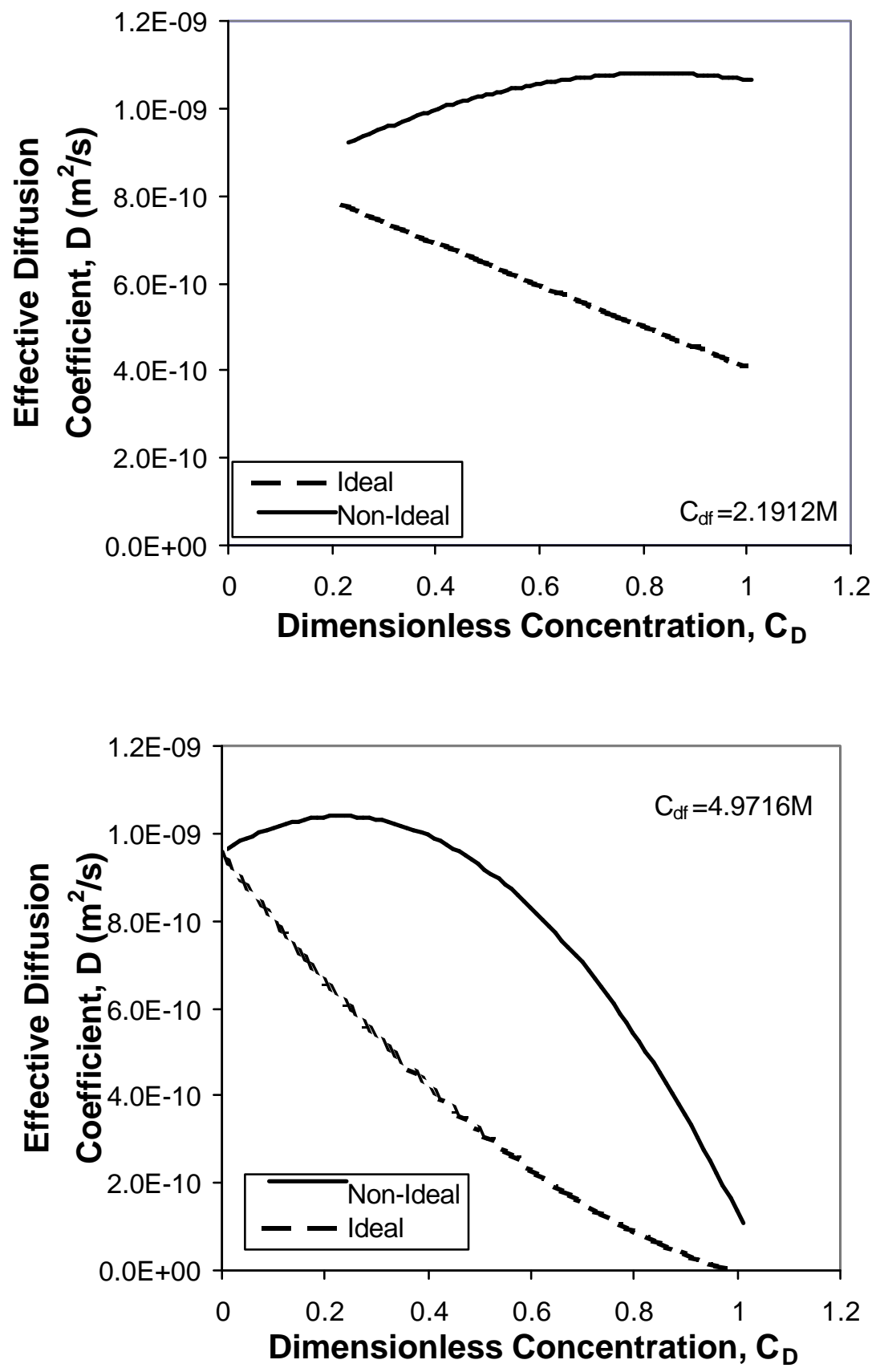

Figure 3.7 Diffusion coefficient as a function of dimensionless concentration. 

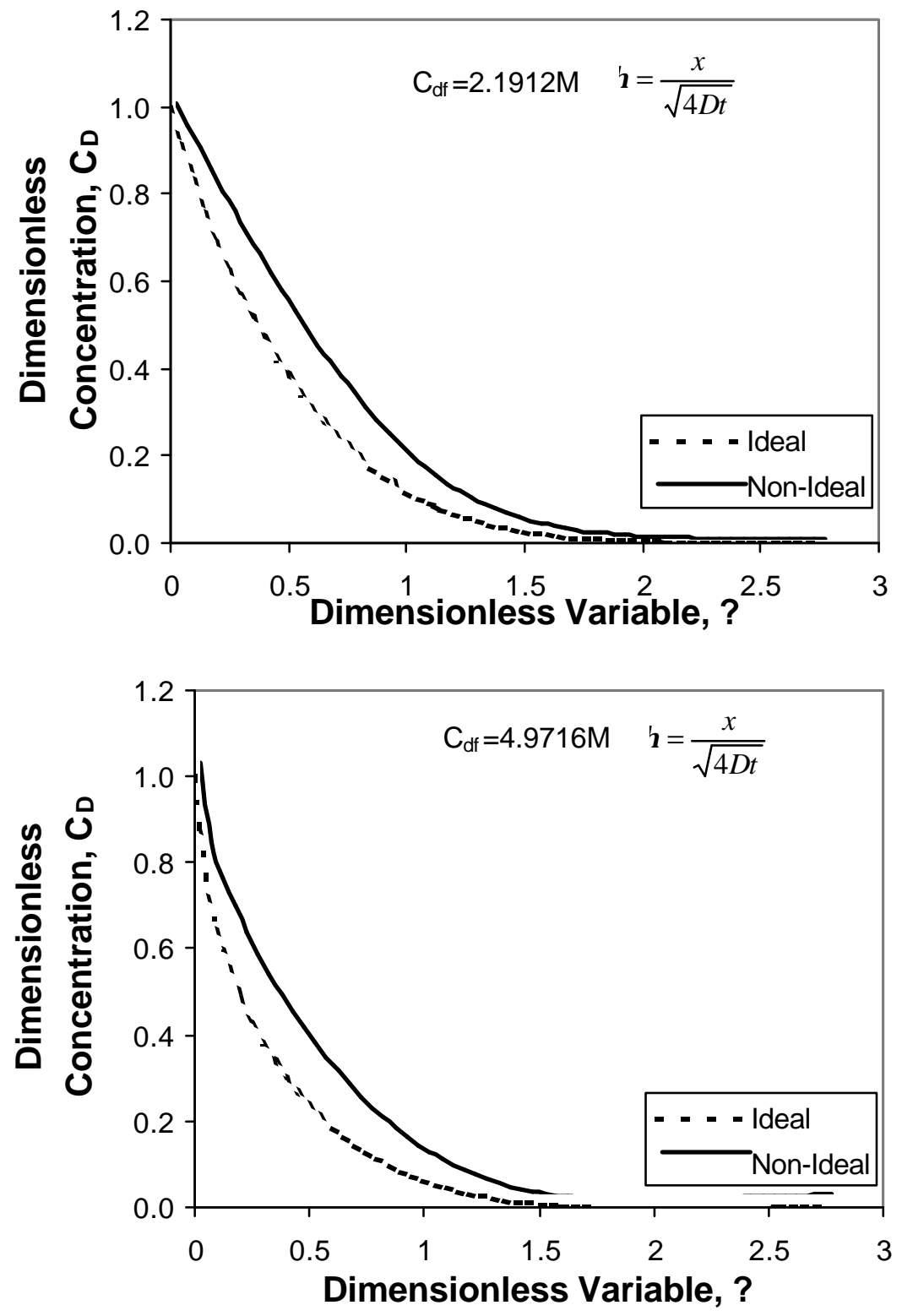

Figure 3.8 Dimensionless concentration profiles calculated from ideal model and nonideal model. 

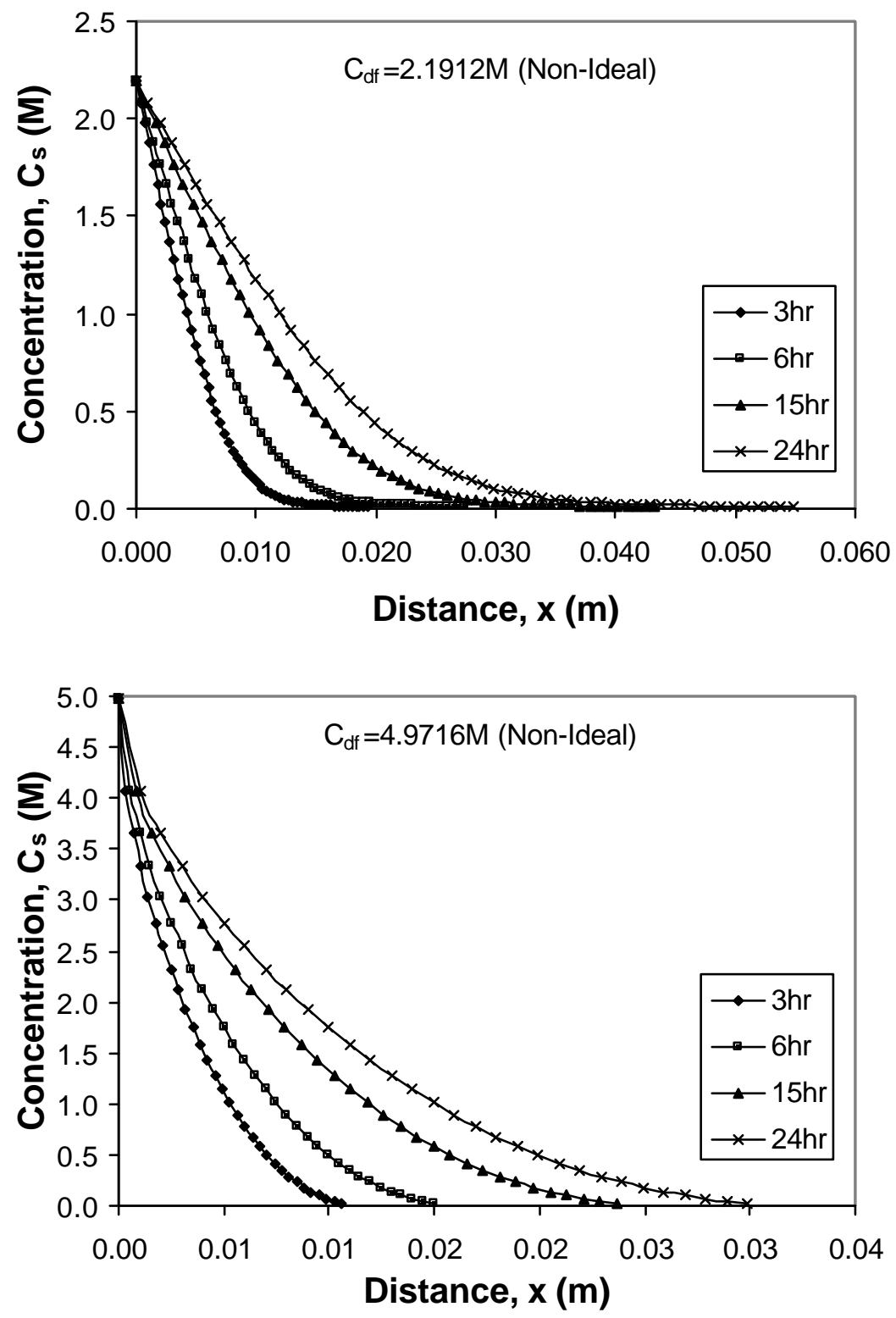

Figure 3.9 Concentration profile at different time. This concentration profile was computed from the non-ideal model. 


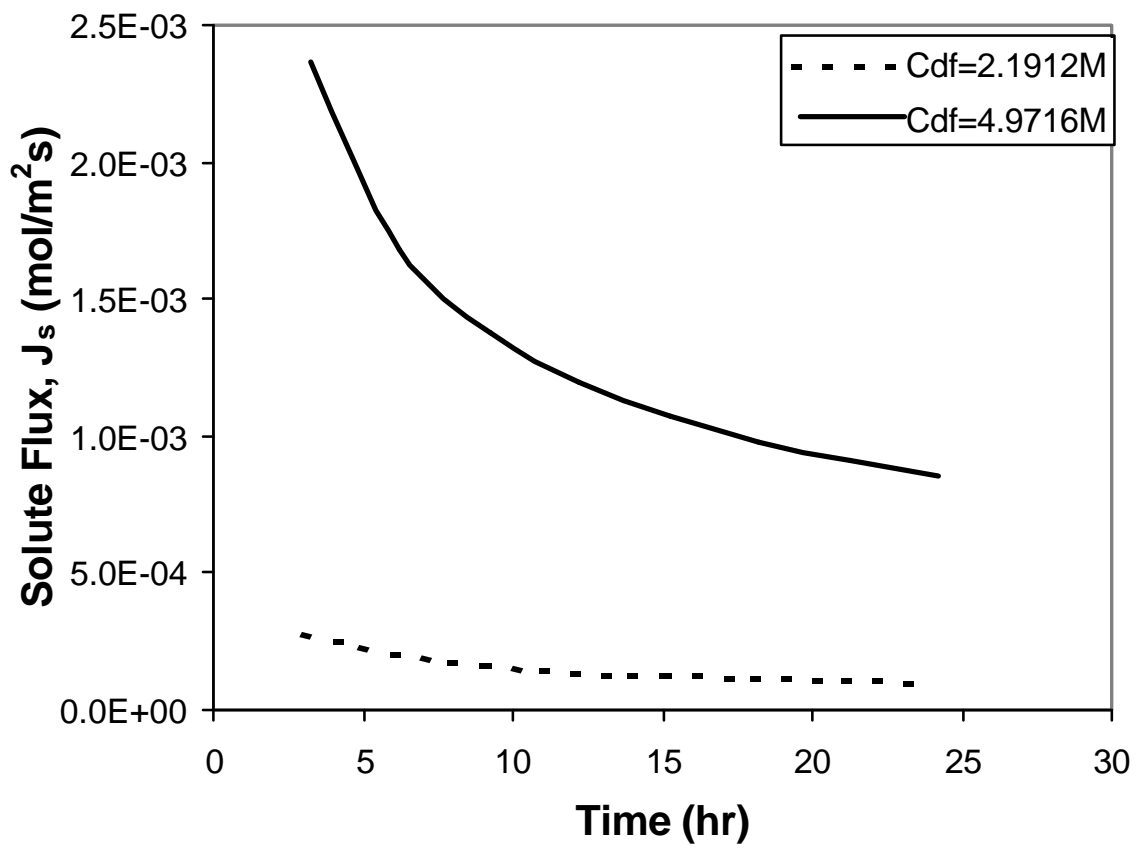

Figure 3.10 Solute flux from the non-ideal model for $\mathrm{C}_{\mathrm{dr}}=2.1912 \mathrm{M}$ and $\mathrm{C}_{\mathrm{d}}=4.9716 \mathrm{M}$. High bulk concentration gives a higher solute flux 


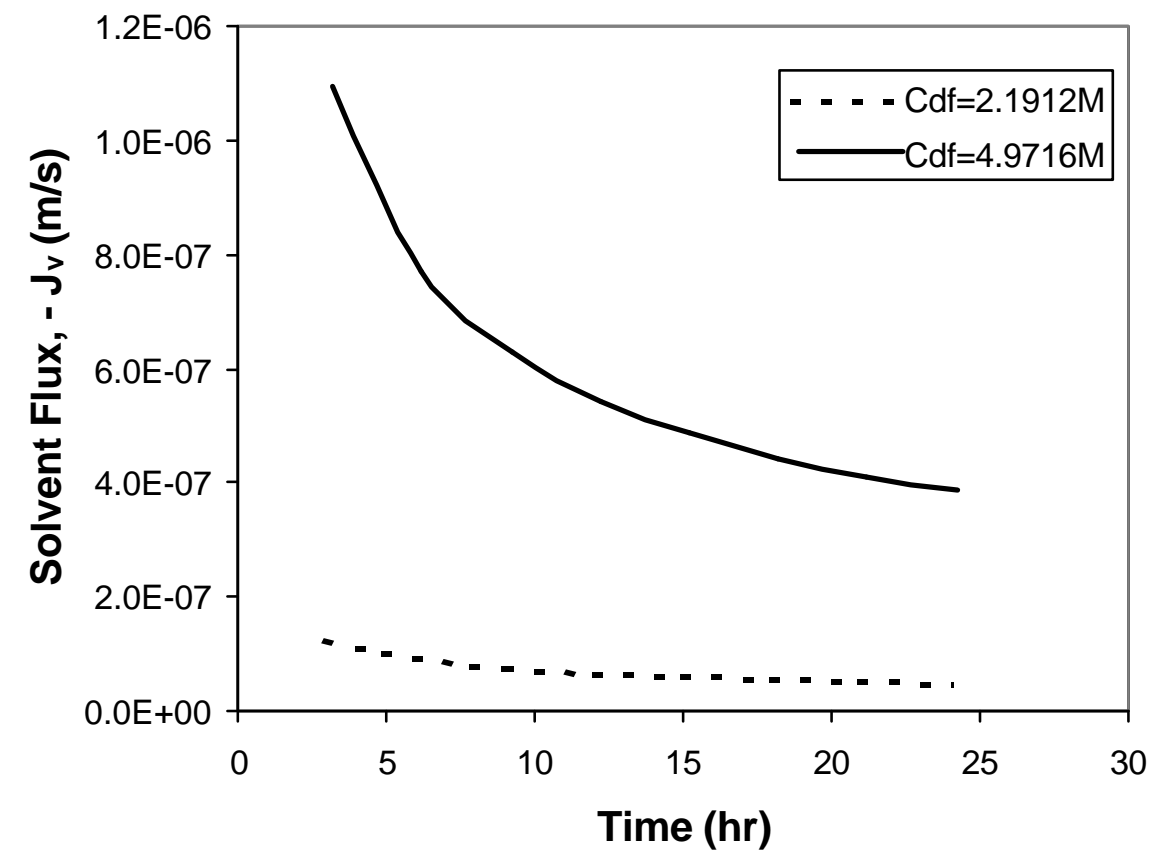

Figure 3.11 Water flux from the non-ideal model for $\mathrm{C}_{\mathrm{d}}=2.1912 \mathrm{M}$ and $\mathrm{C}_{\mathrm{d}}=4.9716 \mathrm{M}$. High bulk concentration gives a higher water flux. 

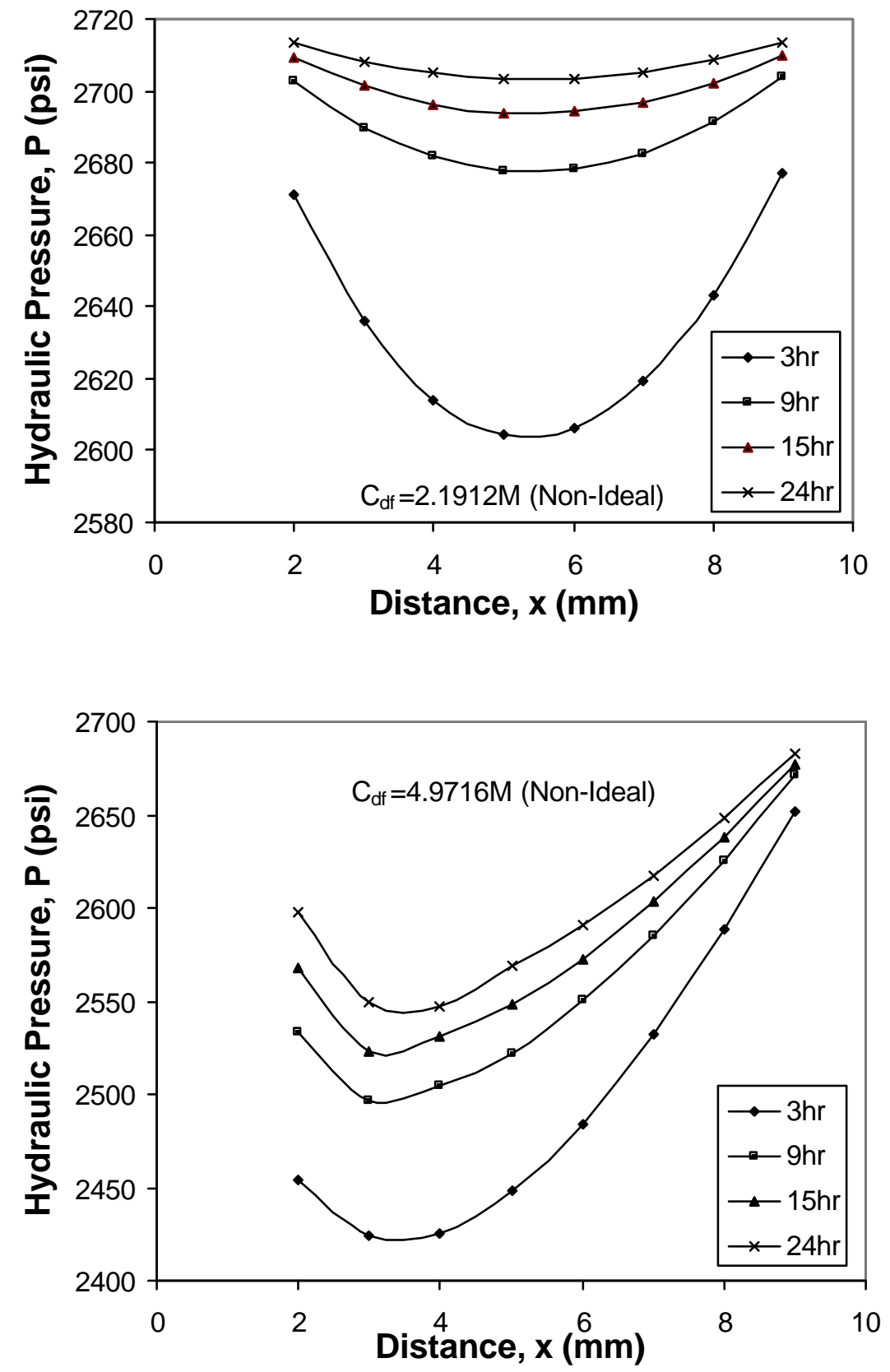

Figure 3.12 Hydraulic pressure profile at different time. This profile was computed from the non-ideal model. 

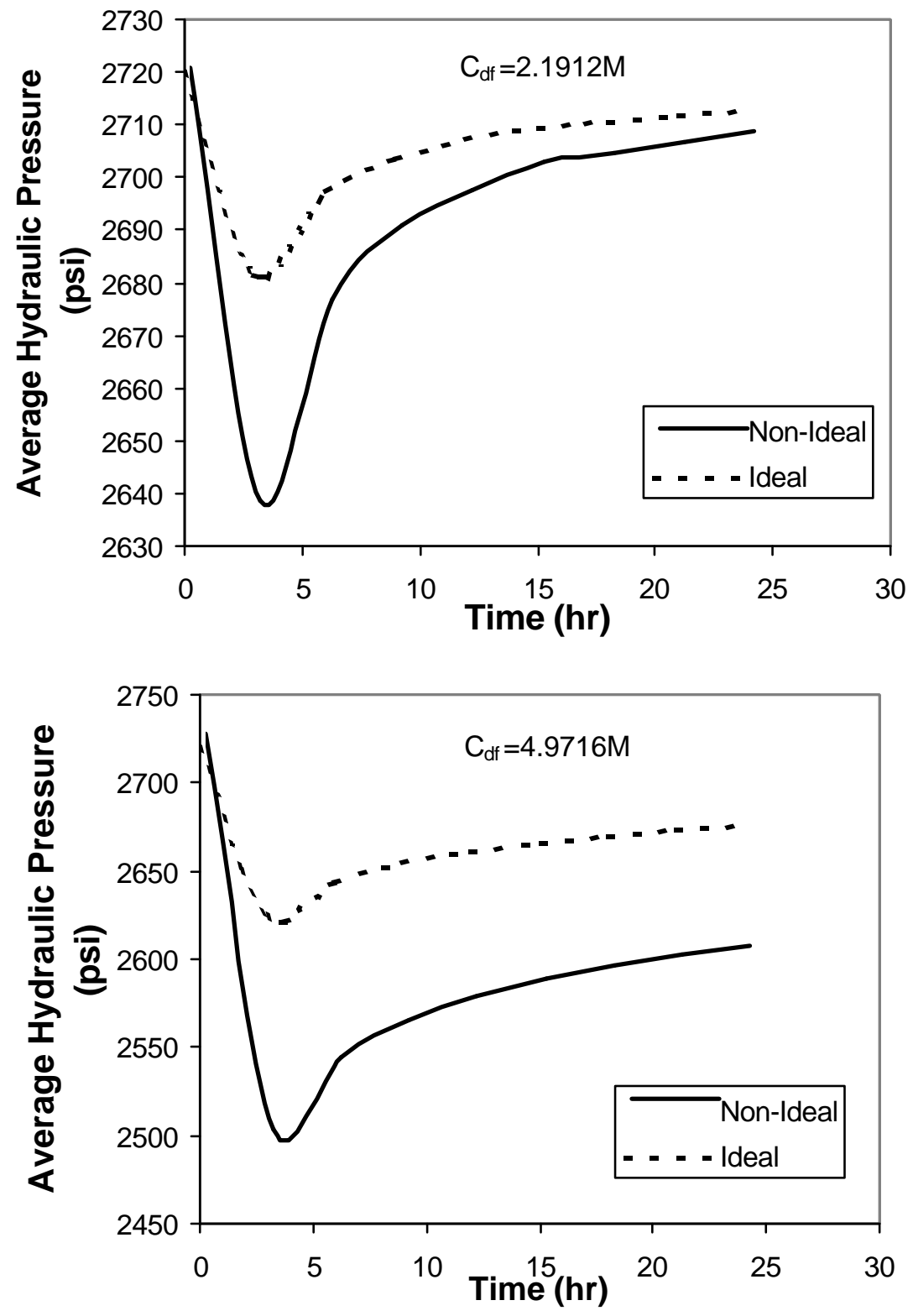

Figure 3.13 Average hydraulic pressure varies with time from ideal model and non-ideal model. 

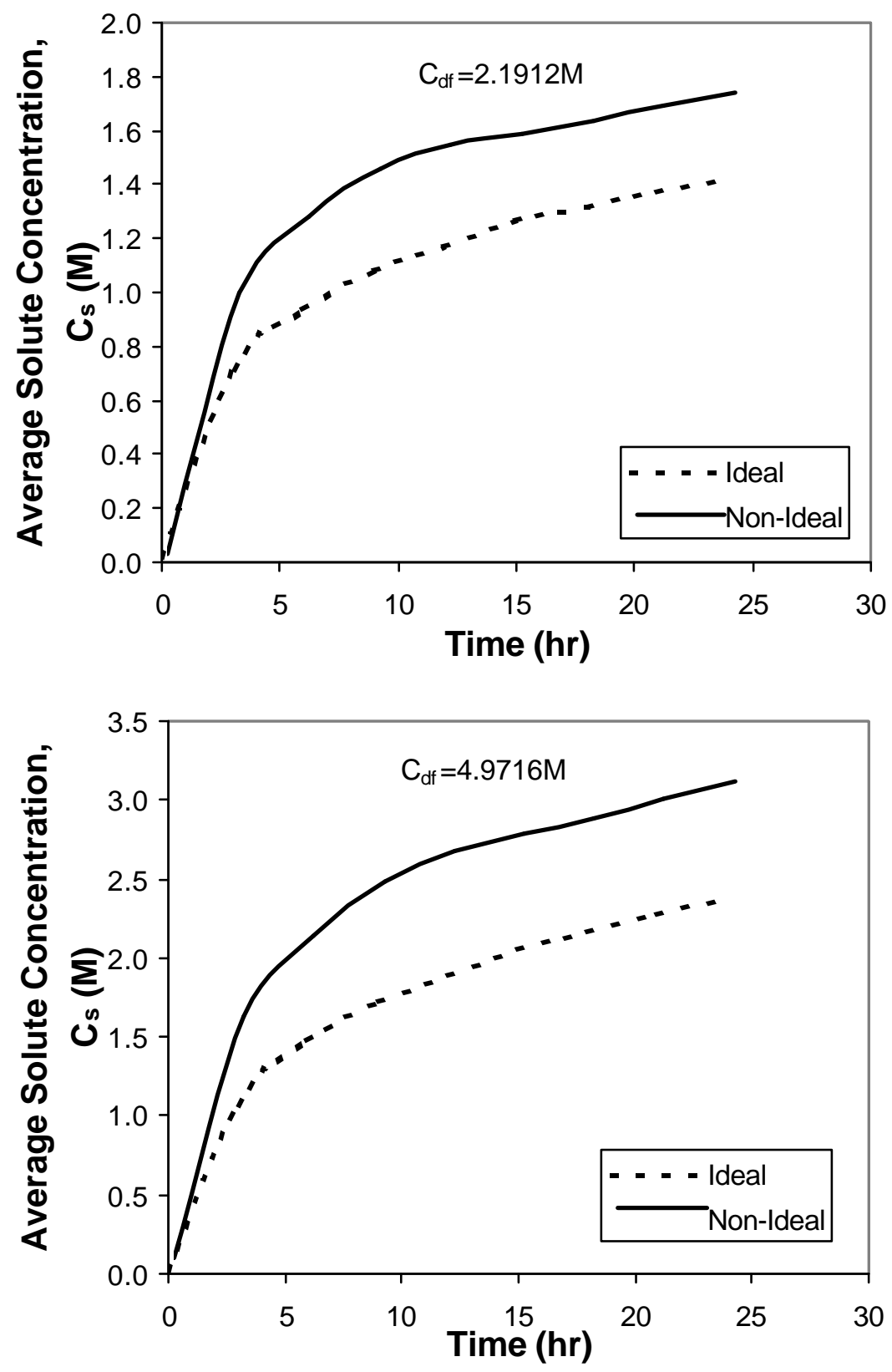

Figure 3.14 Average solute concentration inside the shale varies with time computed from ideal model and non-ideal model. 


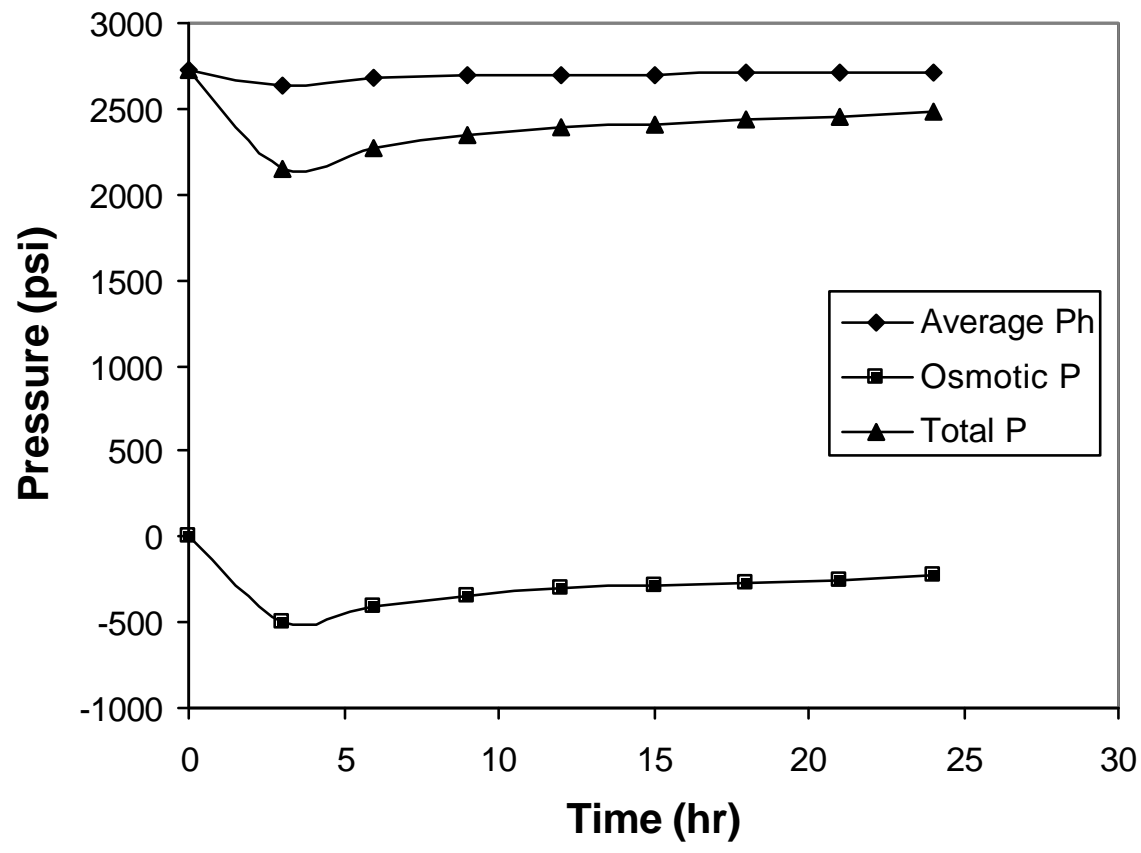

Figure 3.15a The average hydraulic pressure, osmotic pressure and total pressure from non-ideal model for $\mathrm{C}_{\mathrm{d}}=2.1912 \mathrm{M}$. 


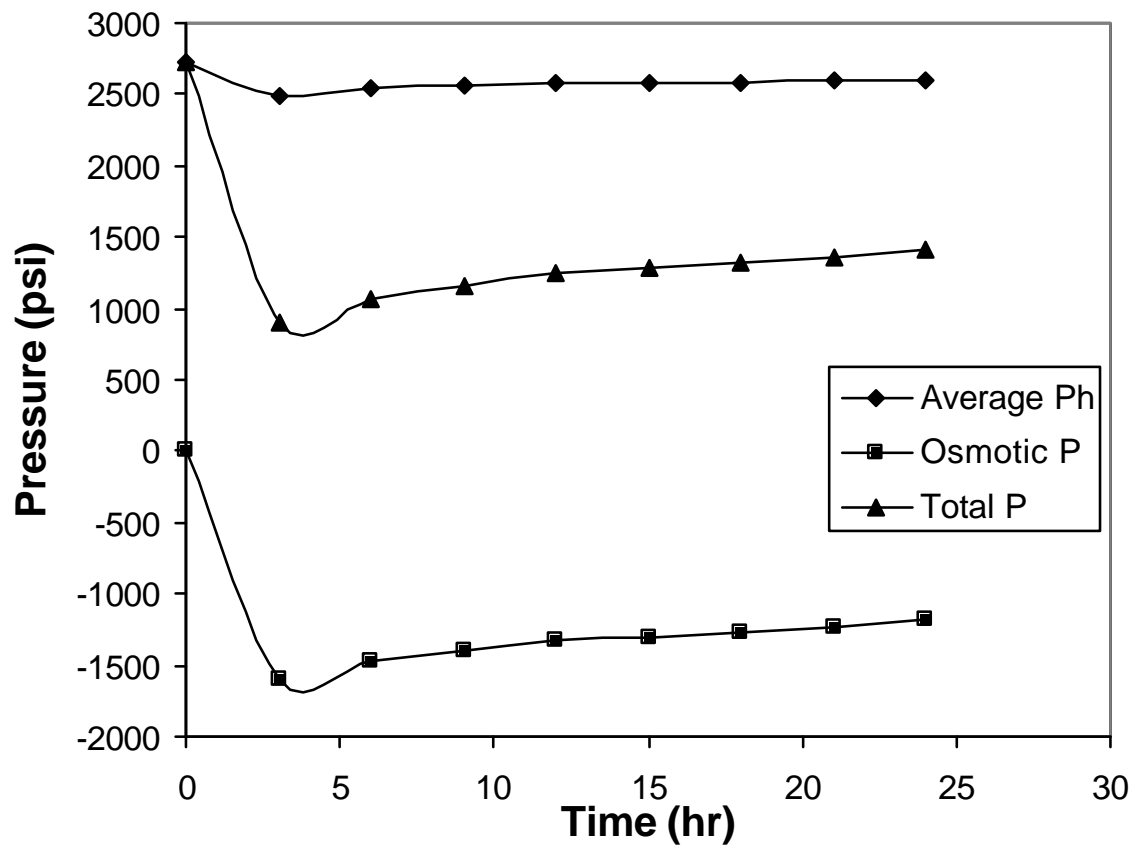

Figure 3.15b The Average hydraulic pressure, osmotic pressure and total pressure from non-ideal model for $\mathrm{C}_{\mathrm{d}}=4.9716 \mathrm{M}$. 


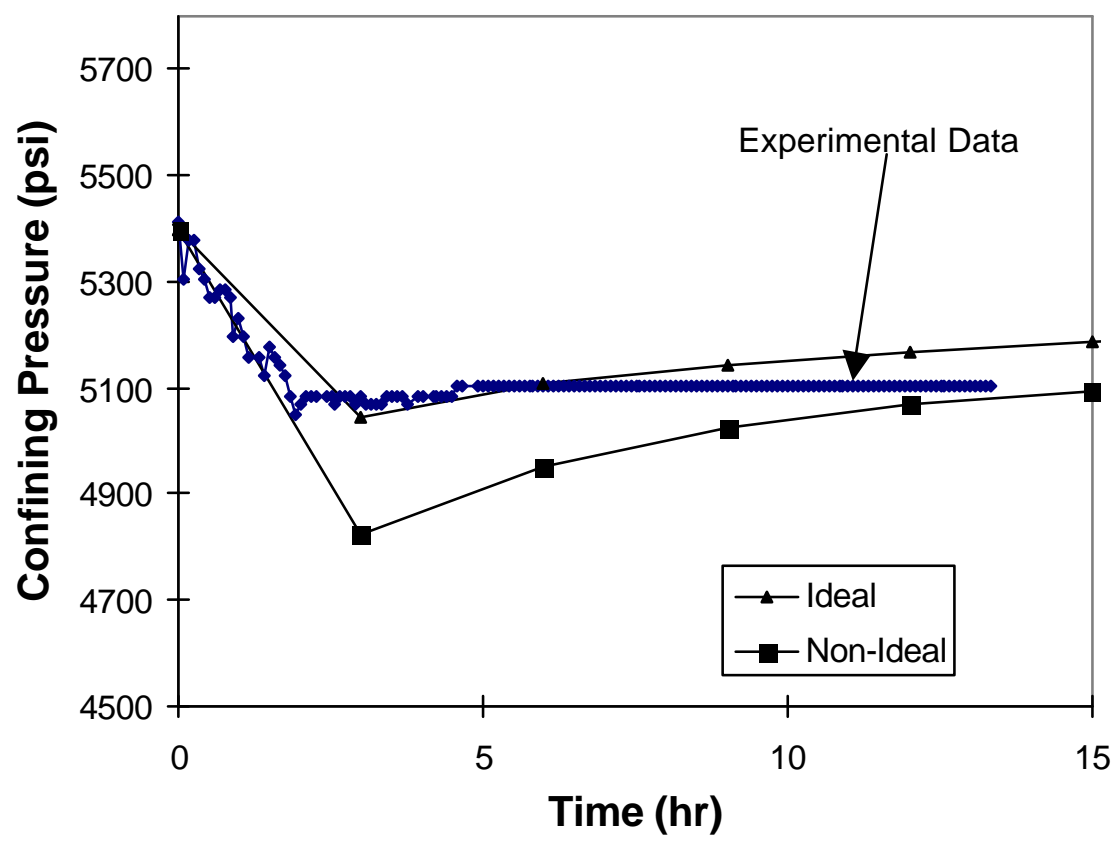

Figure 3.16 Comparison of model and experimental data for $\mathrm{C}_{\mathrm{d}}=2.1912 \mathrm{M}$. In this case both the ideal model and non-ideal model give good agreement. 


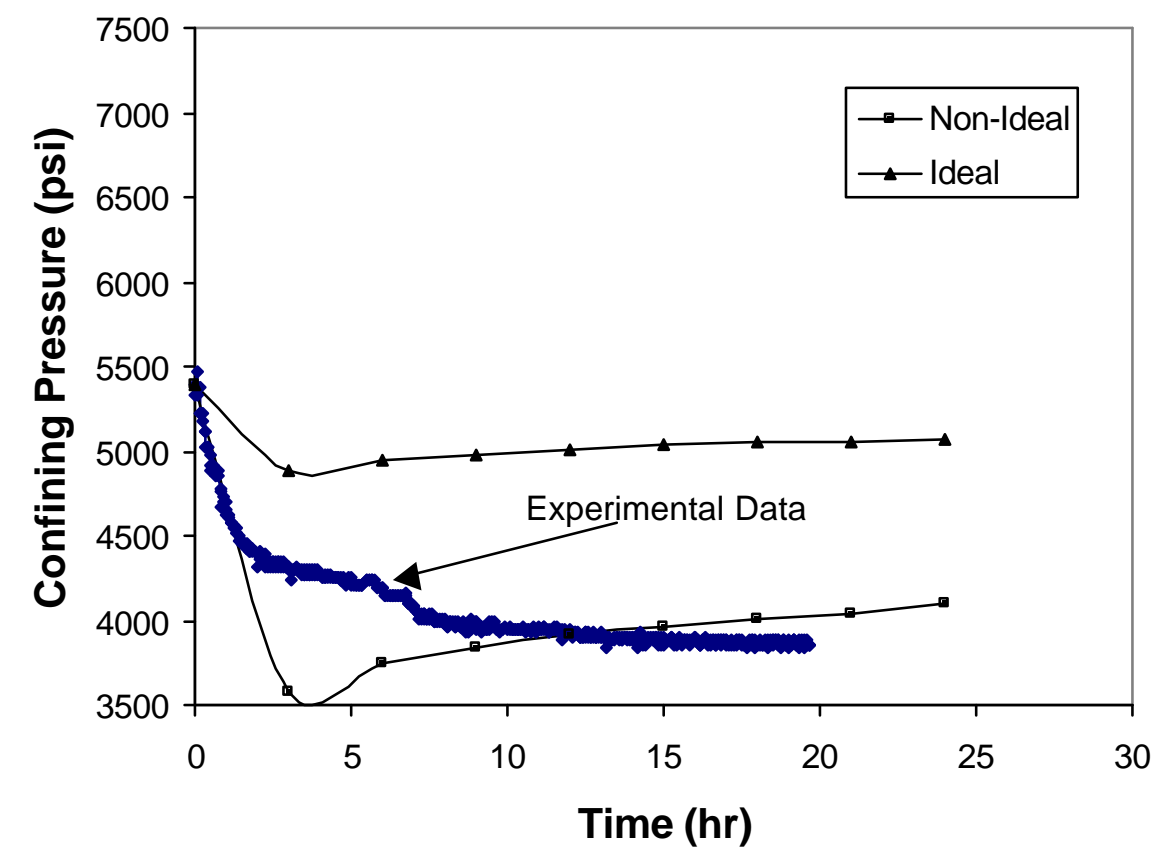

Figure 3.17 Comparison of model and experimental data for $\mathrm{C}_{\mathrm{d}}=4.9716 \mathrm{M}$. In this case the non-ideal model gives good agreement but the ideal doesn't. 


\title{
Chapter 4: Water \& Solute Transport in Shales: A Comparison of Simulations with Experiments
}

\begin{abstract}
The model presented in Chapter 2 is compared with experimental data presented by Ewy and Stankovich [2000]. It is shown that the relative magnitude of the hydraulic conductivity of the shale $\left(\mathrm{K}_{\mathrm{I}}\right)$, the membrane efficiency of the shale $\left(\mathrm{K}_{\mathrm{II}}\right)$, and the effective diffusion coefficient of solute $\left(\mathrm{D}_{\text {eff }}\right)$ all have an influence on the net pore pressure behavior of a shale exposed to a drilling mud. After the model has been calibrated with one set of experimental data, excellent predictions under other operating conditions can be made. Good agreement with experimental data is obtained for such predictions.
\end{abstract}

\subsection{INTORDUCTION}

With increasing environmental demands placed on drilling fluids, the use of water based muds is growing. The use of such mud systems when drilling through troublesome shales can often result in wellbore instability problems due to shale swelling. It has been well documented that swelling shales and wellbore stability depend to a very large extent on the activity of the water and solutes in the aqueous phase in the mud.

Shale instability is generally caused by changes in pore pressure induced by both hydraulic and chemical effects. Differences in both hydraulic and osmotic pressure between the wellbore and the shale result in flow of solute and solvent into or out of the 
shale. Lomba et al [2000], and Yu and Sharma [2001] have estimated the flux of both solute and solvent into or out of the shales using models for transport in non-ideal membranes. Membrane efficiency of the shales can be estimated from models presented by Basu and Sharma [1997], Fritz [1986], and Gross and Osterle [1968]. Shales can also be characterized by a "reflection coefficient" as defined by Kedem and Katchalsky [1962].

Several different experimental tests can be performed to characterize shales. One of the most commonly run tests is a pressure transmission test in which shale is placed between two solutions at different hydrostatic pressures but with the same osmotic pressure (Van Oort [1997]). The rate of the propagation of pressure through the shale is a direct measure of the hydraulic conductivity of the shale $\left(\mathrm{K}_{\mathrm{I}}\right)$. In another test, a shale is placed between two solutions with different hydraulic and osmotic pressures. The rate of the propagation of the pressure that responds to the change in osmotic pressure can then be used to estimate the membrane efficiency of the shale. In this test, the change in pressure at the outlet end of the shale is a direct indication of the flux of water and ions through the shale.

In experiments conducted by Ewy and Stankovich [2000], the outlet of the shale is sealed so that a no-flux boundary exists at the outlet end. The pressure at this outlet end is monitored as a function of time. In this study, these experiments have been used to compare with model calculations. In the following section, these experiments are briefly described. The model developed by Yu and Sharma [2001] is summarized and its applications to the experiments by Ewy and Stankovich [2000] are discussed in the following sections. 


\subsection{MODEL FORMULATION}

Both hydraulic and chemical potential gradients induce the flow of solute and water into or out of the shale to alter the pore pressure. In this study the pore pressure profile is coupled with the flux of both water and solute. The coupled equation for pore pressure can be expressed as (Lomba et al [2000]):

$$
\frac{\partial p}{\partial t}-\frac{K_{I}}{c_{f}} \nabla^{2} p-\frac{n R T K_{I I}}{c_{f}} \frac{\partial^{2} C_{S}}{\partial x^{2}}=0
$$

Where $\mathrm{K}_{\mathrm{I}}$ is the "hydraulic diffusivity" of the formation and $\mathrm{K}_{\mathrm{II}}$ is related to the "membrane efficiency" (or "reflection coefficient") of the formation. $\mathrm{K}_{\mathrm{I}}$ determines the rate of pressure propagation into the shale while $\mathrm{K}_{\mathrm{II}}$ determines the shape of the pore pressure profile i.e. the maximum (or minimum) in pore pressure.

A no-flow boundary condition was applied to simulate Ewy and Stankovichi's [2000] pore pressure propagation procedure. The initial and boundary conditions can be written as,

$$
\begin{aligned}
& t=0, \quad 0 \leq x \leq L, C_{S}=C_{0} ; p=p_{0} \\
& x=0, \quad t>0, \quad C_{S}=C_{d f} ; p=p_{w} \\
& x=L, \quad t>0, \quad \text { No fluxes of water and solute }
\end{aligned}
$$

When a drilling fluid is brought into contact with the formation, solutes can flow into or out of the shale. Therefore, a solute concentration profile will build up within the shale. The solute concentration profile can be calculated by the following diffusivity equation:

$$
\frac{\partial C_{S}}{\partial t}-D_{e f f} \nabla^{2} C_{S}=0
$$


where $D_{\text {eff }}$ is an effective "diffusion coefficient". See Lomba et al [2000] for a derivation and a more detailed discussion.

Again under the experimental conditions used boundary conditions and initial conditions can be described as,

$$
C_{S}=C_{d f} \text { at shale surface for } \mathrm{t}>0
$$

$C_{S}=C_{0}$ for $\mathrm{t}<0$

No flow at $\mathrm{x}=\mathrm{L}$

In general, the "diffusion coefficient" in Eq. 43 varies with concentration. In order to simplify the problem and minimize computing time, the "diffusion coefficient" is assumed to be constant.

\section{Shale Pore Pressure Transmission Test}

Ewy and Stankovich [2000] performed a series of tests on preserved shales under simulated in situ conditions. They developed a technique for measuring changes in shale pore pressure caused by the simultaneous application of hydraulic and osmotic gradients.

Figure 4.1 is a schematic graph of their experimental apparatus. Pore pressure was recorded by high-precision linear variable differential transformers (LVDT's). In summary, a preserved shale sample with dimensions 0.75 -inch diameter by 0.5 -inch length is jacketed between two steel end caps and is subjected to confining pressure. Once at equilibrium, a test fluid is placed in contact with the top of the sample, and the test fluid pressure is immediately set to $\sim 1000$ psi. The fluid is flowed at a very slow rate $(0.1-0.5 \mathrm{cc} / \mathrm{hr})$ to keep the fluid composition constant. Prior to fluid contact, the sample is saturated only with its native pore fluid and has essentially zero pore pressure. 
The higher fluid pressure at the top of the sample causes a time-dependent rise of pore pressure within the sample. This pressure rise is measured directly at the bottom end of the sample, which is a no-flow boundary.

Their experiments were performed under no-flow boundary conditions at $\mathrm{x}=\mathrm{L}$. The model presented above replicates this boundary condition to simulate their experiments.

Three types of shale samples (A1, A2, N1) were used in their tests. Only shales A2 and N1 (Ewy et al [2000]) showed any significant membrane behavior. Our work, therefore, focuses on these two shales. A permeability of 1-2 microdarcy was reported by Ewy et al [2000] for shale A1. It is a highly permeable shale in which chemical effects can be easily overwhelmed by convection. Shale A2 and N1 were reported to have a permeability of 0.002-0.008 and 0.001-0.004 microdarcies, respectively. Under such low permeabilities, fluxes of solvent and solute are significantly hindered. Therefore, osmotic effects are very important in shales A2 and N1.

Ewy and Stankovich [2000] (Figure 4.1) performed a series of measurements of pore pressure for shales with a no-flow boundary conditions at the outlet. The pore pressure at the outlet end was measured and recorded continuously. In their work, they used the following equation to fit the data:

$$
\frac{\partial P}{\partial t}=c \frac{\partial^{2} P}{\partial x^{2}}
$$

where $c$ is the hydraulic diffusivity.

Using this equation, they reported the $\mathrm{c}$ values of their samples as listed in Table 4.1. 
The authors reported a very good match if $c=0.09 \mathrm{in}^{2} / \mathrm{hr}$ was used in the case where $22.2 \% \mathrm{NaCl}$ (wt\%) was used as circulating fluid contacting with shale $\mathrm{N} 1$. This $c$ value corresponds to a (hydraulic) diffusion coefficient of $1.61 \times 10^{-8} \mathrm{~m}^{2} / \mathrm{s}$. This is about 100 time faster than the free $\mathrm{NaCl}$ diffusion coefficient. So the pressure propagation is very fast compared to ion diffusion. This means that at early times, the pore pressure change was mainly due to pressure propagation. Solute diffusion plays an insignificant role at early times, but is expected to contribute at longer times. Unfortunately, their measurements stopped after 12 hours of exposure to the $\mathrm{NaCl}$ fluid. This is too short a time to see the effects of solute diffusion.

The parameter $c$ used in their work is the hydraulic diffusivity. Simply using the hydraulic pressure diffusivity equation does not explain he pressure variation when different concentrations of circulation fluid were applied. Because chemical effects play an important role in determining the pore pressure, equation 4 is not sufficient to describe the whole process. To account for chemical effects, equations 1 and 2 are applied to simulate the experiments.

\subsection{RESULTS AND DISCUSSIONS}

In examining the model equations described above, one finds that pore pressure is mainly controlled by the following parameters: an effective "diffusion coefficient" $\left(\mathrm{D}_{\mathrm{eff}}\right)$, a hydraulic diffusivity $\left(\mathrm{K}_{\mathrm{I}}\right)$, and a "membrane efficiency" $\left(\mathrm{K}_{\mathrm{II}}\right)$. $\mathrm{D}_{\text {eff }}$ controls the rate of solute diffusion. $\mathrm{K}_{\mathrm{I}}$, the hydraulic diffusivity coefficient, controls the rate of hydraulic pressure propagation. $\mathrm{K}_{\mathrm{II}}$ controls how much the chemical potential contributes to the 
pore pressure variation. The effects of these three parameters in controlling the pore pressure behavior are discussed in the following sections.

\subsubsection{Hydraulic Diffusivity $K_{I}$}

If the concentration of drilling fluid is equal to the concentration of the solute in the shale $\left(\mathrm{C}_{0}=\mathrm{C}_{\mathrm{df}}\right)$, only hydraulic effects are important. In this case, the propagation of pressure into the shale is controlled by the hydraulic diffusivity $\left(\mathrm{K}_{\mathrm{I}}\right)$. Figure 4.2 shows simulations run for three different values of $\mathrm{K}_{\mathrm{I}}$. For a large value of $\mathrm{K}_{\mathrm{f}}$, the pore pressure profile approaches equilibrium very quickly. As $\mathrm{K}_{\mathrm{I}}$ decreases, the propagation

of pressure is slower. It is clear from these simulations that the rate of the propagation of pressure is directly related to the magnitude of $\mathrm{K}_{\mathrm{I}}$. This is a well-known result that is expected in the absence of osmotic effects.

\subsubsection{Membrane Efficiency $K_{\text {II }}$}

When hydraulic pressures in the shale and in the drilling fluid are initially equal, the flux of solute and solvent are driven by an osmotic pressure gradient. Figures 4.3 and 4.4 show the pressure variation with time for two different values of $K_{\mathrm{II}}$ and different values of the diffusion coefficient of solute. For the case for large $K_{I I}\left(K_{I I}=-\right.$ $4.524 \times 10^{-16} \mathrm{~m}^{3} \mathrm{~s} / \mathrm{kg}$ ), one finds that large changes in pore pressure (4500 psi) can occur over a period of several hours. Note that all of the changes in pore pressure in Figures 4.3 and 4.4 are due to osmotic pressure variations. Larger values of membrane efficiency $\left(\mathrm{K}_{\mathrm{II}}\right)$ result in a large contribution from the osmotic pressure. The magnitude of the change in pore pressure is controlled by $\mathrm{K}_{\mathrm{II}}$. The rate of propagation of pore 
pressure into the shale is controlled by the effective diffusion coefficient $\left(\mathrm{D}_{\text {eff }}\right)$. Large values of $\mathrm{D}_{\text {eff }}$ result in rapid transmission of the pressure throughout the shale. Small values of the diffusion coefficient result in little or no propagation of this pore pressure into the shale over the 100 hours of simulation time shown in Figures 4.3 and 4.4.

The pressure profiles shown in Figure 4.3 and 4.4 relate two regions of propagation. The first region of the pressure propagation is controlled by the rate of solvent flux. This effect is clearly shown in Figure 4.5. Here up to a period of 10 hours, the rate of pressure propagation is controlled by the solvent flux i.e. by the value of $\mathrm{K}_{\mathrm{I}}$. After this, the rate of solute transport acts on the pressure at which the pressure builds up. If the effective diffusion coefficient of the solute is small, the pressure buildup is slow. However, if the effective diffusion coefficient of solute is large, the rate of pore pressure propagation is fast. Note that the pressure plateau observed in the figures is not a true equilibrium in that the solute flux is still finite and still results in small changes in pore pressure over a long period of time. When $\mathrm{D}_{\text {eff }}$ approaches zero, the shale behaves like an ideal membrane in which only solvent flux plays an important role.

In summary, the membrane efficiency $\left(\mathrm{K}_{\mathrm{II}}\right)$ controls the magnitude of osmotic pressure contribution. The hydraulic diffusivity $\left(\mathrm{K}_{\mathrm{I}}\right)$ controls the rate of hydraulic pressure propagation while the effective diffusion coefficient of solute $\left(\mathrm{D}_{\text {eff }}\right)$ controls the rate of osmotic pressure propagation due to solute transport. In cases where he hydraulic diffusivity $K_{I}$ is much larger than solute diffusion coefficient, pressure propagation is controlled by $\mathrm{K}_{\mathrm{I}}$ at early time and by $\mathrm{D}_{\mathrm{eff}}$ at later time. However, for cases where the hydraulic diffusivity is comparable to the effective diffusion coefficient, both effects can occur simultaneously and pressure propagation behavior can be rather complicated. 


\subsubsection{Comparison with Experiments}

The procedure used in this study to simulate the experiments is as follows: For a given shale, one set of data is used to obtain the hydraulic diffusivity $\mathrm{K}_{\mathrm{I}}$ and the membrane efficiency $K_{I I}$. This value of $K_{I}$ is then used to simulate the other experiments. Because the experiments do not last long enough, the effects of $\mathrm{D}_{\text {eff }}$ are not clearly revealed in the experiments. Therefore, small values of $D_{\text {eff }}$ that do not affect the pore pressure within the experimental time period are enough to simulate the experiments. After the three parameters are obtained we apply them to experiments conducted at different concentrations of circulation fluids. Comparisons can be made by plotting model predictions and experimental data at different solute concentrations.

There are three different types of shales used in the experiments. The shale mineralogy, CEC, and surface area data can be obtained from Ewy et al [2000]. In comparison to the other two shales, shale A1 has a lower clay content, lower CEC and lower surface area. Shale A1 also has a permeability of 1-2 microdarcies which is very high.

\subsubsection{Results for shale A1}

Figures $4.6 \mathrm{a}$ and $4.6 \mathrm{~b}$ show the experimental data for shale A1. Clearly there are no chemical effects exhibited in the experiment. By taking $\mathrm{K}_{\mathrm{II}}=0$, equation 2 reduces to equation 4 . Therefore, both equations 2 and 4 can be used to fit the data. Because there are no chemical effects exhibited in shale A1, our study will mainly focus on the other two shales A2 and N1. 


\subsubsection{Results for shale N1}

Figure $4.7 \mathrm{a}$ is used to obtain the parameters $K_{1}, K_{\mathrm{II}}$ and $\mathrm{D}_{\mathrm{eff}}$ for Shale N1 contacting a $267 \mathrm{~g} / \mathrm{L} \mathrm{CaCl}$ solution. By curve fitting the data, the parameters were obtained and are listed in Table 4.2.

Figure $4.7 \mathrm{~b}$ shows the application of these parameters to Shale N1 contacting a $413 \mathrm{~g} / \mathrm{L} \mathrm{CaCl}$ solution. Because the same shale and same type of solutions were used in the experiment, parameters $\mathrm{K}_{\mathrm{I}}, \mathrm{K}_{\mathrm{II}}$ and $\mathrm{D}_{\mathrm{eff}}$ should have the same values as obtained from Figure 4.7a (Table 4.2). Clearly the model predictions show very good agreement with experimental data (Figure 4.7b). Since highly concentrated $\mathrm{CaCl}$ was used in the experiment, pore pressure was lowered significantly from 880 psi to 670 psi. This is caused by the higher chemical potential (high concentration difference) applied to the shale. Chemical effects played an important role in altering the pore pressure in this case.

Figures $4.8 \mathrm{a}$ and $4.8 \mathrm{~b}$ show parameters obtained from the experiments and applied to predict the pore pressure for shale N1 contacting $\mathrm{NaCl}$ solutions. A $272 \mathrm{~g} / \mathrm{L}$ $\mathrm{NaCl}$ solution was used in Figure $4.8 \mathrm{a}$ to obtain $\mathrm{K}_{\mathrm{II}}$ and a $156 \mathrm{~g} / \mathrm{L} \mathrm{NaCl}$ solution was used in Figure $4.8 \mathrm{~b}$ to compare the model predictions and experimental data. Because circulating fluid was changed from $\mathrm{CaCh}_{2}$ to $\mathrm{NaCl}, \mathrm{K}_{\mathrm{II}}$ must be measured but $\mathrm{K}_{\mathrm{I}}$ remains the same (because Shale N1 is used in both these two experiments). The new value of $n \times \mathrm{K}_{\mathrm{II}}, 2 \times\left(-0.724 \times 10^{-19}\right) \mathrm{m}^{3} \mathrm{~s} / \mathrm{kg}$, was obtained from Figure 4.8a. Note there is only a small change in pore pressure between Figures $4.8 \mathrm{a}$ and $4.8 \mathrm{~b}$. Since the $\mathrm{CaCh}_{2}-\mathrm{Shale}$

$\mathrm{N} 1$ system has a $n \times \mathrm{K}_{\text {II }}$ of $3 \times\left(-7.494 \times 10^{-20}\right) \mathrm{m}^{3} \mathrm{~s} / \mathrm{kg}$ which is much larger than that for 
the NaCl-shale $\mathrm{N} 1$ system, there is a larger chemical potential contribution to the pore pressure in $\mathrm{CaCh}_{2}$-shale $\mathrm{N} 1$ system.

\subsubsection{Results for shale A2}

Figures 4.9a, 4.9b, 4.10a and 4.10b show the experiments and model prediction for shale $\mathrm{A} 2$ contacting $\mathrm{CaCl} 2$ and $\mathrm{NaCl}$ solutions at different concentrations. Model parameters were obtained from Figures 4.9a and 4.10a for a $\mathrm{CaCl}_{2}$-shale $\mathrm{A} 2$ system and a $\mathrm{NaCl}$-shale $\mathrm{A} 2$ system respectively and are listed in Table 4.3

Figures $4.9 \mathrm{~b}$ and $4.10 \mathrm{~b}$ show good agreement of model predictions with experimental data. Because the $\mathrm{CaCh}_{2}$-shale $\mathrm{A} 2$ system and $\mathrm{NaCl}$ shale $\mathrm{A} 2$ system have very close $n \times \mathrm{K}_{\mathrm{II}}$ values in these experiments, the contribution of chemical potential to the pore pressure is very close to each other provided the same chemical potential is applied. Note shale A2 has a higher $K_{\mathfrak{f}}$, so it takes a shorter time to approach the equilibrium pressure compared to Shale N1.

\subsection{CONCLUSIONS}

The model provided by Yu and Sharma [2001] has been modified to simulate the experiments conducted by Ewy and Stankovich [2000] which include a no flow boundary at the outlet end of the shale.

The pore pressure behavior observed under the experimental conditions of the Ewy and Stankovich [2000] can be adequately simulated by the model. Comparisons of the model with the experiments show excellent agreement. One set of experimental 
data was used to obtain the parameters for the shale. This parameter set then is used to predict the behavior observed in other experiments with that shale.

It is clearly shown that the hydraulic diffusivity $\left(\mathrm{K}_{\mathrm{I}}\right)$ influences the rate of the pressure propagation in response to the hydraulic pressure gradient. The effective diffusion coefficient of solute $\left(\mathrm{D}_{\mathrm{eff}}\right)$ controls the rate of osmotic pressure propagation. In cases where $D_{\text {eff }}$ is much less than $K_{I}$, it is seen that hydraulic effects become evident at short times whereas pressure propagation due to solute diffusion may require a much longer time period.

The magnitude of the osmotic pressure generated in the shale is directly related to the membrane efficiency $\left(\mathrm{K}_{\mathrm{II}}\right)$ in our model. The comparisons with experimental data clearly show that this effect is adequately modeled through $\mathrm{K}_{\mathrm{II}}$. Good agreement with experimental observations with different solute concentrations is observed.

Both the magnitude and the rate of the pressure propagation can now be adequately modeled in a single model provided the three parameters $K_{I}, K_{I I}$ and $D_{\text {eff }}$ can be obtained by an appropriate experimental technique such as that proposed by Ewy and Stankovich [2000]. 
Table 4.1 Values of c and k reported by Ewy and Stankovich [2000]

\begin{tabular}{|l|l|l|}
\hline Shale & c range $\left(\mathrm{in}^{2} / \mathrm{hr}\right)$ & k range (microdarcies) \\
\hline A1 & $\sim 35$ & $1-2$ \\
\hline N1 & $0.03 \sim 0.075$ & $0.001-0.004$ \\
\hline A2 & $0.07 \sim 0.15$ & $0.002-0.008$ \\
\hline
\end{tabular}

Table 4.2 Parameters for shale N1.

\begin{tabular}{|l|l|}
\hline Parameters & Values \\
\hline $\mathrm{D}_{\text {eff }}$ & $8.942 \times 10^{-11} \mathrm{~m}^{2} / \mathrm{s}$ \\
\hline $\mathrm{K}_{\mathrm{I}}$ & $1.1344 \times 10^{-18} \mathrm{~m}^{3} \mathrm{~s} / \mathrm{kg}$ \\
\hline $\mathrm{K}_{\mathrm{II}}\left(\mathrm{CaCl}_{2}\right)$ & $-7.494 \times 10^{-20} \mathrm{~m}^{3} \mathrm{~s} / \mathrm{kg}$ \\
\hline $\mathrm{K}_{\mathrm{II}}(\mathrm{NaCl})$ & $-0.724 \times 10^{-19} \mathrm{~m}^{3} \mathrm{~s} / \mathrm{kg}$ \\
\hline $\mathrm{C}_{\mathrm{f}}($ compressibility coefficient $)$ & $1 \times 10^{-6} \mathrm{psi}^{-1}$ \\
\hline $\mathrm{C}_{\mathrm{df}}(\mathrm{CaCl}$ concentration $)$ & $267 \mathrm{~g} / \mathrm{L} \mathrm{CaCl}$ \\
\hline Pore fluid concentration $(\mathrm{CaCh})^{*}$ & $0.01 \mathrm{M}$ \\
\hline Pore fluid concentration $(\mathrm{NaCl})^{*}$ & $1.5 \mathrm{M}$ \\
\hline
\end{tabular}

* Values were estimated based on Simpson [1997]. 
Table 4.3 Model parameters for Shale A2

\begin{tabular}{|l|l|}
\hline Parameters & Values \\
\hline$D_{\text {eff }}$ & $8.942 \times 10^{-11} \mathrm{~m}^{2} / \mathrm{s}$ \\
\hline $\mathrm{K}_{\mathrm{I}}$ & $2.344 \times 10^{-18} \mathrm{~m}^{3} \mathrm{~s} / \mathrm{kg}$ \\
\hline $\mathrm{K}_{\mathrm{II}}\left(\mathrm{CaCl}_{2}\right)$ & $-1.394 \times 10^{-19} \mathrm{~m}^{3} \mathrm{~s} / \mathrm{kg}$ \\
\hline $\mathrm{K}_{\mathrm{II}}(\mathrm{NaCl})$ & $-2.294 \times 10^{-19} \mathrm{~m}^{3} \mathrm{~s} / \mathrm{kg}$ \\
\hline
\end{tabular}




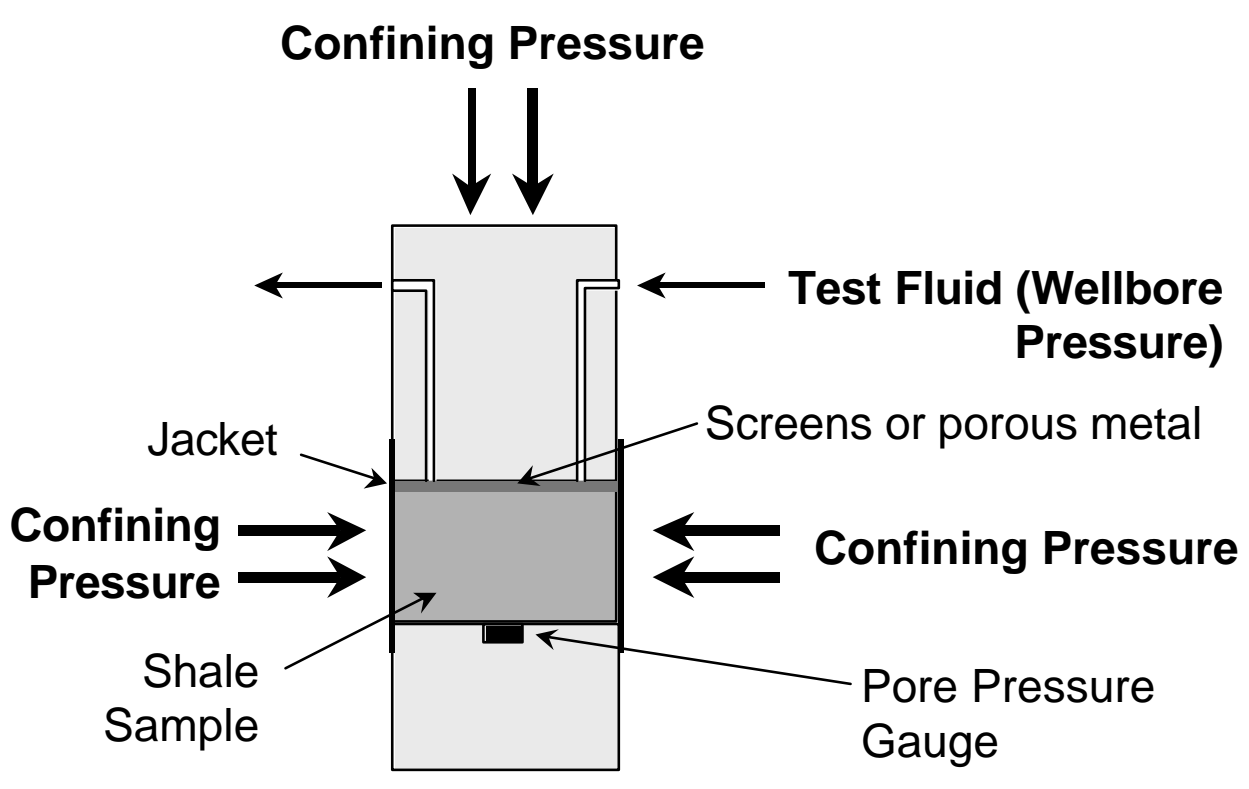

Figure 4.1 Schematic of shale sample assembly and loading. Ewy and Stankovich [2000]. 


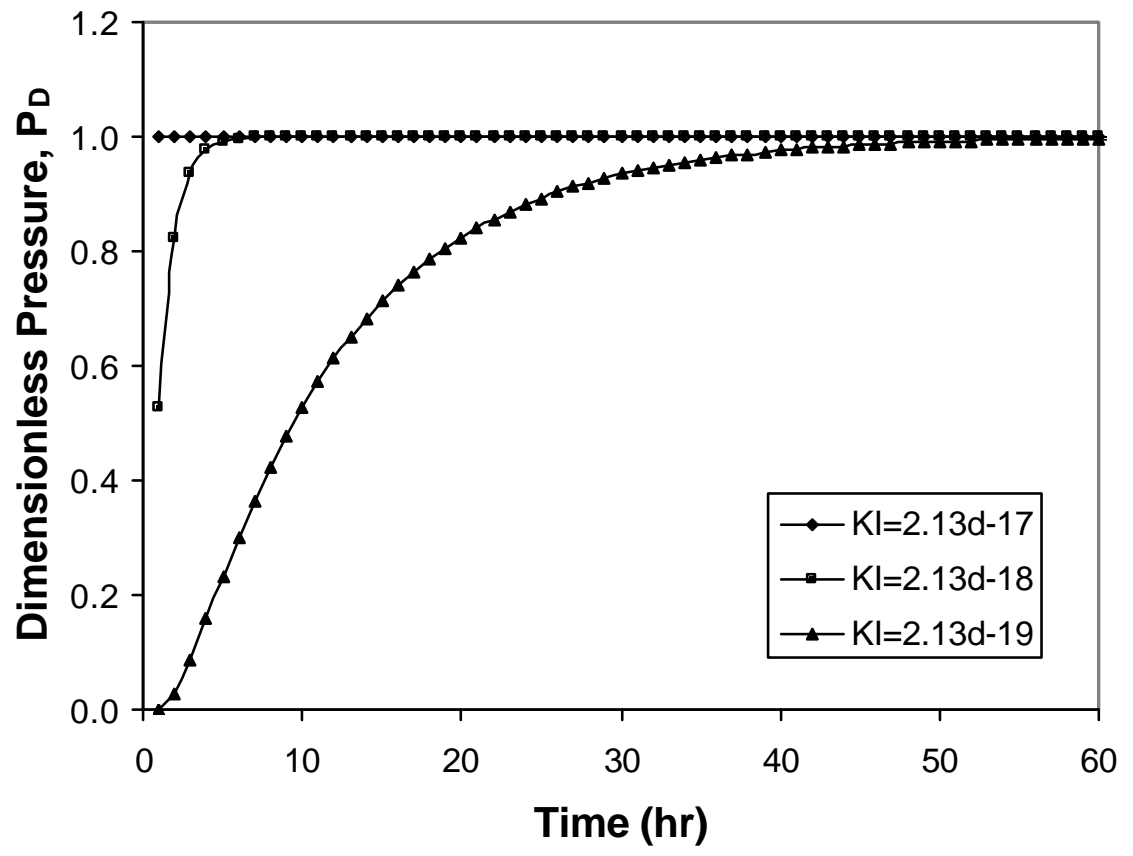

Figure 4.2 Dimensionless pore pressure as a function of time for different hydraulic diffusion coefficient $\mathrm{K}_{\mathrm{I}}$. No chemical effects applied on shale. 


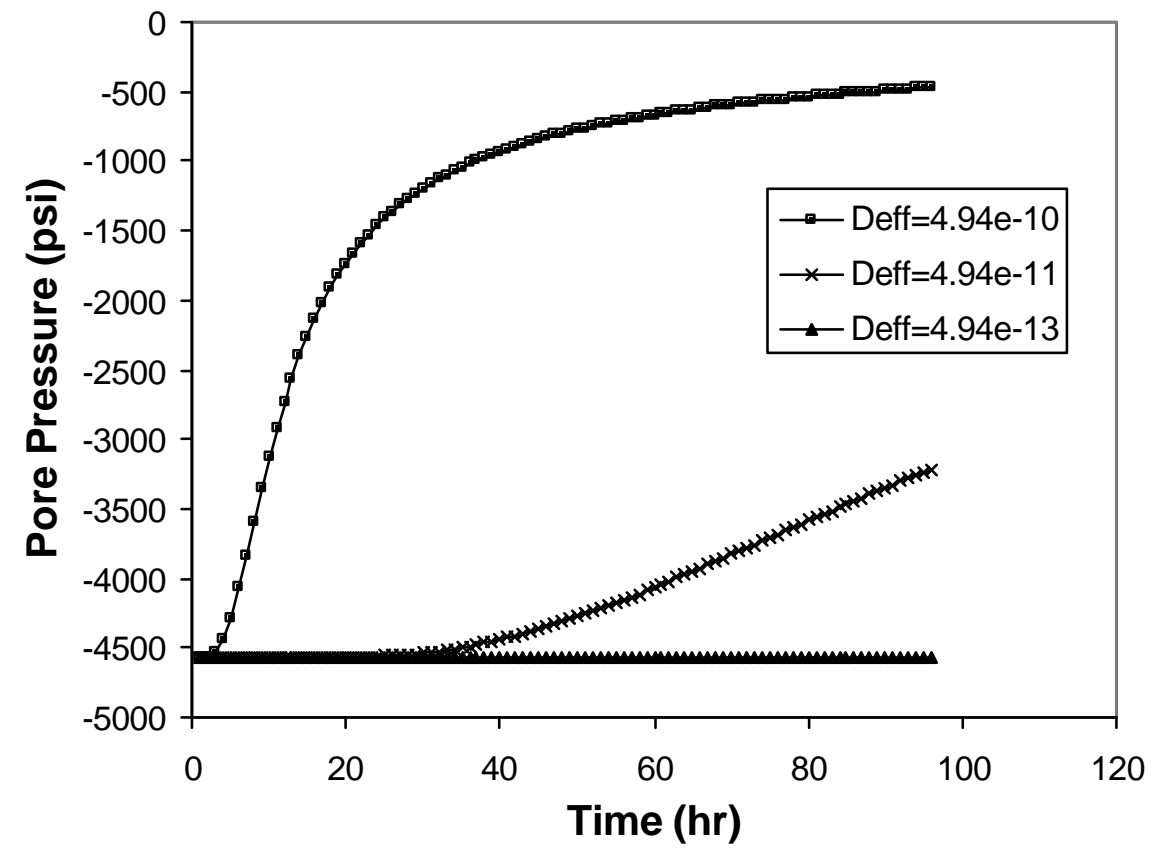

Figure 4.3 Pore pressure as a function of time under large membrane efficiency condition. 


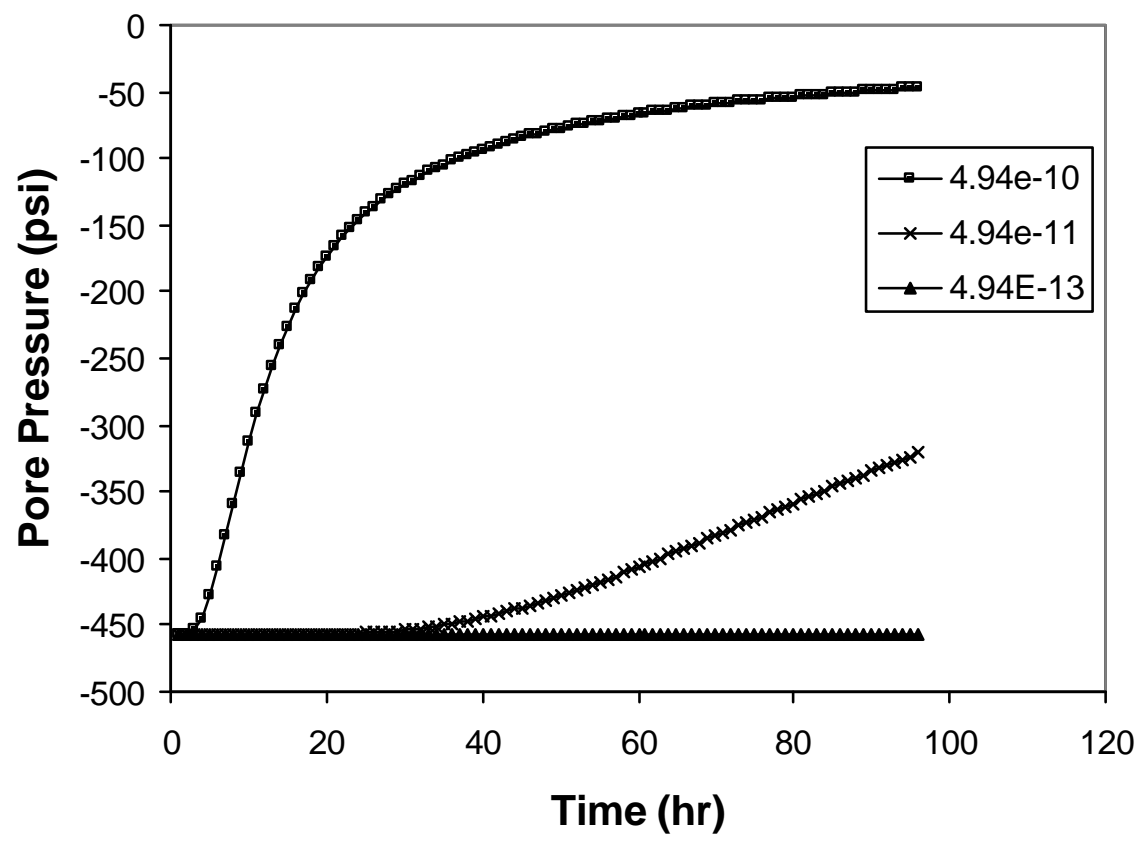

Figure 4.4 Pore pressure as a function of time under median membrane efficiency condition. 


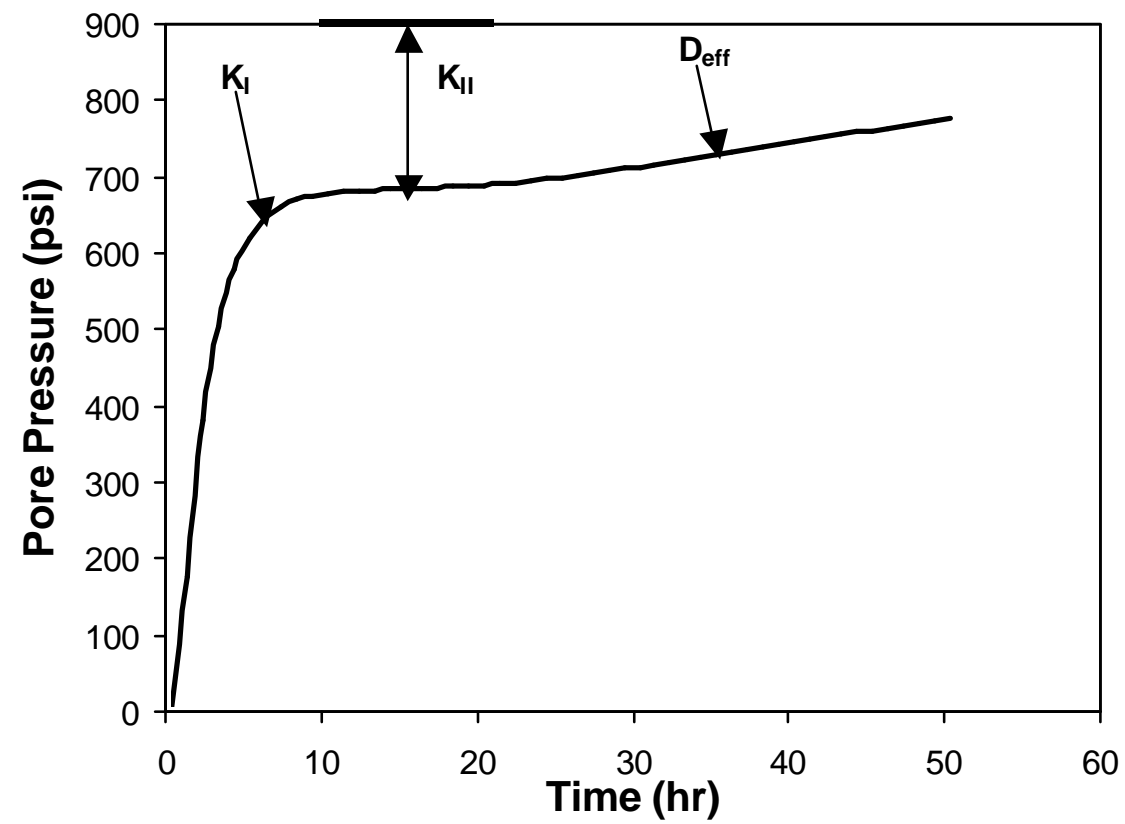

Figure 4.5 Summary of model parameters and their effects in controlling the behavior of pore pressure. 


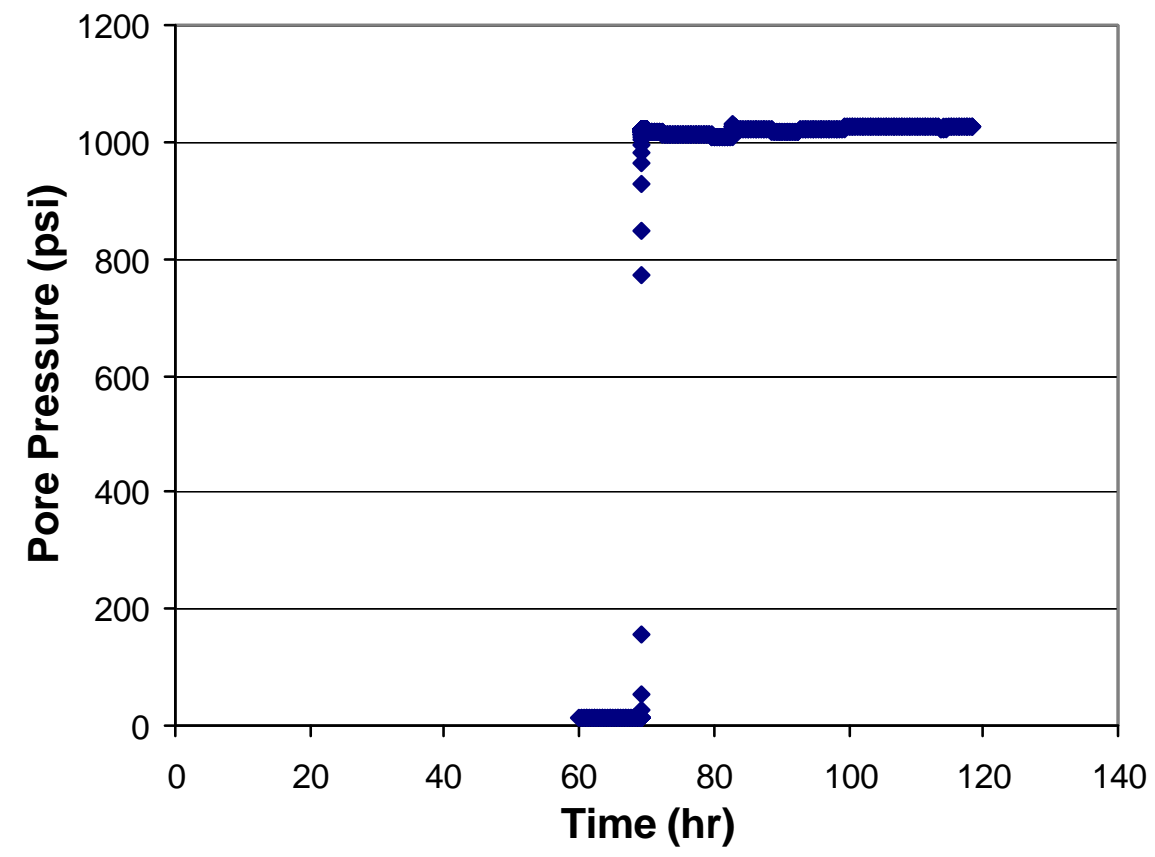

Figure 4.6a Measured pore pressure for shale A1 contacting with $272 \mathrm{~g} / \mathrm{L} \mathrm{NaCl}$. No membrane behavior exhibited. 


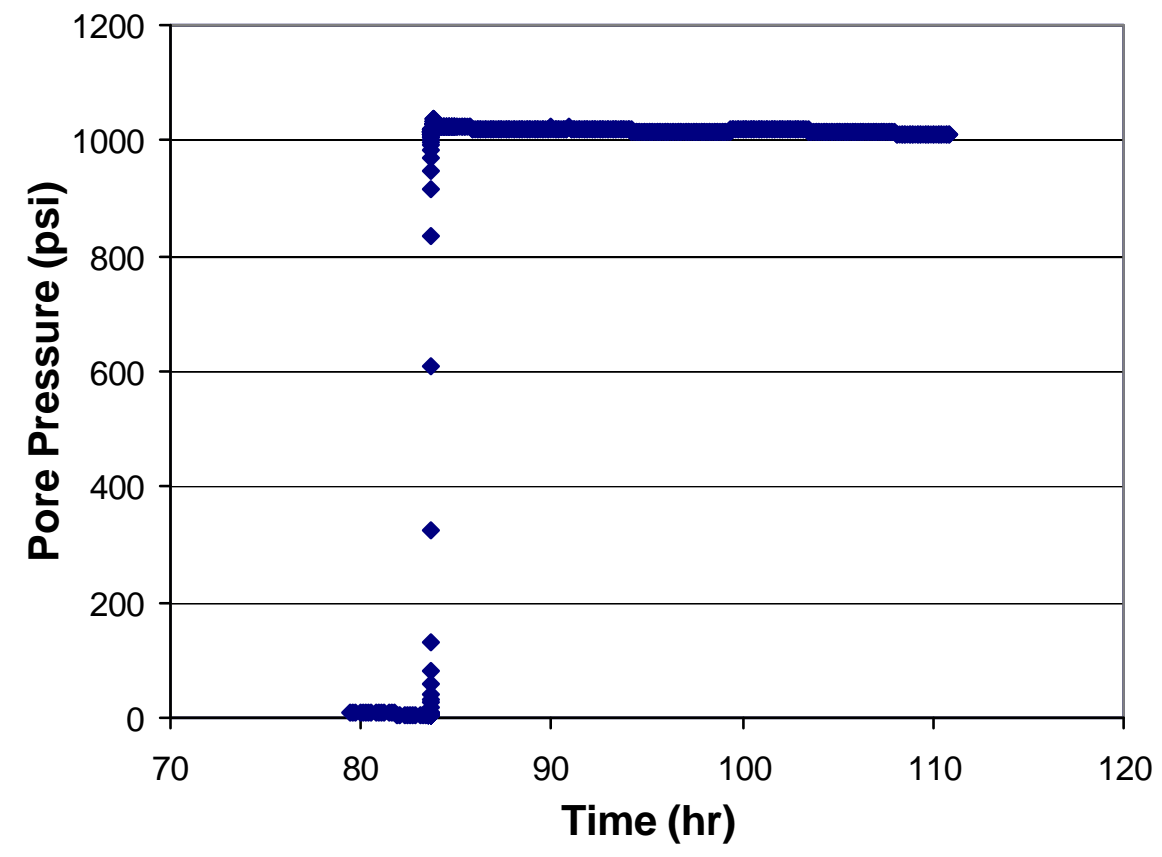

Figure 4.6b Measured pore pressure for shale A1 contacting with $156 \mathrm{~g} / \mathrm{L} \mathrm{NaCl}$. No membrane behavior exhibited. 


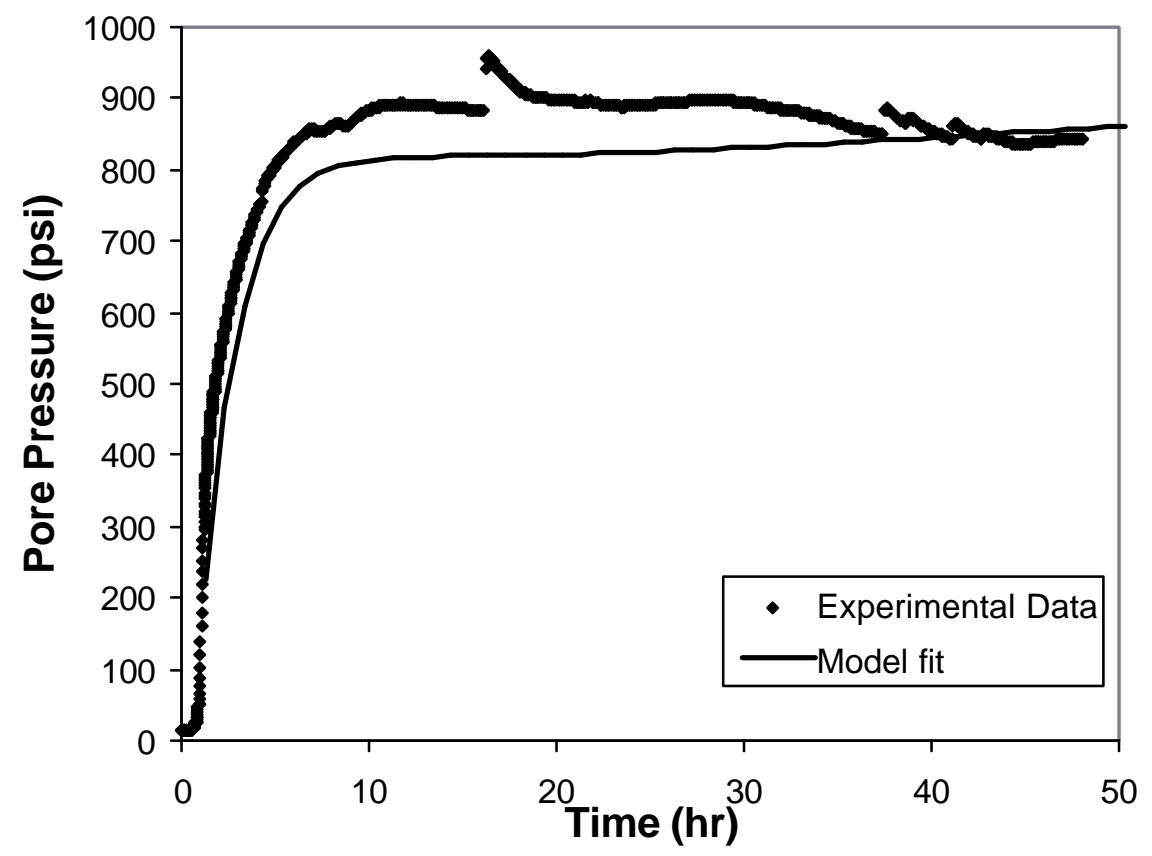

Figure 4.7a Matching model predictions with measured data for shale N1 contacting with $267 \mathrm{~g} / \mathrm{L} \mathrm{CaCh}$ to obtain parameters. $\mathrm{P}_{\mathrm{w}}=985 \mathrm{psi}, \mathrm{P}_{\mathrm{o}}=15 \mathrm{psi}$. 


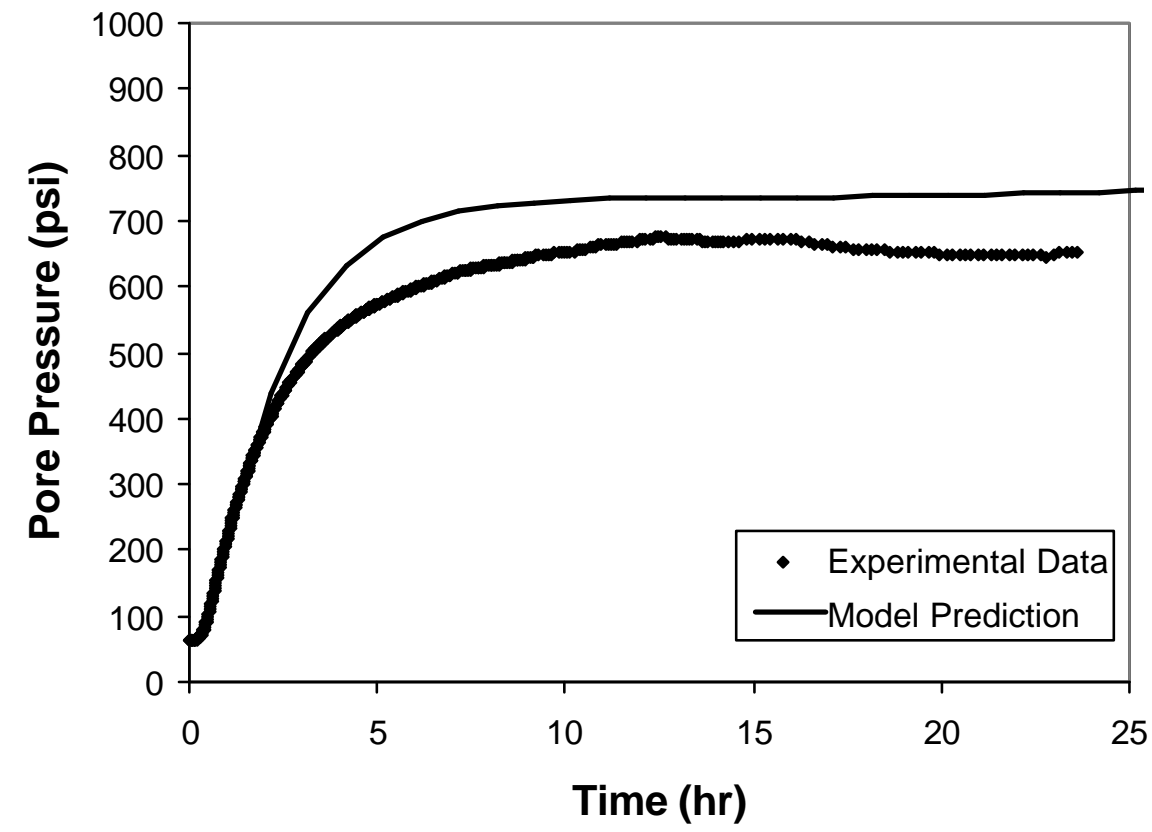

Figure 4.7b Comparison of model predictions with experimental data for shale N1 contacting with $413 \mathrm{~g} / \mathrm{L} \mathrm{CaCb}$ (using parameters obtained from Figure 4.7a). $\mathrm{P}_{\mathrm{w}}=995 \mathrm{psi}, \mathrm{P}_{\mathrm{o}}=60 \mathrm{psi}$. 


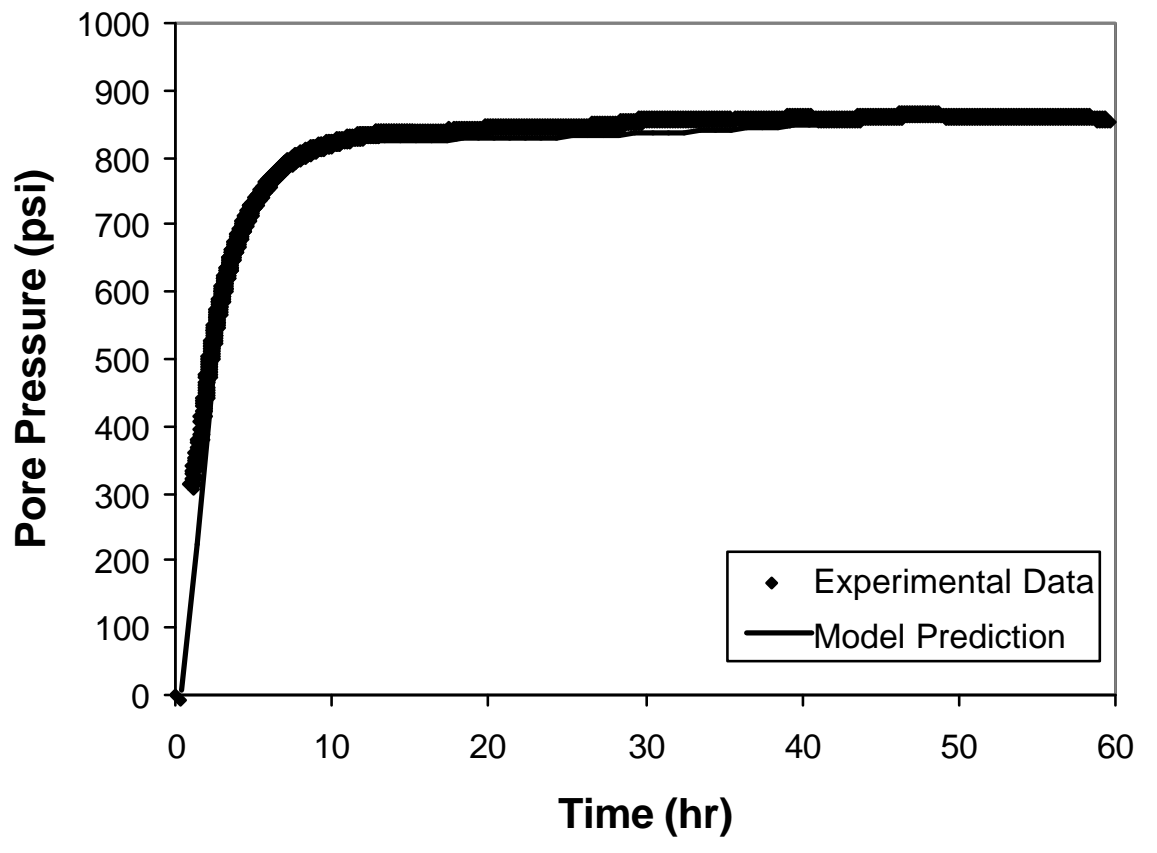

Figure 4.8a Matching model predictions with measured data for shale N1 contacting with $272 \mathrm{~g} / \mathrm{L} \mathrm{NaCl}$ to obtain parameters. $\mathrm{P}_{\mathrm{w}}=965 \mathrm{psi}, \mathrm{P}_{\mathrm{o}}=10 \mathrm{psi}$. 


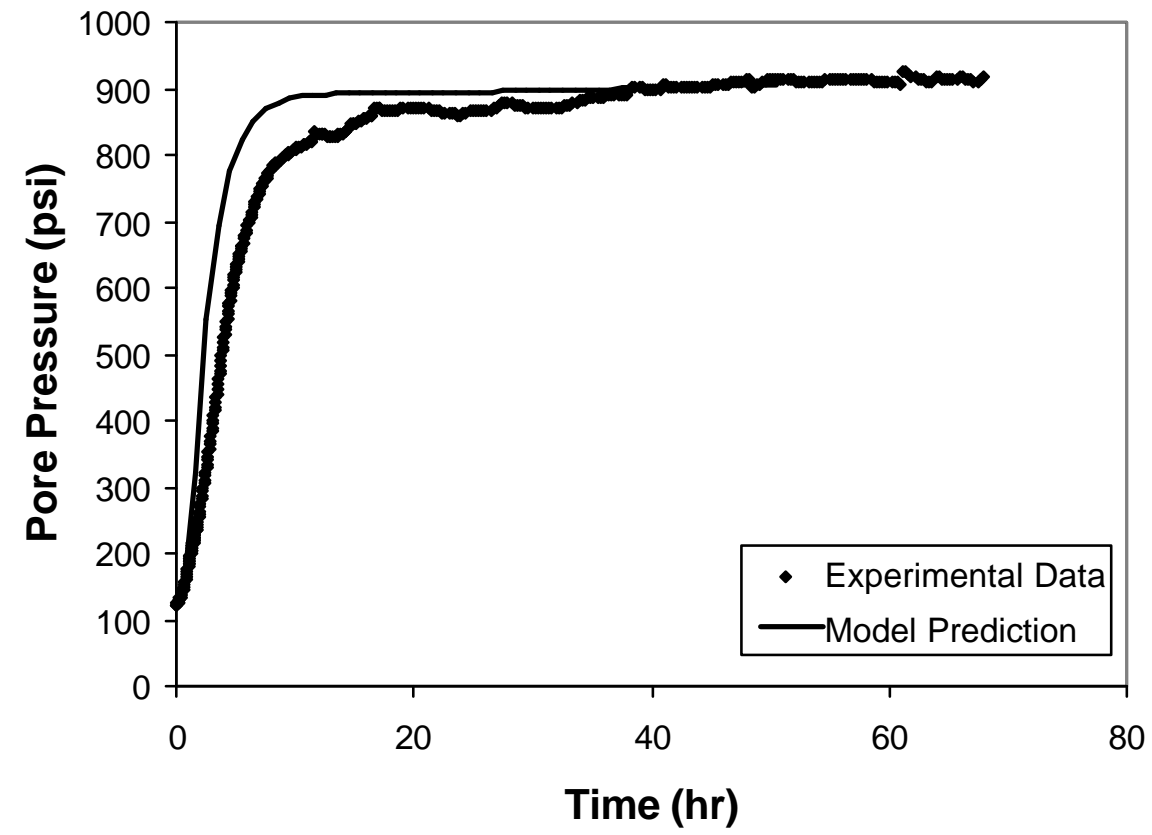

Figure 4.8b Comparison of model predictions with experimental data for shale N1 contacting with $156 \mathrm{~g} / \mathrm{L} \mathrm{NaCl}$ (using parameters obtained from Figure 4.8a). $P_{w}=940 p s i, P_{o}=120 p s i$. 


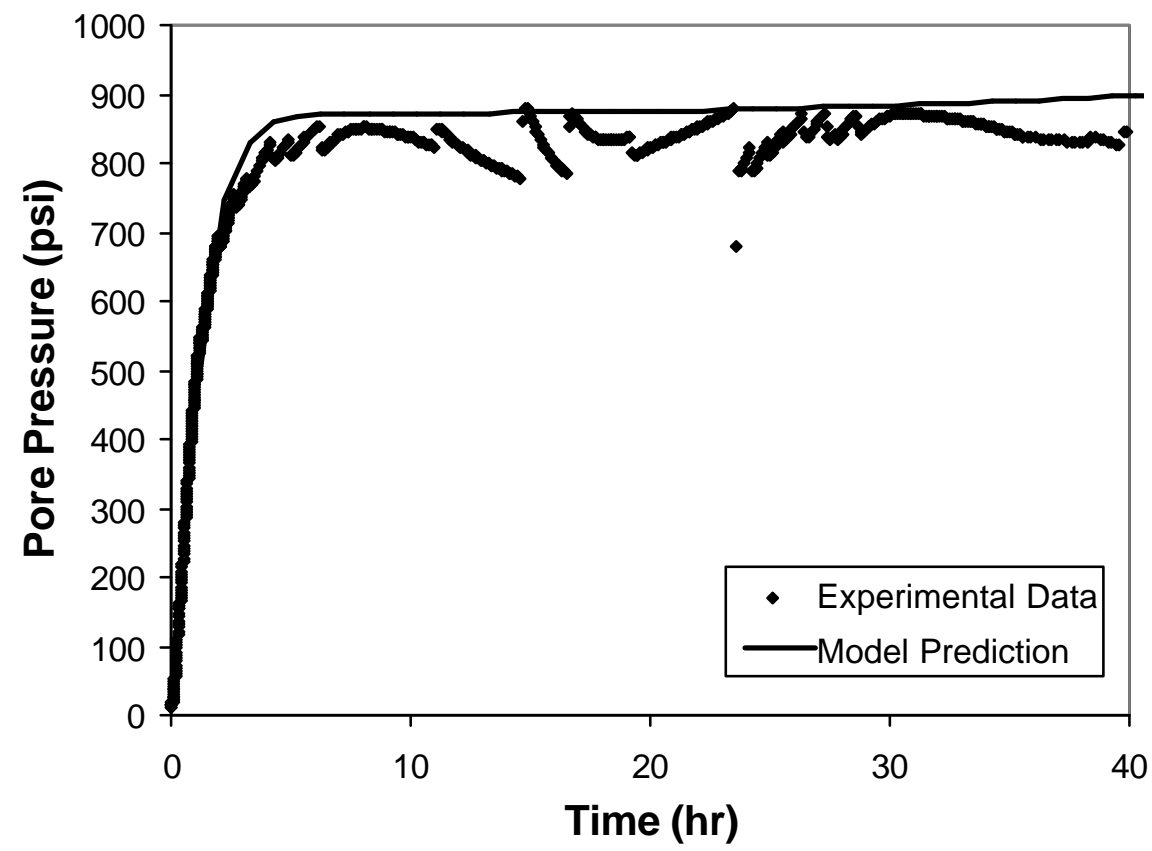

Figure 4.9a Matching model predictions with measured data for shale A2 contacting with $267 \mathrm{~g} / \mathrm{L} \mathrm{CaCh}$ to obtain parameters. $\mathrm{P}_{\mathrm{w}}=1020 \mathrm{psi}, \mathrm{P}_{\mathrm{o}}=5 \mathrm{psi}$. 


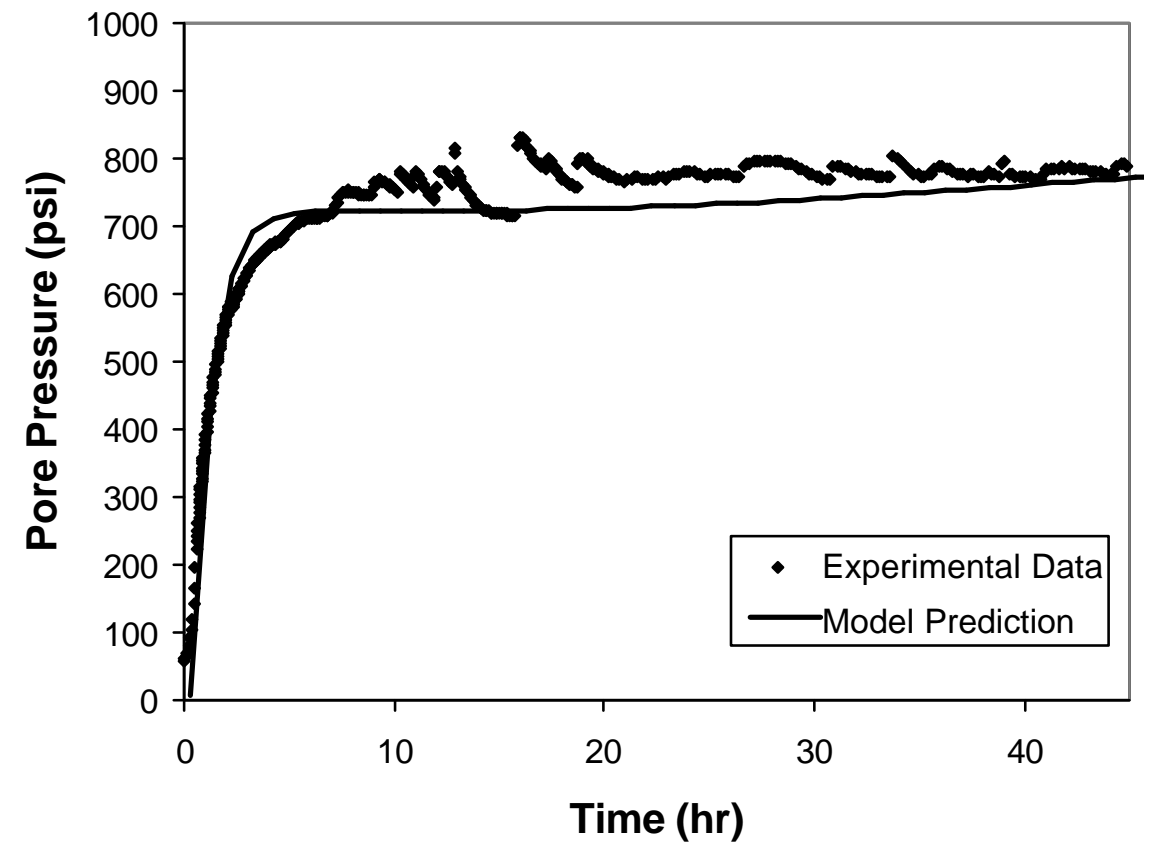

Figure 4.9b Comparison of model predictions with experimental data for shale A2 contacting with $413 \mathrm{~g} / \mathrm{L} \mathrm{CaCh}$ (using parameters obtained from Figure 4.9a). $\mathrm{P}_{\mathrm{w}}=955 \mathrm{psi}, \mathrm{P}_{\mathrm{o}}=50 \mathrm{psi}$. 


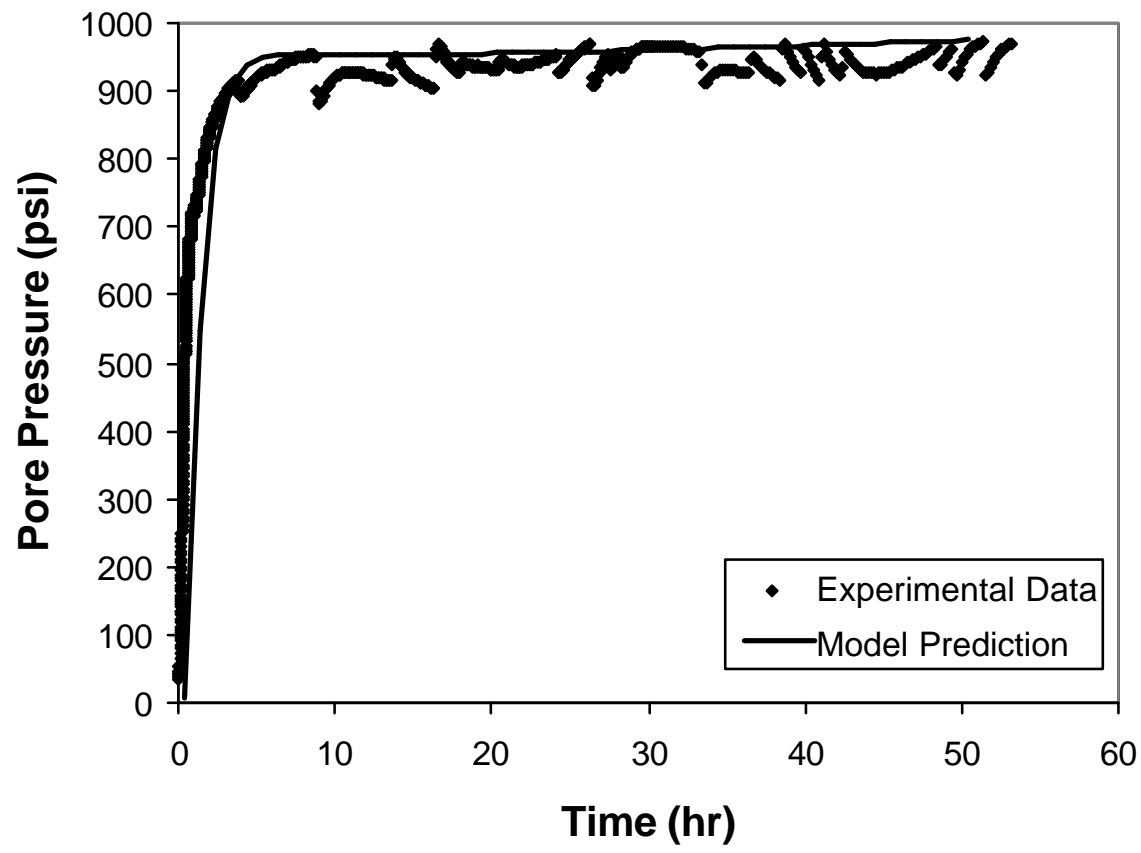

Figure 4.10a Matching model predictions with measured data for shale A2 contacting with $272 \mathrm{~g} / \mathrm{L} \mathrm{NaCl}$ to obtain parameters. $\mathrm{P}_{\mathrm{w}}=1030 \mathrm{psi}, \mathrm{P}_{\mathrm{o}}=0 \mathrm{psi}$. 


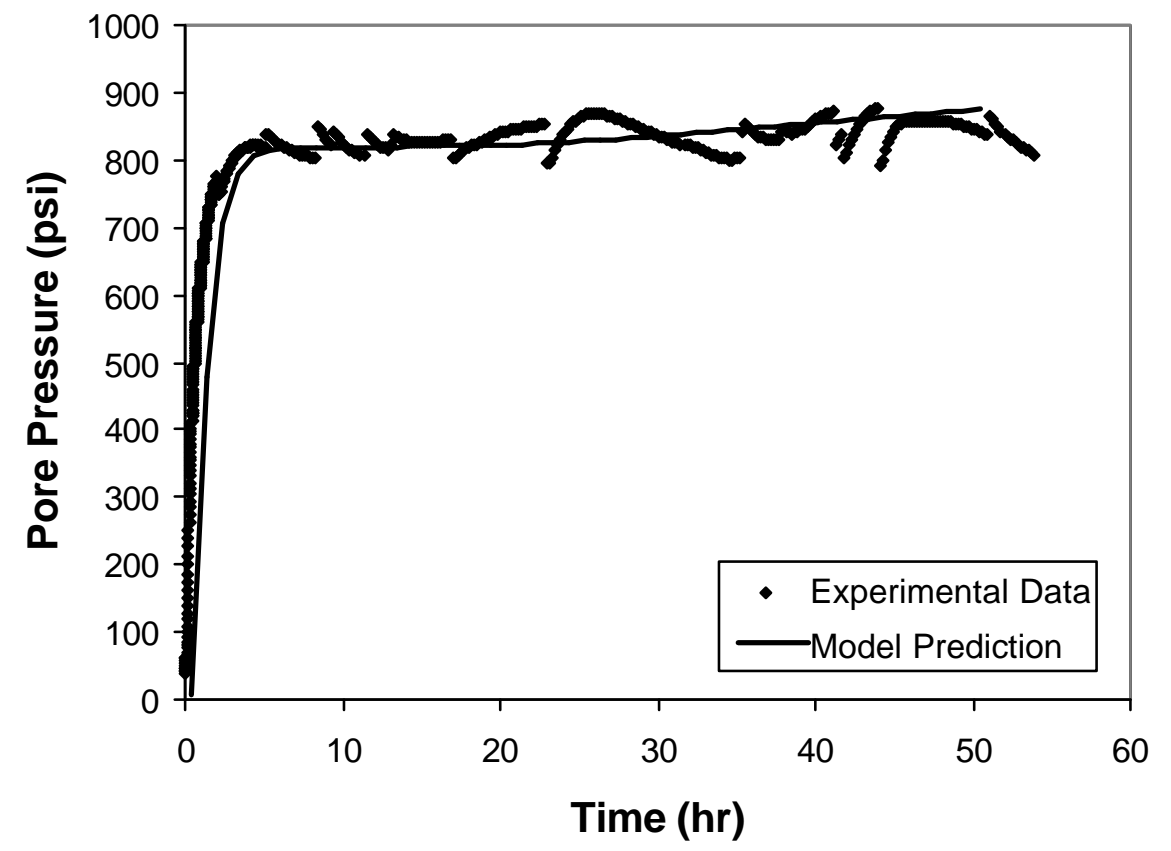

Figure 4.10b Comparison of model predictions with experimental data for shale A2 contacting with $156 \mathrm{~g} / \mathrm{L} \mathrm{NaCl}$ (using parameters obtained from Figure 4.10a). $\mathrm{P}_{\mathrm{w}}=1035 \mathrm{psi}, \mathrm{P}_{\mathrm{o}}=15 \mathrm{psi}$. 


\title{
Chapter 5: Chemical-Mechanical Wellbore Instability Model for Shales
}

\begin{abstract}
A model that combines chemical effects (Chapter 2) with mechanical effects and provides a quantitative tool for evaluating wellbore stability is presented. In the past, wellbore stability models have introduced chemical effects by adding an osmotic potential modified by an membrane efficiency to the pressure acting at the wellbore wall (Fonseca, 2000). In this chapter, an entirely different approach is adopted. The fluxes of water and ions into and out of the shale are accounted for. As a consequence, the pressure profiles obtained using our model differ significantly from the error function decline in pressure that is predicted by earlier models. As a consequence of this near wellbore pore pressure profile, wellbore failure can now occur inside the shale, not just at the wellbore wall (as predicted by earlier models). The onset of instability now depends not only on the activity of the water but also on the properties of the solutes.
\end{abstract}

\subsection{INTRODUCTION}

Wellbore instability is a major concern during drilling operations. The chemical interaction of shales with water-based fuids may cause serious wellbore instability problems. It is well known that the pore pressure distribution has a strong influence on wellbore stability when drilling a shale. Because shales are low permeability formations, the diffusion of ions and water is very slow. This means that significant pore pressure variations occur near the wellbore wall. Large, chemically induced, pore pressure gradients can be built up in this small region. 


\subsection{LITERATURE REVIEW}

Fonseca [1998] introduced chemical effects into a mechanical model in his wellbore stability study. At that time there was not a good understanding of the pore pressure distribution in the shale. He assumed that the pore pressure profile was given by the solution of the diffusivity equation. He noted that shales are not ideal membranes and that this may significantly affect the pore pressure. He introduced a membrane efficiency $\mathrm{I}_{\mathrm{n}}$ for the shale and used the following boundary condition at the wellbore wall:

$$
P_{w f}=P_{0}-I_{m} \Pi
$$

where $\mathrm{P}_{\mathrm{wf}}$ is the hydraulic pressure on the wellbore wall, $\mathrm{P}_{\mathrm{o}}$ is the pore pressure far from the wellbore wall and $\Pi$ is the osmotic pressure for an ideal membrane.

$$
\Pi=-\frac{R T}{V} \ln \left(\frac{a_{\text {shale }}}{a_{d f}}\right)
$$

Yew and Liu [1992] introduced poroelasticity effects into their wellbore stability model. The flow of fluids into or out of the formation creates additional normal stresses in their model. They found that these stresses could lead to borehole failure in some cases. Hsiao [1988] used a similar approach and analyzed the influence of poroelasticity for a horizontal well. Detournay and Chang [1988] and Cui [1995] applied the poroelastic approach to investigate vertical and directional wells. Wang [1992] used elasticity theory and introduced chemical effects into a wellbore instability simulator. The water content profile is calculated using the convection-diffusion equation. Wang observed that the maximum stress level occurs inside the formation. 
Mody and Hale [1993] assume that chemical effects are proportional to the difference in activities between the drilling fluid and the shale. They used poroelastic theory to calculate the changes in pore pressure and stress distribution.

A new theory for incorporating coupled chemical and mechanical effects in wellbore stability is presented. Numerical simulation results are then presented to show how chemical effects can play an important role in determining wellbore stability. Comparisons with early models are made to show that accounting for water and solute fluxes is important to correctly predict wellbore stability in shales.

\subsection{THEORY}

\subsubsection{Near Wellbore Stress Distribution}

Consider a directional well drilled through an undisturbed formation at a particular depth with a pore pressure $\mathrm{P}_{0}$. Figures 5.1 and 5.2 show the wellbore configuration. A drilling fluid creates a wellbore pressure $\mathrm{P}_{\mathrm{w}}$ at each depth. The flowinduced stress components can be written as:

$$
\begin{aligned}
& \sigma_{r r}=\frac{\alpha(1-2 v)}{1-v} \frac{1}{r^{2}} \int_{r_{w}}^{r} p^{f}(r, t) r d r+\frac{r_{w}^{2}}{r^{2}} p_{w} \\
& \sigma_{\theta \theta}=-\frac{\alpha(1-2 v)}{1-v}\left[\frac{1}{r^{2}} \int_{r_{w}}^{r} p^{f}(r, t) r d r-p^{f}(r, t)\right]-\frac{r_{w}^{2}}{r^{2}} p_{w} \\
& \sigma_{z z}=\frac{\alpha(1-2 v)}{1-v} p^{f}(r, t)
\end{aligned}
$$

where the net pressure $\mathrm{p}^{\mathrm{f}}(\mathrm{r}, \mathrm{t})$ is defined as:

$$
p^{f}(r, t)=p(r, t)-p_{0}
$$


One special solution that has been well studied is the solution for stresses at the wall of a cylindrical wellbore. The flow-induced stresses at the wellbore wall can be written as:

$$
\begin{aligned}
& \sigma_{r r}=p_{w} \\
& \sigma_{\theta \theta}=\frac{\alpha(1-2 v)}{1-v} p^{f}(r, t)-p_{w} \\
& \sigma_{z z}=\frac{\alpha(1-2 v)}{1-v} p^{f}(r, t)
\end{aligned}
$$

\subsubsection{Compressive Failure Criterion}

There are several failure criteria available in the literature. A "three-principalstress" criterion, called the Drucker-Prager failure criterion (Drucker and Prager, 1952), is discussed in this paper. Other failure criteria such as the Mohr-Coulomb Failure Criteria or Modified Lade Failure Criteria have also been implemented in the model but are not discussed here.

The Druker-Prager failure criterion can be categorized as an extended von Mises criteria:

$$
\sqrt{J_{2}}=A J_{1}^{e f}+B
$$

where

$$
\begin{aligned}
J_{1}^{e f}= & \frac{\sigma_{r r}+\sigma_{\theta \theta}+\sigma_{z z}}{3}-p(r, t) \\
J_{2}= & \frac{1}{6}\left(\left(\sigma_{r r}-\sigma_{\theta \theta}\right)^{2}+\left(\sigma_{\theta \theta}-\sigma_{z z}\right)^{2}+\left(\sigma_{z z}-\sigma_{r r}\right)^{2}\right) \\
& +\sigma_{r \theta}^{2}+\sigma_{\theta Z}^{2}+\sigma_{r z}^{2}
\end{aligned}
$$

Failure takes places when the effective collapse stress $\sigma_{\mathrm{cl}}$ at a particular point around the borehole or at the wallbore wall is less than zero:

$$
\sigma_{c l}=-\sqrt{J_{2}}+m J_{1}^{e f}+\tau_{0} \leq 0
$$


The constants in the Drucker-Prager criterion can be calculated using material constants such as the Young's modulus and Poisson's ratio. McLean and Addis [1990b] presented the following relationships between the constants,

$$
\begin{aligned}
& B=\frac{2 \sqrt{2} c \cos \phi}{3-\sin \phi} \\
& A=\frac{2 \sqrt{2} \sin \phi}{3-\sin \phi}
\end{aligned}
$$

where $\mathrm{c}$ is the cohesive strength and $\phi$ is the friction angle.

\subsubsection{A Model for Pore Pressure Propagation}

Wellbore instability problems occur when interactions with the drilling mud cause changes in the pore pressure. Such changes occur due to both hydrostatic and osmotic pressure gradients.

In this section the pore pressure profile is calculated based on models developed by Yu, et. al. [2001]. For solutes in non-ideal solutions:

$$
\frac{\partial p}{\partial t}-\frac{K_{I}}{c_{f}} \frac{\partial^{2} p}{\partial x^{2}}+\frac{K_{I I}}{c_{f}} \frac{R T}{V} \frac{\partial}{\partial x}\left\{\frac{f^{\prime}\left(C_{S}\right)}{f\left(C_{S}\right)} \frac{\partial C_{S}}{\partial x}\right\}=0
$$

Here $f\left(C_{s}\right)$ is the activity of water which is a function of the solute concentration $\left(C_{s}\right)$

For ideal solutions, the equations reduce to,

$$
\frac{\partial p}{\partial t}-\frac{K_{I}}{c_{f}} \frac{\partial^{2} p}{\partial x^{2}}-\frac{n R T K_{I I}}{c_{f}} \frac{\partial^{2} C_{s}}{\partial x^{2}}=0
$$

Where $\mathrm{K}_{\mathrm{I}}$ and $\mathrm{K}_{\mathrm{II}}$ are defined as follows, 


$$
\begin{aligned}
& K_{I}=K_{11}-\frac{K_{13} K_{31}}{K_{33}} \\
& K_{I I}=K_{12}-\frac{K_{13} K_{32}}{K_{33}}
\end{aligned}
$$

where Kij are the phenomenological coefficients (Lomba, et. al. 2000a,b).

Figure 5.3 shows the boundary conditions and the initial conditions as follows:

$$
\begin{array}{ll}
p(r, 0)=p_{0} & C(r, 0)=C_{0} \\
p\left(r_{w}, t\right)=p_{w} & C\left(r_{w}, t\right)=C_{d f} \\
p(\infty, t)=p_{0} & C(\infty, t)=C_{0}
\end{array}
$$

\subsubsection{Estimating Model Input Parameters}

In addition to the mechanical properties of the shale and an estimate of the initial pore pressure, there are three input parameters that need to be determined. They are, the effective diffusion coefficient $D_{\text {eff }}$, and the transient pressure parameters $K_{I}$ and $K_{I I}$.

$D_{\text {eff }}$ can be measured by radioactive tracer diffusion experiments. Here $P_{1}=P_{2}$ and $C_{1} \neq C_{2}$. Lomba [2000] performed these types of experiments to obtain the effective diffusion coefficients of several salts.

$\mathrm{K}_{\mathrm{I}}$ can be measured by pressure transmission tests without solute diffusion. Here $\mathrm{P}_{1} \neq \mathrm{P}_{2}$ and $\mathrm{C}_{1}=\mathrm{C}_{2}$. The pressure buildup is recorded as a function of time in the low pressure chamber. Such tests have been performed by Van Oort[1997]

$\mathrm{K}_{\mathrm{II}}$ can be measured by pressure transmission tests with ionic diffusion. Here $\mathrm{P}_{1} \neq \mathrm{P}_{2}$ and $\mathrm{C}_{1} \neq \mathrm{C}_{2}$. In this test both hydraulic and osmotic pressures propagate through the shale sample (Van Oort [1997], Ewy and Stankovich [2000]). 


\subsubsection{Computer Implementation of the Model}

Equations 5-10 and 5-11 presented in the previous section are solved numerically using a central difference finite difference scheme. The concentration is assumed to follow the error function solution. This solution is substituted into Equation 5-10 to obtain the pore pressure as a function of distance and time. Since the rate of solute transport to the shale is relatively slow compared to the pressure propagation, the spatial steps have to be chosen to be very small. Since the numerical scheme chosen is explicit, $\Delta \mathrm{t}$ needs to be relatively small to ensure stability. This results in large CPU time. For a typical simulation, a minimum 8 hours of CPU time is required on an IBM PC with a $300 \mathrm{MHZ}$ PII processor. In the following section we describe a simplification that allows the computation time to be reduced significantly.

\subsubsection{Reducing Computation Time}

It was seen from the numerical solutions obtained that the pressure profile calculated for distances larger than the distance of penetration of the solute, the pressure profile followed an error function solution. To speed up the computation, Equation 5-10 was numerically solved up to a short distance away from the wellbore face where solute concentration gradients are high. For the remainder of the shale, an error function solution for the pressure provides an excellent approximation (results shown later).

$$
\begin{aligned}
& \text { We define } \\
& \eta=\frac{x}{\sqrt{4 D_{\text {eff }} t}}
\end{aligned}
$$


For large $\eta$, say $\eta=3.0$, the solute concentration $C_{s}$ is approximately equal to the original solute concentration $\left(\mathrm{C}_{0}\right)$. Therefore, for $\mathrm{x}_{\mathrm{D}}>\mathrm{x}_{\mathrm{D}}{ }_{\mathrm{D}}$ the pressure profile was assumed to be given by the error function solution. Where,

$$
x_{D}^{*}=3 \sqrt{4 D_{\text {eff }} t_{D}}
$$

We define the above $x_{D}^{*}$ as the diffusion length for a given time $t_{D}$. For $x_{D}>x_{D}{ }_{D}$, $\mathrm{C}_{\mathrm{s}} \approx \mathrm{C}_{0}$, i.e., the solute concentration is equal to the initial solute concentration and osmotic effects are negligible. Since $\mathrm{D}_{\mathrm{eff}}$ is very small, the diffusion length is very short. This implies that equation 5-10 and equation 5-11 reduce to:

$$
\frac{\partial p}{\partial t}-\frac{K_{I}}{c_{f}} \frac{\partial^{2} p}{\partial x^{2}}=0
$$

Which is a diffusivity equation with the following boundary conditions,

$$
\begin{aligned}
& x=x_{D}, p=p_{D} \\
& x \rightarrow \infty, p=p_{0}
\end{aligned}
$$

For every time step, a new boundary condition must be calculated. With this method, the equations need to be solved only for a very small range of $\mathrm{x}$. For $\mathrm{x}>\mathrm{x}_{\mathrm{D}}$, the pressure is obtained from the error function solution.

Figure 5.5 shows a comparison of the solution obtained from a complete numerical solution and from the hybrid numerical scheme described above. The solutions are essentially indistinguishable. Computation times for the hybrid scheme are 10 to 50 times smaller than for the complete numerical solution. 


\subsubsection{Visual Wellbore Analysis Tool}

The model generates massive amounts of output. To present this output data in a reasonable format, a Visual Wellbore Analysis Tool (VWAT) was developed. This is a $\mathrm{C}++$ program working in a Windows environment. Physical properties such as stresses, pore pressures etc. can be displayed in a radial arrangement so that variation of these parameters with $\mathrm{r}$ and $\theta$ can be clearly viewed. This tool has allowed us to better represent the results from our model. Many of the plots shown in the subsequent section are generated using this tool.

In addition, all input and output windows have been rendered in Visual Basic to make the program more user friendly.

\subsection{RESULTS AND DISCUSSION}

\subsubsection{Input Data}

Table 5.1 provides input data that is required to calculate changes in pore pressure, in situ stresses, and failure indices. A discussion about how this data is obtained has been provided in the previous section. The parameters provided in Table 5.1 were used as a base case in our simulations. Any sensitivity analysis done was conducted by varying one parameter at a time from this base case.

\subsubsection{Pore Pressure Profile}

Figure 5.6 and Figure 5.7 show simulation results obtained when the solute concentration is $1 \mathrm{M}$ in the shale and a drilling fluid with a solute concentration of $4 \mathrm{M}$ (or 
$0.01 \mathrm{M}$ ) is brought into contact with it. Results are presented for a contact time of 5 hours and mud weights between $14.1 \mathrm{lbm} / \mathrm{gal}$ and $17.1 \mathrm{lbm} / \mathrm{gal}$ are used for the calculations. As seen in Figure 5.6 due to a combination of hydrostatic and osmotic effects, the pore pressure declines with distance away from the wellbore. For $r / r_{\mathrm{W}}$ values between 1 and 1.1 the impact of osmotic pressure is evident. This is clearly seen in the steeper pore pressure profiles near the wellbore. Water is sucked out of the shale with a resulting decrease in the pore pressure in the shale. Figure 5.7 shows a pore pressure profile for a case when osmotic effects attempt to drive water into the shale while the ions are being pulled out of the shale. A very different pressure profile is observed. A maximum in pore pressure is seen at $r / r_{\mathrm{w}}$ of about 1.05. This maximum pore pressure is a consequence of the balance between osmotic and hydrostatic effects. As discussed in the next section, these changes in the pore pressure have profound effects on the stability of the wellbore. In particular, the maximum in pore pressure observed in Figure 5.7 can cause failure of the wellbore at some distance away from the wellbore wall.

\subsubsection{Failure Index}

A Failure Index has been defined as follows (Equation 5-8),

$$
F I=\text { Failure Index }=-\sqrt{J_{2}}+A J_{1}^{e f}+B
$$

Failure occurs when FI $<0$. Clearly the FI depends on the pore pressure which changes with position and time. 
In our simulations compressive failure has been observed to occur in three different ways:

Failure at the wellbore wall

Failure inside the formation

Time-dependent failure

\subsubsection{Failure at the Wellbore Wall}

Wellbore stability calculations conducted for a vertical well in which the minimum and maximum horizontal stresses are assumed to be equal are presented in Figure 5.8. In this case, because of the low mud weight chosen for this calculation, the failure index becomes negative at the wellbore wall. In such cases, failure will occur at the wellbore wall. In the example shown, hydrostatic effects are dominant. Wellbore stability can be achieved simply by increasing the mud weight and ensuring that the Failure Index is positive for all values of $\mathrm{r} / \mathrm{r}_{\mathrm{w}}$. Figure $5.8 \mathrm{~b}$ shows the value of the failure index around the wellbore. The outer portion of the circle represents a value of 43.0 and the inner portion -180.5 . Being a vertical well, the Failure Index is symmetric with respect to $\theta$. This sort of representation provides us with a useful indication of the orientation of the failure planes. Examples of this are presented in the next section.

\subsubsection{Failure Inside the Formation}

Most of the currently available wellbore stability models assume that wellbore failure occurs at the borehole wall. However, laboratory experiments as well as field experience indicates that this may not be true. Wellbore failure often results in shale sluffing. Previous authors have suggested that this may be a consequence of failure 
occurring along planes inside the shale. In Figures 5.9 and 5.9b, we show examples of how shales can fail at a point some distance away from the wellbore wall. The results shown in Figure 5.9 are at a condition where water is being driven into the shale as a result of the mud water activity being higher than the shale water activity. This results in an increase in pore pressure some distance into the shale. The elevated pore pressure results in the Failure Index profile shown in Figure 5.9. Clearly for this case, the wellbore wall is stable whereas a short distance into the shale conditions favor instability. In such cases, it is likely that the shale will fail some distance away from the wellbore wall. This behavior is clearly time dependent as seen in Figure 5.9. Figure 5.9b shows the failure zone around the wellbore wall. The outer portion of the circle represents a value of -2593.0 and the inner portion 2820.6. The region of failure occurs some distance away from the wellbore wall.

\subsubsection{Time Dependent Failure}

Figure 5.10 shows a case where a wellbore is initially stable. However, as water and solute are exchanged between the wellbore and the shale a region of instability develops. The formation of this instability is a direct consequence of changes in pore pressure that occur due to water and solute influx into the shale. In the example shown in Figure 5.10 failure occurs after a contact time of 12 hours. Clearly the time required for failure to be achieved will depend on the properties of the shale and the competition between hydrostatic and osmotic effects.

\subsubsection{What Happens after Failure}

One of the questions that we need to address is what occurs after the wellbore wall fails. Fresh surface of shale will be exposed to the drilling mud and the process of 
water and solute exchange will continue. The question that can be posed is: Will the enlarged borehole continue to develop instabilities? To answer this question, simulations were conducted with wellbores of increasing radius from 5 inches to 15 inches. Simulation results for a 15-inch borehole are shown in Figure 5.11 with other parameters being identical to those used in Figure 5.10. Clearly, while the 5-inch borehole is unstable after 12 hours, a 15 -inch borehole is not. This demonstrates that as the borehole size increases, a point will be reached when the size of the borehole is large enough to prevent any further instability from occurring.

If the in-situ stresses are anisotropic, failure will occur approximately along the direction of the maximum horizontal stress and an elliptic borehole will result. Since equations for stresses presented in this paper are limited to boreholes of circular cross section, this situation cannot be adequately adressed here. Equations for stress distributions for elliptical boreholes are available and need to be used.

\subsubsection{The Effect of Mud Weight}

One of the most common methods for preventing wellbore failure is to increase the mud weight. This hydrostatic method of wellbore control can be used in situations where it is possible to increase the mud weight sufficiently to overcome pore pressure and osmotic effects. Figure 5.12 shows how by increasing mud weight from $14 \mathrm{lbm} / \mathrm{gal}$ to $16.5 \mathrm{lbm} / \mathrm{gal}$ the failure index becomes positive for all values of $\mathrm{r} / \mathrm{r}_{\mathrm{w}}$. This of course may not always be true since increasing the mud weight can sometimes result in significant invasion of water and solute resulting in wellbore instability due to osmotic effects. 


\subsubsection{The Effect of Shale Properties}

Three important shale properties were discussed in a previous section. The effective diffusion coefficient is a measure how rapidly solute and water can migrate into the shale. The coefficient $K_{I}$ is a measure of the hydraulic permeability of the shale. The coefficient $\mathrm{K}_{\mathrm{II}}$ indicates how much the osmotic pressure will contribute to wellbore stability. $\mathrm{K}_{\mathrm{II}}$ is in this sense similar to the reflection coefficient defined earlier by Mody and Hale [1993]. Increasing the hydraulic diffusivity or permeability $\left(\mathrm{K}_{\mathrm{I}}\right)$ of the shale results in faster propagation of the hydraulic pressure into the shale. Everything else being constant, increasing $\mathrm{K}_{\mathrm{I}}$ will reduce the pressure gradients around the wellbore and result in more stable boreholes. On the other hand, increasing $K_{I I}$ will increase the

osmotic contribution to the pore pressure. In cases where $\mathrm{a}_{\mathrm{w}, \mathrm{mud}}>\mathrm{a}_{\mathrm{w}, \text { shale, }}$, larger values of $\mathrm{K}_{\mathrm{II}}$ will result in more unstable boreholes. When $\mathrm{a}_{\mathrm{v} \text {,mud }}<\mathrm{a}_{\mathrm{w}, \text { shale }}$ (water is being sucked out of the shale) larger values of $\mathrm{K}_{\mathrm{II}}$ will result in larger decreases in pore pressure and more stable boreholes.

\subsubsection{The Effect of Solute Diffusivity}

In our model an additional parameter, the effective solute diffusion coefficient also plays an important role. Figure 5.13a demonstrates the important role of the effective diffusion coefficient. Increasing the effective diffusion coefficient by an order of magnitude results in a stable wellbore as shown in Figure 5.13a. This is because the pore pressure gradient obtained is much higher for low values of diffusion coefficient. High values of the pore pressure result in a decrease in the failure index resulting in wellbore failure. Since $\mathrm{D}_{\mathrm{ff}}$ controls the rate of penetration of solute into the shale, it is 
expected that at some later time wellbore instability will occur. Indeed, as observed in Figure $5.13 \mathrm{~b}$, wellbore instability occurs at $\mathrm{t}=15 \mathrm{hr}$ for the case of $\mathrm{D}_{\mathrm{eff}}=4.92 \mathrm{e}-9 \mathrm{~m} / \mathrm{s}$. The trends shown in Figures 5.13b and 5.14 are not universally valid. Indeed, $\mathrm{D}_{\text {eff }}$ is not independent of the other parameters (such as shale permeability, $\mathrm{K}_{\mathrm{I}}$ ).

Increasing $\mathrm{K}_{\mathrm{I}}$ will in general result in more unstable wellbores as it is easier for water to penetrate into the shale and raise the pore pressures. Increasing the value of $\mathrm{K}_{\mathrm{II}}$ also results in more unstable boreholes with everything else being constant. It should again be pointed out that the three parameters $D_{\text {eff }}, K_{I}$ and $K_{I I}$ are not entirely independent. In general, low permeability shales (small $\mathrm{K}_{\mathrm{I}}$ ) will tend to have low values of $\mathrm{D}_{\mathrm{eff}}$ and high values of $\mathrm{K}_{\mathrm{II}}$. However, only rather complex relationships (Basu and Sharma, 1997) exist between the three shale parameters at this time.

\subsubsection{The Effect of Drilling Fluid Solute Concentration}

Figure 5.14 shows the effects of drilling fluid solute concentration on wellbore stability. It is observed that at low drilling fluid solute concentrations, the flux of water into the shale results in wellbore instability. A higher solute concentration negates the osmotic effects and results in a stable wellbore. Such behavior has been widely reported in the literature and is commonly observed in the field where salt is used in muds to provide better performance than can be obtained with fresher water muds. As has been reported in the past it is desirable to match the activity of the drilling fluid with the water activity in the shale. Our simulations clearly show that this is an important effect. However, this is not the only effect since even when the water activities are balanced, flux of solutes can occur. In such cases solutes with high $\mathrm{D}_{\text {eff }}$ will be preferred. 


\subsubsection{The Effect of $\sigma_{H}$ and $\sigma_{h}$}

All the simulations presented earlier have been for vertical wellbores in an isotropic stress state. Figure 5.15 shows a general case of a deviated wellbore and an anisotropic stress condition. All the components of stress can be obtained from the following equations:

$$
\left[\begin{array}{l}
\sigma_{x x} \\
\sigma_{y y} \\
\sigma_{z z} \\
\sigma_{x y} \\
\sigma_{y z} \\
\sigma_{x z}
\end{array}\right]=\left[\begin{array}{lll}
\cos ^{2} d_{w} \cos ^{2} i_{w} & \sin ^{2} d_{w} \cos ^{2} i_{w} & \sin ^{2} i_{w} \\
\sin ^{2} d_{w} & \cos ^{2} d_{w} & 0 \\
\cos ^{2} d_{w} \sin ^{2} i_{w} & \sin ^{2} d_{w} \sin ^{2} i_{w} & \cos ^{2} i_{w} \\
-\sin d_{w} \cos d_{w} \cos i_{w} & \sin d_{w} \cos d_{w} \cos i_{w} & 0 \\
-\sin d_{w} \cos d_{w} \sin i_{w} & \sin d_{w} \cos d_{w} \sin i_{w} & 0 \\
\cos ^{2} d_{w} \sin i_{w} \cos i_{w} & \sin ^{2} d_{w} \sin i_{w} \cos i_{w} & -\sin i_{w} \cos i_{w}
\end{array}\right]\left[\begin{array}{l}
\sigma_{H} \\
\sigma_{h} \\
\sigma_{v}
\end{array}\right]
$$

With the calculation of these stress components, the wellbore failure model can be applied just as before. Figure 5.16 shows that decreasing the minimum horizontal stress from 0.83 to 0.75 can result in a stable wellbore. Clearly this depends on the orientation of the stresses and the coupling of these two osmotic effects. Similarly, wellbore azimuth plays an important role in determining wellbore stability as shown in Figure 5.17.

\subsection{CONCLUSIONS}

A wellbore stability model has been developed taking into account both mechanical and chemical effects. Based on the model results, the following conclusions can be drawn:

Wellbore failure may occur either on the borehole surface or inside the shale. Traditional wellbore stability models that assume failure occurring only on the wellbore surface do not adequately represent the various possible conditions under which failure can occur. Changes in pore pressure induced by osmotic effects can often result in the failure criteria being satisfied at some distance away from the wellbore wall. 
It is shown that the flux of both water and solutes can play an important role in determining the pore pressure profiles and, therefore, wellbore stability. Matching the water activity in the mud and the shale is only the first step. Selecting solutes with low $D_{\text {eff }}$ values is important to ensure that this activity balance is preserved over time. High values of $D_{\text {eff }}$ will result in high fluxes of solute that will cause an imbalance in water activity over time.

Due to the time dependent fluxes of water and solute into or out of the shale, wellbore failure is also time dependent. The model presented in this study clearly shows this time dependence. Several cases have been documented which show wellbore stability at early time and wellbore instability as the drilling mud is allowed to contact the shale over an extended period of time.

It is shown that wellbore instability is a self-regulating process in that as the wellbore gets larger it also becomes more stable. This results in enlarged elliptic boreholes. The model presented here can be used to approximately estimate the ultimate size of circular boreholes after failure occurs.

Both osmotic and hydraulic effects play an integral part in the wellbore stability model. The magnitude of the osmotic contribution is clearly dependent on the properties of the shale. Such shale properties have been quantified through three parameters, $D_{\text {eff, }}$ $\mathrm{K}_{\mathrm{I}}$ and $\mathrm{K}_{\mathrm{II}}$.

Factors such as in situ stresses, wellbore inclination and azimuth, and mud weight clearly play an important role. The effects of these can be quantified by using the computer program developed in this research.

The model presented here can be used to design mud programs that yield stable boreholes. Both chemical and mechanical effects are properly accounted for. 
Additional data and information need to be made available on shale properties to adequately use the model presented in this paper. An experimental program to measure these parameters has been proposed. Laboratory tests such as the pore pressure transmission test can be used to evaluate these parameters.

\section{NOMENCLATURE}

$A, B=$ material constants, for outer circle

$c=$ cohesive strength, $m / L t^{2}, p s i$

$c_{f}=$ fluid compressibility, $L t^{2} / m, p s i^{-1}$

$C_{0}=$ initial pore fluid concentration, $\mathrm{mols} / \mathrm{L}^{3}$, mols/liter

$C_{d f}=$ drilling fluid solute concentration, mols $/ L^{3}$, mols/liter

$C_{S}=$ pore fluid solute concentration, mols $\Lambda^{3}$, mols /liter

$D_{\text {eff }}=$ effective water diffusion coefficient, $L^{2} / t, \mathrm{~m}^{2} / \mathrm{s}$

$E=$ Young's modulus, $m / L t^{2}, p s i$

$J_{1}{ }^{e f}=$ the effective mean stress, $m / L t^{2}$, psi

$J_{2}{ }^{1 / 2}=$ the shear stress, $m / L t^{2}$, psi

$K_{i j}=$ phenomenological coefficients

$K_{I}=$ "permeability", $L^{3} t / m, m^{3} s / k g$

$K_{I I}=$ "membrane efficiency", $L^{3} t / m, m^{3} s / k g$

$n=$ number of constituent ions of the dissociating solute.

$p=$ pore pressure, $m / L t^{2}, p s i$

$p_{0}=$ initial pore pressure, $m / L t^{2}, p s i$

$p_{w}=$ wellbore pressure, $m / L t^{2}, p s i$ 
$p^{f}(r, t)=$ pore pressure fluctuations, $m / L t^{2}, p s i$

$r=$ near wellbore radial position, $L$, in

$r_{w}=$ wellbore radius, $L$, in

$R=$ universal gas constant, $\mathrm{mL}^{2} \mathrm{t}^{-2} \mathrm{mols}^{-1} \mathrm{~T}^{-1}, 8.3144 \times 10^{7} \mathrm{~g} \mathrm{~cm}^{2} \mathrm{~s}^{-2} \mathrm{~g}$-mols

${ }^{1 \circ} K^{-1}$

$t=$ time, $t, s$

$T=$ temperature, $T,{ }^{\circ} \mathrm{K},{ }^{\circ} \mathrm{F},{ }^{\circ} \mathrm{C}$

$x_{D}, x_{D}^{*}=$ diffusion length

$\alpha=$ Biot's constant

$\phi=$ friction angle, radians, degree

$v=$ Poisson's ratio

$\sigma_{c l}=$ collapse failure index, $m / L t^{2}, p s i$

$\sigma_{h}=$ minimum horizontal stress

$\sigma_{H}=$ maximum horizontal stress

${\sigma_{\text {min }}}^{e f}=$ minimum effective stress, $m / L t^{2}$, psi

$\sigma_{r r}, \sigma_{\theta \theta}$, and $\sigma_{z z}=$ radial, hoop, and axial stress, $m / L t^{2}$, psi

$\sigma_{\theta z}=$ shear stress component, $m / L t^{2}$, psi 
Table 5.1 Input data for the base case runs

\begin{tabular}{|l|c|}
\hline Overburden in-situ stress $\sigma_{\mathrm{v}}(\mathrm{psi} / \mathrm{ft})$ & 0.86 \\
\hline $\begin{array}{l}\text { Maximum } \sigma_{\mathrm{H}} \text { horizontal in-situ stress } \\
(\mathrm{psi} / \mathrm{ft})\end{array}$ & 0.83 \\
\hline $\begin{array}{l}\text { Minimum } \sigma_{\mathrm{h}} \text { horizontal in-situ stress } \\
(\mathrm{psi} / \mathrm{ft})\end{array}$ & 0.83 \\
\hline Well inclination $\mathrm{i}_{\mathrm{w}}($ degree$)$ & 0 \\
\hline Well direction $\mathrm{d}_{\mathrm{w}}($ degree $)$ & 0 \\
\hline Depth TVD $(\mathrm{ft})$ & 5000 \\
\hline Mud weight $\mathrm{p}_{\mathrm{w}}(\mathrm{lbm} / \mathrm{gal})$ & 14.0 \\
\hline Pore pressure $\mathrm{p}_{\mathrm{o}}(\mathrm{lbm} / \mathrm{gal})$ & 13.1 \\
\hline Geothermal gradient GG $\left({ }^{\circ} \mathrm{F} / 100 \mathrm{ft}\right)$ & 1.1 \\
\hline Exposure time $\mathrm{t}(\mathrm{hour})$ & $6,9,12,15$ \\
\hline Borehole radius $\mathrm{r}_{\mathrm{w}}(\mathrm{in})$ & 5 \\
\hline Poisson's ratio $\mathrm{v}$ & 0.22 \\
\hline Biot's parameter $\alpha$ & 0.80 \\
\hline Cohesive Strength $(\mathrm{psi})$ & 1,000 \\
\hline Tensile Strength $(\mathrm{psi})$ & 100 \\
\hline Drilling fluid salt concentration $(\mathrm{M})$ & $0.01,0.5,4$ \\
\hline Pore fluid salt concentration $(\mathrm{M})$ & 1.0 \\
\hline $\mathrm{K}_{\mathrm{I}},\left(\mathrm{m}^{3} \mathrm{~s} / \mathrm{kg}\right)$ & $2.13441 \times 10^{-16}$ \\
\hline $\mathrm{K}_{\mathrm{II}},\left(\mathrm{m}^{3} \mathrm{~s} / \mathrm{kg}\right)$ & $-4.52366 \times 10^{-17}$ \\
\hline $\mathrm{D}_{\text {eff }}\left(\mathrm{m}^{2} / \mathrm{s}\right)$ & $4.9420 \times 10^{-10}$ \\
\hline
\end{tabular}




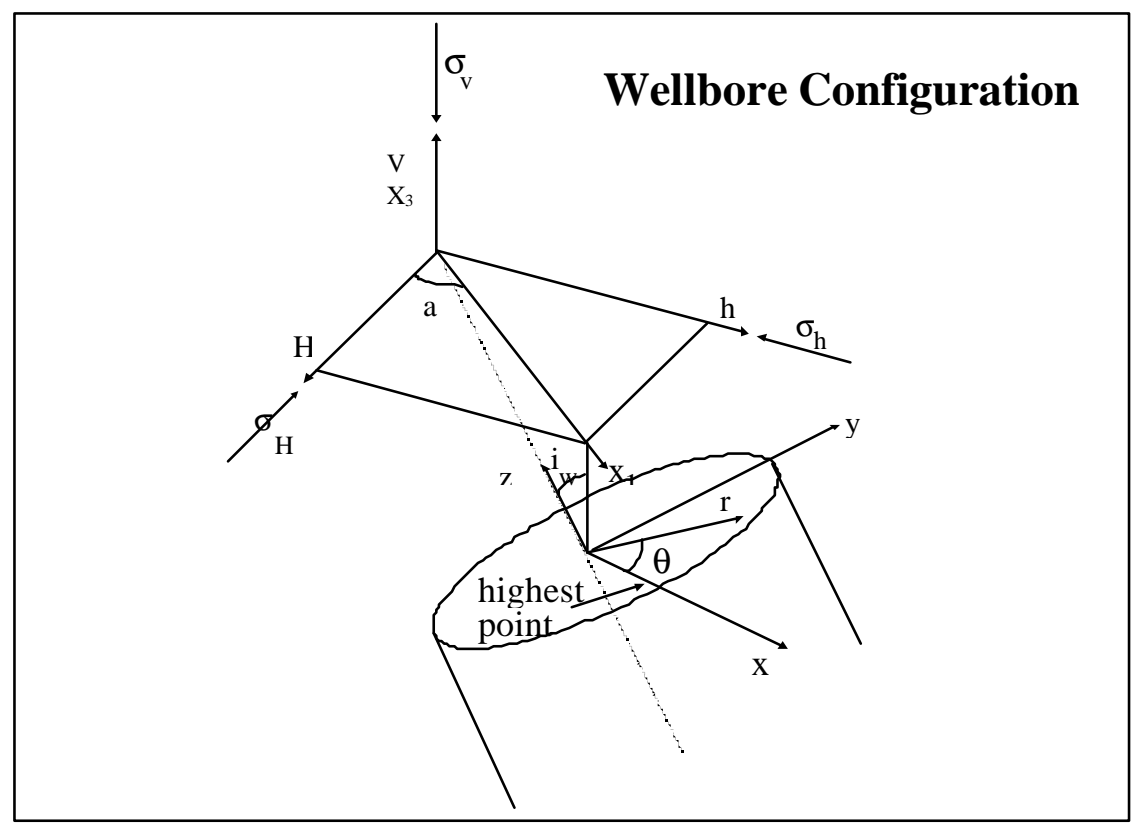

Figure 5.1 Wellbore configuration and definition of axes and angles. 


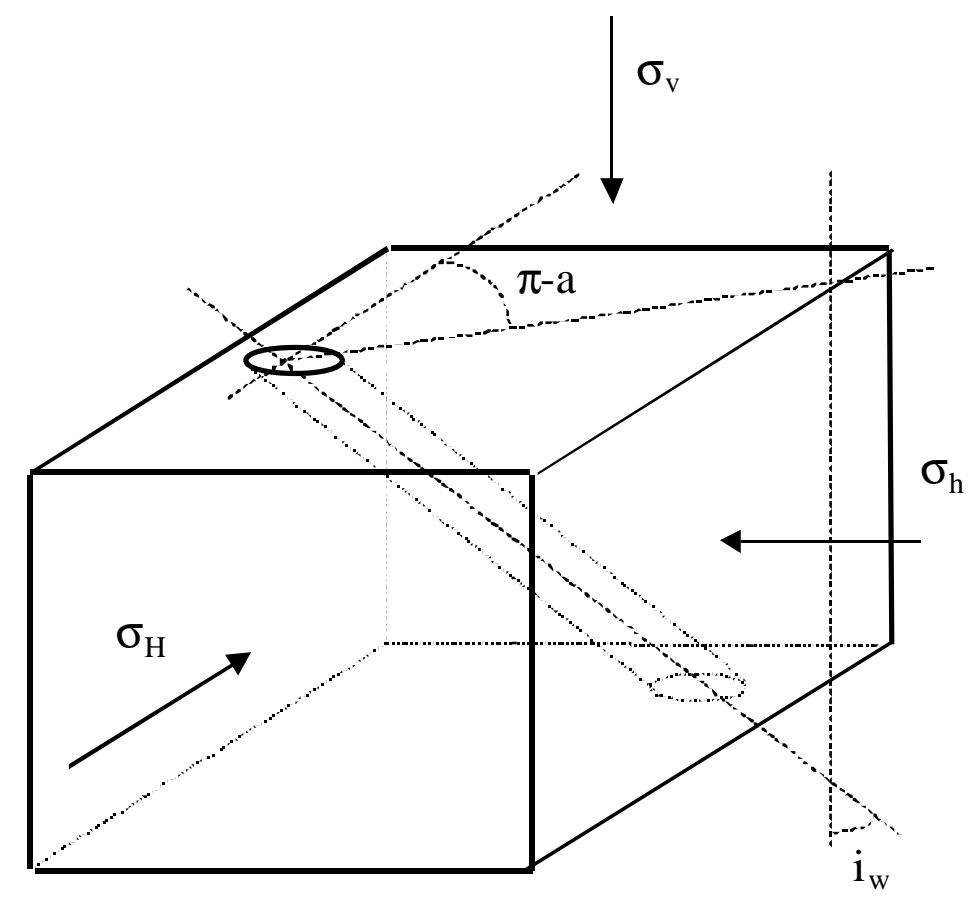

Figure 5.2 Wellbore configuration. 


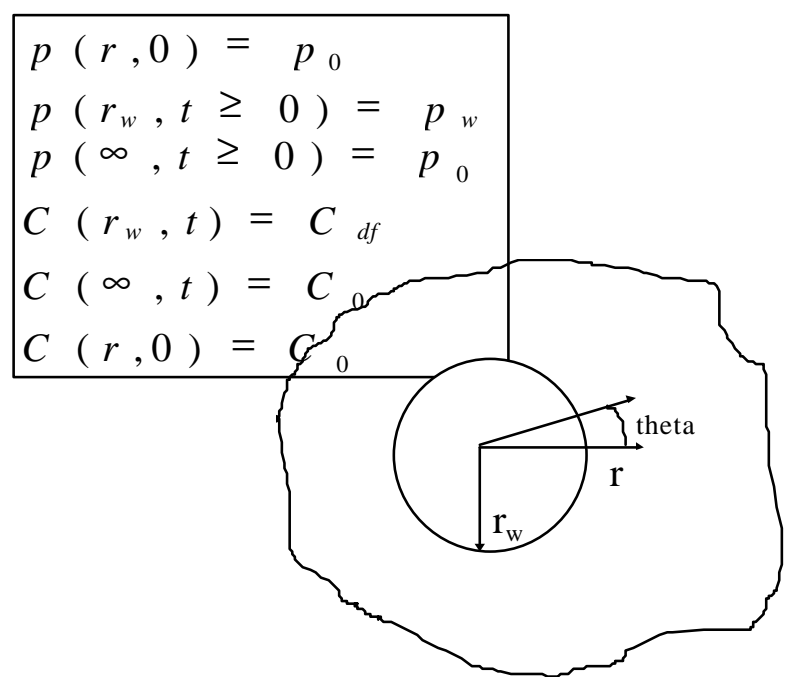

Figure 5.3 Boundary conditions and initial conditions used. 


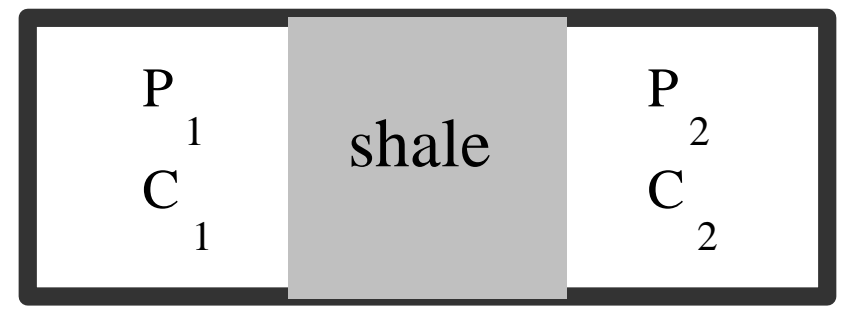

Test 1: $\mathrm{P}_{1}=\mathrm{P}_{2}, \mathrm{C}_{1} \neq \mathrm{C}_{2}$, Radioactive tracer $\Rightarrow \mathrm{D}_{\text {eff }}$

Test 2: $\mathrm{P}_{1} \neq \mathrm{P}_{2}, \mathrm{C}_{1}=\mathrm{C}_{2}$, Pressure buildup $\Rightarrow \mathrm{K}_{\mathrm{I}}$

Test 3: $\mathrm{P}_{1} \neq \mathrm{P}_{2}, \mathrm{C}_{1} \neq \mathrm{C}_{2}$, Pressure buildup $\Rightarrow \mathrm{K}_{\mathrm{II}}$

Figure 5.4 Laboratory measurement of shale properties needed for the model. 


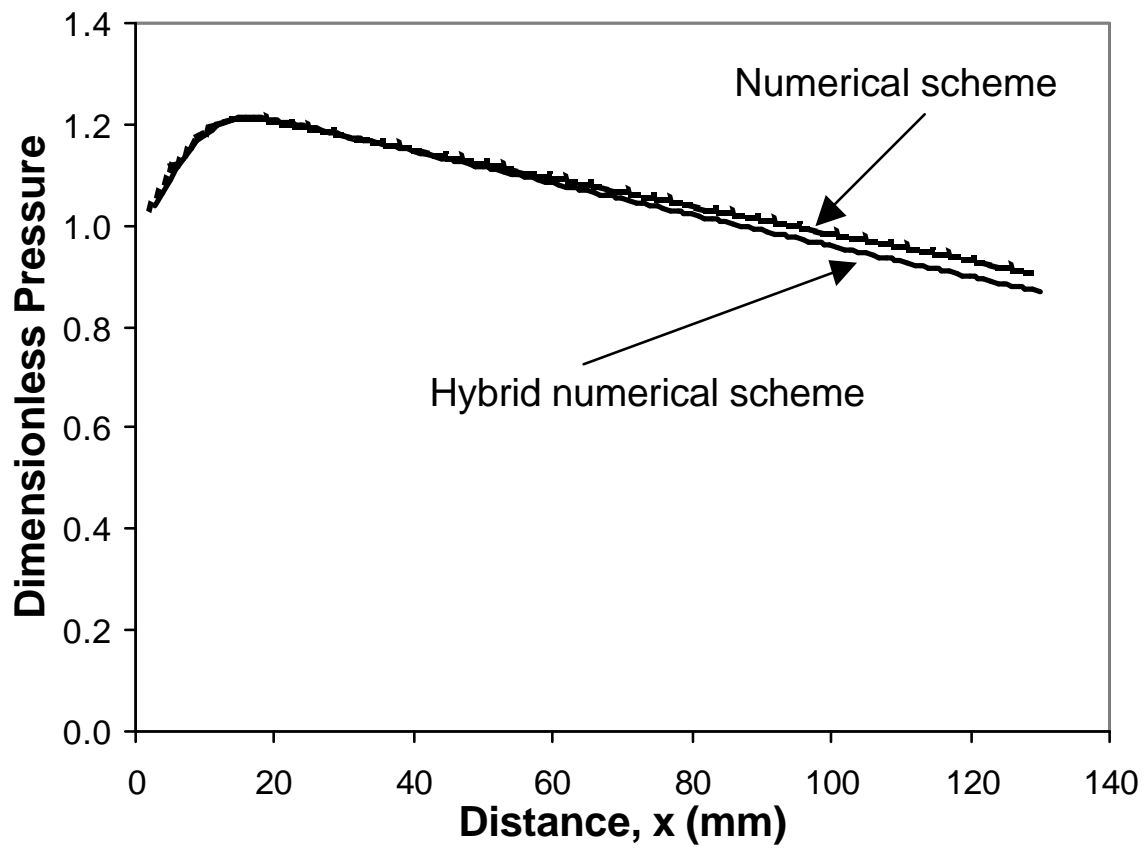

Figure 5.5 A comparison of numerical and hybrid numerical model. 


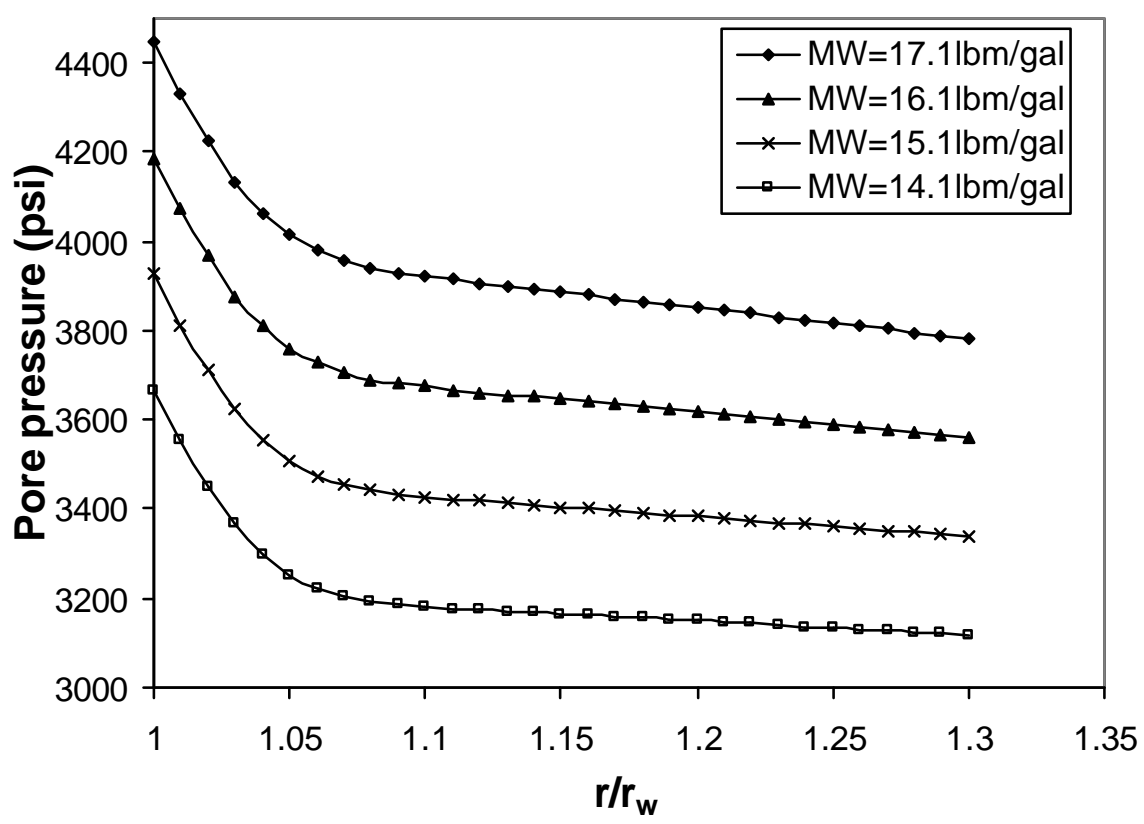

Figure 5.6 Pore pressure profile at $\mathrm{t}=5 \mathrm{hr}, \mathrm{C}_{\mathrm{df}}=4 \mathrm{M} \mathrm{C} \mathrm{C}_{0}=1 \mathrm{M}$. Water is being sucked out of the shale as solutes migrate in. 


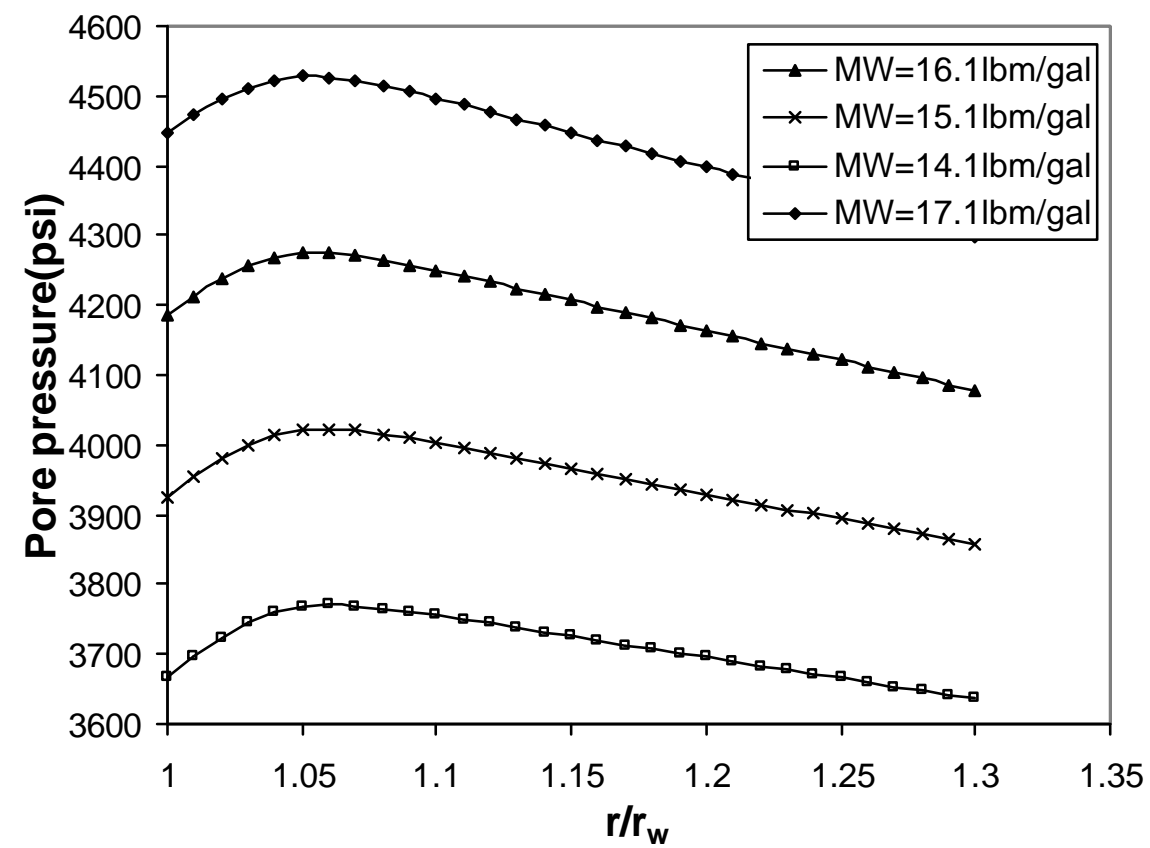

Figure 5.7 Pore pressure profile at $\mathrm{t}=5 \mathrm{hr}, \mathrm{C}_{\mathrm{di}}=0.01 \mathrm{M} \mathrm{C}=1 \mathrm{M}$. Here water is being sucked into the shale as solutes are pushed out. This leads to a maximum in pore pressure away from the wellbore wall. 


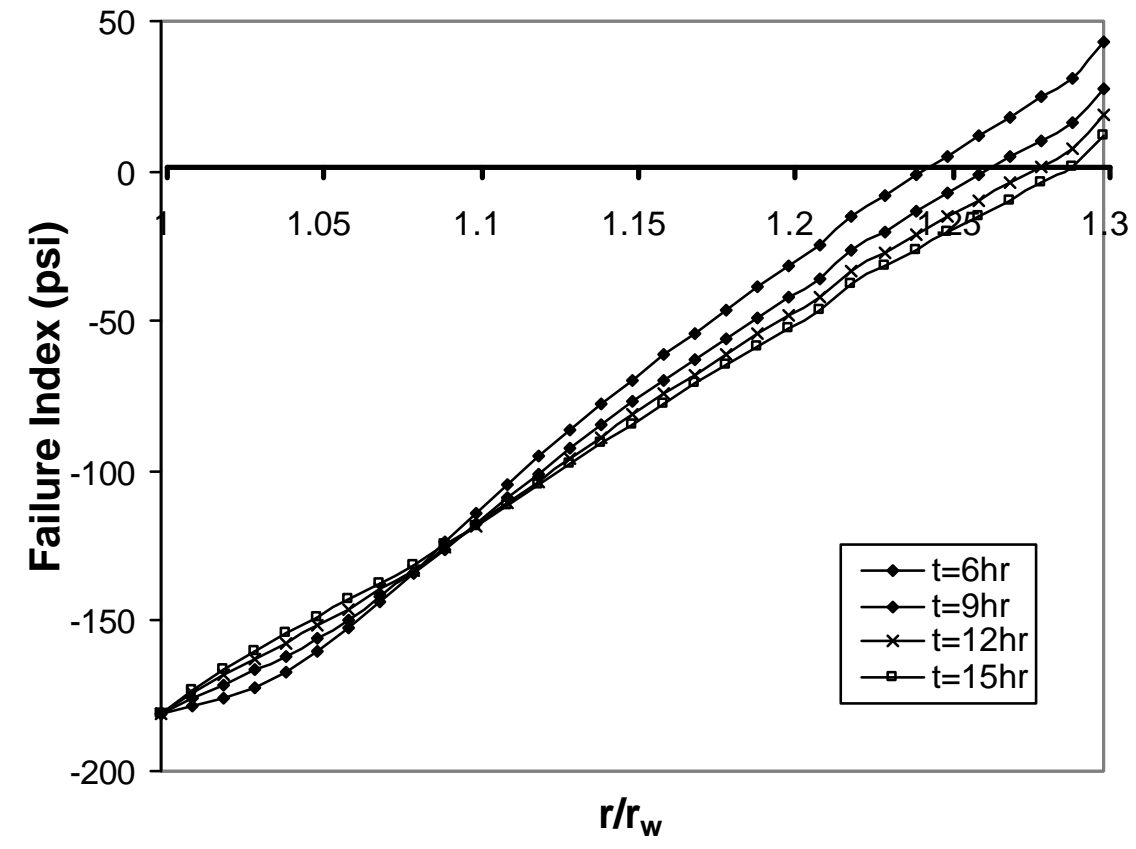

Figure 5.8 An example of Failure at the wellbore wall. (Parameters used are listed in Table 5.1).

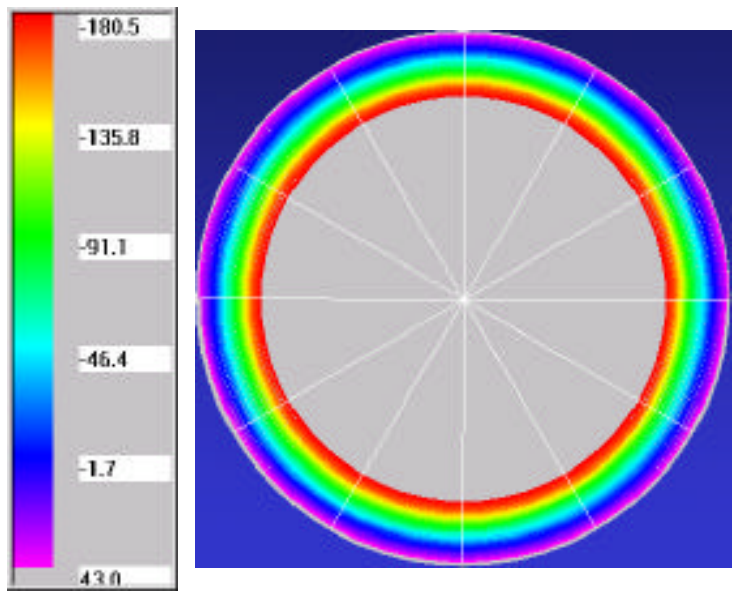

Figure 5.8b Failure at wellbore wall. Red color and yellow color indicate failure. 


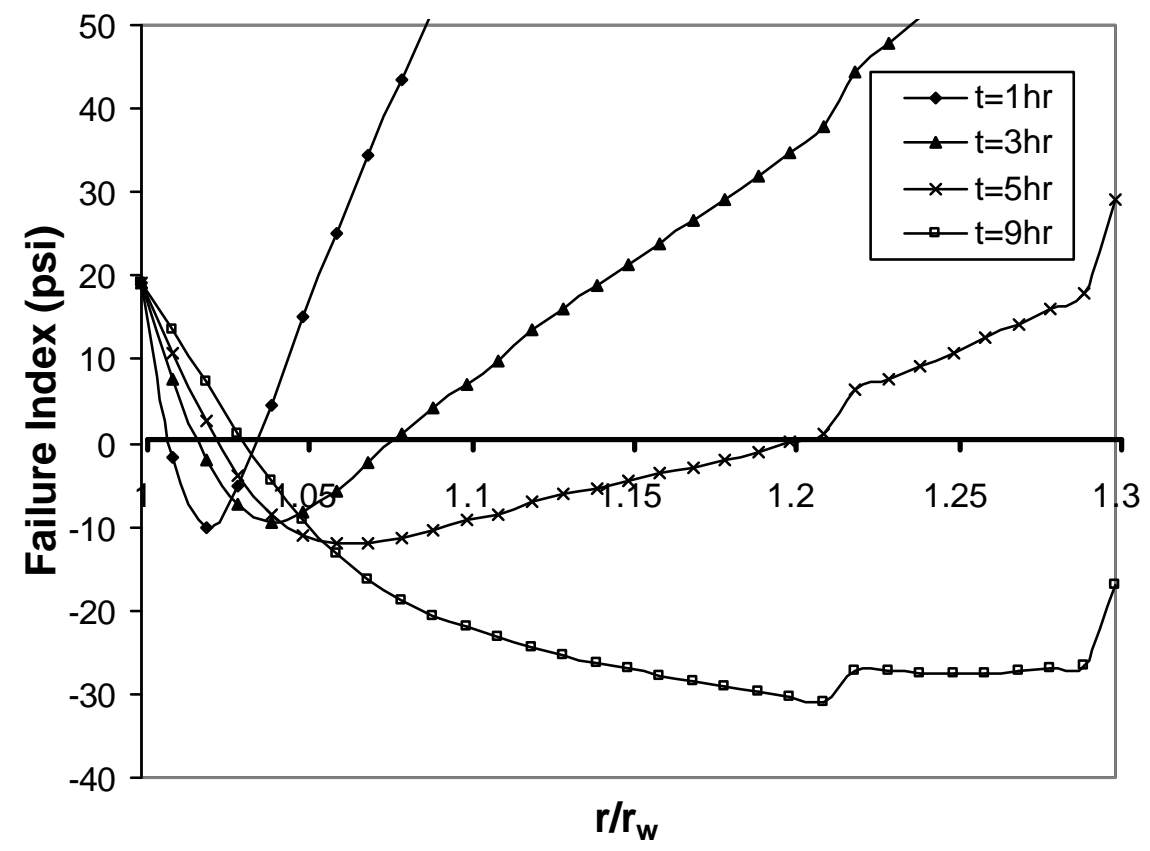

Figure 5.9 An example of failure inside the formation. (MW=18lbm/gal, $\mathrm{C}_{\mathrm{d}}=4 \mathrm{M}$, $\mathrm{C}_{\mathrm{o}}=1 \mathrm{M}$, Vertical well, $\sigma_{\mathrm{h}}=\sigma_{\mathrm{H}}$ ).

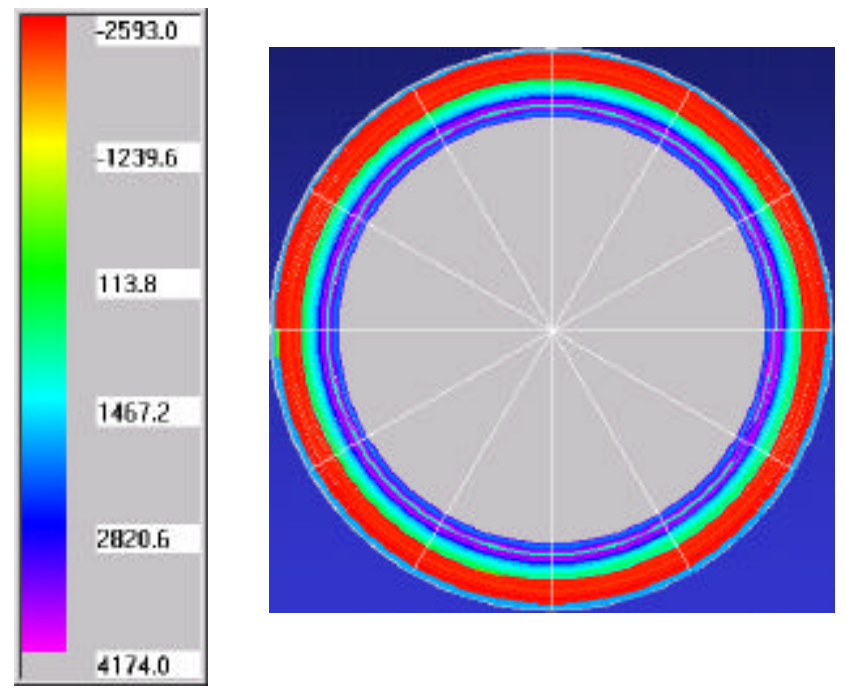

Figure 5.9b Failure inside the formation. Red color indicates the failure region. It is clearly seen that the failure region is inside the formation. 


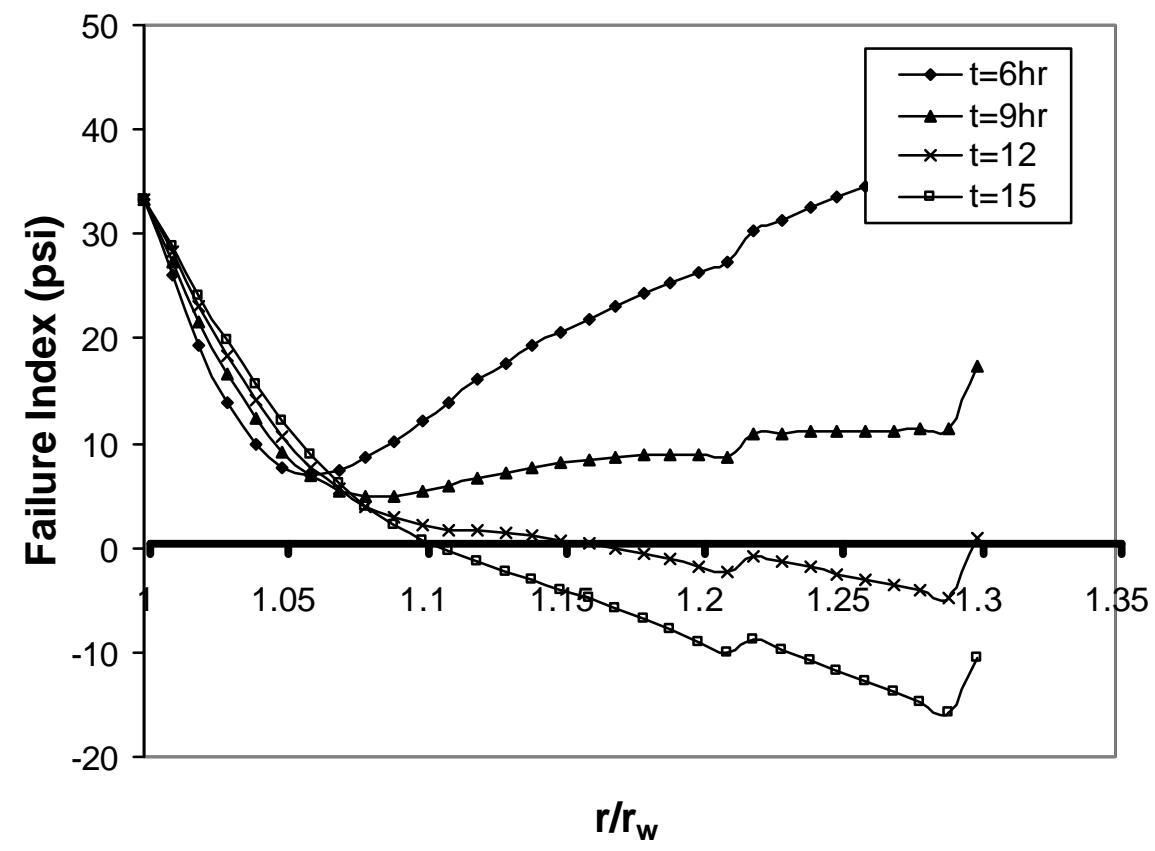

Figure 5.10 An example of time dependent failure ( $\mathrm{r}_{\mathrm{w}}=5$ in). The wellbore starts to become unstable after 12 hours.
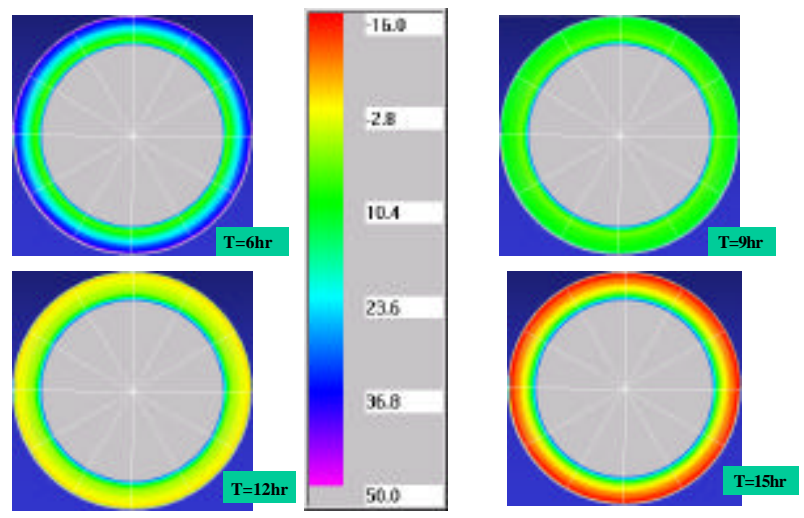

Figure 5.10b A graphical representation of time dependent failure $\left(r_{w}=5\right.$ in). The read and yellow colors indicate failure. 


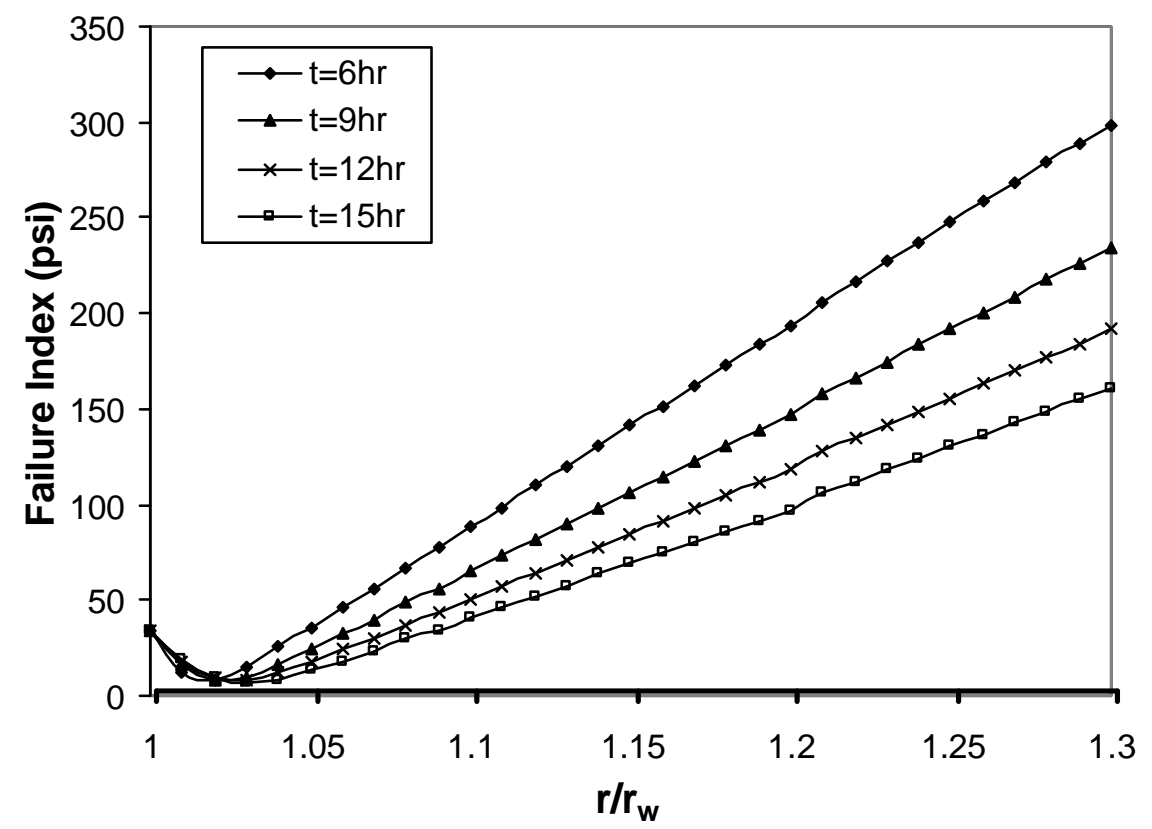

Figure 5.11 Time dependent failure. $r_{w}=15$ in. This graph demonstrates that increasing wellbore radius makes the borehole more stable. This implies that the borehole will achieve an enlarged stable radius. 


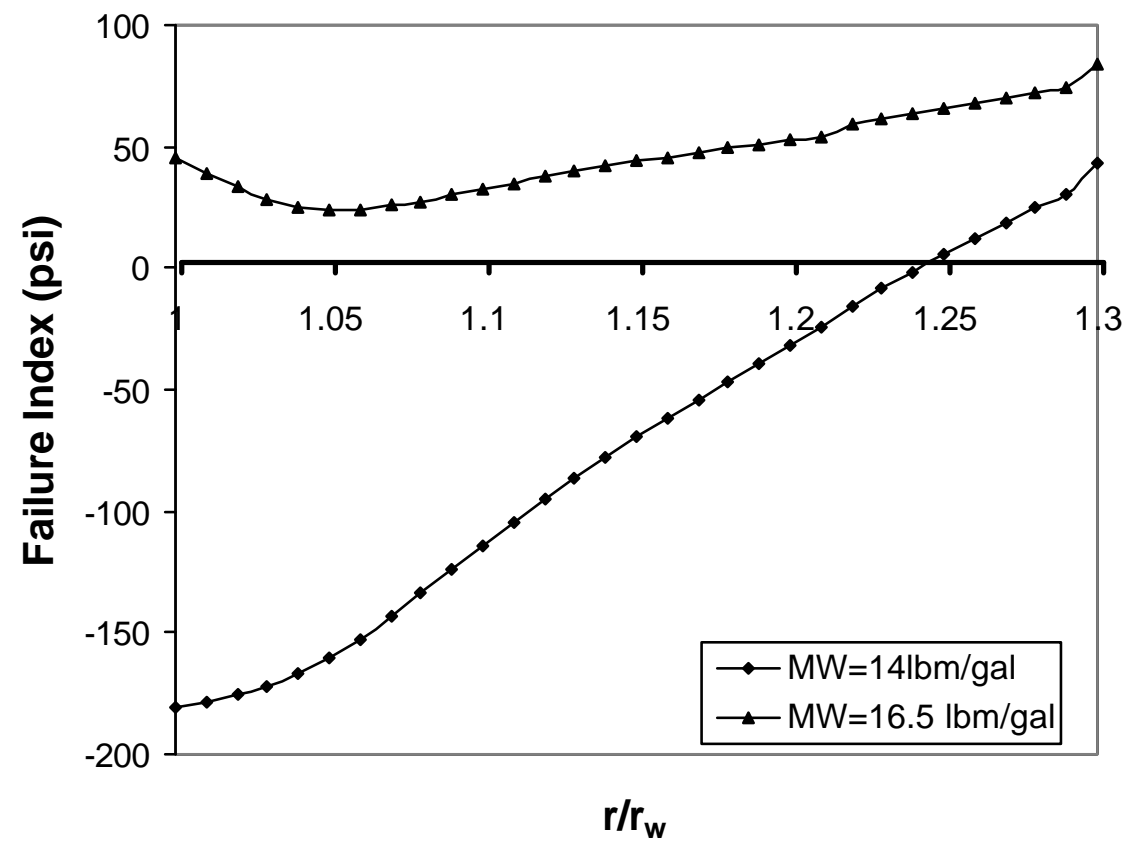

Figure 5.12 The effect of mud weight on Failure Index. Clearly, as expected, increasing MW leads to stable boreholes. 


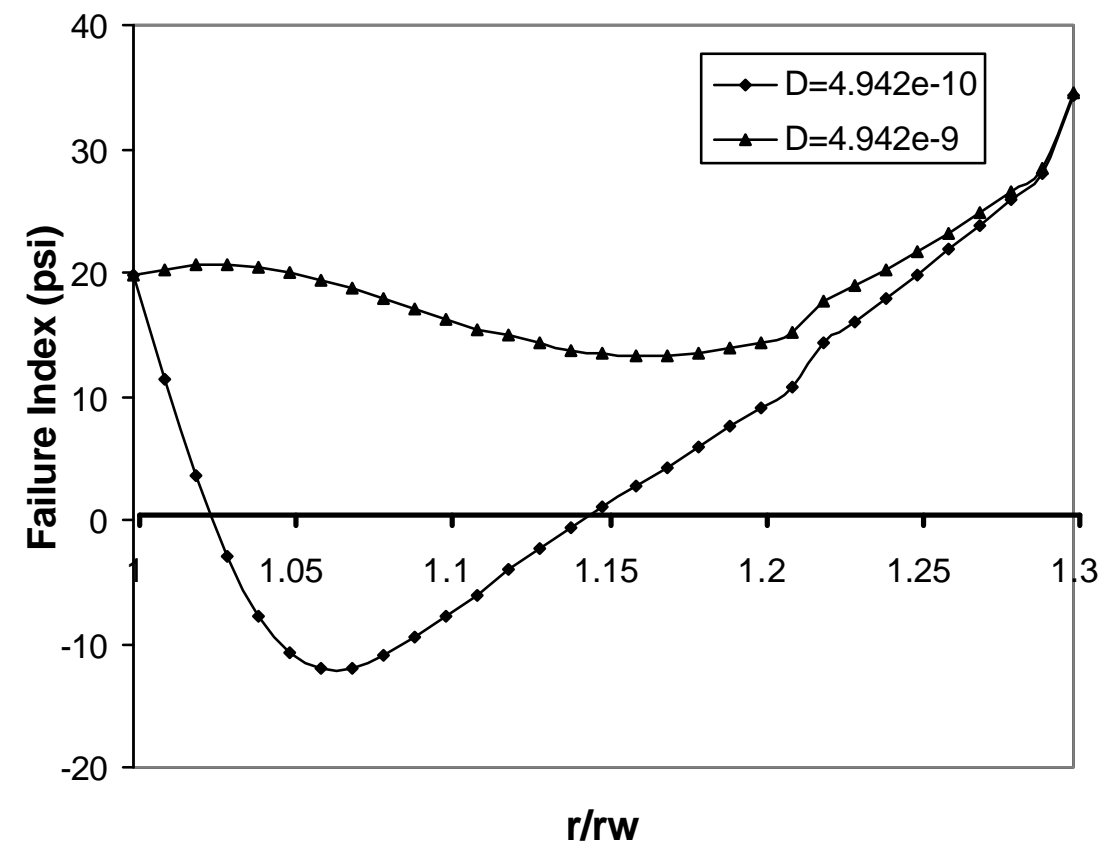

Figure 5.13a The effect of diffusion coefficient $\mathrm{D}_{\text {eff }}$ on Failure Index. $(\mathrm{t}=6 \mathrm{hr})$. Slower diffusing solutes lead to more unstable boreholes. 


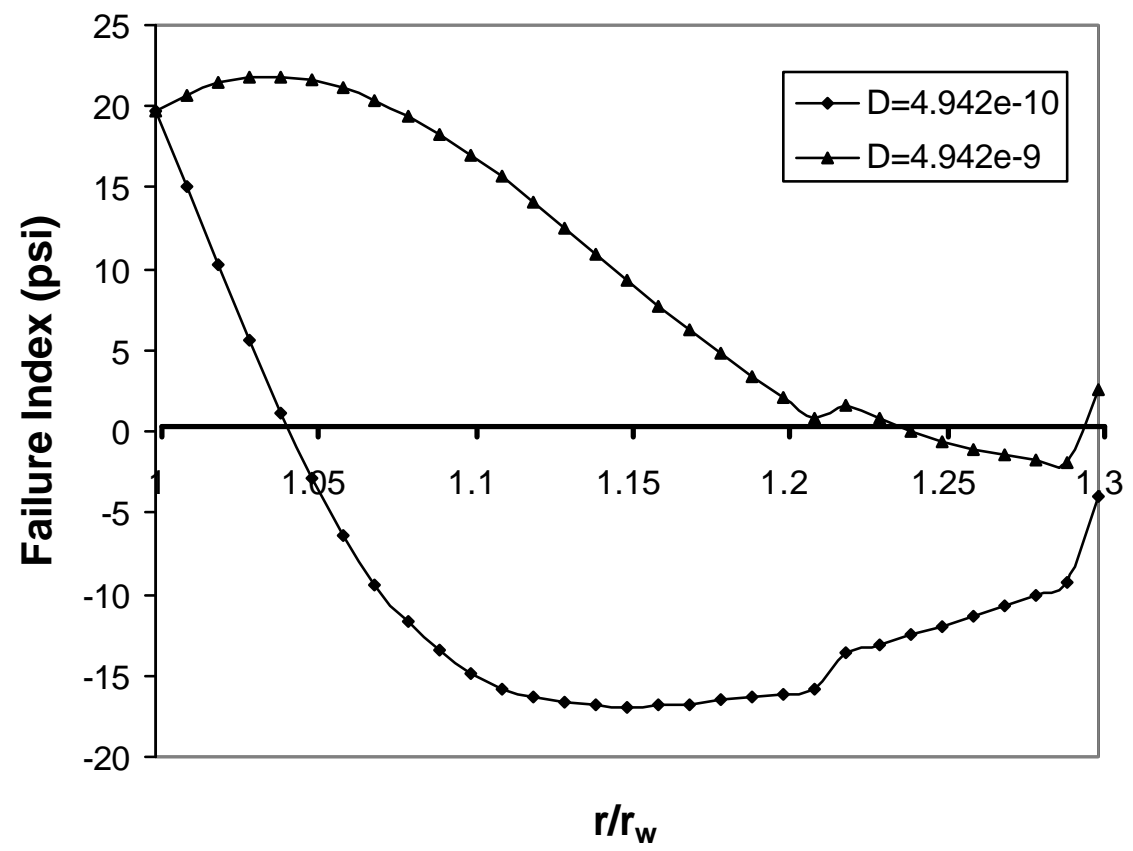

Figure 5.13b The effect of diffusion coefficient $\mathrm{D}_{\text {eff }}$ on Failure Index. ( $\left.\mathrm{t}=15 \mathrm{hr}\right)$. 


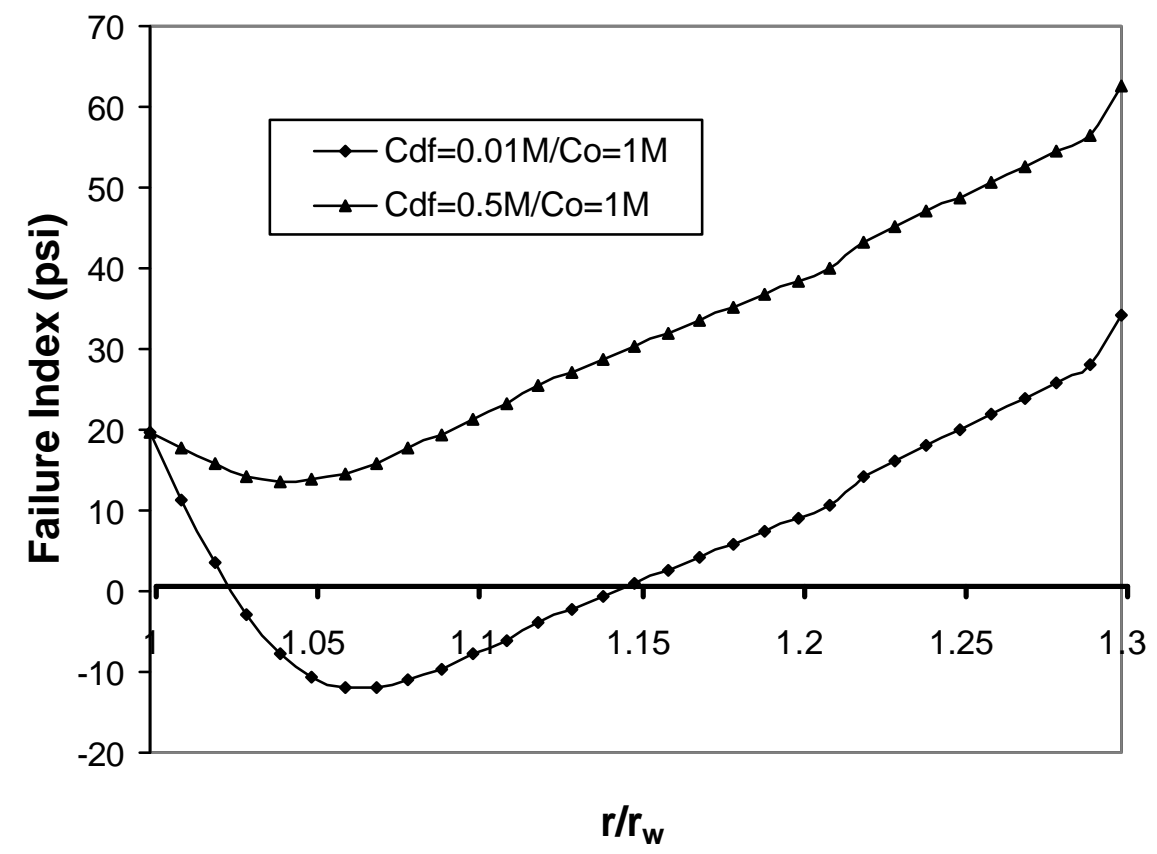

Figure 5.14 The effect of drilling fluid salt concentration on Failure Index. Increasing the salt concentration helps to stabilize the wellbore. 

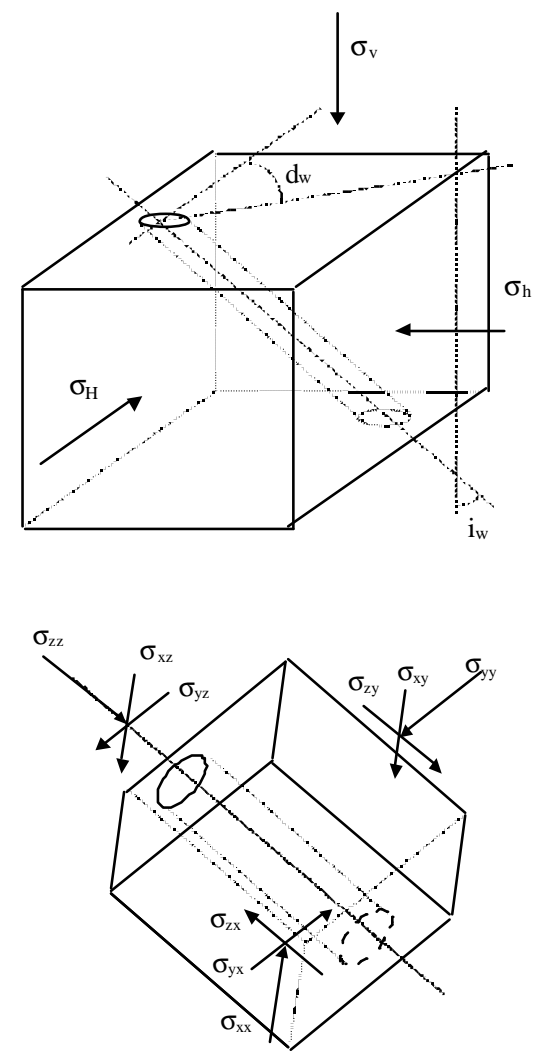

(b)

Figure 5.15 Stresses and reference coordinate systems (a) In - situ stresses; (b) Stresses in the local wellbore coordinate system. 


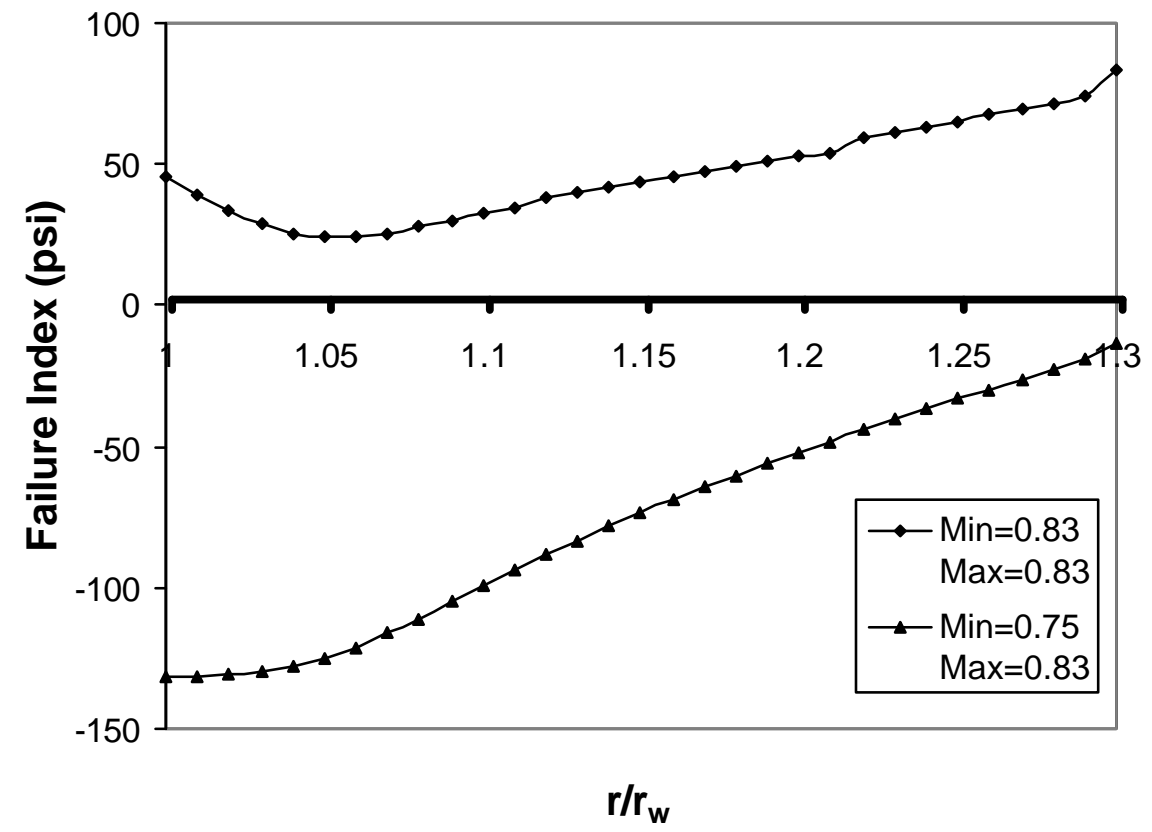

Figure 5.16 The effect of maximum and minimum horizontal stress. Stress anisotropy can induce failure. 


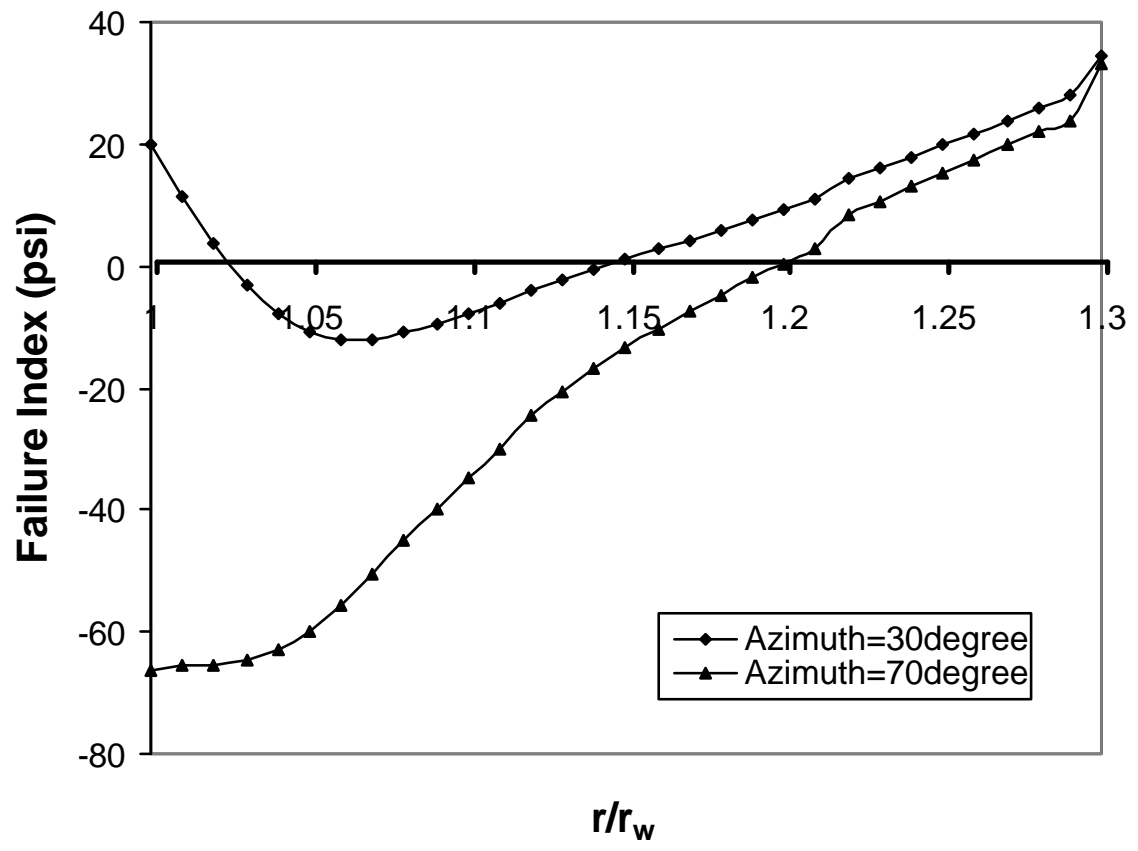

Figure 5.17 The effect of wellbore azimuth $\left(\sigma_{\mathrm{h}}=0.75, \sigma_{\mathrm{H}}=0.83\right)$. Larger well inclinations usually lead to less stable boreholes. 


\title{
Chapter 6: Chemical and Thermal Effects on Wellbore Stability of Shale Formations
}

\begin{abstract}
A new three-dimensional wellbore stability model is presented that takes into account thermal stresses and the flux of both water and solutes from drilling fluids (muds) into and out of shale formations. This model is an extension of the work presented in Chapter 5. Mechanical stresses around a wellbore placed at any arbitrary orientation in a 3-dimensional stress field are coupled with changes in temperature and pore pressure due to water and solute fluxes. The radial and azimuthal variation in the stress distribution and the "failure index" are computed to check for wellbore failure. This model accounts for the hindered diffusion of solutes as well as the osmotically driven flow of water into the shale. The model for the first time allows a user to study the role of solute properties on wellbore stability.

Results from the model show that a maxima or minima in pore pressure can be obtained within a shale. This leads to wellbore failure not always at the wellbore wall as is most commonly assumed but to failure at some distance inside the shale. Since the fluxes of water and solute, and temperature, are time dependent, a clearly time dependent wellbore failure is observed. The time to wellbore failure is shown to be related to the rate of solute and water invasion. Comparisons with experiments conducted with a variety of solutes on different shales show excellent agreement with model results.
\end{abstract}


It is shown in this study that the solutes present in the mud play an important role in determining not only the water activity but also in controlling the alteration of pore pressures in shales. To account for this phenomenon a model is presented to compute the flux of both water and solutes into or out of shales. The relative magnitudes of these fluxes control the changes in pore pressure in the shale when it is exposed to the mud. The effect of the molecular size of the solute, the permeability of the shale and its membrane efficiency are some of the key parameters that are shown to determine the magnitude of the osmotic contribution to pore pressure. A range of behavior is observed if the solute is changed while the water activity is maintained constant. This clearly indicates the importance of the solute flux in controlling the pore pressure in shales.

Critical mud weights are obtained by inspecting the stability of the wellbore wall and the entire near wellbore region. Pore pressures at different time and position are investigated and presented to explain the model results. It is shown in this study that the critical mud weights are strongly time dependent. The effects of permeability, membrane efficiency of shale, solute diffusion coefficient, mud activity and temperature changes are presented in this work. The collapse and fracture effects of cooling and heating the formations are also presented.

A powerful tool has been developed which can be used to perform thorough investigations of the wellbore stability problem. A user-friendly interface has been developed to ease usage. 


\subsection{INTRODUCTION}

The oil and gas industry sustains financial losses due to wellbore failure of over $\$ 1$ billion each year. Wellbore instability is a complex problem that includes rock mechanics, stress analysis, in-situ stress calculations, pore pressure prediction, and shale/fluid chemical reactions. Borehole stability problem occurs when the rock stress exceeds rock strength. To prevent the problem, balance between the stress and strength must be restored and maintained during drilling through control over drilling fluid composition, mud weight, well trajectory and many other factors.

Since shales can act as semi-permeable membranes, an osmotic pressure due to flow of water and solute into or out of shale formations has been successfully measured in the laboratory (Chenevert [1970], Ewy and Stankovich [2000]). This osmotic pressure can also be calculated provided the membrane efficiency and water activity ratio are known (Marshall [1964], Chenevert and Pernot [1998]). The contribution of the osmotic effect can be regarded as a modification of the hydraulic potential (Mody and Hale [1993]). Unfortunately, shales are seldom perfect semi-permeable membranes (only water flow). The transport of both water and solute changes the chemical potential of all the components in the system; consequently, the water activity in the shale will no longer be a constant (Lomba, Chenevert and Sharma [2000]). In order to remove the limitation of a constant osmotic contribution, a new hydraulic-chemical model is developed and presented herein, from which pore pressure as a function of wellbore distance and hydration time can be solved. Results from the model are displayed in the form of a "mud weight window" which gives the minimum and maximum mud weight 
allowed for a given formation as a function of time. In addition, rock pore pressure and failure status are displayed.

Sherwood [1995] pointed out that ion exchange plays an important role, affecting not only the rates of transport of ions, but also the mechanical and swelling properties of the shale. The equilibrium state of shale was assumed to be independent of composition and only dependent on the pore pressure. For simplicity, the solution in the pore was ideal with only a single solute present. Van Oort [1997] recently presented solutions for fluid pressure, solute diffusion and filtrate invasion around a wellbore. Transient effects were not considered in the study, however, these effects play an important role and affect pressure transmission and solute diffusion. Fritz and Whitworth [1993] performed experiments to measure the reflection coefficients and membrane efficiency to predict osmotically induced hydraulic pressure.

Mechanical stresses in the near wellbore rock immediately after the drilling perturbation can be obtained from linear elasticity (Bradly [1979]). For a linear and isotropic case, the solution can be applied to deviated wells rather than to vertical wells only. Since most petroleum rocks are porous, poroelastic effects have to be considered for rock failure (Biot [1941], Skempton [1954])because fluid pressure in pores play an important role in distributing rock total stress. Rice and Cleary [1976] developed basic stress diffusion equations for fluid-saturated elastic porous media. Detournay and Cheng [1988] derived the borehole poroelastic response and presented numerical solutions of wellbore stress and pore pressure by superposing the three-mode loading aspects. The solutions are presented in the Laplace domain. Their solutions are extended for application to deviated boreholes (Cui et. al. [1999]). Explicit analytical solutions for wellbore stress and pore pressure distribution are also presented by Yew and Liu 
[1992] for a deviated well. Fluid diffusion into or out of rock formations is considered in the above poroelastic analyses.

Wang and Papamichos [1994] showed that thermally induced pore pressure changes can be significant inside a low-permeability formation. An increase of $30 \%$ over the isothermal pore pressure case can be obtained for certain specified changes of temperature. For shale, thermal effects on wellbore stability are also important because thermal diffusion is much faster than hydraulic diffusion. In shale formations, convective heat transfer can be neglected because of their low permeability. In the case wherein the shale formation is cooled by the mud, a shale stability effect is achieved because both the pore pressure and the borehole hoop stress are reduced (Charlez [1997]). Most boreholes have an annular neutral point, the point at which the annular mud temperature is equal to the formation temperature. The thermal effect results in a less stable borehole above this point and a more stable borehole below this point. Fortunately, the cooling effect tends to move upwards as the cool mud is circulated, which is beneficial to maintaining wellbore stability in the lower part of the hole. Another contribution of the cooling effect is that the critical failure position is displaced to inside the formation away from the wellbore wall (Charlez [1997]). This phenomenon is also found in the poroelastic analysis of Detournay and Cheng [1988]. The thermal effects on the "critical mud weight window" will be discussed in this paper.

\subsection{THEORY}




\subsubsection{Stresses Induced by Pore Pressure and Formation Temperature Changes}

The stresses induced by chemical, hydraulic and thermal diffusion, which are driven by chemical potential, hydraulic difference and temperature difference, respectively, are computed as follows:

$$
\begin{aligned}
& \sigma_{r r}= \frac{\alpha(1-2 v)}{1-v} \frac{1}{r^{2}} \int_{r_{w}}^{r} p^{f}(r, t) r d r \\
&+\frac{E \alpha_{m}}{3(1-v)} \frac{1}{r^{2}} \int_{r_{w}}^{r} T^{f}(r, t) r d r+\frac{r_{w}^{2}}{r^{2}} p_{w} \\
& \sigma_{\theta \theta}=-\frac{\alpha(1-2 v)}{1-v}\left[\frac{1}{r^{2}} \int_{r_{w}}^{r} p^{f}(r, t) r d r-p^{f}(r, t)\right] \\
&-\frac{E \alpha_{m}}{3(1-v)}\left[\frac{1}{r^{2}} \int_{r_{w}}^{r} T^{f}(r, t) r d r-T^{f}(r, t)\right]-\frac{r_{w}^{2}}{r^{2}} p_{w} \\
& \sigma_{z z} \frac{\alpha(1-2 v)}{1-v} p^{f}(r, t)+\frac{E \alpha_{m}}{3(1-v)} T^{f}(r, t) \\
& p^{f}(r, t)=p(r, t)-p_{0} \\
& T^{f}(r, t)=T(r, t)-T_{0}
\end{aligned}
$$

In the $\sigma_{r r}, \sigma_{\theta \theta}$, and $\sigma_{z z}$ equations shown above, the first term relates to chemical effects, the second term relates to thermally-induced stresses, and the third term is the stress induced by the borehole pressure.

At the borehole surface, the above equations reduce to constant values as follows:

$$
\begin{aligned}
& \sigma_{r r}=p_{w} \\
& \sigma_{\theta \theta}=\frac{\alpha(1-2 v)}{1-v}\left(p_{w}-p_{0}\right)+\frac{E \alpha_{m}}{3(1-v)}\left(T_{w}-T_{0}\right)-p_{w} \\
& \sigma_{z z}=\frac{\alpha(1-2 v)}{1-v}\left(p_{w}-p_{0}\right)+\frac{E \alpha_{m}}{3(1-v)}\left(T_{w}-T_{0}\right)
\end{aligned}
$$


The pressure difference $\left(\mathrm{P}_{\mathrm{w}}-\mathrm{P}_{\mathrm{o}}\right)$ includes both hydraulic and osmotic contributions.

\subsubsection{Solute Concentration Profile}

When a drilling fluid is brought into contact with the formation, solutes can flow into or out of the shale. Thus a solute concentration profile will build up within the formation. The solute concentration profile can be calculated by the following diffusivity equation:

$$
\frac{\partial C_{S}}{\partial t}-D_{e f f} \nabla^{2} C_{S}=0
$$

where $D_{\text {eff }}$ is an effective "diffusion coefficient". See Refs. 6 and 7 for a derivation and a more detailed discussion.

Boundary conditions and initial conditions can be described as,

$$
\begin{array}{ll}
C_{S}=C_{d f}, & \text { at the borehole surface for } \mathrm{t}>0 \\
C_{S}=C_{0}, & \text { far-field for } \mathrm{t}>0 \\
C_{S}=C_{0}, & \text { for } \mathrm{t}<0
\end{array}
$$

Usually the "diffusion coefficient" in Eq. 6-5 varies with concentration. In order to simplify the problem and minimize computing time, the "diffusion coefficient" is assumed to be constant.

\subsubsection{Pore Pressure}

Both hydraulic and chemical potential gradients induce the flow of solute and water which alters pore pressures. In this study the pore pressure profile is coupled with 
the flux of both water and solute. The coupled equation for pore pressure can be expressed as (Ref. 6, 7):

$$
\frac{\partial p}{\partial t}-\frac{K_{I}}{c_{f}} \nabla^{2} p-\frac{n R T K_{I I}}{D_{e f f} c_{f}} \frac{\partial C_{S}}{\partial t}=0
$$

Where $\mathrm{K}_{\mathrm{I}}$ is the "hydraulic diffusivity" of the formation and $\mathrm{K}_{\mathrm{II}}$ is related to the "membrane efficiency" (or "reflection coefficient") of the formation. $\mathrm{K}_{\mathrm{I}}$ determines the rate of pressure propagation into the shale while $\mathrm{K}_{\mathrm{II}}$ determines the shape of the pore pressure profile i.e. the maximum (or minimum) in pore pressure.

A typical semi-infinite boundary condition was applied for this pore pressure propagation procedure. The initial and boundary conditions can be written as,

$$
\begin{array}{lll}
t=0, & r_{w} \leq r \leq \infty, & C_{S}=C_{0} ; p=p_{0} \\
r=r_{w}, & t>0, & C_{S}=C_{d f} ; p=p_{w} \\
r=\infty, & t>0, & C_{S}=C_{0} ; p=p_{0}
\end{array}
$$

\subsubsection{Formation Temperature}

For a radial system, the formation temperature equation can be expressed as,

$$
\frac{\partial T}{\partial t}=c_{0}\left(\frac{\partial^{2} T}{\partial r^{2}}+\frac{1}{r} \frac{\partial T}{\partial r}\right)
$$

where $c_{0}$ is thermal diffusivity of the porous medium.

The initial conditions and boundary conditions are considered to be the following:

$$
\begin{array}{lll}
t=0, & \mathrm{r}_{\mathrm{w}} \leq r \leq \infty, & T=T_{0} \\
r=r_{w}, & t>0, & T=T_{w} \\
r=\infty, & t>0, & T=T_{0}
\end{array}
$$

Eqs. 6-5, 6-6 and 6-8 are solved with their corresponding initial and boundary conditions so as to obtain the pore pressure and temperature profile. 


\subsubsection{Failure of the Wellbore}

\subsubsection{Collapse Failure}

Collapse failure occurs when rock stress exceeds rock strength, i.e., the collapse "failure index", $\sigma_{c l}$, becomes non-positive. Drucker-Prager criteria are used to determine if the rock experiences collapse failure.

$$
\begin{aligned}
& \sigma_{c l}=-\sqrt{J_{2}}+A J_{1}^{e f}+B \leq 0 \\
& J_{1}^{e f}=\frac{\sigma_{r r}+\sigma_{\theta \theta}+\sigma_{z z}}{3}-p \\
& J_{2}=\frac{1}{9}\left[\left(\begin{array}{l}
\left(\sigma_{r r}-\sigma_{\theta \theta}\right)^{2}+\left(\sigma_{\theta \theta}-\sigma_{z z}\right)^{2}+ \\
\left(\sigma_{z z}-\sigma_{r r}\right)^{2}
\end{array}\right)+6 \sigma_{\theta z}^{2}\right]
\end{aligned}
$$

Other failure criteria have also been implemented but are not discussed in this work.

\subsubsection{Tensile (Breakdown) Failure Criteria}

Rock tensile failure occurs once the least compressive effective principal stress exceeds the tensile srength, i.e., the breakdown failure index, $\sigma_{b d}$, becomes nonpositive,

$$
\begin{aligned}
& \sigma_{b d}=\sigma_{\min }^{e f}+\sigma_{t} \leq 0 \\
& \text { or } \\
& -\sigma_{\min }^{e f}=-\sigma_{3}^{e f} \geq \sigma_{t}
\end{aligned}
$$

Note that the tensile strength, $\sigma_{t}$, is a non-negative value in the above equation. 


\subsection{COMPUTER IMPLEMENTATION}

A computer program (DRILLER) has been developed which calculates the concentration, pore pressure and temperature profiles using the equations shown above. The stresses around the wellbore are then calculated based on the pore pressure and temperature profiles. Critical mud weights are determined using Drucker-Prager or other failure criteria.

All calculations include chemical, thermal and mechanical effects and the many input parameters are listed in Tables 6.1 through 6.5. Management of these input parameters are performed through a user-friendly interface developed in Visual Basic. The parameters are grouped into 5 different categories: thermal effects (Table 6.1), chemical effects (Table 6.2), mechanical effects (Table 6.3), wellbore information (Table 6.4) and miscellaneous parameters (Table 6.5). Figure 6.1 shows a typical screen from DRILLER with the input parameters and the graphical output for the mud weight window as a function of salt concentration. Note that other displays can be selected by clicking on the tool bar above the plot.

Pore pressure, temperature, and failure indices can be visualized using a Visual Wellbore Analysis Tool. A full graphical view of the pore pressure, temperature or failure index can be obtained via this tool. Figure 6.2 shows an example for the visualization of the pore pressure distribution around the wellbore.

This program (DRILLER) is a powerful tool for both field use and for research. One can easily conduct a sensitivity study on any of the input parameters by plotting the mud weight window as a function of any selected input parameter. Chemical and 
thermal effects can be turned on or off as desired by the user. The input parameters can be set to default values or estimated based on methods suggested in the program. It is capable of linking with other log analysis programs and operating remotely in a clientserver mode.

\subsection{RESULTS AND DISCUSSION}

\subsubsection{Input Data}

The model presented in this work is quite general and consequently requires several input parameters. Each calculation can take into account chemical, thermal, and mechanical effects, wherein over 40 parameters are required to run a single simulation. Some parameters can be found in the literature and others have to be measured using appropriate techniques (See section 5.3.4) or computed via available theories or empirical correlations.

A default input data set is shown in Tables 6.1 to 6.5. The input data are grouped into 5 different categories: thermal, chemical, and mechanical effects, wellbore information, and miscellaneous parameters. The examples shown in this paper were based on this default input data set. One parameter has been changed for each case in the following studies, the corresponding effects of that parameter are shown and discussed.

\subsubsection{Effect of Hydraulic Diffusivity of the Shale}

The rate of pore pressure propagation is controlled by the hydraulic diffusivity of the formation " $\mathrm{K}_{\mathrm{I}}$ ". Faster pressure propagation occurs in formations with higher $\mathrm{K}_{\mathrm{I}}$, or higher permeability. Figure 6.3 clearly shows that the pore pressure propagates much 
faster for a shale with a $K_{I}$ of $1.01 \times 10^{-18} \mathrm{~m}^{3} \mathrm{~s} / \mathrm{kg}$ than a shale with a $\mathrm{K}_{\mathrm{I}}$ of $5.13 \times 10^{-19}$ $\mathrm{m}^{3} \mathrm{~s} / \mathrm{kg}$ after a shale/drilling fluid contact time of 24 hours. For Figure 6.4, a $0.001 \mathrm{M}$ mud in contact with a shale located at $10,000 \mathrm{ft}$ and containing a pore pressure of 4680 psi was used.

Figure 6.4 shows the minimum mud weight required to prevent collapse for different values of $\mathrm{K}_{\mathrm{I}}$. Clearly the minimum collapse mud weight requirement decreases with increasing $\mathrm{K}_{\mathrm{I}}$. This can be explained using Figure 6.3. Because the pore pressure is lowered more significantly in a higher $\mathrm{K}_{\mathrm{I}}$ formation, the effective stresses in a high $\mathrm{K}_{\mathrm{I}}$ formation are higher at any given time compared to a low $\mathrm{K}_{\mathrm{I}}$ formation, resulting in a more stable wellbore. This observation may be one of the reasons why high permeability formations (such as sandstones) can be drilled with a mud weight lower than that required for low permeability shales.

\subsubsection{Effect of Membrane Efficiency}

In Eq. 6-6, $\mathrm{K}_{\mathrm{II}}$ represents the "Membrane Efficiency". When $\mathrm{K}_{\mathrm{II}}=0$, chemical effects play no role and Eq. 6-6 reduces to the pressure diffusivity equation. Note that $\mathrm{K}_{\mathrm{II}}$ is negative, therefore, more negative numbers (greater absolute values) contribute more to the pore pressure as shown by Eq. 6-6. $\mathrm{K}_{\mathrm{II}}$ measures how much the osmotic potential contributes to the pore pressure.

Consider a vertical well with a 4680 psi initial pore pressure being drilled using a $0.1 \mathrm{M} \mathrm{NaCl}$ fluid through a formation with different membrane efficiencies $\left(\mathrm{K}_{\mathrm{II}}\right)$. Figure 6.5 shows that a higher mud weight is required to drill a stable well when the formation acts more like a semi-permeable membrane (with greater absolute value of $\left.\mathrm{K}_{\mathrm{II}}\right)$. It clearly shows that the contribution of the chemical potential to the pore pressure 
is greater for higher "membrane efficiency", resulting in a greater osmotic contribution to wellbore stresses.

\subsubsection{Effect of the Diffusion Coefficient}

The solute diffusion process is very slow; therefore, diffusion can be easily "overwhelmed" by convection in a high permeability formation. Thus it is very hard to see the effects of diffusion in a high permeability formation (with large $\mathrm{K}_{\mathrm{I}}$ ). In general, diffusion is negligible for high permeability formations, like sandstones. Shales have very low permeabilities, therefore, convection in shales is significantly hindered, and the solute diffusion process becomes prominent.

Figure 6.6 shows results for a vertical well drilled using drilling fluids containing solutes which have different diffusion coefficients. All of the drilling fluids are assumed to have the same solute concentration of $0.001 \mathrm{M}$. In order to see a significant effect of the diffusion process, a low permeability shale $\left(\mathrm{K}_{\mathrm{I}}=3.13 \times 10^{-19} \mathrm{~m}^{3} \mathrm{~s} / \mathrm{kg}\right)$ is used in the simulation. Figure 6.6 shows that the minimum mud weight required to drill a stable well decreases as the diffusion coefficient increases. Because the solute concentration of the drilling fluid is lower than that of the pore fluid, water moves into the shale as the solute simultaneously moves out of the shale. This counter movement of solutes reduces the pore pressure. Higher values of solute diffusivity allow the rapid movement of solute in the shale in response to gradients in water or solute chemical potentials. This prevents large pore pressure gradients from building up in the shale. It is this lack of large pore pressure gradients that stabilizes the shale for large values of the diffusion coefficient.

Note that it is the competition between the water and solute fluxes that generates the 
pore pressure gradients. Therefore, the effect of solute diffusivity is closely tied to the flux of water i.e. to $\mathrm{K}_{\mathrm{I}}$.

\subsubsection{Effect of Wellbore Inclination}

Figure 6.7 shows the minimum mud weight necessary to drill a stable deviated well under different wellbore inclinations with and without chemical effects. A low drilling fluid solute concentration, $0.001 \mathrm{M}$, is used in this example. For wellbore inclinations less than $30^{\circ}$, a maximum difference of $0.7 \mathrm{lbm} / \mathrm{gal}$ mud weight is observed when chemical effects are considered. Chemical effects are clearly less important for highly deviated wells because a higher earth stress environment usually exists which overshadows chemical effects. The presence of chemical effects increases the mud weight required significantly in vertical wells.

\subsubsection{Effect of Drilling Fluid Concentration and Time-Dependent Collapse Mud Weight}

Figure 6.8 displays pore pressure conditions as a function of distance from the wellbore for increasing times for a shale drilled using a drilling-fluid/pore-fluid concentration ratio of $4 \mathrm{M} / 1 \mathrm{M}$. An original wellbore pressure of $5772 \mathrm{psi}$ and a shale pore pressure of 4680 psi are assumed. As shown, the pore pressure of the shale formation drops quickly to $4500 \mathrm{psi}$ at a distance of 0.05 inches from the wellbore and this minimum pore pressure proceeds to extend into the shale with time. Note that even though the shale away from the borehole wall is becoming more stable (lower pore pressure) with time the pore pressure at the wellbore wall does not decrease therefore 
one should not assume that after a given time the shale is more stable at all points and then proceed to reduce the mud weight.

Figure 6.9 displays results for pore pressure conditions similar to Figure 6.8 except that a drilling-fluid/pore-fluid concentration ratio of $0.001 \mathrm{M} / 1 \mathrm{M}$ is used. Note that after 1 hour the pore pressure has increased from 4680 to $6000 \mathrm{psi}$ at a distance of about 0.05 inches from the wellbore wall, and this "pressure wave" continues to extend deeper into the shale with time. Assuming that the instantaneous increase in pore pressure to 5772 psi at the wellbore wall (due to drilling fluid hydraulic pressure) does not produce wellbore collapse, it is conceivable that the further increase of pore pressure to 6000 psi within the formation could cause collapse as time progresses.

Figure 6.10 shows the minimum collapse mud weight required to drill a stable well at a time of 1 hour for different values of drilling fluid concentrations. Note that increasing the concentration to $0.5 \mathrm{M}$ allows the well to be drilled with a lower mud weight, however no additional benefits are achieved for drilling fluid concentrations above $0.5 \mathrm{M}$. Although higher mud concentrations lower the pore pressure inside the formation, the pressure on the wellbore wall does not decrease (Figure 6.8), therefore, the failure occurs on the wellbore wall first. Lower mud concentrations cause abnormally high pore pressures inside the formation (Figure 6.9), resulting in wellbore failure inside the formation. Because of the higher pore pressure (higher than pressure on wellbore wall), a greater mud weight is required to prevent wellbore failure when lower mud concentrations are used. 


\subsubsection{Thermal Effects}

\subsubsection{Effect of Cooling / Heating on Required Mud Weights}

Figures 6.11 and 6.12 show the mud weight window for deviated wells when temperature differences between the circulating drilling mud and the formation are -25 , 0 , and $25{ }^{\circ} \mathrm{C}$. The minimum and maximum mud weight requirements for both breakdown (Figure 6.11) and collapse (Figure 6.12) as a function of borehole inclinations are plotted. Required mud weights to prevent breakdown failure (fracture) experience more alteration than collapse mud weight. For example, cooling the formation by $25^{\circ} \mathrm{C}\left(\Delta \mathrm{T}=\right.$ mud temperature - formation temperature $\left.=-25^{\circ} \mathrm{C}\right)$, the breakdown mud weight (Figure 6.11) decreases by $0.7 \mathrm{lbm} / \mathrm{gal}$ uniformly for all deviations, while the collapse mud weight (Figure 6.12) is only slightly lower. Cooling the formation by $25^{\circ} \mathrm{C}$ reduces the collapse mud weight by only $0.2 \mathrm{lbm} / \mathrm{gal}$. This cooling effect is caused by a reduction in pore pressure in the near wellbore area ${ }^{20}$. In addition, a wellbore is more apt to fracture (lose circulation) when a formation is cooled because the cooling effect can reduce the hoop stress and thereby make it more tensile.

Heating the formation increases both the required collapse and breakdown mud weights, but presents a smaller effect on collapse mud weights than on breakdown mud weights.

In addition, the flow of cooler mud can move the thermal neutral point upward, which is beneficial because the lower sections of the borehole will benefit. However, the shallow formations above the thermal neutral point are heated up and may experience instability. 


\subsubsection{Effect of Temperature Alterations on Mud Weights}

Figures 6.13 and 6.14 show mud weight alterations with temperature differences between the drilling fluid and the formation for vertical and horizontal wells. A linear relationship is obtained for each condition except for excessive cooling of a horizontal well (Figure 6.14, $\Delta \mathrm{T}<-25^{\circ} \mathrm{C}$ ). A mud weight / temperature change gradient can be deduced from these figures. For example, the breakdown mud weight decreases by $0.03 \mathrm{lbm} / \mathrm{gal}$ and the collapse mud weight decreases by $0.013 \mathrm{lbm} / \mathrm{gal}$ for every $1^{\circ} \mathrm{C}$ of cooling of a vertical well, as shown in Figure 6.13.

Temperature changes influence a horizontal well more severely than a vertical well. The breakdown mud weight also decreases by $0.03 \mathrm{lbm} / \mathrm{gal}$ for every $1^{\circ} \mathrm{C}$ of cooling for a horizontal well; however, the collapse mud weight only decreases by $0.006 \mathrm{lbm} / \mathrm{gal}$.

The effect of cool muds assisting in the fracture of a wellbore can also be observed from the horizontal well curves of Figure 6.14. In this example, when the drilling fluid cools down the formation more than $25^{\circ} \mathrm{C}$, a horizontal well can not be drilled safely.

\subsubsection{Effect of Thermal Expansion Coefficients on Mud Weights}

Volumetric expansion coefficients of different rocks range from $4.32 \times 10^{-5}{ }^{\circ} \mathrm{C}^{-1}$ for basalts to $9.9 \times 10^{-5}{ }^{\circ} \mathrm{C}^{-1}$ for sandstones (Prats [1986]). Breakdown mud weights change with increasing volume expansion coefficients. Figure 6.15 shows that for a horizontal well the breakdown mud weight decreases by $0.15 \mathrm{lbm} / \mathrm{gal}$ for an increase of 
$1 \times 10^{-5}{ }^{\circ} \mathrm{C}^{-1}$ of the thermal expansion coefficient. Thus, formations with higher thermal expansion coefficients fracture at a lower wellbore pressure. The effect of thermal expansion on collapse mud weight is insignificant.

\subsection{CONCLUSIONS}

Existing models for wellbore stability account for osmotic pressure effects through membrane efficiency. It is often assumed that solutes (ions, polymers etc.) present in the mud change the water activity but otherwise are assumed to play no role. It is shown in this study that the solutes present in the mud also play an important role in controlling the alteration of pore pressure inside the formation.

Traditionally, critical mud weights are determined by investigating the failure index only at the wellbore surface. This study shows that shear failure (collapse) could occur not only on the wellbore wall, but also inside the formation. Therefore, the near wellbore area must be examined to obtain accurate critical mud weights.

A new three-dimensional wellbore stability model has been developed with a user-friendly interface. The stress field around a wellbore is computed taking account both chemical and thermal effects. Pore pressure, temperature, failure index and critical mud weights are calculated and displayed.

Results presented in this study show that indeed wellbore failure may first occur inside the formation, not on the wellbore wall. Such failure points also result in timedependent critical mud weights. Because pressure propagation takes a relatively long time in low permeable formation like shales, locations away from the wellbore wall control wellbore stability. For overbalanced drilling, the failure point is on the wellbore wall when a high solute concentration is used. 
Chemical effects play an important role in determining critical mud weights for low permeable formations. Abnormal pore pressure conditions inside the formation can significantly alter the stress distribution, resulting in different critical mud weights required to maintain the wellbore stable. The "membrane efficiency" of the formation determines how much osmotic pressure contributes to the pore pressure. Formations with a high "membrane efficiency" can significantly alter the critical mud weight required to maintain the well stable. Solute diffusion coefficients play an important role when a very low permeability shale is drilled.

Cooling the wellbore reduces the breakdown pressure as well as the collapse pressure, for all hole inclinations. However, the cooling effect is most prominent for low deviations because of the dominance of lower stress fields.

Hotter muds need a higher pressure to fracture the wellbore. This is true for both vertical and horizontal wells. Also, a higher mud weight is required to prevent collapse failure when using hotter muds.

The effect of temperature on horizontal wells is smaller as compared to the effect on vertical wells when determining collapse mud weights, because a higher earth stress environment dominates rock compressive failure for horizontal wells.

Formations with higher thermal expansion coefficients can cause higher thermal stresses under the same temperature difference and can therefore be fractured with less pressure.

When the drilling mud cools the formation below the thermal neutral point, it also heats up the formation above this point. This results in more stability below the thermal neutral point and less stability above. 


\section{NOMENCLATURE}

$A, B=$ material constants, for outer circle $A=\frac{2 \sqrt{2} \sin \phi}{3-\sin \phi}, B=\frac{2 \sqrt{2} c \cos \phi}{3-\sin \phi}$

$c=$ cohesive strength, $m / L t^{2}, p s i$

$c_{0}=$ thermal diffusivity, $\mathrm{L}^{2} / \mathrm{t} \mathrm{in}^{2} / \mathrm{s}$

$c_{f}=$ fluid compressibility, $L t^{2} / m, p s i^{-1}$

$C_{0}=$ initial pore fluid concentration, $\mathrm{mols} / \mathrm{L}^{3}$, mols/liter

$C_{d f}=$ drilling fluid solute concentration, mols $/ L^{3}$, mols/liter

$C_{S}=$ pore fluid solute concentration, mols $/ L^{3}$, mols /liter

$D_{\text {eff }}=$ effective water diffusion coefficient, $L^{2} / t, \mathrm{~m}^{2} / \mathrm{s}$

$E=$ Young's modulus, $m / L t^{2}, p s i$

$J_{1}{ }^{e f}=$ the effective mean stress, $m / L t^{2}$, psi

$J_{2}{ }^{1 / 2}=$ the shear stress, $m / L t^{2}$, psi

$K_{I}=$ "permeability", $L^{3} t / m, m^{3} s / k g$

$K_{I I}=$ "membrane efficiency", $L^{3} t / m, m^{3} s / k g$

$n=$ number of constituent ions of the dissociating solute.

$p=$ pore pressure, $m / L t^{2}, p s i$

$p_{0}=$ initial pore pressure, $m / L t^{2}, p s i$

$p_{w}=$ wellbore pressure, $m / L t^{2}, p s i$

$p^{f}(r, t)=$ pore pressure fluctuations, $m / L t^{2}$, psi

$r=$ near wellbore radial position, $L$, in

$r_{w}=$ wellbore radius, $L$, in 
$R=$ universal gas constant, $\mathrm{mL}^{2} \mathrm{t}^{-2} \mathrm{mols}^{-1} \mathrm{~T}^{-1}, 8.3144 \times 10^{7} \mathrm{~g} \mathrm{~cm}^{2} \mathrm{~s}^{-2} \mathrm{~g}-\mathrm{mols}$ ${ }^{1 \circ} K^{-1}$

$t=$ time, $t, s$

$T=$ temperature, $T,{ }^{\circ} \mathrm{K},{ }^{\circ} \mathrm{F},{ }^{\circ} \mathrm{C}$

$T_{0}=$ initial formation temperature, $T,{ }^{\circ} \mathrm{F},{ }^{\circ} \mathrm{C}$

$T_{w}=$ wellbore wall temperature, $T,{ }^{\circ} \mathrm{F},{ }^{\circ} \mathrm{C}$

$T^{f}(r, t)=$ temperature fluctuations, $T,{ }^{\circ} \mathrm{F},{ }^{\circ} \mathrm{C}$

$\alpha=$ Biot's constant

$\alpha_{m}=$ thermal expansion coefficient of rock matrix, $1 / \mathrm{T}, 1 / \mathrm{\rho} \mathrm{F}, 1{ }^{\circ} \mathrm{C}$

$\Delta T=$ mud - formation temperature, $T,{ }^{\circ} \mathrm{F},{ }^{\circ} \mathrm{C}$

$\phi=$ friction angle, radians, degree

$v=$ Poisson's ratio

$\sigma_{3}{ }^{e f}=$ least effective principal stress, $m / L t^{2}$, psi

$\sigma_{b d}=$ breakdown failure index, $m / L t^{2}, p s i$

$\sigma_{c l}=$ collapse failure index, $m / L t^{2}, p s i$

$\sigma_{\text {min }}{ }^{e f}=$ minimum effective stress, $m / L t^{2}$, psi

$\sigma_{r r}, \sigma_{\theta \theta}$, and $\sigma_{z z}=$ radial, hoop, and axial stress, $m / L t^{2}$, psi

$\sigma_{t}=$ tensile strength, $m / L t^{2}, p s i$

$\sigma_{\theta z}=$ shear stress component, $m / L t^{2}, p s i$

\section{ACKNOWLEDGEMENTS}

The financial support of the Drilling Research Consortium at the University of Texas is gratefully acknowledged. 


\section{SI METRIC CONVERSION FACTORS}

\begin{tabular}{|c|c|}
\hline Btu $\times 1.0550$ & $\mathrm{E}+03=\mathrm{kgm}^{2} \mathrm{~s}^{-2}$ \\
\hline${ }^{\circ} \mathrm{C}+273.15^{*}$ & $={ }^{\circ} \mathrm{K}$ \\
\hline $\mathrm{ft} \times 3.048^{*}$ & $E-01=m$ \\
\hline${ }^{\circ} \mathrm{F} \times 5.5556$ & $\mathrm{E}-01={ }^{\circ} \mathrm{K}(\Delta \mathrm{T})$ \\
\hline gal $\times 3.785$ & $E-03=m^{3}$ \\
\hline in $\times 2.54^{*}$ & $E-02=m$ \\
\hline $\mathrm{in}^{2} \times 6.452$ & $E-04=m^{2}$ \\
\hline $\mathrm{lbm} \times 4.54$ & $\mathrm{E}-01=\mathrm{kg}$ \\
\hline psi $\times 6.8948$ & $\mathrm{E}-03=\mathrm{MPa}$ \\
\hline
\end{tabular}


Table 6.1 Input data: Thermal Effects

\begin{tabular}{|l|c|}
\hline \multicolumn{1}{|c|}{ Variables } & Values \\
\hline Thermal effect & Yes/No \\
\hline Geothermal gradient & $1.1^{\circ} \mathrm{F} / 100 \mathrm{ft}$ \\
\hline Thermal diffusivity constant & $1.48 \mathrm{e}-3 \mathrm{in}^{2} / \mathrm{s}$ \\
\hline Volumetric thermal expansion of matrix & $2.7 \mathrm{e}-51 /{ }^{\circ} \mathrm{F}$ \\
\hline Volumetric thermal expansion of fluid & $2.78 \mathrm{e}-41 /{ }^{\circ} \mathrm{F}$ \\
\hline Inlet mud temperature & $132^{\circ} \mathrm{F}$ \\
\hline Earth surface temperature & $75^{\circ} \mathrm{F}$ \\
\hline Drilling fluid heat conductivity & $1 \mathrm{btu} / \mathrm{hr}-\mathrm{ft}-{ }^{\circ} \mathrm{F}$ \\
\hline Drilling fluid specific heat & $0.4 \mathrm{btu} / \mathrm{lbm}-{ }^{\circ} \mathrm{F}$ \\
\hline Earth conductivity & $1.3 \mathrm{but} / \mathrm{hr}-\mathrm{ft}-{ }^{\circ} \mathrm{F}$ \\
\hline Earth specific heat & $0.2 \mathrm{btu} / \mathrm{lbm}-{ }^{\circ} \mathrm{F}$ \\
\hline Overall heat transfer coefficient in drill pipe & $30 \mathrm{btu} / \mathrm{hr}-\mathrm{ft}^{2}-{ }^{\circ} \mathrm{F}$ \\
\hline Overall heat transfer coefficient in annulus & $1 \mathrm{btu} / \mathrm{hr}-\mathrm{ft}^{2}-{ }^{\circ} \mathrm{F}$ \\
\hline
\end{tabular}

Table 6.2 Input data: Chemical Effects

\begin{tabular}{|l|c|}
\hline \multicolumn{1}{|c|}{ Variables } & Values \\
\hline Chemical effects & Yes $/ \mathrm{No}$ \\
\hline $\mathrm{K}_{\mathrm{I}}$ & $1.13 \mathrm{e}-18 \mathrm{~m}^{3} \mathrm{~s} / \mathrm{kg}$ \\
\hline $\mathrm{K}_{\mathrm{II}}$ & $-6.75 \mathrm{e}-19 \mathrm{~m}^{3} \mathrm{~s} / \mathrm{kg}$ \\
\hline Drilling fluid concentration & $0.001,0.1,1,2,4 \mathrm{M}$ \\
\hline Pore fluid concentration & $1 \mathrm{M}$ \\
\hline Fluid compressibility & $1 \mathrm{e}-6 \mathrm{psi}^{-1}$ \\
\hline Diffusion constant & $4.94 \mathrm{e}-11 \mathrm{~m}^{2} / \mathrm{s}$ \\
\hline
\end{tabular}


Table 6.3 Input data: Mechanical Effects

\begin{tabular}{|l|c|}
\hline \multicolumn{1}{|c|}{ Variables } & Values \\
\hline Model type & Poroelasticity \\
\hline Failure criteria & Drucker-Prager \\
\hline Overburden stress gradient & $1 \mathrm{psi} / \mathrm{ft}$ \\
\hline Maximum horizontal stress gradient & $0.9 \mathrm{psi} / \mathrm{ft}$ \\
\hline Minimum horizontal stress gradient & $0.83 \mathrm{psi} / \mathrm{ft}$ \\
\hline Pore pressure, equivalent & $9 \mathrm{lbm} / \mathrm{gal}$ \\
\hline Poisson's ratio & 0.22 \\
\hline Biot's constant & 0.9 \\
\hline Young's modulus & $1 \mathrm{e} 6 \mathrm{psi}$ \\
\hline Cohesion & $890 \mathrm{psi}$ \\
\hline Friction angle & $30^{\circ}$ \\
\hline Tensile strength & $100 \mathrm{psi}$ \\
\hline
\end{tabular}

Table 6.4 Input data: Wellbore Information

\begin{tabular}{|l|c|}
\hline \multicolumn{1}{|c|}{ Variables } & Values \\
\hline Borehole radius & $4.9375 \mathrm{in}$ \\
\hline Drill pipe inner radius & $3.0325 \mathrm{in}$ \\
\hline Drilling fluid flow rate & $600 \mathrm{bbl} / \mathrm{hr}$ \\
\hline Depth & $10,000 \mathrm{ft}$ \\
\hline Azimuth & $0^{\circ}$ \\
\hline Well inclination & $0^{\circ}-90^{\circ}$ \\
\hline Mud weight & $10.4,11.1,12.4 \mathrm{lbm} / \mathrm{gal}$ \\
\hline
\end{tabular}

Table 6.5 Input data: Miscellaneous Parameters

\begin{tabular}{|l|c|}
\hline \multicolumn{1}{|c|}{ Variables } & Values \\
\hline Earth density & $165 \mathrm{lbm} / \mathrm{gal}$ \\
\hline Time1 & 0.1 hour \\
\hline Time2 & 1 hour \\
\hline Time3 & 10 hours \\
\hline Time4 & 24 hours \\
\hline
\end{tabular}




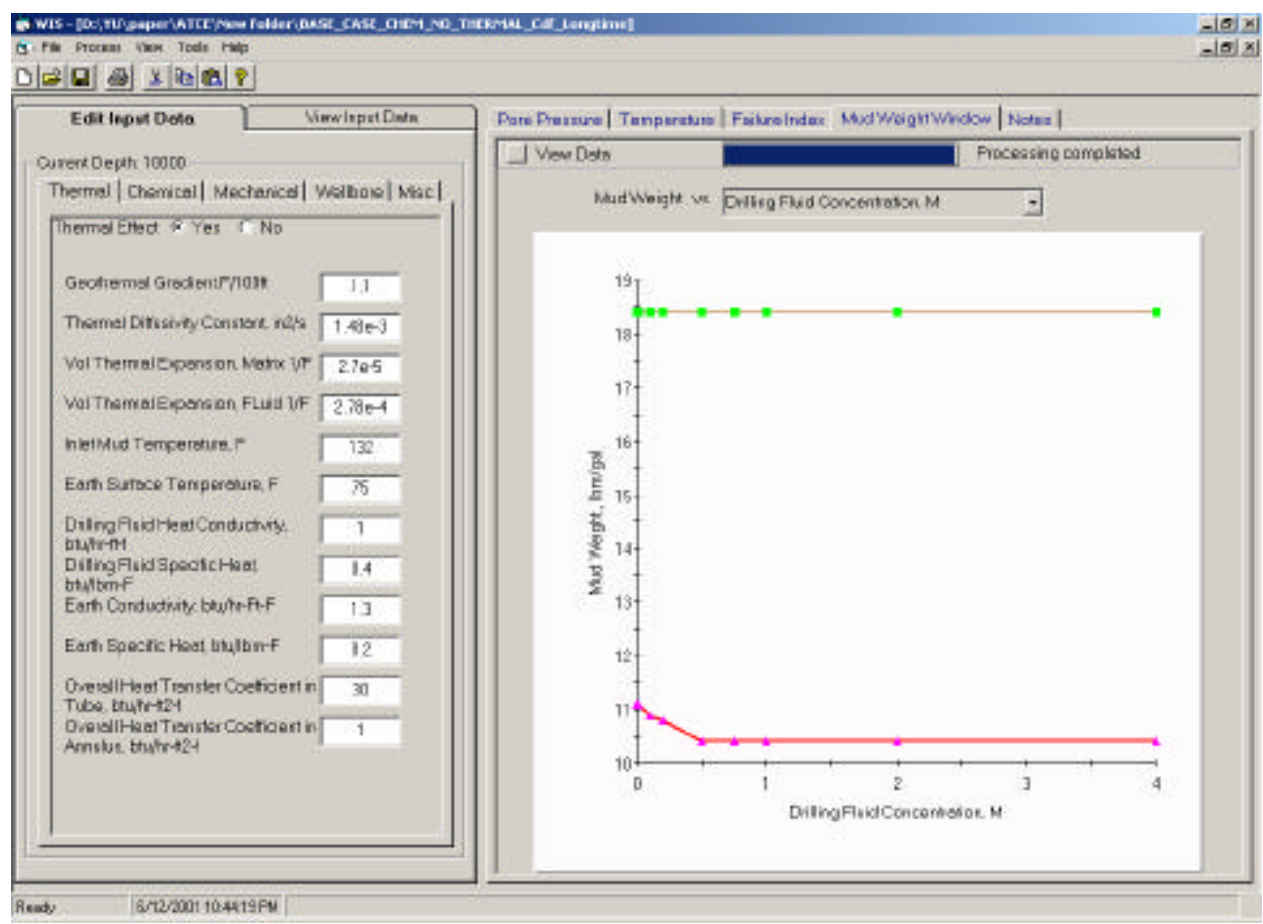

Figure 6.1 Example of the thermal inputs and the mud-weight-window output for various drilling fluid concentrations. 


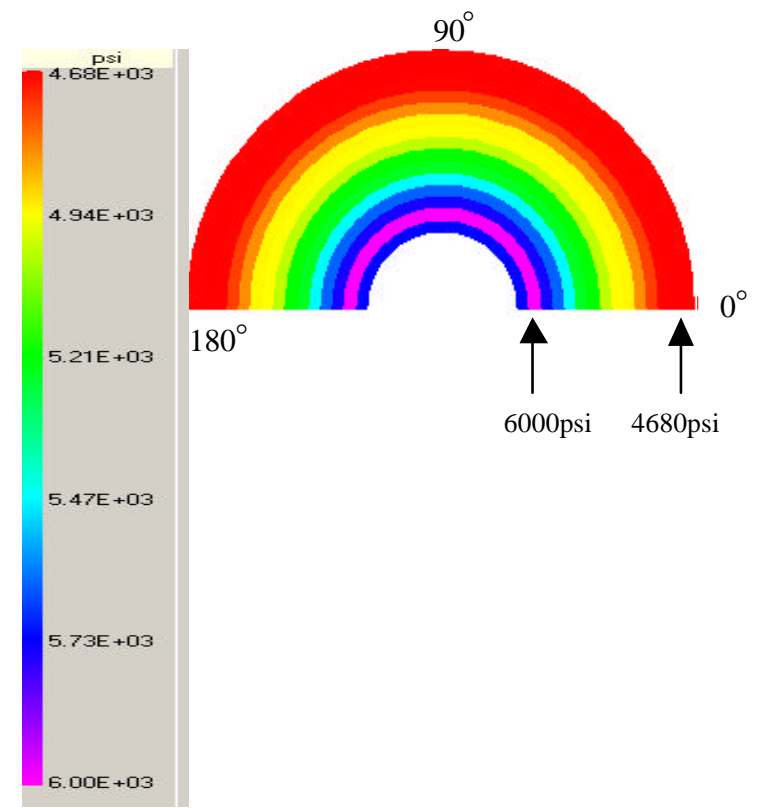

Figure 6.2 Output example of pore pressure distribution around a wellbore after 1 hour. 


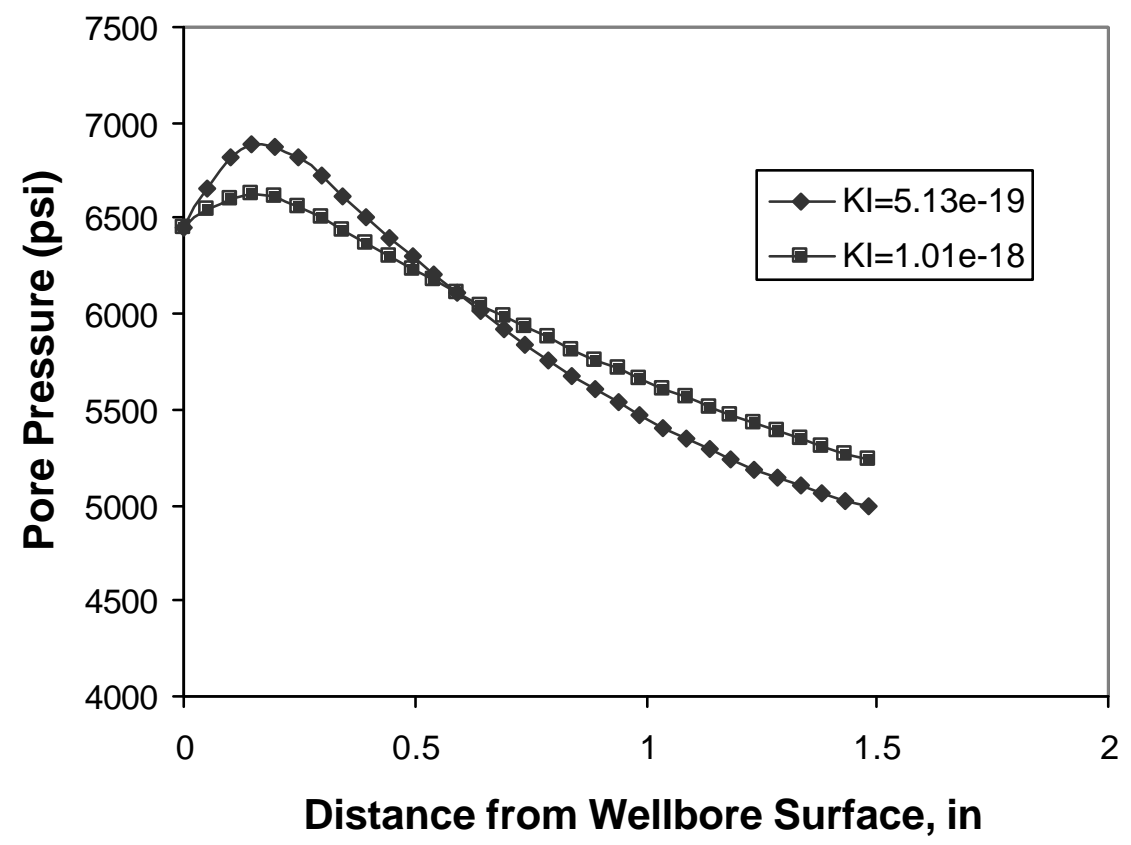

Figure 6.3 Pore pressure under different permeability conditions as a function of distance from the wellbore surface. 


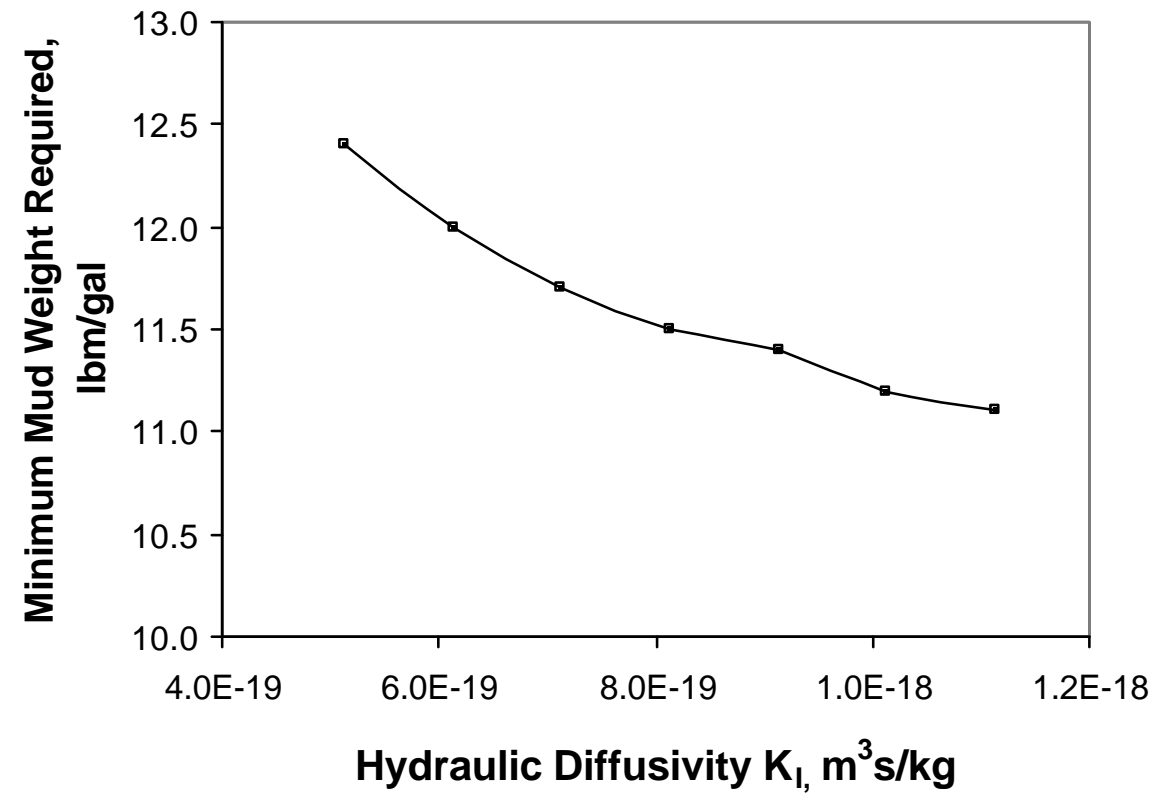

Figure 6.4 Minimum mud weight required to prevent wellbore collapse as a function of hydraulic diffusivity. 


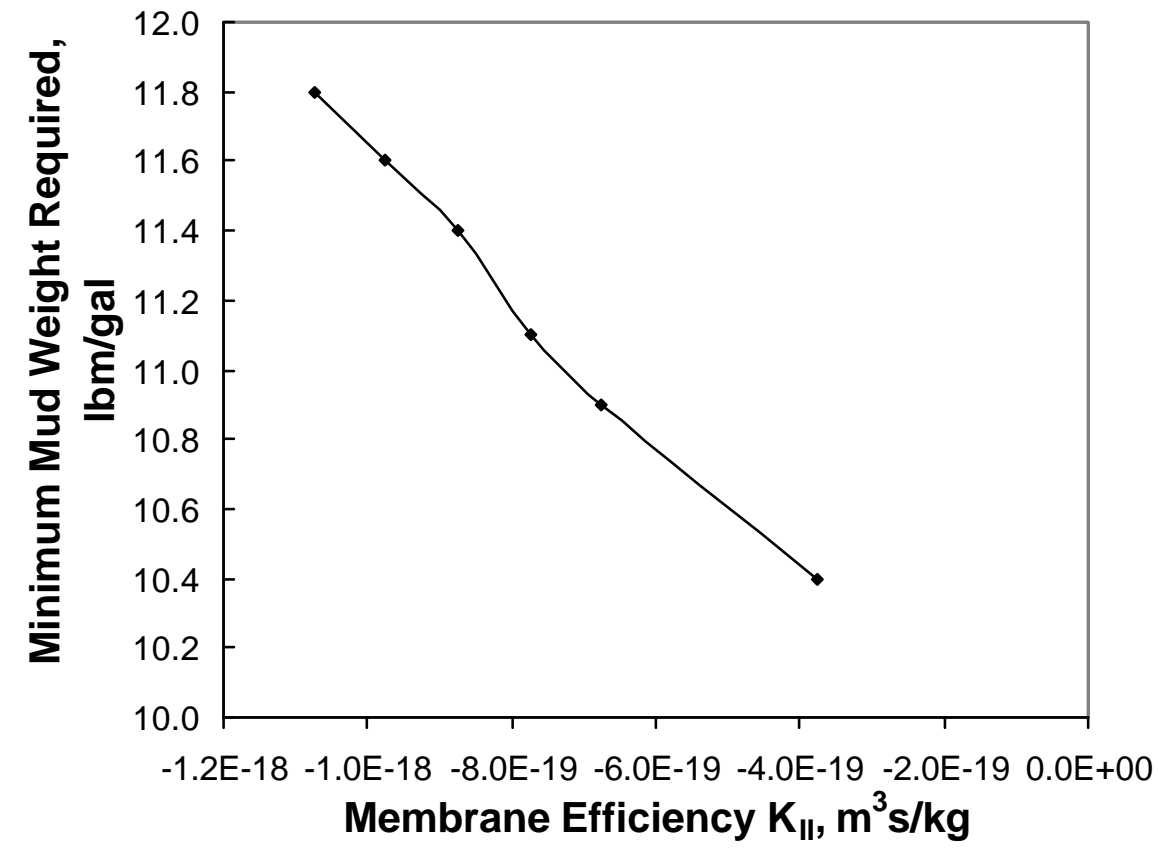

Figure 6.5 Minimum mud weight required to prevent wellbore collapse as a function of membrane efficiency. 


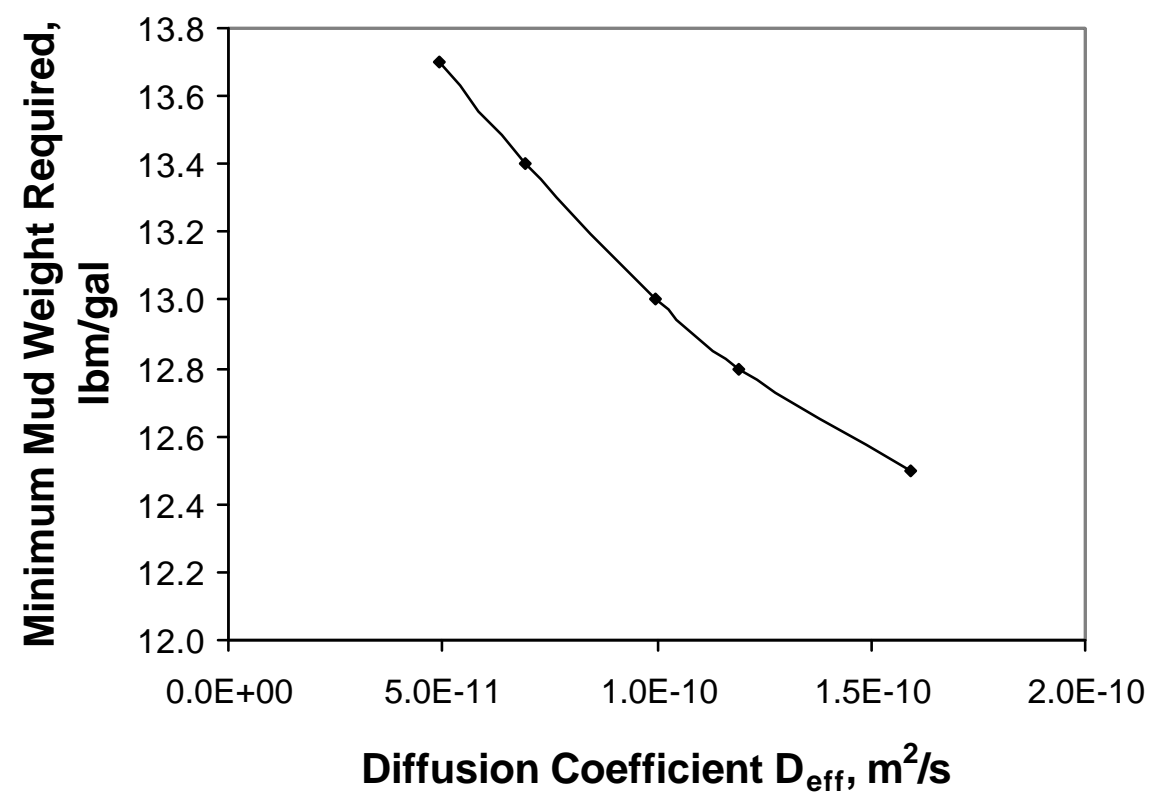

Figure 6.6 Minimum mud weight required to prevent wellbore collapse as a function of the diffusion coefficient. 


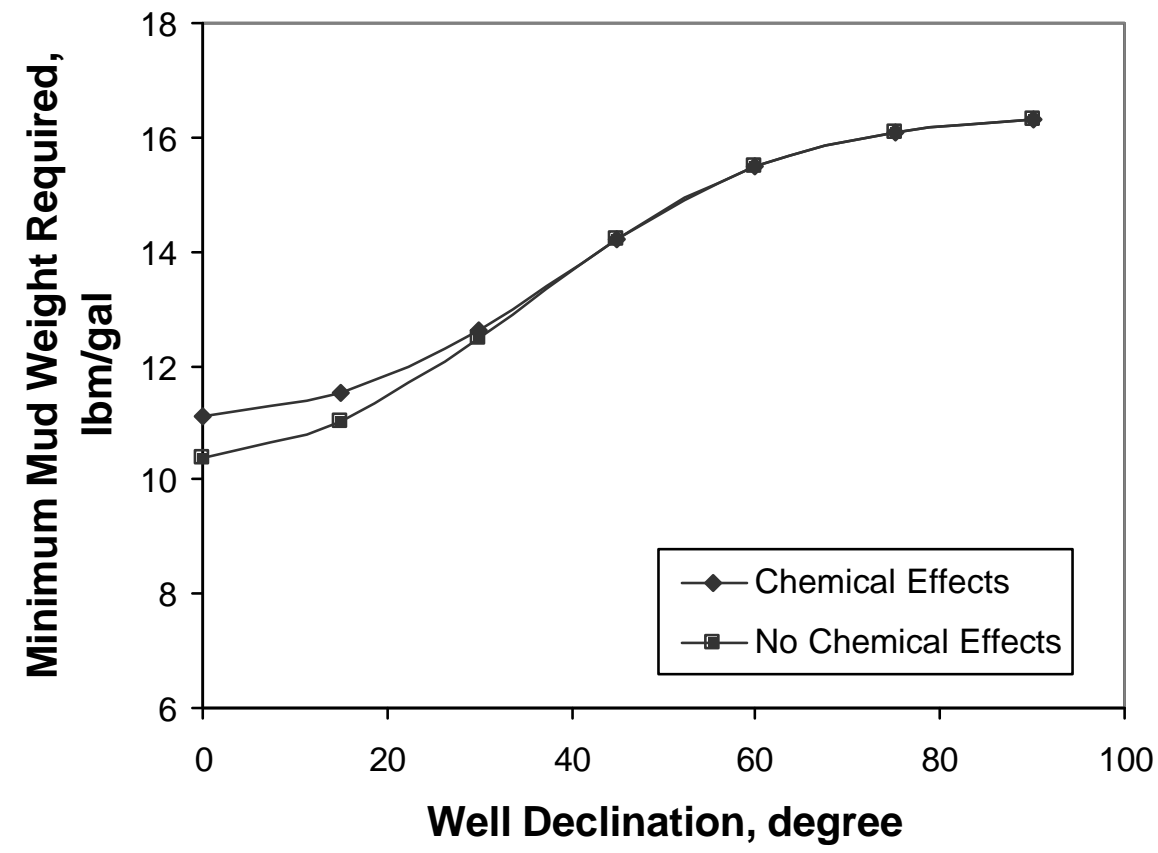

Figure 6.7 Minimum mud weight required to prevent wellbore collapse for deviated wells having effective chemical and non-chemical factors acting. 


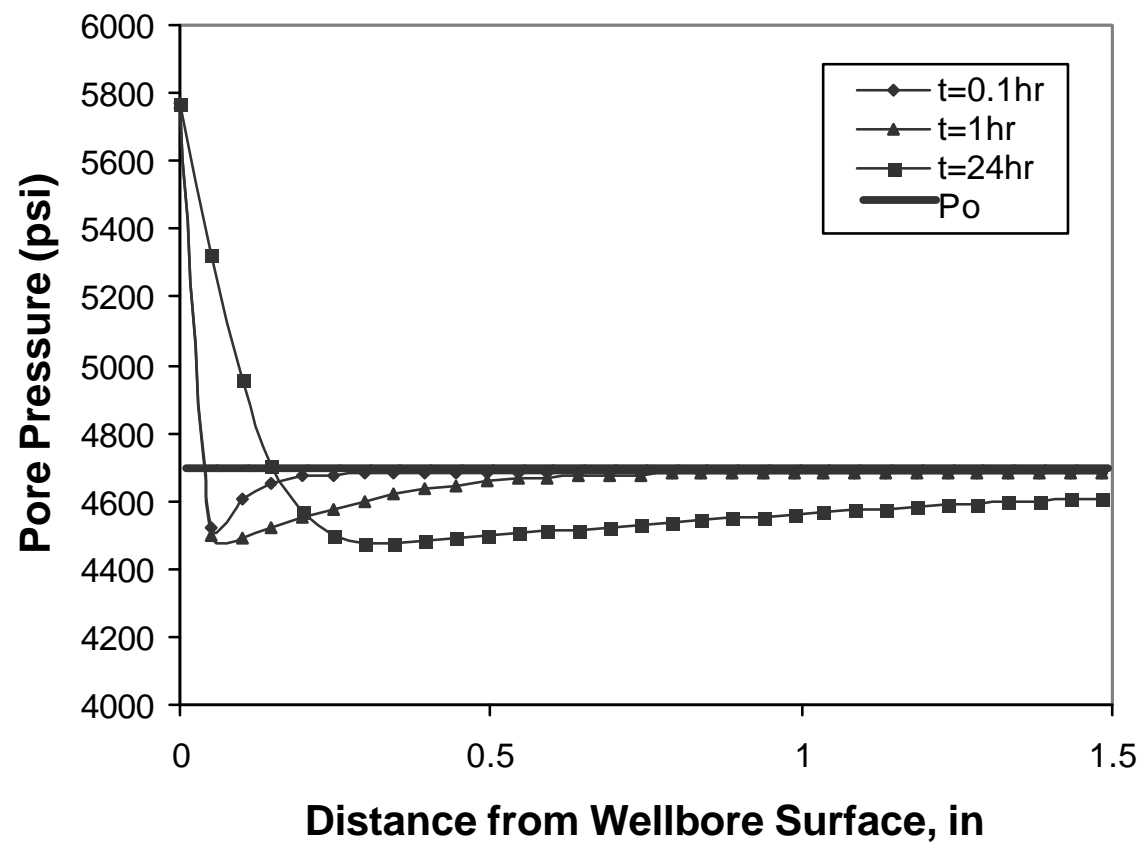

Figure 6.8 Pore pressure profiles as a function of distance from the wellbore surface, time, and drilling fluid solute concentration greater than shale. 


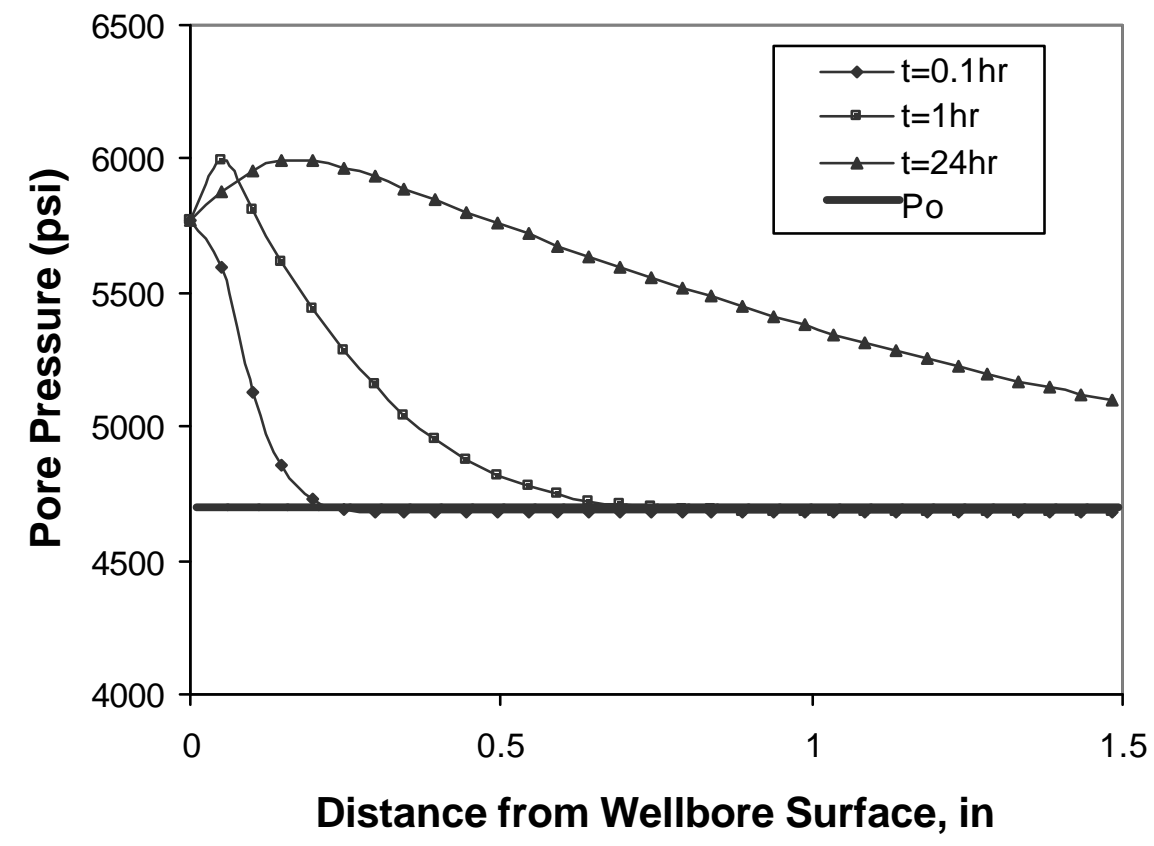

Figure 6.9 Pore pressure profiles as a function of distance from the wellbore surface, time, and drilling fluid solute concentration less than shale. 


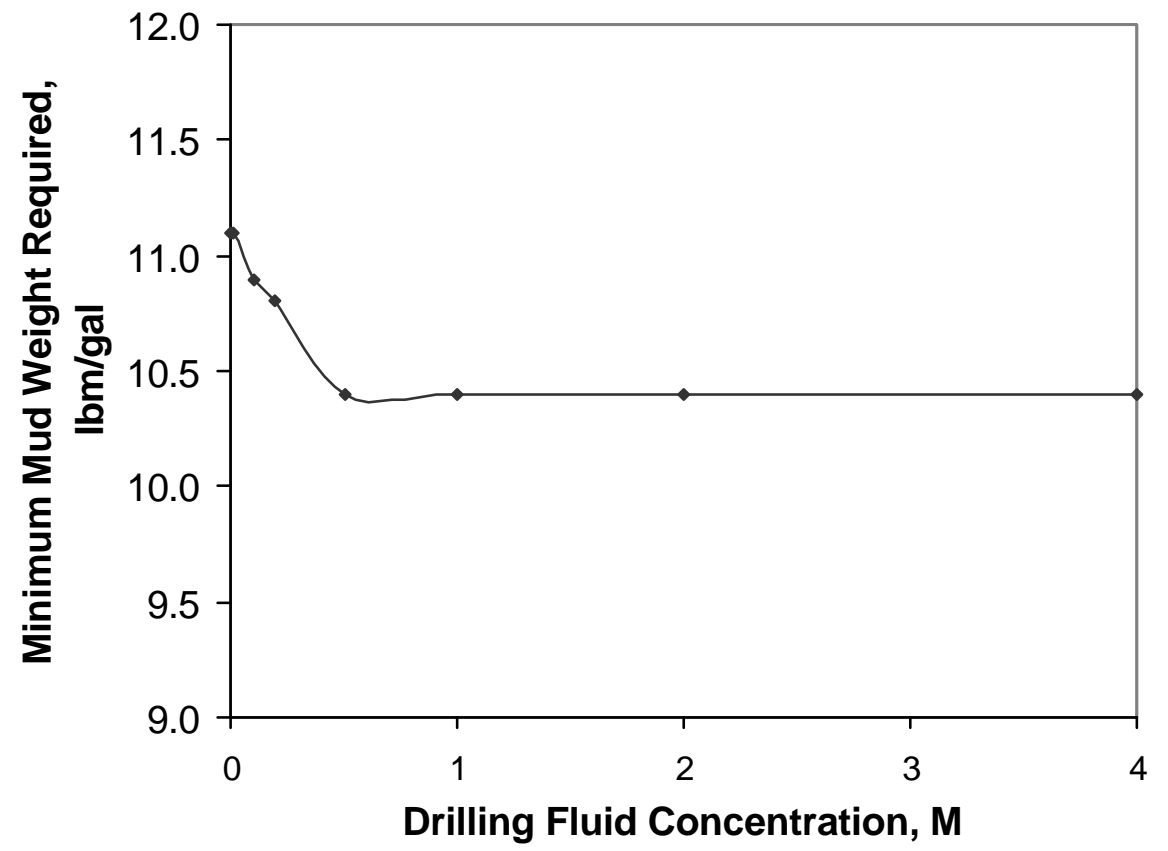

Figure 6.10 Minimum mud weight required to prevent wellbore collapse as a function of drilling fluid solute concentration. 


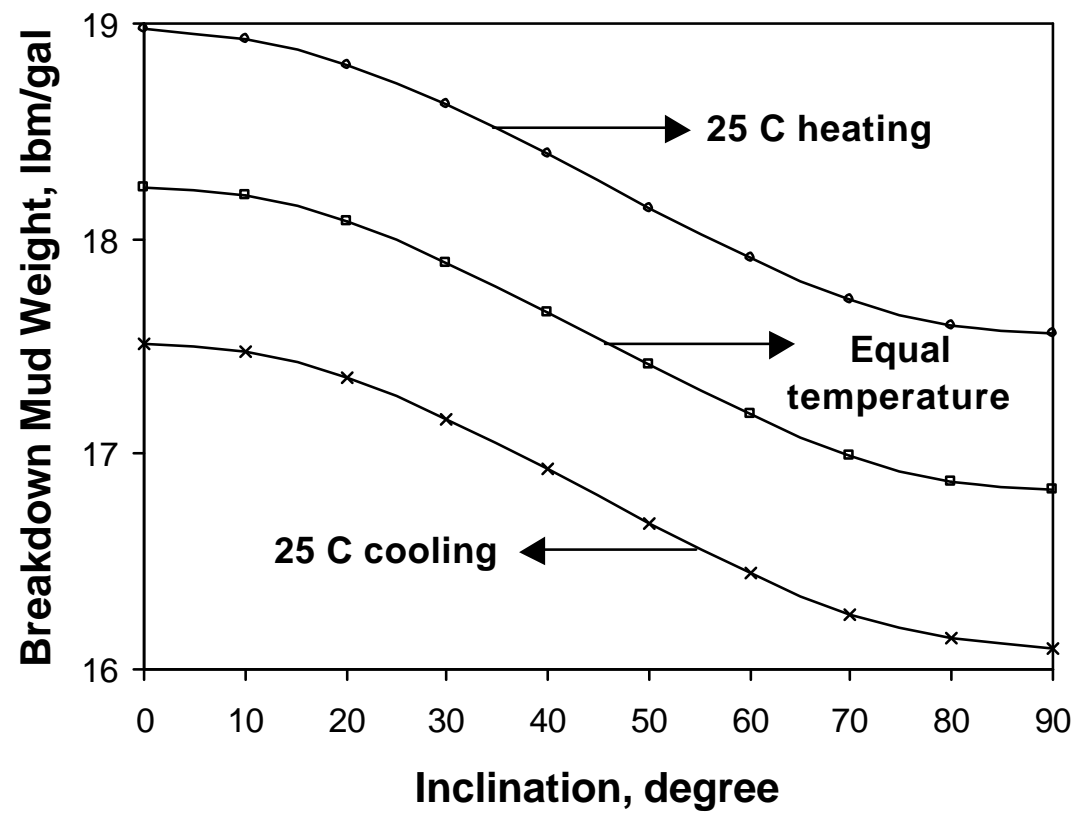

Figure 6.11 Thermal effects on breakdown mud weights for inclined wellbores. 


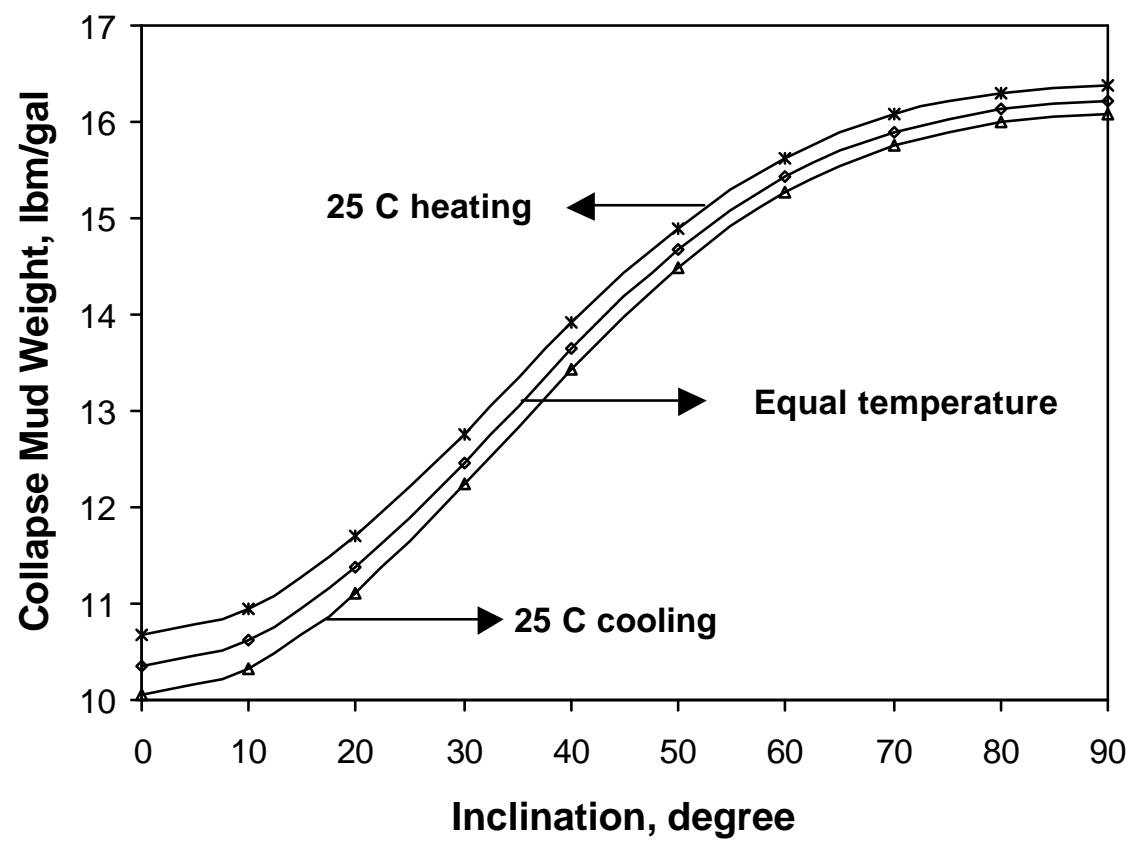

Figure 6.12 Thermal effects on collapse mud weights for inclined wellbores. 


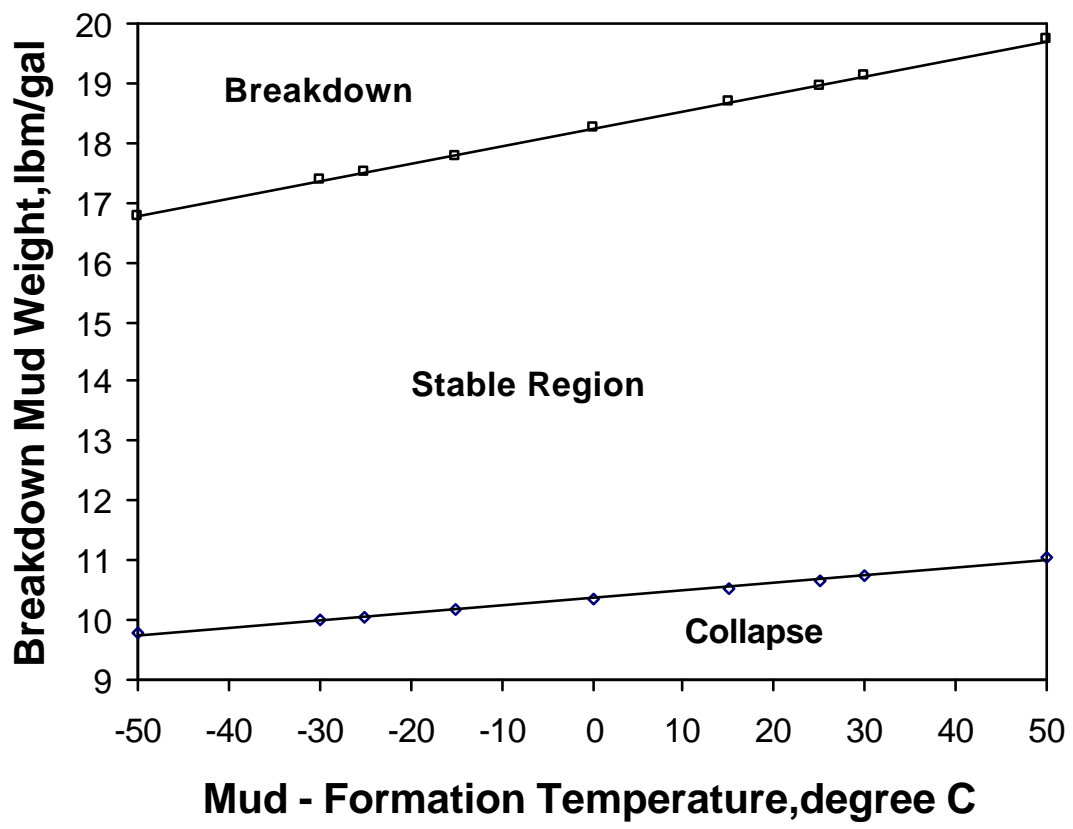

Figure 6.13 Effect of temperature changes on critical mud weights for vertical wellbores. 


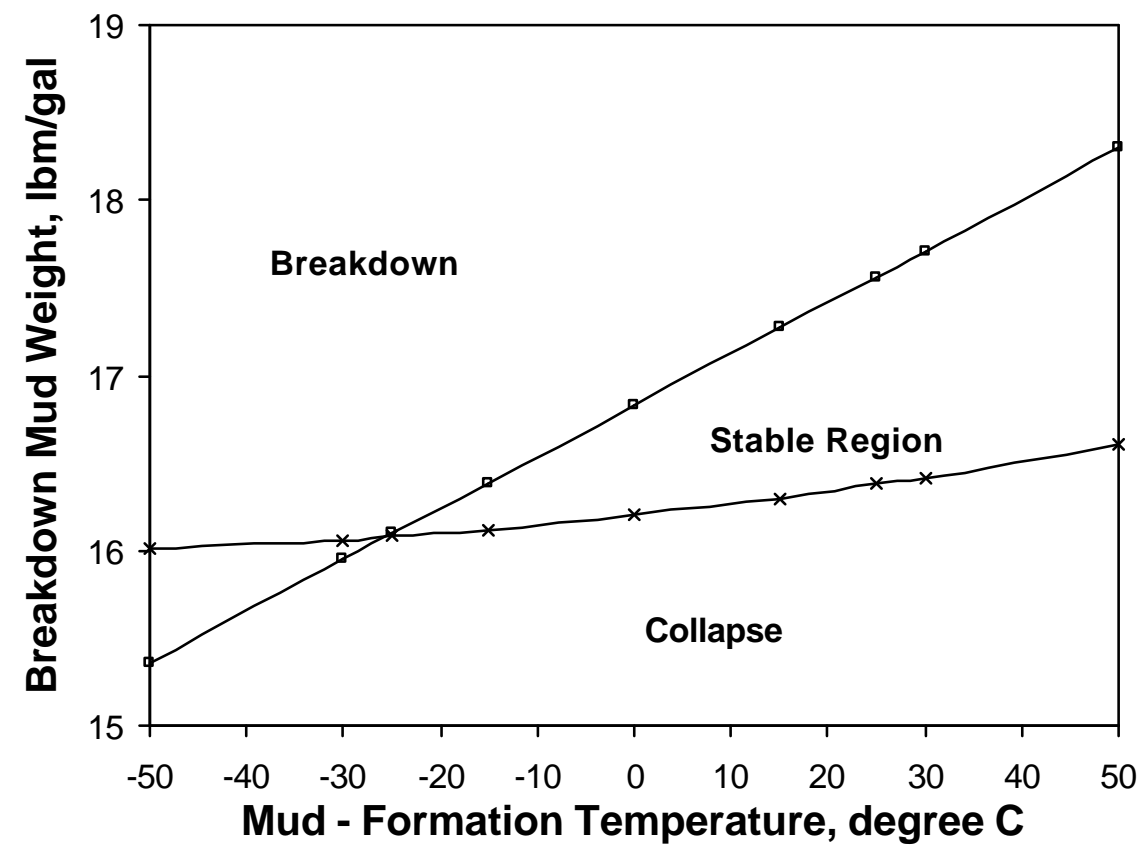

Figure 6.14 Effect of temperature changes on critical mud weights for horizontal wellbores. 


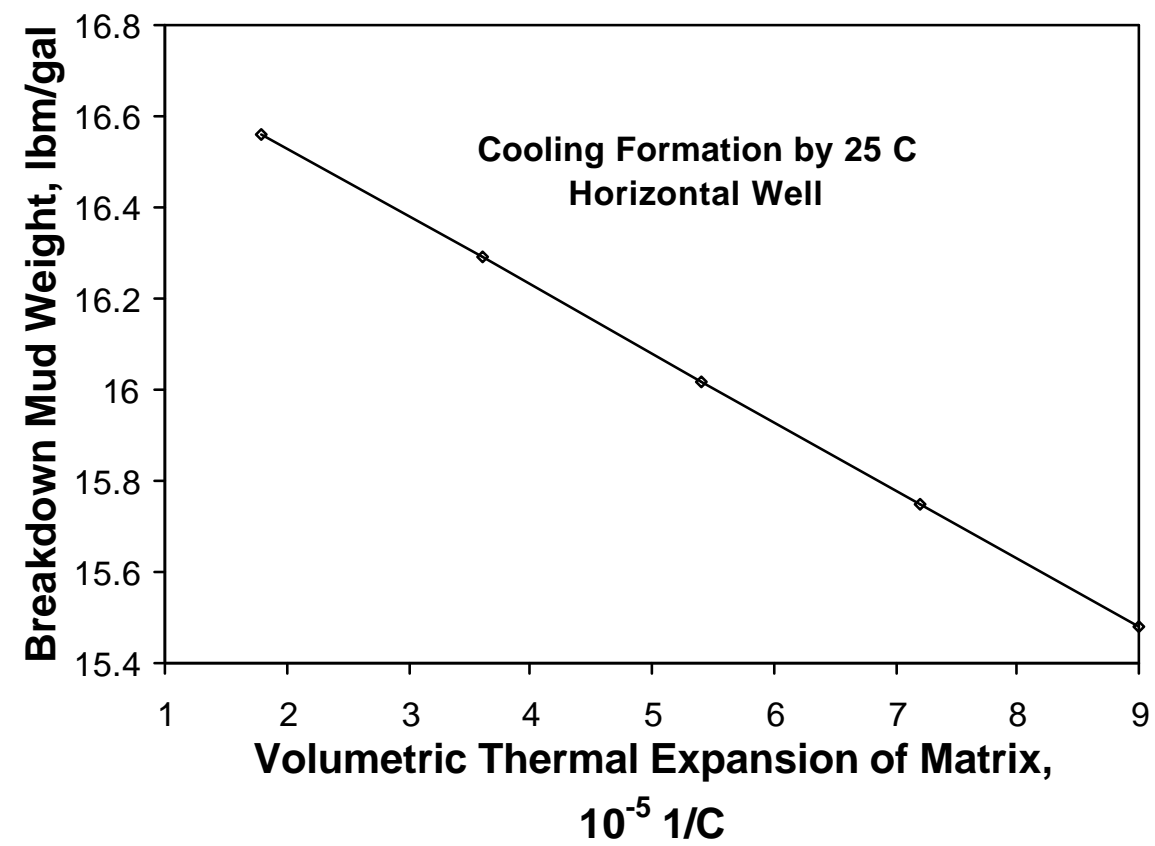

Figure 6.15 Effect of thermal expansion coefficients on breakdown mud weights. 


\section{Appendix A}

The analytical pore pressure solution of equation 6-6 can be written as (Wang and Papamichos [1994])

$$
\begin{aligned}
p(r, t)-p_{o}= & \left(\left(p_{w}-p_{o}\right)-\frac{c^{\prime}\left(C_{d f}-C_{0}\right)}{1-c / c_{0}}\right) \times \\
& {\left[1+\frac{2}{\pi} \int_{0}^{\infty} e^{-c \xi^{2} t} \frac{J_{o}(\xi r) Y_{o}\left(\xi r_{w}\right)-J_{o}\left(\xi r_{w}\right) Y_{o}(\xi r)}{J_{o}^{2}\left(\xi r_{w}\right)+Y_{o}^{2}\left(\xi r_{w}\right)} \frac{d \xi}{\xi}\right] } \\
& +\frac{c^{\prime}\left(C_{d f}-C_{0}\right)}{1-c / c_{0}} \times \\
& {\left[1+\frac{2}{\pi} \int_{0}^{\infty} e^{-c_{0} \xi^{2} t} \frac{J_{o}(\xi r) Y_{o}\left(\xi r_{w}\right)-J_{o}\left(\xi r_{w}\right) Y_{o}(\xi r)}{J_{o}^{2}\left(\xi r_{w}\right)+Y_{o}^{2}\left(\xi r_{w}\right)} \frac{d \xi}{\xi}\right] }
\end{aligned}
$$

where

$$
\begin{aligned}
& c=\frac{K_{I}}{c_{f}} \\
& c^{\prime}=\frac{n R T K_{I I}}{D_{\text {eff }} c_{f}} \\
& c_{0}=D_{\text {eff }}
\end{aligned}
$$




\section{References}

Basu, S. and Sharma, M. M. (1997), "An improved space-charge model for flow through charged microporous membranes", Journal of Membrane Science, 124, 77-91.

Biot, M.A.: "General Theory of Three-Dimensional Consolidation,” Journal of Applied Physics, 12 (Feb. 1941) 155-164.

Bradley, W.B.: "Mathematical Concept - Stress Cloud Can Predict Borehole Failure," The Oil and Gas Journal, (Feb. 1979).

Bradley, W.B.: "Failure of Inclined Boreholes," Journal of Energy Resources Technology, Transactions of ASME, 101 (Dec. 1979) 232-239.

Charlez, Ph.A.: Rock Mechanics: Volume 2, Petroleum applications, Editions Technip, Paris, France (1997).

Chenevert, M.E.: “Shale Alteration by Water Adsorption,” JPT (Sept. 1970).

Chenevert, M.E. and Pernot V.: "Control of Shale Swelling Pressures Using Inhibitive Water-Base Muds," paper SPE 49263 presented at the 1998 SPE Annual Technical Conference and Exhibition, New Orleans, Sept. 27-30

Cui, L. (1995), "Poroelasticity with Application to Rock Mechanics," Ph.D. Dissertation, The University of Delaware.

Cui, L, Cheng A.H-D., Abousleisman, Y., Roegiers, J.-C., "Time-Dependent Failure Analysis of Inclined Boreholes in Fluid-Saturated Formations," Journal of Energy Resources Technology, 121 (Mar. 1999) 31-39.

Detournay, E. and Cheng, A. H-D. (1988), "Poroelastic Response of a Borehole in a Non-Hydrostatic Stress Field,” Int. J. Rock Mech. Min. Sci. \& Geomech. Abstr., No. 25, No. 3, pp. 171-182.

Drucker, D. C. and Prager, W., (1952) "Soil Mechanics and Plastic Analysis or Limit Design”, Quat. Of Appl. Math., Vol. 10, pp. 157-165. 
Ewy, R.T. and Stankovich, R.J., "Pore Pressure Change due to Shale-Fluid Interactions: Measurements under Simulated Wellbore Conditions," Pacific Rocks 2000, Fourth North American Rock Mechanics Symposium, Seattle, July 31-August 2, 2000, pp. 147-154, Balkema, Totterdam.

Fonseca, C.F. (2000) "Chemical-Mechanical Modeling of Wellbore Instability in Shales", Proceeding of ETCE 2000 \& OMAE 2000 Joint Conference: Energy for the New Millenium, Feb. 14-17, 2000, New Orleans, LA.

Fritz S. J., and Marine I. W., [1983]: " Experimental support for a Predictive Osmotic Model of Clay Membranes", Geochim. Cosmochim. Acta 47, 1515-1522.

Fritz, Steven J. (1986), "Ideality of clay membranes in osmotic process: A review", Clays and Clay Minerals, 34, No. 2, 21-223.

Fritz, Steven J. and Whitworth, T. M. (1993), "Measuring phenomenological coefficients of membranes for use in predicting osmotically-induced hydraulic pressures", Hydrologic Science and Technology.

Gross, R. G. and Osterle, J. F. (1968), "Membrane transport characteristics of ultrafine capillaries", The Journal of Chemical Physics, 49, No.1, Jul., 228-234.

Hsiao, C. (1988), "A Study of Horizontal-Wellbore Failure," SPE Production Engineering, November, pp. 489-494.

Kedem, O. and Katchalsky, A. (1962), "Permeability of Composite Membranes. I: Electric Current, Volume flows and Flow of Solute Through Membranes", Trans. Faraday Soc. 59, 1918-1930

Lomba, R.; Chenevert, M.E.; and Sharma, M.M. (2000), "The Ion-Selective Behavior of Native Shales", J. Pet. Sci. Engr., 25 9-23.

Lomba, R.; Chenevert, M.E.; and Sharma, M.M. (2000), "The Role of Osmotic Effects in Fluid Flow Through Shales", J. Pet. Sci. Engr., 25 25-35.

Low P.F., Anderson D. M., [1958]: "Osmotic Pressure Equations for Determining Thermodynamic Properties of Soil Water", Soil Science, V. 86, 251-258. 
Marshall, C.E.: "The Physical Chemistry and Mineralogy of Solids," John \& Wiley Sons, Inc., New York (1964).

McLean, M. R. and Addis, M. A. (1990b), "Wellbore Stability: The Effect of Strength Criteria on Mud Weight Recommendations," SPE 20405, 65th Annual SPE Technical Conference and Exhibition, New Orleans, LA, September 23-26.

Mody F. K. and Hale A. H., [1993], "A Borehole Stability Model to Couple the Mechanics and Chemistry of Drilling Fluid Shale Interaction", SPE/IADC Paper 25728, Presented at SPE/IADC Drilling Conference in Amsterdam, The Netherlands, Feb. 23-25.

O'Brien T. B., Goins D. and Simpson J. (1996), "Effects of Drilling Fluid/Shale Interactions on Borehole Stability: Studies Using Speeton Shale", Topical Report.

Onsager, L.(1931a), "Reciprocal relations in irreversible processes. I.", Physical Review, 37, 405-426.

Onsager, L.(1931b), "Reciprocal relations in irreversible processes. II.", Physical Review, 38, 2265-2279.

Pashley R.M. and Israelachvili J.N., [1983]: "DLVO and Hydration Forces between Mica Surfaces in $\mathrm{Mg} 2+, \mathrm{Ca} 2+, \mathrm{Sr} 2+$, and $\mathrm{Ba} 2+$ Chloride Solutions", Journal of Colloid and Interface Science, Vol. 97, No2. Feb.

Prats, M.: "Thermal Recovery," SPE Monograph, Second Printing, (1986) 214.

Sherwood, J. D. (1995), "Ionic transport in swelling shale", Advances in Colloid and Interface Science, 61, 51-64.

Simpson, J. P. (1997), "Studies of the Effects of Drilling Fluid/Shale Interactions on Borehole Instability," Gas Tips, Spring, Vol. 3, No.2, pp. 30-36.

Simpson, J.P. and Dearing, H.L., "Diffusion Osmosis-An Unrecognized Cause of Shale Instability”, IADC/SPE 59190, New Orleans, LA, 23-25 February 2000.

Skempton, A.W.: "The Pore Pressure Coefficients A and B," Pore Pressure and Suction in Soils, Butterworths, (1954) 4-16. 
Rice, J.R. and Cleary, M.P.: "Some Basic Stress Diffusion Solutions for FluidSaturated Elastic Porous Media with Compressible Constituents," Reviews of Geophysics and Space Physics, 14(2) (1976) 227-241.

Van Oort, E.(1997), "Physico-chemical stabilization of shales", SPE paper37263, presented at 1997 International Symposium on Colloid Chemistry, Houston, Texas, USA, Feb. 18-21.

Wang, C. L. (1992), “On Stability of a Deviated Wellbore in Shale Rocks,” Ph.D. Dissertation, The University of Texas at Austin.

Wang, Y.L. and Papamichos, E.: "Conductive Heat Flow and Thermally Induced Fluid Flow Around a Well Bore in a Poroelastic Medium," Water Resources Research, 30(12) (Dec. 1994) 3375-3384.

Yew, C. H. and Liu, G. (1992), "Pore Fluid and Wellbore Stabilities," SPE 22381, SPE International Meeting on Petroleum Engineering, Beijing, China, 24-27 March, pp. 519-527.

Yu, M, Chen G., Chenevert, M.E., and Sharma, M.M. (2001), "Chemical and Thermal Effects on Wellbore Stability of Shale Formations”, SPE 71366, New Orleans, USA, Sept. 30- Oct. 3, 2001.

Yu. M, M. M. Sharma, M. M. Chenevert, "A General Model for Water and Ion Transport in Shales", Annual report of UTDRP, 2000 


\section{Vita}

Mengjiao Yu was born in Jimo, Shandong province of China, on September $10^{\text {th }}, 1971$; the son of Kejun Yu and Yongzhen Li. He received a Bachelor of Science degree in Applied Chemistry from the Tianjin University, China in July 1994. He joined the graduate school of Tsinghua University and obtained the Master of Science degree in Chemical Engineering in July 1997. In January 1998, he entered the Graduate School of the University of Texas at Austin. He is the author of several papers and annual reports in chemical and petroleum engineering related topics.

Permanent address: No. 100 DongYue Rd.

Tai'an

Shandong Province, 271000

China

This dissertation was typed by the author. 